

TEXAS TECH UNIVERSITY

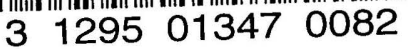







DEPARTMENT OF THE INTERIOR

UNITED STATES GEOLOGICAL SURVEY

GEORGE OTIS SMITH, DIRECTOR

BULletin 405

\section{THE MERCURY MINERALS FROM TERLINGUA, TEXAS}

BY

W. F. HILLEBRAND

AND

W. T. SCHALLER

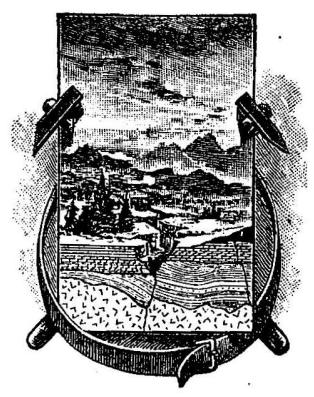

WASHINGTON

GOVIRNMENT PRINTING OFFICE

1909 



\section{CONTENTS.}

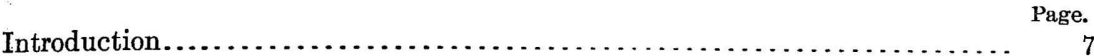

Occurrence and associations of the minerals........................ 8

Geologic occurrence ....................................... 8

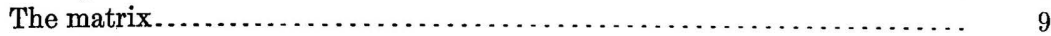

Associations.................................................... 10

Kleinite............................................ 10

Montroydite......................................... 10

Terlinguaite............................................. 11

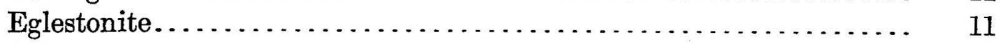

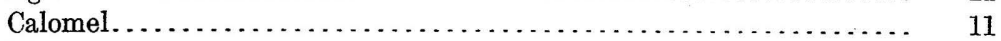

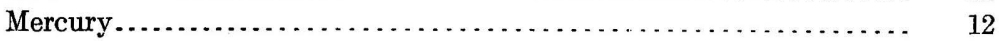

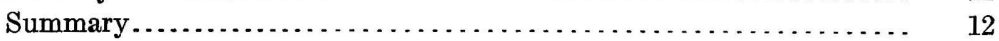

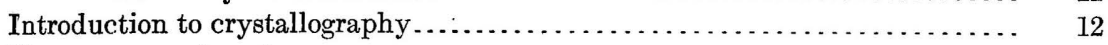

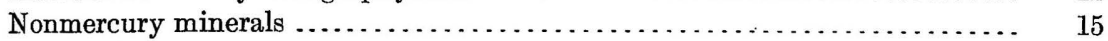

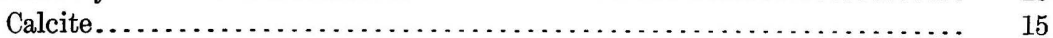

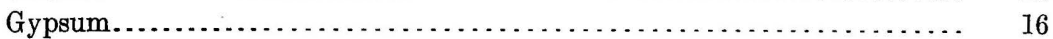

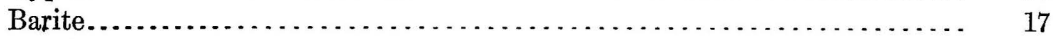

Jarosite..................................................... 17

Mercury minerals................................................ 18

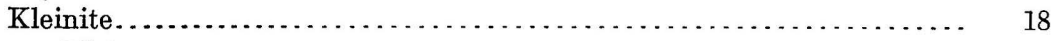

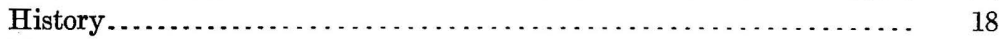

Modes of occurrence................................... $\quad 20$

Physical properties................................... 20

Cohesion, etc ....................................... 20

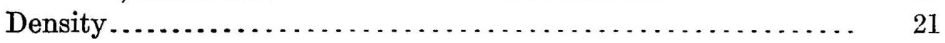

Luster, color, etc................................... 21

Optical properties.................................... 23

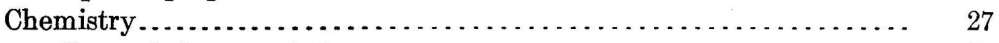

General characteristics................................ 27

Quality of the material ............................ 27

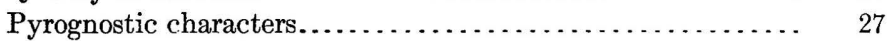

Qualitative behavior toward reagents.................. 28

Additional data ...................................... 28

Data relating chiefly to oxygen, nitrogen, and chlorine...... 28

Data relating to water and hydrogen.................. 32

Analytical methods employed and the results................ 33

Nitrogen...................................... 33

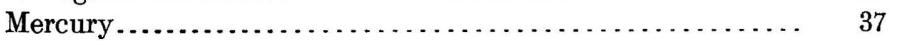

Chlorine and sulphur.............................. 38

Gangue, water (hydrogen?) ....................... $\quad 39$

Analysis....................................... 40

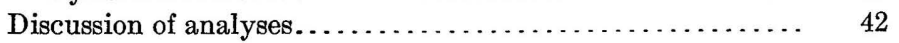

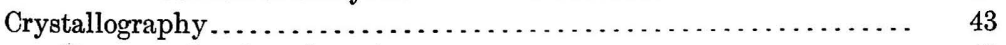

Forms and value of $c$ axis................................ 43

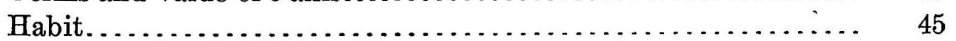

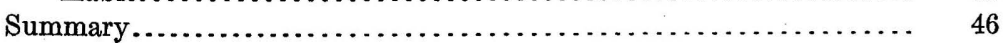


Mercury minerals-Continued. Page.

Montroydite............................................... 47

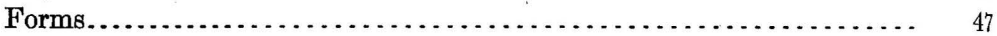

Physical properties......................................... 52

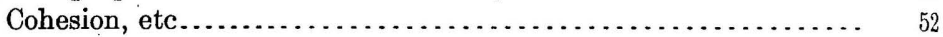

Flexibility .............................................. 53

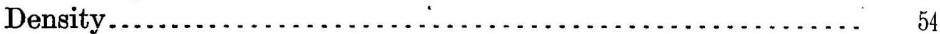

Luster, color, etc.................................... 54

Optical properties...................................... 55

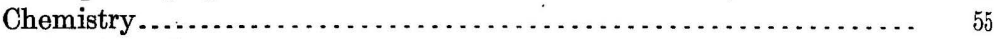

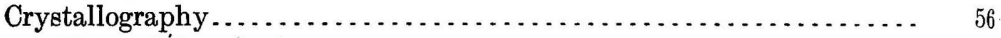

General description................................... 56

Calculation of elements................................ 57

Forms and angles...................................... 59

Description of common forms.......................... 61

Description of less common forms....................... 65

Description of rare forms.................................. 68

Summary of forms...................................... 68

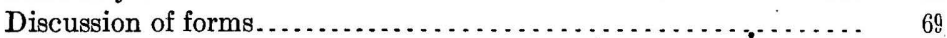

Combinations......................................... 73

Zonal relations, striations, and gnomonic projection of forms ..... $\quad 74$

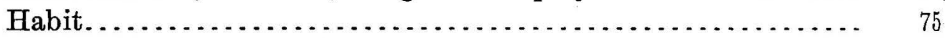

Description of crystals............................... $\quad 78$

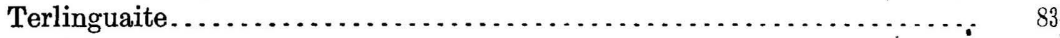

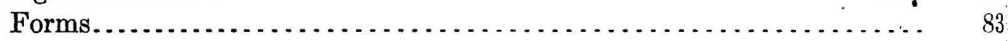

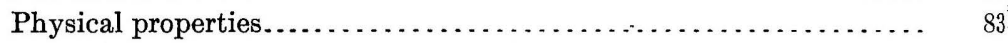

Cohesion, etc...................................... 83

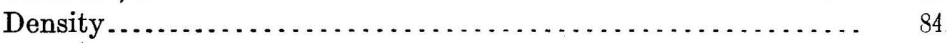

Luster, color, etc................................. 84

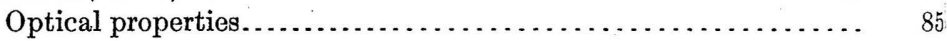

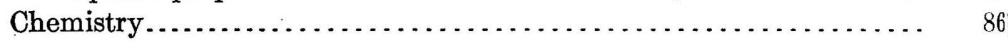

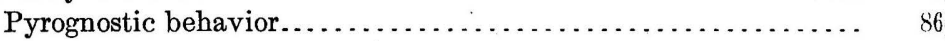

Behavior toward reagents.......................... 86

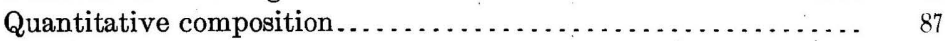

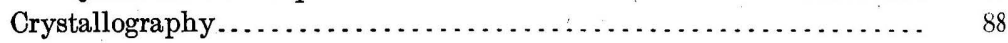

General description.................................... 88

Calculation of elements............................... $\quad 89$

Forms and angles......................................... 93

Description of common forms.......................... 96

Description of less common forms...................... 98

Description of rare forms............................ 107

Doubtful and vicinal forms........................... 108

Discussion of forms.................................. 110

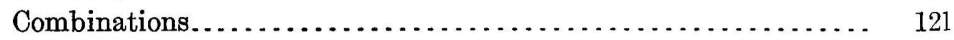

Zonal relations and gnomonic projection................... 124

Habit.............................................. 125

Description of crystals................................. 126

Different orientations and transformation symbols.............. 132

Coordinate angles arranged in order of increasing $\phi$ value........ $\quad 137$

Forms and corresponding angles with (010) as pole............. 140

Eglestonite................................................ 143

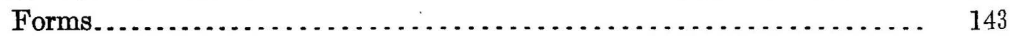

Physical properties........................................... 144

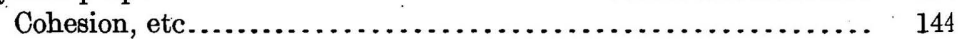


Mercury minerals-Continued.

Eglestonite-Continued.

Physical properties-Continued. Page.

Density ............................................ 144

Luster, color, etc.................................. 144

Optical properties.................................... 144

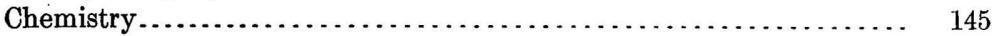

Pyrognostic behavior............................... $\quad 145$

Behavior toward reagents............................ 145

Quantitative composition.............................. 145

Crystallography........................................ 147

General description...................................... 147

Forms and angles:........................................ 147

Description of common forms........................... 149

Description of less common forms...................... $\quad 149$

Description of rare forms.............................. 151

Discussion of forms.................................. 151

Combinations......................................... 152

Zonal relations and gnomonic projection................. 154

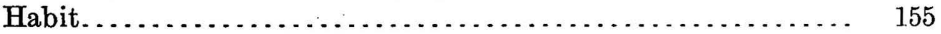

Description of crystals.............................. 156

Calomel................................................. 157

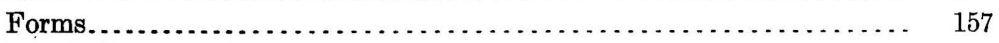

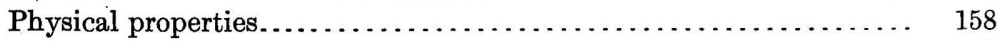

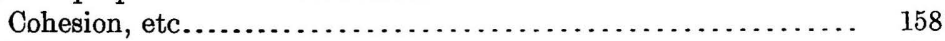

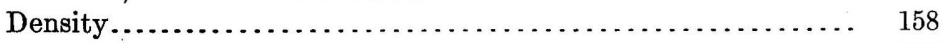

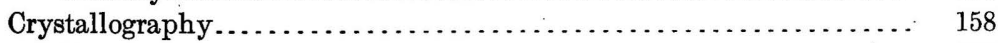

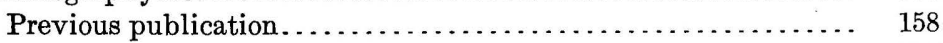

General description.................................. 158

Calculation of elements.............................. 159

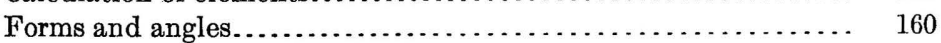

Description of forms................................. 161

Discussion of forms.................................... 165

Combinations............................................ 166

Habit............................................. 167

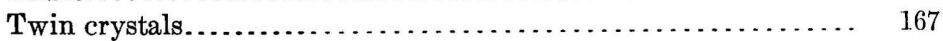

Description of crystals................................ 168

- Form system............................................... 170

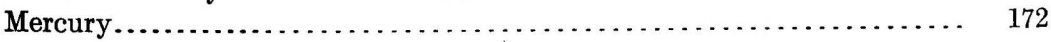

\section{- ILLUSTRATIONS.}

Plate I. Basal section of kleinite showing optical unhomogeneity. (A) Nicols not crossed. $(B)$ Nicols crossed. (C) After the section had been heated to $150^{\circ}$ and allowed to cool, nicols crossed............. 26

II. Montroydite specimen . . . . . . . . . . . . . . . . . . . . . . . . . . . 48

III. Montroydite forms....................................... 50

IV. Gnomonic projection of montroydite forms.................. 74

V. Gnomonic projection of terlinguaite forms.................. 124

VI. Gnomonic projection of eglestonite forms ................. 152 
FIGURE 1.

. Basal section of kleinite showing the imperfect prismatic cleavage.

3. Diagrammatic sketch of basal section of kleinite showing optical unhomogeneity

4. Kleinite, short prismatic habit, with uniform development of the

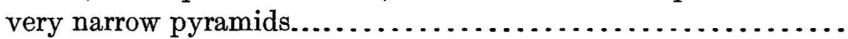

5. Kleinite, short prismatic habit, with large development of the

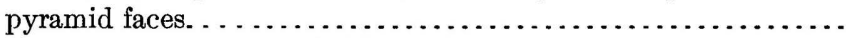

6. Kleinite, short prismatic habit, with unequal development of the

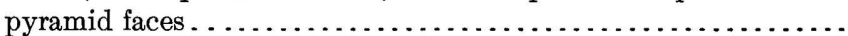

7. Kleinite, equidimensional habit. . . . . . . . . . . . . . . . .

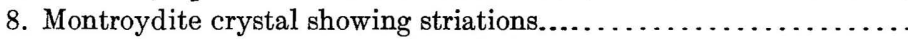

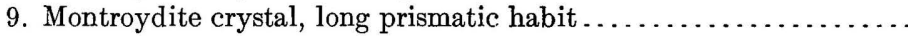

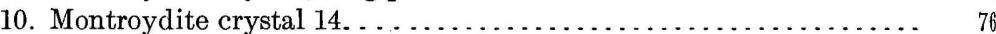

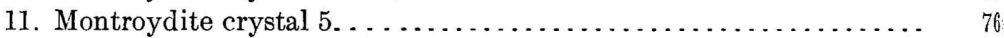

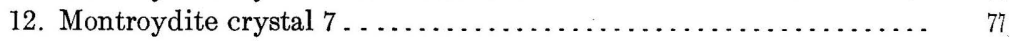

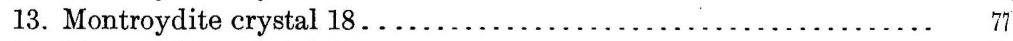

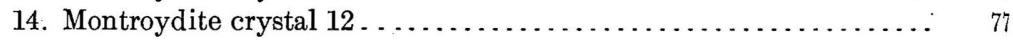

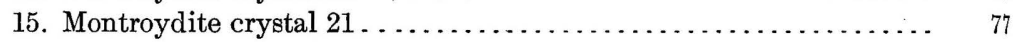

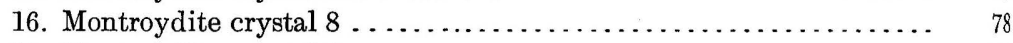

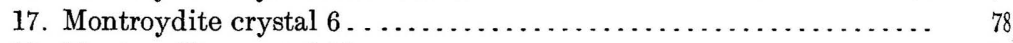

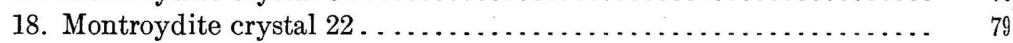

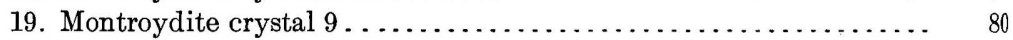

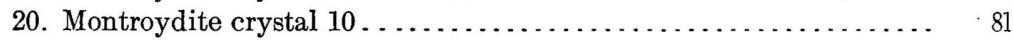

21. Montroydite, scepter crystal (No. 24) ..................... 82

22. Montroydite, distorted crystal (No. 23) . . . . . . . . . . . . . 82

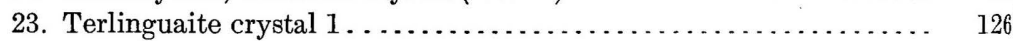

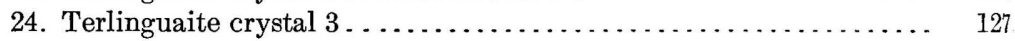

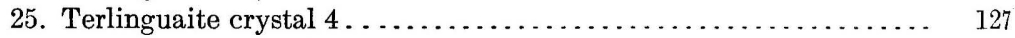

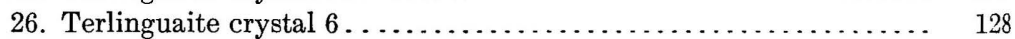

27. Terlinguaite crystal 7 (front) .......................... 129

28. Terlinguaite crystal 7 (back) . . . . . . . . . . . . . . . . . 130

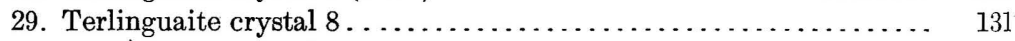

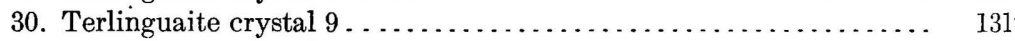

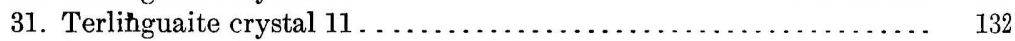

32. Eglestonite, dodecahedral habit (after Moses) .................... 153

33. Eglestonite, dodecahedral habit........................ 153

34. Eglestonite crystal, octahedral habit ..................... 154

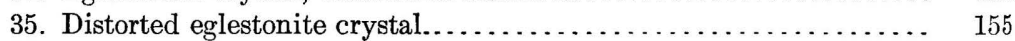

36. Flattened eglestonite crystal........................... 155

37. Striated distorted eglestonite crystal . . . . . . . . . . . . . . . 156

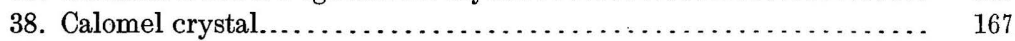

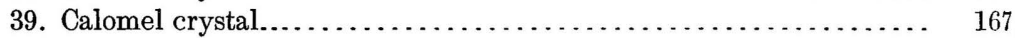

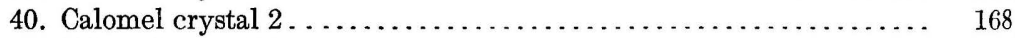

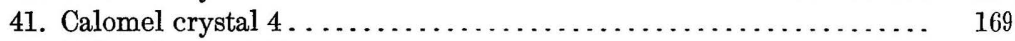

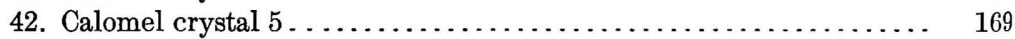

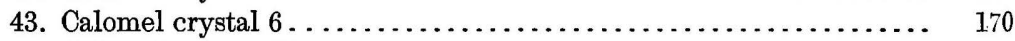

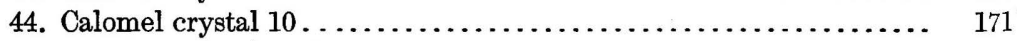




\title{
THE MERCURY MINERALS FROM TERLINGUA, TEXAS.
}

\author{
By W. F. Hillebrand and W. T. Schaller. ${ }^{a}$
}

\section{INTRODUCTION.}

In the late fall of 1905 the senior author received for identification from Mr. H. W. Turner, at that time connected with the Marfa and Mariposa Mining Company, of Terlingua, Tex., specimens of two minerals from the well-known Terlingua mercury field in Brewster County. One of these proved to be the unidentified mineral referred to as No. 5 by A. J. Moses in his paper ${ }^{b}$ on new mercury minerals from this district, namely, terlinguaite, eglestonite, and montroydite, the last of these being mercuric oxide, the others oxychlorides. The composition of Mr. Turner's specimens of this No. 5 proved to be so remarkable, in showing that the mineral belonged to the mercuryammonium compounds hitherto unknown in nature, that more material was solicited, not only of No. 5 , but also of the minerals described more fully by Moses, in order to subject these last to more detailed examination as to their oxygen content. This had been determined solely by difference in the analyses reported by him, and, in the light of the unexpected composition of No. 5, the remainder assumed to be oxygen might not have been wholly such. The result, however, of this examination was to confirm the results published by Moses.

Mr. Turner kindly placed us in correspondence with Mr. J. H. Hartley, also in the employ of the Marfa and Mariposa Mining Company, who during the next few months furnished much excellent material, comprising all the above-indicated species, besides calomel and mercury. Later an additional supply of No. 5 was sent by Mr. R. M. Wilke, of Berkeley, Cal., who had earlier received his material from Mr. Hartley. Prof. A. J. Moses kindly identified the new mineral with his No. 5, and sent his original measurements of it. To all these gentlemen our thanks are tendered, especially to Mr. Hartley for his open-handed liberality and for the information conveyed by some of his letters. To Dr. P. G. Nutting, of the Bureau of Standards, Washington, D. C., and Prof. B. B. Boltwood, of Yale Univer- 
sity, we are also under obligations for tests on this mineral No. 5, which in the following pages will be referred to by the name kleinite.

When this investigation was commenced it was without the slightest anticipation of the magnitude of the work or that such a length of time would elapse before the detailed results could be put in print. In spite of the time consumed at intervals during a year and a half we are well aware that many interesting points have been either not entered on at all or very inadequately studied. This is particularly true with respect to the unique mineral kleinite, partly because the first sendings did not afford sufficient material of selected quality for the completion of the investigations, so that it was necessary to repeat on new samples entire analyses and series of tests that might have been spared if the samples of each mineral had been uniform in quality. Then, again, the importance of certain tests did not become apparent till the test material was exhausted; and furthermore the best available was not suitable for the final settlement of special points.

\section{OCCURRENCE AND ASSOCLATIONS OF THE MINERALS.}

\section{GEOLOGIC OCCURRENCE.}

No attempt will be made to repeat at length the published descriptions of those who are acquainted at first hand with the geologic occurrence of the mercury minerals in Brewster County, Tex., but a very brief statement seems called for on behalf of those readers who are not familiar with the writings of the geologists who have visited the field.

The mercury ores, chiefly cinnabar, are found in both Upper and Lower Cretaceous formations, but up to the present the productive workings have been in the Lower Cretaceous, which is composed mostly of thick-bedded limestones. The lodes, in Turner's words, ${ }^{a}$ "are distinctly of the nature of fissure veins and are mineralized lines of faulting. ***" According to the composition of the vein matter they are either friction-breccia lodes or calcite lodes: In the Upper Cretaceous the deposits are in fissure veins in the Eagle Ford shale. There the veins are filled with clay and gypsum, and less iron oxides and calcite. The only ores in them are cinnabar and mercury, with which is associated considerable pyrite, a mineral that has disappeared from the veins of the Lower Cretaceous. Quartz is wholly absent from the lodes of both formations. The lodes are much cut by igneous dikes, etc., and the ore deposits are said to be invariably near these manifestations of dynamic activity.

The minerals that form the subject of the present report are from the Lower Cretaceous, and, so far as known to us, came from the 
properties of the Marfa and Mariposa Mining Company, especially the Terceiro shaft. Although the chief ore of the region is cinnabar, no trace of this shows on any of the specimens sent us, ${ }^{a}$ the reddish color of parts of some specimens being due to an oxide of iron. The suspicion is forced upon us by this circumstance and by the writings of geologists and letters from Mr. Hartley that the crystals of montroydite have been more than once mistaken for cinnabar.

No precise information is available as to the underground relations of the present specimens to the cinnabar ore or of the different specimens and lots to each other, but from Mr. Hartley's statements it is evident that these minerals in well-crystallized condition are extremely scarce, and that but few cavities containing them have been opened, though it seems no less true that many tons of material inferior or worthless from the mineralogist's point of view have been run through the furnaces.

In the absence of adequate information on which to base a complete theory to account for the origin and succession of these minerals, it is well to avoid what would be profitless discussion of these points, but it is deemed proper to put before the reader the facts of occurrence and association in so far as they are shown by the specimens at command.

\section{THE MATRIX.}

The matrix on which the mercury minerals are deposited is of two kinds: (1) A soft earthy mass, generally of a pink color, and (2) a layer of fairly pure granular calcite. This calcite layer in all our specimens is on the earthy material.

1. The matrix described as a soft earthy mass consists largely of a hydrous siliceous-aluminous material insoluble in hydrochloric acid, stained by iron compounds, and with varying but small amounts of calcium carbonate. It is generally of a pinkish color, rarely white or deep red-brown. When white, it is practically free from calcium carbonate and contains but a trace when red-brown. One of the specimens shows this matrix to have been originally a brecciated limestone cemented together by calcite. Some of the specimens are heavily impregnated with calomel, while others contain a considerable quantity of a yellowish powder, which in one specimen has been qualitatively determined to be kleinite, in others is doubtless terlinguaite, and in still others probably mixtures of terlinguaite and eglestonite (?). All of the specimens of the pinkish matrix that were tested gave a sublimate of calomel in a closed tube, even though no mercury mineral was visible. The white earthy material, which has a clayey appearance and may possibly be somewhat different from the pink, gave no test for carbonates, but did give a sublimate of calomel.

$a$ Since the above was written Mr. Turner has sent us some specimens of vermilion cinnabar in a powdery form. 
2. The calcite layer or second form of matrix reaches a thickness of about 5 centimeters, but is usually from 2 to 3 centimeters thick. It consists of coarse crystalline calcite, showing large cleavage surfaces, but owing to its compactness showing no crystals except those in a few cavities and large scalenohedral crystals on its surface. The spaces between these last seemed peculiarly suited to the growth of the long needles and other peculiar forms of montroydite that will be described later.

\section{ASSOCIATIONS.}

KLEINITE.

Kleinite is found with calcite and gypsum, rarely with barite or calomel. Most of the specimens we have are loose crystals or aggregates of crystals containing only a small amount of the pinkish gangue. The few matrix specimens seen show the kleinite embedded in, impregnating, filling cavities, and crystallized on the pink or mostly light-gray to nearly white earthy matrix that is practically free from carbonates. This clayey material forming the matrix is probably the same as that which is included in the kleinite crystals and which is reported as nonvolatile in the analyses (p. 41). On one specimen received by the Survey (from W. B. Phillips) some years ago from a different locality (working east of California Hill, block $\mathrm{G} 12$ ) there is a single small mass of kleinite on a large specimen of the pink matrix heavily impregnated with calomel. On no specimen is the kleinite directly associated with either native mercury, mercury oxide, or any mercury oxychloride. Kleinite is found on one specimen, which contains also terlinguaite and montroydite, but, as the following description shows, its association is rather indirect. The specimen consists of a mass of the pink earthy matrix, on which is a calcite layer having on its surface crystals of montroydite and terlinguaite. The pink earthy mass contains considerable kleinite in a massive crystalline state and also as a powder. Thus while the terlinguaite and montroydite are found on the same specimen the matrices are different and the kleinite is further separated from the terlinguaite and montroydite by the intervening calcite layer. Kleinite has not been found included in nor does it inclose any other mineral except invariably some of the clayey gangue.

\section{MONTROYDITE.}

Montroydite is found with calcite, terlinguaite, and mercury, and rarely with calomel, gypsum, and eglestonite. It characteristically occurs on the calcite layer with terlinguaite. It is often seen embedded in the calcite, occupying the spaces between the calcite crystals and also deposited on the scalenohedra. The only exception is the specimen showing montroydite with the pink gangue 
heavily impregnated with calomel. The montroydite is so associated with terlinguaite and calcite crystals as to suggest very strongly their contemporaneity of formation. One single needle of montroydite was found to which was attached a gypsum crystal. Montroydite has been observed partly inclosed in calcite, and it itself incloses mercury.

TERLINGUAITE.

Terlinguaite has been found with calcite, montroydite, and mercury, and rarely with eglestonite and calomel. The crystallized variety is, with one exception, found only on the calcite layer, while the powdery form occurs on and in the pink matrix. The exception referred to shows terlinguaite (with a little calomel) directly on the pink matrix. Apparently there is no calcite present. The terlinguaite has not been found inclosed in any other mineral except that it is embedded, together with montroydite, in the calcite layer. The crystals of terlinguaite sometimes inclose mercury.

EGLESTONITE.

Eglestonite is found with calomel, calcite, and mercury and rarely with terlinguaite and montroydite. Its characteristic association is with calomel and mercury on the red-brown matrix nearly free from carbonate, the eglestonite itself resting on the calomel. On some of the specimens of terlinguaite on calcite there are a few isolated crystals of eglestonite, but these are always on the terlinguaite. On the specimen of calomel on limestone (Terceiro shaft, No. 5 lode) there are also a few eglestonite crystals on the calcite. Eglestonite is further found inclosed in a massive material composed of calomel and the red-brown phase of the matrix. It has not been found included in or inclosing any other mineral except native mercury, and that only partly.

CALOMEL.

Calomel is associated with native mercury, calcite, and eglestonite, and rarely with kleinite, terlinguaite, and montroydite. Its matrix is characteristically the altered rock of pink or deep red-brown color and carrying only a small amount of carbonates. One small specimen from the Terceiro shaft, No. 5 lode, shows a group of calomel on limestone with calcite crystals, and some specimens of the pink matrix are heavily impregnated with calomel. These last sometimes inclose small pieces of limestone, in the cavities of which is found montroydite. The two specimens which show calomel with kleinite and montroydite, respectively, are free from any native mercury. Calomel has not been found included in or inclosing any other mineral than mercury. It is to be noted that the calomel is found directly on the pink matrix, while eglestonite, calcite, and mercury are found on the calomel. 
MERCURY.

Native mercury accompanies all the other mercury minerals, except kleinite. On the pink matrix it is found deposited on calomel and eglestonite, but on the calcite layer it occurs with montroydite and terlinguaite. It is also found inclosed in both of these last.

SUMMARY.

We may thus divide these mercury minerals and their characteristic associates into three groups based on their common occurrence and association. In the first group are kleinite, calcite, and gypsum on a pink to white clayey matrix free from carbonates. In the second group are calomel, eglestonite, mercury, and calcite on the pink matrix. In the third group are montroydite, terlinguaite, and mercury on the calcite layer.

\section{INTRODUCTION TO CRYSTALLOGRAPHY.}

The crystallographic work done on these minerals is a striking illustration of the wonderful capabilities of the two-circle goniometer. In order to show this tersely it will here suffice to mention instances. On one-half of an eglestonite crystal, measuring less than one millimeter in diameter, 102 faces were measured and determined. Terlinguaite crystal No. 11, measuring 2 by $1 \frac{1}{2}$ by $1 \frac{1}{4}$ millimeters, allowed 96 faces to be measured and determined, and on crystal No. $6,1 \frac{3}{4}$ by 15 millimeters, 174 faces were determined. While one has generally a good idea of the great simplicity and of the various possibilities of two-circle measurements, it is only during and after the study of a group of minerals such as we have here that one fully realizes what a debt the science of mineralogy owes to Professor Goldschmidt for his development of two-circle measurement. Almost all of the six systems of crystallography are represented by these mercury minerals: Eglestonite, isometric; calomel, tetragonal; kleinite, hexagonal; montroydite, orthorhombic; and terlinguaite, monoclinic; and the phenomenon of twinning is well illustrated by calomel.

Most of the crystals described in this paper are small, being rarely over a few millimeters large. As they all possess a good zone of reference, no difficulty was had in adjusting the crystals in polar position, and rapidly making the necessary measurements. Many of these were repeated, often after a considerable length of time, whenever it seemed advisable to obtain verification of the results first obtained. It was found, as has been observed previously on other minerals, that where the crystals could be accurately adjusted and the faces gave good reflections, the second measurements seldom varied more than two or three minutes from those first obtained. 
In his "Development of crystal forms," Goldschmidt ${ }^{a}$ has given us a remarkable means of critically analyzing a given form system and showing what forms are most likely to actually occur on a crystal. This furnishes also a most valuable criterion as to whether or not the correct symbols have been deduced from the measurements. Such a discussion of the forms is given in this report for all mercury minerals here described and this has been of the greatest value in deciphering many of the rich combinations observed. The finished discussion does not reveal its value so much to the reader, since the results presented are the final ones obtained after a consideration of all points brought out.

Nothing need be said here relating purely to two-circle goniometric measurements. To those not familiar with the methods reference to any of the recent volumes of the Zeitschrift für Krystallographie und Mineralogie will show many papers by Goldschmidt and others, not only describing the method in its various forms but also eloquently testifying to its value. The different books by Goldschmidt also contain the principles of the method, and to these, together with some particular papers by him, showing the application of the method to crystals of the various systems, the reader who is desirous of acquiring fuller knowledge of this subject is referred.

In order to render the discussion of the forms more intelligible to the reader who has not followed the recent developments along this line, the following short description is given. It may be here mentioned that an excellent summary in English of Goldschmidt's paper on the development of crystal forms is given by A. J. Moses. ${ }^{b}$ The paper on "Formulæ and graphic methods for determining crystals in terms of coordinate angles and Miller indices," by Alfred J. Moses and Austin F. Rogers ${ }^{c}$ contains much information in a valuable and compact form for the various calculations incidental to two-circle measurement, and the formulæ there given have been used by the writer in preference to the more ponderous ones given by Goldschmidt in the front part of his Winkeltabellen.

In a discussion of the form system of a mineral, it is desirable to reduce each zone under discussion to a form comparable with one of the normal series as previously developed. These normal series are:

$$
\begin{array}{lllllllll}
N_{0}=0 & \infty & & & & & & \\
N_{1}=0 & 1 & \infty & & & & & \\
N_{2}=0 & \frac{1}{2} & 1 & 2 & \infty & & & & \\
N_{3}=0 & \frac{1}{3} & \frac{1}{2} & \frac{2}{3} & 1 & \frac{3}{2} & 2 & 3 & \infty \\
\text { Etc. } & & & & & & & &
\end{array}
$$

\footnotetext{
$a$ Goldschmidt, V, “Ueber Entwickelung der Krystallformen:” Zeitschr. Kryst. Min., vol. 28, 1897, pp. 1-36, 414-451.

$b$ Note on recent mineralogical literature: School of Mines Quart., vol. 25, 1904, p. 415.

cSchool of Mines Quart., vol. 24, 1902, pp. 1-36.
} 
If a zone or zone section of a crystal can be reduced to a form identical with one of the normal series given above, it is probable that that zone or zone section of the crystal is normal and that its growth or formation has suffered little or no disturbance. The individual crystal forms comprising such a normal series have a "probability" of correctness that is greater than the "probability" of forms that do not reduce to a member of the normal series. Therefore, those crystal forms which fail to accord by proper manipulation with some member of the normal series $N_{n}$ invite criticism to see whether the form really exists or whether the indices have been incorrectly determined. Three results may follow such a criticism of a nonaccording form:

(a) The form was determined by an error and does not exist.

(b) The indices of the form were incorrectly determined.

(c) The determination of the form was correct in every way.

As a result of the last of these $(c)$, we must conclude that a part of the crystal zone was affected by disturbing influences during its growth and that, therefore, the particular form was not allowed to grow in its natural position. If, therefore, by a discussion of a zone we produce a series, parts of which do not agree with the normal series, we are not necessarily warranted in casting doubts upon the existence of these nonagreeing forms. But if, by measurements or other means, we offer proof that such forms do exist on the crystal, we may say that the zone has suffered disturbance at that point. In fact, the disturbing influences at work during the formation of a crystal are so numerous. and diverse in their effects that it is very seldom that a zone will reduce to a series which, upon comparison with a normal series, shows perfect agreement. This nonagreement with the normal series may take place in three ways:

(a) The nonagreeing form may be extra.

(b) The nonagreeing form may differ from the corresponding member of the normal series.

(c) The form that should agree with a member of the normal series may be missing.

In the discussion in this paper, if a form be extra it is included in the normal series $N_{n}$, but is inclosed in parentheses. It is generally ascribed to the effect of "disturbing influences" and criticism of the form leads only to the two questions, (a) Does the form actually exist? and $(b)$ Is it a vicinal form? If the form differs from the corresponding member of the normal series, it is included in the series $N_{n}$ but is inclosed in brackets, and generally invites discussion as to the correctness of its indices. When the form to agree with a member of the normal series is missing in the zone under discussion, its absence is indicated in the series $N_{n}$ by a dot. 
The use of these three signs has been introduced by the writer, as he believes that they simplify the discussion and render the comparison of the zone under discussion with the normal series easier.

\section{NONMERCURY MINERALS.}

\section{CALCITE.}

Calcite is the most abundant of all the minerals found at Terlingua and has been noticed with all of our mercury minerals. Judging from two published papers ${ }^{a}$ deścribing calcite crystals from this region, there are two distinct habits, namely, (1) rhombohedral, due to the large development of the form $f\{02 \overline{2} 1\}$ and (2) scalenohedral, due to the large development of the common form $v\{21 \overline{3} 1\}$. All of our crystals are of the latter habit. While the rhombohedral crystals are apparently rather rich in forms, the scalenohedral crystals are very simple, seldom showing any other form than $\{21 \overline{3} 1\}$. A few crystals have, in addition, $r\{10 \overline{1} 1\}$ as small faces and $f\{02 \overline{2} 1\}$ as very narrow dull faces, while one face each of $e\{01 \overline{1} 2\}$ and $d:\{13.1 . \overline{14} .15\}$ were also noticed. A single incomplete crystal measuring 6 millimeters high and 4 millimeters thick showed a somewhat richer combination, namely: $r\{10 \overline{1} 1\}, \varepsilon\{01 \overline{1} 1\}, v\{21 \overline{3} 1\}, t\{21 \overline{3} 4\}, \mathfrak{n}\{12 \overline{3} 2\}$ and the new positive scalenohedron $\mathfrak{h}\{11.5 . \overline{16} \cdot 21\}$. This crystal is shown in ideal development in figure 1 , which, however, does not show the new form $\mathfrak{h}\{11.5 \cdot \overline{1} \overline{6} \cdot 21\}$ or the form $\sharp\{12 \overline{3} 2\}$. The following table shows the most important of the measured angles.

Measured and calculated angles of calcite.

\begin{tabular}{|c|c|c|c|c|}
\hline \multirow{2}{*}{ Form. } & \multicolumn{2}{|c|}{ Measured. } & \multicolumn{2}{|c|}{ Calculated. } \\
\hline & $\phi$ & $\rho$ & $\phi$ & $\rho$ \\
\hline - & 0,1 & $\circ \quad$, & 0,1 & $\circ \quad 1$ \\
\hline $01 \overline{1} 1$ & 002 & 4437 & 000 & 4436 \\
\hline 2134 & 1923 & 3307 & 1906 & $\begin{array}{lll}33 & 07\end{array}$ \\
\hline$-12 \overline{3} 2$ & 1906 & 5134 & 1906 & 5232 \\
\hline 11. 5. $\overline{1} \overline{6} .21$ & $17 \quad 39$ & 3343 & 1747 & 3340 \\
\hline 13. 1. 14. 15 & 2620 & 4122 & 2619 & $41 \quad 39$ \\
\hline
\end{tabular}

The negative unit rhombohedron $\varepsilon\{01 \overline{1} 1\}$, 'a rare form, is present as three faces, all very small and giving poor reflections. The new scalenohedron shows only one face, very narrow, not striated, and giving a fair reflection. It is very close to $\{21 \overline{3} 4\}$ with which it

a Eakle, A. S., Notes on lawsonite, columbite, beryl, barite and calcite: Bull. Dept. Geology Univ. California, vol. 5, 1907, p. 91 , Sạchs, A., Gypsum and calcite crystals from Terlingua, Tex.: Centralbl. Min., Gẹol. ụ. Pạl., 1907, p. 18. 
occurs. The signal is slightly blurred and measurements of the two sides of the signal gave $\phi=17^{\circ} 25^{\prime}$ to $17^{\circ} 53^{\prime} ; \rho=33^{\circ} 42^{\prime}$ to $33^{\circ} 44^{\prime}$. While the indices are rather complex, if we change them to the orientation as given by Goldschmidt $\left(G_{2}\right)$ in his Winkeltabellen, the indices become $\{72 \overline{9} 7\}$ and the form fits in well between the two known forms $\{21 \overline{3} 4\}$ and $\{52 \overline{7} 3\}$.

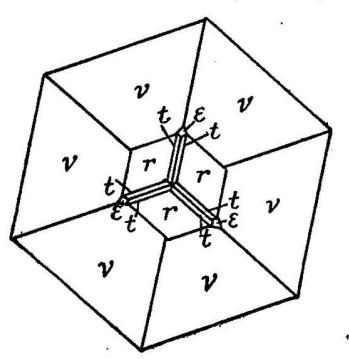

Symbol $\{52 \overline{7} 3\}$ becomes $\{62 \overline{8} 6\} G_{2}$.

Symbol $\{11.5 . \overline{1} \overline{6} .21\}$ becomes $\{72 \overline{9} 7\} \quad G_{2}$ (new form).

Symbol $\{21 \overline{3} 4\}$ becomes $\{8.2 . \overline{1} \overline{0} .8\} G_{2}$.

The following list shows the 29 forms observed on calcite from Terlingua, Tex., with the names of the observers: ${ }^{a}$

\section{Forms.noted on calcite from Terlingua, Tex.}

10̄̄0, E., Sa. $\quad 21 \overline{3} 1$, E., Sa., Sch. $17.2 . \overline{1} \overline{9} .5$, E. $11 \overline{2} 3$, E. $\quad 21 \overline{3} 4$, E., Sch. $\quad 71 \overline{8} 6$, E.

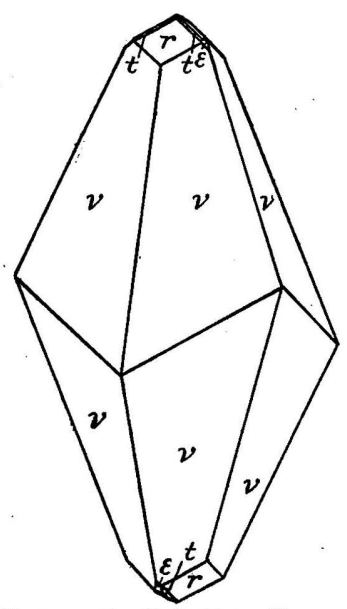

FIgURE 1.-Calcite. Forms, $r\{10 \overline{1} 1\}, e\{01 \overline{1} 1\}, v\{21 \overline{3} 1\}$, $t \quad\{21 \overline{3} 4\}$. The new form h $\{11.5 . \overline{1} \overline{6} .21\}$ is not shown but it lies very near $t\{2134\}$.

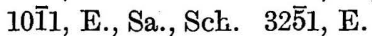

$20 \overline{2} 1, \mathrm{E}$.

$01 \overline{1} 2$, E., Sch.

$01 \overline{1} 1$, Sch.

$02 \overline{2} 1$, E., Sa., Sch.

0.11.11.1, E.

$0.13 . \overline{1} \cdot 1, \mathrm{Sa}$.

$0.14 . \overline{14} .1, \mathrm{E}$.

11.5. $\overline{16} .21$, Sch.

7.2. $\overline{9} .11$, Sa.

17.11. $\overline{2} \overline{8} .6, \mathrm{Sa}$.

? 16.8. $\overline{24} .3, \mathrm{Sa}$.

16.7. $\overline{2} \overline{3} .3, \mathrm{E}$.

$52 \overline{7} 9$, E.

$41 \overline{5} 6$, E.
51 $\overline{6} 4, \mathrm{E}$.

$41 \overline{5} 3$, E.

7.4.11.3, E.

8.5. $\overline{13} .3, \mathrm{E}$.

10.4. $\overline{14} .3, \mathrm{E}$.

13.1. $\overline{14} .15$, Sch.

$12 \overline{3} 2$, Sch.

The scalenohedral crystals often reach a length of several centimeters and are usually of a brownish shade. This is due to the fact that while the interior is colorless the outside layer of the crystal, several millimeters thick, includes some iron oxides.

\section{GYPSUM.}

Gypsum is present on only a few of our specimens, though it occurs rather abundantly with the crystallized kleinite. It has

been noticed once on a group of large calcite scalenohedra with montroydite and terlinguaite, and one needle of montroydite was found attached to a mass of gypsum. The abundance of gypsum with the only mercury mineral that contains the $\mathrm{SO}_{4}$ radicle is noteworthy. It forms small crystal masses, often striated but usually not developed in distinct crystals. ${ }^{b}$ On one piece a number of forms were measured in the prism zone on a crystal tabular to the clinopinacoid, with the following results: 
NONMERCURY MINERALS.

Measured and calculated angles for gypsum.

\begin{tabular}{|c|rc|rc|}
\hline Symbol. & Measured. & \multicolumn{2}{|c|}{ Calculated. } \\
\hline & & & \multicolumn{2}{|c|}{} \\
\hline & $\circ$ & \multicolumn{1}{|c|}{$\circ$} &, \\
$b \wedge m=010: 110$ & 55 & 42 & 55 & 44 \\
$b \wedge r=010: 140$ & 20 & 33 & 20 & 09 \\
$b \wedge h=010: 120$ & 36 & 48 & 36 & 17 \\
$b \wedge \alpha=010: 210$ & 71 & 04 & 71 & 11 \\
$b \wedge z=010: 310$ & 77 & 11 & 77 & 12 \\
\hline
\end{tabular}

The form $l\{111\}$ is also probably present, but too poorly developed to be measured. Sachs ${ }^{a}$ has described gypsum crystals from this locality showing $\{010\},\{110\},\{111\}$.

\section{BARITE.}

A very few minute barite crystals were found with a lot of loose kleinite crystals received from Mr. Wilke, of Berkeley, Cal. They showed the forms $\{001\},\{011\}$, and $\{110\}$.

Measured and calculated angles for barite.

\begin{tabular}{|c|c|c|}
\hline Symbol. & Measured. & Calculated \\
\hline & & 。 \\
\hline $\begin{array}{l}010 \wedge 110 \\
001 \wedge 011\end{array}$ & $\begin{array}{ll}50 & 44 \\
52 & 40\end{array}$ & $\begin{array}{ll}50 & 49 \\
52 & 43\end{array}$ \\
\hline
\end{tabular}

JAROSITE.

A specimen of a brown brecciated rock (not a limestone) was received some years ago from Mr. W. B. Phillips, the accompanying label reading "Vein filling-Sec. 100. Blk. G. 12-Brewster Co., Tex." The relation in place of the specimen to the mercury minerals is not known to us. The fragments of rock are cemented together by a porous brown mass consisting largely of very fine grained compact jarosite. The abundant cavities therein are lined with numerous minute, brilliant, dark-brown crystals of the same mineral. They have a cubic aspect due to the predominance of the $r$ faces. Other forms present, usually as very small triangular faces, are $c\{0001\}$ and $s\{02 \overline{2} 1\}$. The averages of the measured angles are shown below.

Measured and calculated angles for jarosite.

\begin{tabular}{|c|c|c|}
\hline Symbol. & Measured. & Calculated. \\
\hline & & \\
\hline$c \wedge r(0001: 10 \overline{1} 1)$ & 55 & 55 \\
\hline$c \wedge s(0001: 02 \overline{2} 1)$ & 70 & 70 \\
\hline$r \wedge r^{\prime}(10 \overline{1} 1: \overline{1} 101)$ & 91 & 90 \\
\hline
\end{tabular}

$a$ Centralbl. Min., Geol., u. Pal., 1907, p. 18.

4494-Bull. $405-09-2$ 


\section{MERCURY MINERALS.}

\section{KLEINITE.}

\section{HISTORY.}

The senior author announced in the winter of $1905-6^{a}$ the discovery that the yellow mineral from Terlingua, which Moses had thought might be an oxychloride of mercury (his No. 5) related to terlinguaite and eglestonite, was in reality a mercury-ammonium compound containing chlorine and the sulphate radicle, probably with oxygen and possibly with hydrogen. Quantitative data had been obtained, which as to the four main constituents were in close agreement with the values hereinafter submitted, but these were not published for the reason that it was desired to secure confirmatory results on a number of different specimens. Nor was a name for the new mineral offered, because it was intended to give one indicative in a measure of the composition of this unique mineral in case the opinion formed as to its character should be verified. The name that naturally suggested itself was mercurammonite. On the day preceding the appearance of the first of the preliminary announcements (the one in Science) Prof. A. Sachs, of Breslau, offered in a meeting of the Prussian Academy of Sciences a paper ${ }^{b}$ on what was evidently the same mineral, but which his analyses showed to be an oxychloride- $-\mathrm{Hg}_{4} \mathrm{Cl}_{2} \mathrm{O}_{3}$ or $\mathrm{HgCl}_{2}+3 \mathrm{HgO}$ - and to which he gave the name kleinite, after the eminent mineralogist Carl Klein. His analytical data were:

Sachs's original analyses of kleinite.

\begin{tabular}{|c|c|c|c|c|}
\hline & 1. & 2. & 3. & 4. \\
\hline \multirow[t]{2}{*}{$\begin{array}{l}\mathrm{Hg} \\
\mathrm{Cl} \\
\mathrm{O} \\
\text { Residue }\end{array}$} & $\begin{array}{r}86.78 \\
7.94 \\
b 5.28 \\
\ldots . . .\end{array}$ & $\begin{array}{r}82.83 \\
7.25 \\
c 4.99 \\
4.93\end{array}$ & $\begin{array}{r}84.26 \\
8.02 \\
c 4.93 \\
b 2.79\end{array}$ & $\begin{array}{c}a 87.07 \\
\ldots \ldots \ldots \\
\ldots \ldots \ldots \\
\ldots \ldots \ldots\end{array}$ \\
\hline & 100.00 & 100.00 & 100.00 & \\
\hline
\end{tabular}

The above-mentioned announcement of the mercury-ammonium mineral caused Professor Sachs to make new analyses and to find indeed that his material was of the same nature, ${ }^{c}$ but he was disin-

$a$ Science, vol. 22, 1905, p. 844; Am. Jour. Sci., 4th ser., vol. 21, 1906, p. 85; Jour. Am. Chem. Soc., vol. 28,1906, p. 122.

$b$ Published Jan. 11, 1906, Sitzungsber. K. preuss. Akad. Wiss., Berlin, 1905, p. 1091.

c Centralbl. Min., Geol. u. Pal., 1906, pp. 200-202. 
clined to believe that the material first analyzed by him contained any nitrogen or sulphur. His quantitative data were:

Sachs's later analyses of kleinite.

\begin{tabular}{|c|c|c|c|}
\hline & \multicolumn{2}{|c|}{$\begin{array}{l}\text { Sulphur-yellow } \\
\text { crystals. }\end{array}$} & $\begin{array}{c}\text { Orange } \\
\text { crystals. }\end{array}$ \\
\hline$\underset{\mathrm{Cl}}{\mathrm{Hg}}$ & & & $\begin{array}{r}85.29 \\
6.97\end{array}$ \\
\hline $\begin{array}{l}\mathrm{SO}_{3} \\
\mathrm{NH}_{3}\end{array}$ & $\begin{array}{l}1.05 \\
0.44\end{array}$ & $\begin{array}{l}0.85 \\
1.09\end{array}$ & $\begin{array}{l}2.57 \\
2.79\end{array}$ \\
\hline
\end{tabular}

Assuming the greater purity of the sulphur-yellow crystals, he argued from the varying values for sulphur and nitrogen that these could not be integral components of the mineral, and suggested as perhaps plausible the formula $\mathrm{Hg}_{4}\left(\mathrm{Cl}, \frac{1}{2} \mathrm{SO}_{4}\right)_{2}\left[\mathrm{O},\left(\mathrm{NH}_{2}\right)_{2}\right]_{3}$, which is of the same type as his oxychloride formula, and from which he deduced the following composition for the three samples tested, the constituents other than nitrogen and sulphur being calculated for the first and second columns, and oxygen and hydrogen (of the $\mathrm{NH}_{2}$ radicle) in no case directly determined:

Sachs's later analyses recalculated by himself.

\begin{tabular}{|l|r|r|r|}
\hline & \multicolumn{1}{|c|}{1.} & \multicolumn{1}{|c|}{2.} & \multicolumn{1}{c|}{3.} \\
\cline { 1 - 3 } & & \multicolumn{1}{c|}{} \\
\cline { 1 - 2 } & 86.52 & 86.29 & 85.29 \\
$\mathrm{Hg}$ & 6.79 & 6.96 & 6.97 \\
$\mathrm{SO}_{4}$ & 1.26 & 1.02 & 3.09 \\
$\mathrm{NH}_{2}$ & 0.41 & 1.03 & 2.63 \\
$\mathrm{O}$ & 5.02 & 4.70 & 2.02 \\
& 100.00 & 100.00 & 100.00 \\
& & & \\
\hline
\end{tabular}

It may be said that the surmises of Professor Sachs have not been verified by the work hereinafter set forth, that the composition of the light-yellow crystals at our disposal does not appear to differ in any essential respect from that of the deep-yellow to orange ones, and that oxygen and hydrogen, if belonging at all to the mineral, are present in such trifling amounts that the composition can not be that assumed by Professor Sachs or even remotely like it.

As to the name, in view of the facts that kleinite has entered into the literature and that no exception can possibly be taken to it other than the above-expressed preference for one more indicative of the nature of the mineral, the senior author waives his right by priority of identification and publication to give it a name in consonance with this feeling, and accepts the name "kleinite." 


\section{MODES OF OCCURRENCE.}

The various specimens of kleinite may be grouped under three headings, depending on the form of the mineral.

1. Most of the material occurs in distinct crystals rarely over a millimeter in length and usually much less. These came either attached to the white or pinkish, clayey gangue, or more commonly in loose crystals or aggregates of crystals with but a small amount of gangue matter attached. In regard to this separate and loose form, kleinite differs from all the other mercury minerals (except a few large calomel crystals), which are, or at least were originally, attached to a matrix. The crystals vary from equidimensional to prismatic, the various habits being described and illustrated on pages 45 and 46 .

2. Sometimes the kleinite is found as a crystalline crust, showing crystal faces but no distinct crystals. This crust, while generally thin, is sometimes of considerable extent, though the total amount of kleinite found in this form is small.

3. One specimen shows the kleinite as a yellow powder impregnating the pink, earthy gangue, and it seems probable that the powdery form also occurs on some of the other specimens, particularly those in which the yellow color of the powder does not change to a different color on exposure to light. In some of these the results of chemical tests would seem to indicate that the powder consists of a mixture of kleinite with some other mineral, though such an association could not be proved to exist.

\section{PHYSICAL PROPERTIES.}

COHESION, ETC.

The cleavage of kleinite is basal, good, and prismatic (parallel $m\left\{10^{\circ} 0\right\}$ ), imperfect. While it is easy to obtain the basal cleavage, the resulting surface is never plane, but always rounded and uneven, and on the goniometer gives a mass of reflections that extend through several degrees. All of these reflections, moreover, are about of the same quality; that is, there are no one or two signals that stand out from the rest. The prismatic cleavage is not always easy to obtain, but can be seen on some of the crystals as natural cleavage faces. The surfaces of these faces are not very smooth and do not have a high polish. This prismatic cleavage was accidentally developed in a basal section by pressing a cleavage piece between two glass plates. Figure 2 shows a diagrammatic sketch of the section. The fracture is uneven. No indication of plasticity or sectility was observed.

The crystals are rather brittle; in fact, it is extremely difficult to prevent thin cleavage pieces from breaking in handling. 
The crystals will scratch calcite but not fluorite, though rarely it seemed as if faint lines could be produced on a cleavage surface of fluorite by kleinite. The hardness is therefore about 3.5, probably a little higher.

DENSITY.

Density determinations resulted as follows:

Results of determinations of density of kleinite.

\begin{tabular}{|c|c|c|c|}
\hline Material and method. & $\begin{array}{c}\text { Tempera- } \\
\text { ture. }\end{array}$ & $\begin{array}{l}\text { Weight of } \\
\text { sample. }\end{array}$ & Density. \\
\hline 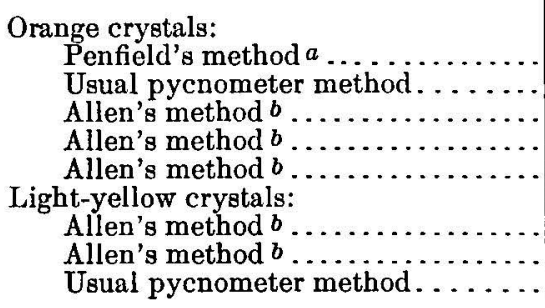 & \begin{tabular}{r|}
${ }^{\circ} C$. \\
23 \\
23 \\
25 \\
25 \\
22 \\
\\
22 \\
22 \\
$(?)^{2}$
\end{tabular} & $\begin{array}{c}\text { Grams. } \\
3.77 \\
3.77 \\
7.593 \\
7.636 \\
3.016\end{array}$ & $\begin{array}{l}7.98 \\
7.96 \\
7.967 \\
7.99 \\
7.98 \\
\\
7.94 \\
7.98 \\
8.04\end{array}$ \\
\hline
\end{tabular}

a Penfleld, S. L., Am. Jour. Scl., 3d ser., vol. 50, 1895, p. 448. Also Bull. U. S. Geol. Survey No. 305, 1907, p. 42.

b Day, A. L., and Allen, E. T., Pub. Carnegle Inst. No. 31, 1905, p. 55. Am. Jour. Scl., 4th ser., vol. 19, 1905, p. 93. Bull. U. S. Geol. Survey No. 305, 1907, p. 43.

The variations in results for the larger weights are due in part to different degrees of contamination by the earthy gangue, but for the light-yellow crystals are more probably to be ascribed chiefly to the small amount of material available for the tests. The average for the orange crystals is 7.975 and for the light-yellow 7.987 , but the results are all low with the possible exception of the value 8.04 , because of the attached and included foreign matter. They are, however, much higher than the figure (7.441) given by Sachs, who does not mention the weight of material used or its degree of purity.

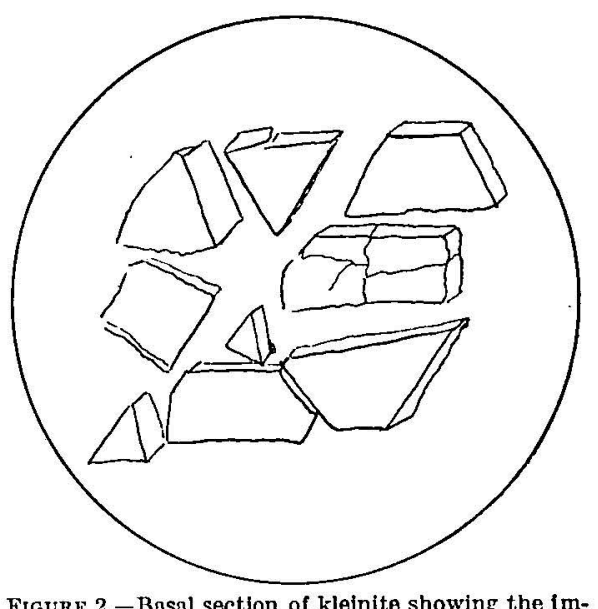

FIGURE 2.-Basal section of kleinite showing the imperfect prismatic cleavage.

LUSTER, COLOR, ETC.

The luster is adamantine to greasy.

Most of our kleinite showed a peculiarity in color at once noteworthy and singular. When exposed to sunlight or even to the dif- 
fused light of a room after having been in the dark, the crystals, at first yellow, almost immediately became much deeper in color, generally reddish yellow or orange, but they regained their original color very soon when placed again. in the dark. The sulphur-yellow powder immediately darkened in strong light, without becoming orange, however. These color changes could be reproduced at will as often as desired. The contrast in color between exposed specimens and those protected from light was most pronounced and could be strikingly, seen by disturbing the contents of a small tray of the mineral fragments. The unexposed parts thus brought to the surface contrasted strongly with those that were still undisturbed. An opposite change has been noticed in East Indian sodalite from Rajputana by T. H. Holland. ${ }^{a}$ In this mineral the original carmine color faded out in bright light, but was restored after some weeks in the dark.

It was also noticed that the exposed crystals were not all of the same color; there were some that had not changed at all, and others that showed all gradations between almost colorless and orange, and one was seen with a dark hexagonal core and a light outer zone. Professor Sachs noticed a similar association of colors. One of the first specimens received was composed entirely of pale-yellow coherent crystal masses, held together by or holding together an earthy reddish gangue. It was suspected that with this difference in color might go a certain chemical dissimilarity, nothwithstanding absolute identity of form and qualitative behavior; therefore the lightest colored crystals and aggregates were picked out and separately analyzed. In disagreement with Professor Sachs, no certain evidence of difference in composition between the permanent and changeable crystals was shown by the analyses (p. 41). It should be said that even the lighter-colored material that was picked out from the samples of loose crystals varied in color, but in mass was very much lighter than the rest in daylight, although it is probable that light was not wholly without effect on it.

The original color of the mineral in the mine is evidently almost canary yellow for the most part, grading from this to a very pale yellow. The permanence of the color of kleinite, except as to the deepening mentioned, makes it easy to distinguish the mineral from eglestonite and terlinguaite after exposure to light, for the former of these turns brown, then black, the latter gray-green, or perhaps olivegreen when earthy.

In transmitted light the crystals vary in shades of yellow corresponding to those seen by reflected light. No pleochroism was noticed. Most of the kleinite is opaque, being in a somewhat granular crystalline state, but the minute crystals that are bounded by 
smooth faces are fairly transparent to translucent. Some of this opacity is doubtless due to the inclusion of an opaque dust. (See "Optical properties.")

The streak is pale yellow, immediately darkening, but regaining its color in the dark.

OPTICAL PROPERTIES.

The mineral being geometrically hexagonal, a basal section should remain dark under crossed nicols. But, as described by Moses, such a section shows double refraction, and if thin enough will be seen to be composed of innumerable individuals, none of which is large enough to show interference figures. The double refraction is strong, the colors being of the third and higher orders. At about $130^{\circ}$ the double refraction begins to decrease, as seen by the descending colors, until finally it becomes zero and the mineral remains dark under crossed nicols. The section now gives a uniaxial, positive interference figure. Upon cooling, the section remains dark, but after the lapse of many months is seen to be slowly returning to its doubly refracting condition. This phenomenon seems to show that kleinite is dimorphous and that the uniaxial optical state agreeing with its outward hexagonal form is stable only above $130^{\circ}$ approximately, while below that temperature its stable condition is biaxial, probably triclinic. According to this the hexagonal crystals of kleinite must have been formed at a temperature not much, if any, below $130^{\circ}$. As is stated just below, it is at a point but a few degrees higher than this that the first permanent browning of the mineral becomes visible when it is heated, and considerable loss of water has then taken place. What connection, if any, there may be between these two phenomena is not known.

The foregoing paragraph gives the essential features of the optical phenomena, which will now be given in more detail.

Most of the sections, viewed under the microscope, showed no difference when the nicols were crossed. As much light passed through as when the nicols were not crossed, and on revolving the stage of the microscope there was not the slightest indication of any extinction. When, however, a basal section was ground down thin enough, or a natural cleavage piece of sufficient thinness was observed, it was found that parts of the section would show extinction while other parts remained uniformly light. The thinnest sections were seen to be composed of a large number of crystal units with no definite shape or orientation either to each other or to the hexagonal outline of the section. Some of these extinguished, others did not. Where there was a straight edge to one of these apparently homogeneous units, the extinction to this edge was oblique. Some of these units seemed to show indications of a biaxial brush when tested for an interference figure, but no definite result was obtained. A dia- 
grammatic view of such a section is shown in figure 3, where the shaded portions represent the parts that showed extinction. The outline of these parts is usually indefinite, and there were also numerous smaller areas, often no larger than a point, that showed extinction, but which are not shown in the figure. . These areas did not extinguish at the same time; in fact, no two areas were found that extinguished together. As can be seen, the light part representing the part of the section that showed no extinction whatsoever on a revolution of the stage of the microscope is by far the larger part of the section. From a study of various sections it appears probable that it is merely due to the thickness of the section that parts do not extinguish. As is well known, a section made up of superimposed biaxial plates will give a resultant grouping that will not extinguish. Such a phenomenon is common with some micas, the superimposed plates of which are often in twin position. With kleinite, however, there is

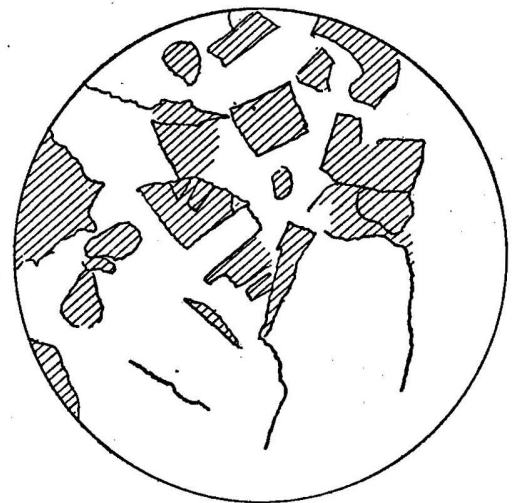

FIGURE 3.-Diagrammatic sketch of basal section of kleinite showing optical unhomogeneity, in polarized light, nicols crossed. probably no twinning, but simply a superimposition of plates of biaxial material, with a result that a basal section of kleinite will in general show no extinction. If a section be ground so thin that the thickness is not greater than that of any of the individual plates, then the entire section will show extinction, but not uniformly. Such sections as show extinction have a very high birefringence, since in the thinnest sections obtainable the colors are all high in the third order and above. It should be remarked, however, that the brittleness of the mineral is a serious detriment to the grinding of very thin sections, as the mineral will often crumble to pieces and the section be lost.

The fact that the mineral undergoes an optical change at about $130^{\circ}$ was found by accident. A section which showed some areas that extinguished, but of which the greater part showed no extinction, was being mounted in Canada balsam in order to grind the section still thinner. When the slide had cooled, it was found that the section remained dark under crossed nicols; and the section was found on testing to give a uniaxial, positive interference figure: In other words, the section behaved as a basal section of a hexagonal mineral would.

The explanation of the phenomenon is, of course, that the optical state agreeing with the hexagonal geometrical form is not stable for the ordinary temperature, but has a range of stability from about $130^{\circ}$ to the temperature at which the mineral is decomposed. In 
other words, the mineral is dimorphous. From the fact that the extinction in such sections of the mineral as show extinction was always oblique and that apparently parts of a biaxial interference figure could sometimes be seen, the state or condition in which the mineral is stable below approximately $130^{\circ}$ is that of either the monoclinic or the triclinic system, and probably the latter.

The particular section in which the change to the optically uniaxial condition was first noticed did not soon revert to the doubly refracting state on cooling, but now, thirty months after the section was heated, almost its entire substance is again doubly refracting, only a very few points remaining dark. Therefore the complete reversion of the entire section from the uniaxial to the biaxial condition takes place, though the change is a very slow one.

After the above facts had been ascertained, the attempt was made to find the exact temperature at which the change took place. Two natural cleavage pieces of sufficient thinness were found and these were heated as follows:

A "heating apparatus" for a goniometer (probably for a universal apparatus of Groth's type) was placed on the stage of the microscope and heated from both ends by two low flames. The thermometers were inserted between the flames and the mineral section, which rested on a glass slide. The heating apparatus was properly insulated by being covered with asbestos, and the mineral section could easily be observed by the microscope. With nicols crossed, the section was watched as the temperature rose, and reversion of the mineral to a uniaxial condition was observed as the colors decreased in the regular scale and finally became black. The following table shows the result of the heating of such basal sections, two different experiments being made. The temperatures given, $T_{1}$ and $T_{2}$, it must be understood, are those read on the two thermometers and are not necessarily the temperature of the mineral. Readings were taken every minute.

Effect of heating first basal section of kleinite.

\begin{tabular}{|r|c|c|l|}
\hline $\begin{array}{r}\text { Time } \\
\text { (a. m.). }\end{array}$ & $\mathrm{T}_{1}$. & $\mathrm{T}_{2}$. & \multicolumn{1}{|c|}{ Remarks. } \\
\hline & ${ }^{\circ} \mathrm{C}$. & ${ }^{\circ} \mathrm{C}$. & \\
9.54 & $\cdots 12$. & $\cdots 127$ & First change noted. \\
10.11 & 126 & 138 & Decided change in color. \\
10.15 & 138 & 138 & \\
10.17 & 142 & 142 & Decided change. \\
10.19 & 145 & 146 & Became dark in spots. \\
10.20 & 147 & 148 & About one-third section dark. \\
10.21 & 149 & 149 & About one-half section dark. \\
10.22 & 151 & 151 & Becoming dark rapidly. \\
10.23 & 152 & 152 & About two-thirds dark. \\
10.25 & 154 & 154 & Almost completely dark. \\
\hline
\end{tabular}


Effect of heating second basal section of kleinite.

\begin{tabular}{|c|c|c|c|}
\hline $\begin{array}{c}\text { Time } \\
\text { (p. m.). }\end{array}$ & $\mathrm{T}_{1}$ & $\mathrm{~T}_{2}$ & Remarks. \\
\hline & ${ }^{\circ} \mathrm{C}$. & ${ }^{\circ} \mathrm{C}$. & \multirow{13}{*}{$\begin{array}{l}\text { Color begins to change. } \\
\text { Heat removed. } \\
\text { Color change decided. } \\
\text { Change stops. } \\
\text { Heat reapplied. } \\
\text { Color change again commences. } \\
\text { Section becomes dark in spots. } \\
\text { Heat removed. } \\
\text { Heat reapplied. } \\
\text { Change very rapid. } \\
\text { Section almost entirely dark. } \\
\text { Heat increased. } \\
\text { Only a few bright spots left. } \\
\text { A few bright spots still remain. }\end{array}$} \\
\hline 12. 30 & & & \\
\hline $\begin{array}{l}12.48 \\
12.49\end{array}$ & 127 & 127 & \\
\hline 12. 50 & 130 & 130 & \\
\hline 12. 52 & 128 & 128 & \\
\hline 12. 53 & & & \\
\hline 1. 03 & 130 & 130 & \\
\hline 1. 07 & 137 & 137 & \\
\hline $\begin{array}{l}1.08 \\
1.14\end{array}$ & & $\cdots \cdot$ & \\
\hline 1. 37 & 140 & 140 & \\
\hline 1. 40 & 142 & 142 & \\
\hline $\begin{array}{l}\text { 1. } 42 \\
\text { 1. } 45\end{array}$ & 160 & 160 & \\
\hline & 170 & & \\
\hline
\end{tabular}

From some preliminary observations made on sections so thick that they showed no extinction, it was found that the change would take place only in very thin sections. Some of the thicker pieces were heated to $175^{\circ}$ without the slightest change taking place. Even the thinnest sections did not become entirely dark, for there were small areas that continued to be doubly refracting for $40^{\circ}$ above the inversion point. These areas, however, were such as showed. no extinction and did not change because of their thickness. The "molecular inertia" of kleinite would seem to be considerable.

An attempt was made to show these changes photographically. In Plate I are reproduced three photomicrographs of a basal section of kleinite: $A$ shows a view of the mineral as it appeared under the microscope in polarized light, the nicols not being crossed; $B$ is the same view with the nicols crossed. While most of the section is doubly refracting, it can be noticed that parts are dark. The section was so placed as to show the maximum amount of extinction. The section was then removed, heated up to about $150^{\circ}$, allowed to cool, and photographed under crossed nicols with the result shown in $C$. With the nicols not crossed the result was the same as in $A$, but the -decided difference between $B$ and $C$ can be seen at a glance. During the manipulation of the section in mounting it for photographing the section became inverted, which accounts for the difference in outline of the fragment. Though heated considerably above $130^{\circ}$, the section still shows considerable area which has not become dark and therefore still retains its birefracting condition.

The sections do not show any pleochroism, and an approximate determination of the mean index of refraction gave a value of about 1.8. The index of refraction would then be considerably lower than that of the other mercury minerals, which fact is in accord with the less brilliant luster of kleinite. 


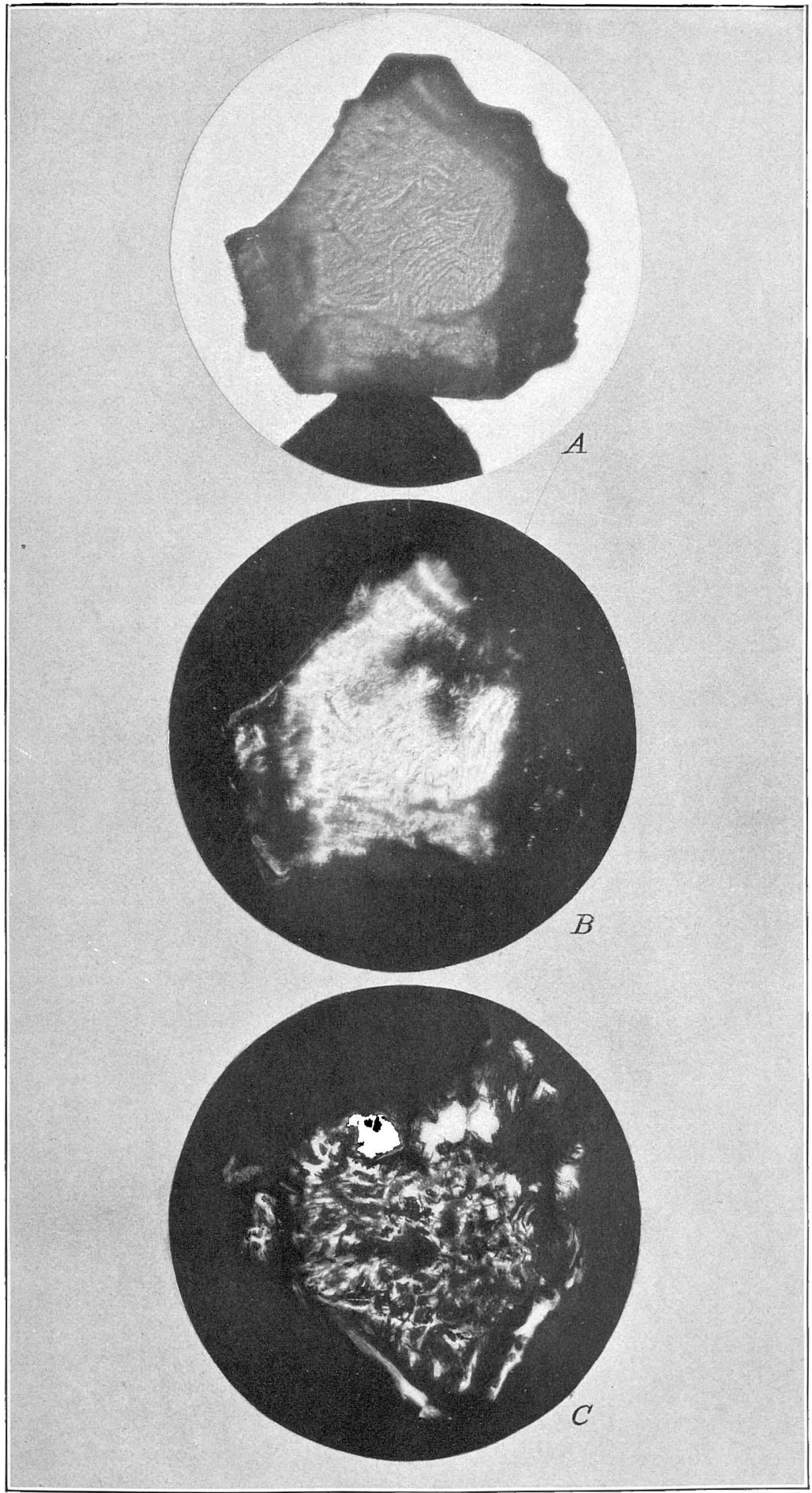

BASAL SECTION OF KLEINITE SHOWING OPTICAL UNHOMOGENEITY.

$A$, Nicols not crossed; $B$, nicols crossed; $C$, nicols crossed, after the section had been heated to $150^{\circ}$ and allowed to cool. 



\section{CHEMISTRY.}

\section{GENERAL CHARACTERISTICS.}

QUALITY OF THE MATERIAL.

While many of the single crystals and crystal aggregates of kleinite were very fine and brilliant, much of the material was far too impure or altered for the chemical tests that were contemplated. It was not difficult to pick out much that was of fair quality, though none was quite faultless, and herein lay the chief obstacle to a satisfactory determination of the actual composition of the crystals themselves, for the water shown by the analysis comes without doubt in part at least from the earthy matter that it was impossible to exclude. Many of the qualitative and orienting quantitative tests were carried out on relatively impure crystals, but most of the quantitative work was done on selected crystals, though the nonvolatile residue from these several portions was in none less than 0.75 per cent, and in one was 3 per cent. Even had it been possible to select crystals absolutely free from external contamination of this kind there would still have remained the difficulty presented by the nonvolatile matter that seemed to permeate the clearest crystals, almost as if in solution, to judge from the microscopic evidence and from the fact that when heated they left a residue similar in its general character to that which was evident to the eye. The majority of the selected crystals were slightly clouded by foreign matter.

PYROGNOSTIC CHARACTERS.

When carefully heated in a closed tube, or in one through which passes a current of air, the mineral loses a little water, begins to brown at $135^{\circ}$ to $150^{\circ}$, and as the temperature rises becomes still darker and yields more water, but gives no other visible sublimate under $260^{\circ}$ even after several hours, though once or twice a gold-leaf plug at the constricted outlet of the tube showed slight amalgamation long before a sublimate appeared. Between $260^{\circ}$ and $280^{\circ}$ mercury and calomel sublime and condense in part together, but most of the mercury just in front of the calomel, the latter being pale yellow when hot. When most of the calomel has passed off, the residue begins to grow lighter colored, then yellowish, and finally nearly white. During the expulsion of the calomel some gas is evolved in minute amount that sets iodine free from potassium iodide solution. (See p. 30.) On increasing the heat to $400^{\circ}$ more of this active gas is evolved, but it is soon followed or accompanied by another that destroys the color of the free iodine. Accompanying the decomposition or volatilization of the white residue at $400^{\circ}-420^{\circ}$ appears a further sublimate less volatile than the calomel. If the test is made in a small closed assay tube this last sublimate and the still unvolatilized 
residue may melt to a dark reddish liquid, which, on cooling, solidifies with a yellowish and then white color. Ammonia turns both sublimates black instantaneously. In the sublimate appearing at the lower temperature can be found all the chlorine of the mineral except a small amount that seems to escape in the free state. (See p. 30.) Below about $400^{\circ}$ nearly all the sulphur is to be found in the residue as mercuric sulphate, and after disappearance of the residue it is mostly in the less volatile sublimate as both mercuric and mercurous sulphate, the relative amounts seeming to depend on the rapidity of the heating.

Most of the nitrogen of the mineral escapes in the elemental state during the formation of the calomel, but not quite all. There is not the least evidence of the formation of ammonia. If the heating is carried out in vacuo the evolution of the active gas, already referred to as taking place during the later stage, is much more marked than at atmospheric pressure.

QUALITATIVE BEHAVIOR TOWARD REAGENTS.

The mineral is soluble in warm hydrochloric as well as nitric acid without deposition of calomel, hence the mercury is in the bivalent state. It is also soluble in sodium sulphide and in ammonium bromide. Ammonium bromide liberates as ammonia for every one part of nitrogen derived from the mineral itself three parts from the reagent. The fixed alkalies do not liberate ammonia. Hydrogen sulphide blackens it speedily, but very superficially. When the mineral is boiled with sodium sulphide for the determination of nitrogen as ammonia much of the mercury often separates in the free state.

ADDITIONAL DATA.

Numerous observations that were made during the quantitative tests will now be detailed, since they bear on the ultimate elucidation of the true nature of the mineral, though it must be confessed that the explanation of some of them is as yet obscure.

DATA RELATING CHIEFLY TO OXYGEN, NITROGEN, AND CHLORINE.

Starting with the idea that the mineral was probably an oxychloride of the same general character as eglestonite and terlinguaite, the first efforts aimed at a direct determination of the oxygen, after decomposing the mineral in a current of carbon dioxide and collecting the gas in a nitrometer over potassium hydroxide solution. The permanence of the gas when tested with alkaline pyrogaliate caused the oxychloride hypothesis to be discarded and suggested the need for similar direct tests on eglestonite, terlinguaite, and montroydite, in order to have indisputable proof of the existence of oxygen in them and that the assumed oxygen was wholly such. The probable identity of the gas from kleinite was shown by the 
well-known test of Lassaigne for the detection of nitrogen in organic bodies, modifying it to the extent of mixing the mineral powder with sugar before heating with sodium. Full proof was afforded by the spectroscopic test kindly made by Dr. P. G. Nutting of the Bureau of Standards. Doctor Nutting on volatilizing a few crystals in an evacuated tube observed no evidence of any of the common gases besides nitrogen and chlorine, though the absence of oxygen could not be asserted owing to the difficulty of its recognition spectroscopically. He reported, however, a faint helium line, which was observed only on the first warming of the mineral. The practically entire absence of radioactivity, as reported by Doctor Boltwood, seems to be in conflict with this observation of Doctor Nutting. The gas was examined by us during our earlier experiments at different stages of its expulsion, using a small spectroscope, and while the different spectra of nitrogen were always in evidence, according to the degree of evacuation of the tubes, no peculiarities were observed that suggested appreciable if any admixture of another gas. When the gas was exposed to phosphorus after contact with solid sodium hydroxide, on at least two occasions evidence of the presence of a little oxygen was very positive. (See next paragraph for its probable source.) Several portions of gas that had been exposed to alkali and phosphorus were combined and passed over hot magnesium, the result being almost complete disappearance of the gas; that unabsorbed was hydrogen that had apparently come from the magnesium itself.

The derivation of the oxygen just mentioned is of much importance, for it might originate from a basic mercury compound and then have to be reported as well as the oxygen of the $\mathrm{SO}_{4}$, or it might be of secondary origin, or it might derive from both sources. It has already been said that it was found possible to separate almost quantitatively the chlorine from the sulphur by slow and careful heating of the mineral, the former volatilizing as calomel, the latter remaining as mercuric sulphate. When this separation was effective, that is, when the chlorine could be recovered almost entirely from the sublimate and no sulphur was to be found with it, then no oxygen was detected with the nitrogen, and nearly all of this latter element had passed out of the mineral. If, on the other hand, the heating was carried to the point of volatilization of the residual sulphate (about $400^{\circ}$ to $420^{\circ}$ ) partial decomposition of this salt often resulted, but not always. (When the sulphate was quickly heated in an assay tube closed at one end a strong odor of sulphur dioxide became apparent.) This partial decomposition must have been accompanied by the liberation of oxygen. The oxygen, if of secondary origin, would result either from direct breaking up of the sulphate radicle or from interaction between the mercury sulphate and the basic constituents of the nonvolatile gangue that was always present 
in varying amount. Sometimes the whole of the sulphur was recoverable from the sublimate that was produced at about $420^{\circ}$; at other times not, but in the former case oxygen seemed to be absent from the gas collected by the pump, and this fact is an argument against assuming a basic salt of mercury as the source of the oxygen.

An attempt to determine the actual composition of the sulphate, not volatile below $400^{\circ}$ to $420^{\circ}$, was not very successful. In one experiment a ratio of near $2 \mathrm{HgO}$ to $3 \mathrm{SO}_{3}$ was obtained, indicative of an acid sulphate, but the needlessness of this assumption is evident when it is considered that the nonvolatile gangue that is always present contains basic substances that are able to bind the sulphate radicle at the temperature employed. A further reason for lack of success was the presence of a small amount of nitrogen (0.05 per cent in one case, 0.20 per cent in another), which indicated either that some of the chloriferous constituent had not been decomposed or that an analogous sulphato compound was present. The results seem to show, however, the probability that the nitrogen belongs mostly, if not entirely, with the chlorine in the mineral and to a. limited extent, if at all, with the sulphur.

Another observation, which at first seemed to have important bearing on the union of the nitrogen and chlorine in the mineral, was the already mentioned appearance (p. 27) of an active gas capable of setting free iodine from potassium iodide. This. reaction was much intensified by heating the mineral in vacuo, and produced serious disturbance in the first quantitative tests involving the use of a Töpler pump. No action of the active gas was apparent in the pump until in the process of transferring the nitrogen to a collecting tube the hitherto expanded gas became compressed to nearly normal density, when it instantly fouled the mercury in the long fall or outlet tube, and also that in the collecting tube. The pump was on one occasion put out of working order until taken apart and cleaned, and several times the gas above the mercury in the collecting tube had exactly the color of chlorine. Agitation of the mercury contents of the tube quickly caused the color to disappear and qualitative test of the scum on the mercury revealed the presence of much chlorine. The formation of this free chlorine could not be fully prevented in vacuo, even when the mineral was first mixed with much lime or sodium carbonate, but it became less as the pressure was increased and a vanishing quantity when the pressure was normal. On one occasion, after heating the mixture under reduced pressure in a platinum boat, the latter was found badly attacked, as after a niter fusion. The phenomenon seemed incompatible with direct union of chlorine and mercury in the molecule, until it was shown that a similar reaction takes place when a mercuric sulphate $\left(3 \mathrm{HgO} . \mathrm{SO}_{3}\right.$ in the test) is heated with a mercury-ammonium chloride $\left(\mathrm{NHg}_{2} \mathrm{Cl} . x \mathrm{H}_{2} \mathrm{O}\right)$. The mercuric sulphate in breaking up doubtless liberates active 
oxygen (or some active oxide. of sulphur?) which acts on either the calomel already sublimed or on still undecomposed chloriferous mineral, setting free chlorine. The free chlorine does not begin to manifest itself till about one quarter of the nitrogen has been expelled. Interposition of a long layer of silver turnings was quite without effect in retaining the chlorine when under reduced pressure.

When decomposition of the mineral is effected by heating it in admixture with sodium carbonate to a sufficient temperature to fully break up the resulting mercuric oxide into its elements, oxygen is liberated in quantity. Theoretically the amount should be exactly equivalent to the $\mathrm{SO}_{4}$ and $\mathrm{Cl}_{2}$ found in the particular sample (see p. 35 ) if the compound is normal and not basic. As a matter of fact, it never did equal the calculated amount, which has a mean value of 2.14 per cent of the weight of the gangue-free mineral, but was rather uniformly between 1.75 and 1.85 per cent, never reaching 2 per cent. No positive explanation for this seemingly anomalous behavior has been found. Various explanations suggest themselves, as the formation of a gaseous oxide of nitrogen or of sodium nitrite or nitrate or of one of the chloroxy salts of sodium. No evidence of a volatile nitrogen compound was obtained, though there was an indication of a retention of oxygen by the flux, for when tested in sulphuric acid solution with diphenylamin a pronounced blue color appeared. From the temperature employed in the experiment of decomposing the mineral it seemed improbable that the effect could have been produced by a hypochlorite or chlorate; in fact, a test for chlorate chlorine proved negative. In another experiment 0.07 per cent of perchlorate chlorine was found after removing the chlorine of other salts, but owing to the small amount of kleinite operated on (0.3 gram) this is not to be regarded as a conclusive test.

A quantitative test for nitrite or nitrate nitrogen was made as follows: After decomposition of the mineral the aqueous solution of the sodium carbonate was acidified with sulphuric acid, chlorine was precipitated by silver sulphate (7.23 per cent $\mathrm{Cl}$ found), to the filtrate excess of chlorine-free sodium hydroxide was added, the solution boiled, aluminum powder then added and the boiling continued as for the Nessler test, the ammonia being collected in hydrochloric acid and determined as chlorplatinate. There was found 0.00033 gram nitrogen, or 0.10 per cent ( 0.35 gram kleinite used). From the acidified solution left in the flask 0.00037 gram chlorine was obtained, or 0.10 per cent, which added to that first found makes a total of 7.33 per cent (analysis $4 a$ ). It is uncertain how much weight should be given to these determinations, which were not duplicated, because the absolute amounts involved were so very small that no positive proof seemed realizable with the available material, but if approximately correct the values for nitrogen and chlorine are of a magnitude sufficient to account for the above calculated deficiency in oxygen set 
free on heating the mineral with sodium carbonate. They probably represent maxima, since in many analyses the chlorine obtained directly from the flux equaled the sum of the two portions above found separately. Of course if such a retention of nitrogen was of constant occurrence in all analyses made with sodium carbonate the mean value for nitrogen given later is slightly low. It is assumed that any oxygenated salts of sodium and chlorine, if actually present in the flux, were formed during the experiment and did not preexist as mercury salts in the mineral.

DATA RELATING TO WATER AND HYDROGEN.

Notwithstanding the failure to find any positive evidence of the evolution of elemental hydrogen or oxygen on heating the mineral by itself, water was evolved. It is certain that this came in part from the clayey gangue and sometimes from traces of gypsum, but there was never enough of these to account for more than a small part of the whole. The presence of the gangue in varying amounts in the different samples. examined has proved a serious stumbling block to the exact determination of some of the constituents of the mercury mineral, besides necessitating a far greater number of quantitative tests than would otherwise have been called for. The results for water, furthermore, vary so widely ( 0.49 to 1.20 per cent) in the different samples that they constitute the weakest link in the chain of quantitative data and little can legitimately be concluded as to the part the hydrogen and oxygen play in the structure of the mineral. It is conceivable that the water, or some of it; particularly of the last portions that came off, may have been derived from oxygen and hydrogen existing in the form of hydroxyl, or even not in direct mutual union in the mineral, though the latter seems a quite unwarranted supposition. None of it is hygroscopic in the common sense, about one-half comes off at a relatively low temperature (under $135^{\circ}-150^{\circ}$, the temperature at which permanent browning of the powder begins), and the total amount found by combustion with copper oxide, preceded in the tube by lead chromate and a roll of copper, was no more than that obtained by heating alone or with dry sodium carbonate. Hence it seems probable that, if not water of crystallization, the combination is that of hydroxyl, though it may exist in a state of solution. ${ }^{a}$ The water determinations were, furthermore, rendered difficult by the uncertainty in some cases that the increase in weight of the absorption tube represented nothing but water, for it was difficult and not always possible to be sure that small amounts of other substances were not carried out of the tube of decomposition and collected with the water.

$a$ That much, and sometimes all, of the water of many hydrous minerals is in a state of solution and does not enter into the chemical molecules, either as hydroxyl or as water of crystallization, is beginning to dawn on mineralogists. Consult the important contribution to the subject by Fr. Zambonini (Mem. Accad. sci. fls. e mat. di Napoli, vol. 14, ser. 2a, No. 1, 1908). 
For the purpose of throwing light on the function of the water the nearest artificial representative of the class of bodies to which kleinite apparently belongs was prepared and analyzed in the same way as kleinite itself. This is the compound having the empirical composition $\mathrm{NHg}_{2} \mathrm{Cl}_{2} x \mathrm{H}_{2} \mathrm{O}$, and it was prepared by long boiling of "infusible white precipitate" with water. It was found not to have quite the theoretical composition, but its properties were in many respects those of kleinite and the concordant values obtained in its analysis favor the correctness of the methods employed for kleinite, in which, however, as is evident from what has gone before, the presence of sulphur and gangue introduce decided complications.

Analyses of artificial mercury-ammonium chloride.

\begin{tabular}{|c|c|c|c|c|c|}
\hline & 1. & 2. & 3. & Mean. & $\begin{array}{c}\text { Theory } \\
\left(\mathrm{NHg}_{2} \mathrm{Cl}_{2} \frac{1}{2} \mathrm{H}_{2} \mathrm{O}\right) \text {. }\end{array}$ \\
\hline $\begin{array}{l}\mathrm{Hg} \ldots \ldots \ldots \ldots \\
\mathrm{Cl} \ldots \ldots \\
\mathrm{N} \ldots \ldots \\
\mathrm{H}_{2} \mathrm{O} \ldots \ldots\end{array}$ & $\begin{array}{r}86.90 \\
8.69 \\
a 2.71 \\
1.60\end{array}$ & $\begin{array}{r}87.06 \\
8.56 \\
b 2.70 \\
1.61\end{array}$ & $\begin{array}{r}\ldots .6 \\
8.63 \\
\ldots \ldots \\
\ldots \ldots\end{array}$ & $\begin{array}{r}86.98 \\
8.63 \\
2.71 \\
1.60\end{array}$ & $\begin{array}{r}87.25 \\
7.73 \\
3.06 \\
1.96\end{array}$ \\
\hline & & & & 99.92 & 100.00 \\
\hline
\end{tabular}

$a$ Determined as $\mathrm{NH}_{3}$ by decomposition with $\mathrm{Na}_{2} \mathrm{~S}$.

$b$ Determined as nitrogen gas.

The water in this compound was driven out by simply heating the substance in a tube provided with gold leaf at the exit and collecting the water in one filled with calcium chloride, and it was noticed that much -in fact, about three-fourths-of the water came off before the appearance of a sublimate of calomel and mercury. No evidence of free chlorine was to be had when the compound was decomposed in vacuo.

ANALYTICAL METHODS EMPLOYED AND THE RESULTS.

Although some reference has been made in the foregoing to methods of analysis, those employed for determining the chief constituents need further notice.

NITROGEN.

Three methods were employed in determining nitrogen: (1) Expulsion as ammonia by sodium sulphide, with collection of the ammonia in hydrochloric acid and gravimetric determination as chloroplatinate; (2) expulsion as ammonia by ammonium bromide in a closed vessel, collection of the liberated ammonia in an excess of titrated oxalic acid, and determination by standard alkali of the acid left over; ${ }^{a}$ (3) direct determination as nitrogen gas, collected by the aid of a Töpler pump and measured in a gas burette after freeing from other gases. 
These methods and the observations made in connection with them will now be considered, not only for their bearing on the particular problem, but also for the aid of future investigators in the examination of this or similar minerals.

1. Little need be said regarding the sodium-sulphide method. The mineral dissolves with ease in sodium sulphide, generally with liberation of much but no fixed amount of metallic mercury, three determinations having given from 25 to 28 per cent, another only 4.97 , and a fourth none at all. It is not thought that this behavior has any bearing on the mode of combination of the mercury in the mineral; if it had, the results should have been in better agreement. The values for nitrogen reported in the table of analyses have been calculated from the weighed chloroplatinate by the factor 0.06283 , which is afforded by the atomic weights 197.2 for $\mathrm{Pt}, 35.45$ for $\mathrm{Cl}, 14.01 \mathrm{for}$ $\mathrm{N}$, and 1.008 for $\mathrm{H}$.

2. The ammonium-bromide method depends on the liberation of - the nitrogen united to mercury in the so-called mercury-ammonium compounds and also three times as much from the reagent, all in the form of ammonia. The powdered mineral (0.3 to 0.5 gram) was spread on a very large inverted porcelain crucible cover, which floated on a shallow layer of mercury in a pan. Astride of this cover was placed a large platinum triangle with its legs bent down so as to elevate the center, on which rested a watch glass containing titrated oxalic acid solution. Over this was inverted a crystallizing dish, the rim of which, entering the mercury in the pan, made a perfect seal. Just before putting this dish in place 10 cubic centimeters of a neutral and nearly saturated solution of ammonium bromide containing neutral litmus solution was run quickly. upon the powder by means of a pipette. At the expiration of two days, generally before, the mineral had wholly disappeared, except for most of the gangue, and the liquid had become red, showing entire freedom from ammonia.

The results by this method, all of them made early in the investigation, taking one-quarter of the ammonia found as belonging to the mercury mineral, were uniformly higher than those obtained by either of the other methods (see below). Two explanations for this offer themselves and both may be correct. It was found that the gangue was rather markedly attacked by the bromide, and ammonia was doubtless liberated by its action. A similar excess of ammonia would appear if the mercury mineral were a basic salt or if it contained any basic component. Were the latter the only explanation a sufficient number of determinations to afford a good average would allow calculating the amount of basic oxygen, but this course could not be adopted because it was practically certain that the gangue itself liberated some, if not all, of the ammonia that was apparently in excess. 
3. In the gas-volumetric method decomposition of the mineral was effected in a horizontal glass tube connected with a Töpler pump and containing gold leaf near the exit. In the first experiments, when direct evidence as to the presence of oxygen was sought, no retainer for the chlorine and sulphur was used. In these tests it was found absolutely necessary to confine the crystals or powdered mineral to a limited space at the extreme end of the tube by means of an asbestos plug, for unless this was done the material would dance about during the later stages of the heating in a most remarkable manner and be projected with violence toward the cooler end of the tube and back again as soon as heat was applied under it in its new position. In subsequent experiments, after sufficient testing of the evolution of free chlorine (p. 30), dry sodium carbonate was used in admixture with the mineral powder. Calcium oxide was far less serviceable. The use of a retainer allowed more accurate determinations of chlorine, sulphur, and mercury than when its use was dispensed with, for if all three were determined in the sublimate that resulted without a retainer there was sure to be some loss of chlorine, if not of sulphur, and the separation of these from the mercury was troublesome and productive of error, whereas with a retainer the separation was effected during the decomposition of the mineral, and the mercury had merely to be weighed after cutting off the part of the tube containing it. As already intimated, however, even here the gases had to be allowed to accumulate in the tube under their own pressure, and not to escape continuously into the pump, if retention of all the chlorine was to be expected.

It was assumed that the collected gas contained all the nitrogen of the mineral, though it is possible, in view of the evidence set forth on page 31 , that a very little of it was retained by the sodium carbonate in the form of nitrite or nitrate. It would also hold, in those cases where no retainer was employed, any basic oxygen that might have been present in the kleinite as well as that set free by partial breaking up of the $\mathrm{SO}_{4}$ radicle.

Where the retainer was used there should have been present, according to expectations, besides possible basic oxygen, an amount of oxygen equivalent to the total chlorine and sulphur, as indicated by the following hypothetical reactions:

$$
\begin{aligned}
& 2 \mathrm{NHg}_{2} \mathrm{Cl}+\mathrm{Na}_{2} \mathrm{CO}_{3}=2 \mathrm{NaCl}+4 \mathrm{Hg}+\mathrm{CO}_{2}+\mathrm{O}+\mathrm{N}_{2} . \\
&\left(2 \mathrm{NHg}_{2}\right)_{2} \mathrm{SO}_{4}+\mathrm{Na}_{2} \mathrm{CO}_{3}=\mathrm{Na}_{2} \mathrm{SO}_{4}+4 \mathrm{Hg}+\mathrm{CO}_{2}+\mathrm{O}+\mathrm{N}_{2} .
\end{aligned}
$$

It has already been said (p. 31) that this last expectation was never realized and a possible explanation was there suggested. It has also been said that, while very small amounts of oxygen were found after at least two of the experiments without retainer, they were accompanied in the gas in one instance by an approximately equivalent amount of sulphur dioxide, this being indicative of derivation from $\mathrm{SO}_{4}$ and not from a basic compound. 
The gases having been collected, they were first exposed to solid potassium or sodium hydroxide as long as any contraction could be noticed. This was to remove a possible trace of chlorine not taken up by the mercury and of sulphur dioxide (from the splitting up of $\mathrm{SO}_{4}$ when the mineral had been heated without retainer) and the carbon dioxide that was present when the retainer had been used. In the last case the carbon dioxide would probably have been exactly equivalent to the chlorine and sulphate radicles of the kleinite were it not for the action of the nonvolatile matter or gangue, which always set free an undeterminable amount of carbon dioxide." Hence the determination of this component of the gas mixture, which might under other conditions have served as a valuable check, was not attempted.

Any oxygen that might be present was removed by a bead of freshly melted and cooled phosphorus. This was allowed to rise in a tube filled with mercury and secured to the glass at the top by momentary application of a flame at the point where the bead showed, only long enough to melt it. The gas was then introduced from the burette. A thin white column of descending oxide instantly manifested itself if exygen was present, but, absorption being very slow, the end was hastened usually by heating the bead till a bright flash resulted. The residual gas was shown to be nitrogen in one test by passing the combined products of two or three analyses over hot magnesium, which removed the whole of it, if, as is believed, the very slight residuum of hydrogen found came from the magnesium.

As intimated before (p. 32), if any nitrite or nitrate was retained by the sodium carbonate, the results for nitrogen by this method are all slightly low, but against their being so is their fair agreement among themselves and of their average with those obtained by the action of sodium sulphide and by direct solution in hydrochloric acid and subsequent precipitation as the platinum salt, which the following comparative table shows:

Nitrogen percentages by different methods.

\begin{tabular}{|c|c|c|c|c|}
\hline \multirow{2}{*}{$\mathrm{Na}_{2} \mathrm{~S}$} & \multirow{2}{*}{ HCl. } & \multicolumn{2}{|c|}{ Gas-volumetric. } & \multirow{2}{*}{$\mathrm{NH}_{4} \mathrm{Br}$. } \\
\hline & & $\begin{array}{c}\text { With } \\
\mathrm{Na}_{2} \mathrm{CO}_{3} .\end{array}$ & $\begin{array}{l}\text { Without } \\
\mathrm{Na}_{2} \mathrm{CO}_{3} \text {. }\end{array}$ & \\
\hline $\begin{array}{l}2.56 \\
2.57 \\
2.55 \\
2.55\end{array}$ & \multirow[t]{3}{*}{2.57} & \multirow[t]{2}{*}{$\begin{array}{l}2.53 \\
2.55 \\
2.60 \\
2.58 \\
2.43\end{array}$} & \multirow[t]{3}{*}{$\begin{array}{l}2.61 \\
2.74 \\
2.67 \\
2.86\end{array}$} & $\begin{array}{l}2.78 \\
2.76 \\
2.74 \\
2.70\end{array}$ \\
\hline \multirow[t]{2}{*}{ Av. 2. 555} & & & & \multirow[t]{2}{*}{ Av. 2.74} \\
\hline & & Av. 2.54 & & \\
\hline
\end{tabular}


The single determination after solution in hydrochloric acid, the last one that was made, is regarded with great confidence. The same is true of those by the sodium-sulphide method. The greater variation among the results of the gas-volumetric tests is to be ascribed to the small amounts of mineral operated on $(0.25$ to 0.5 gram), the uncertainty in the burette readings in the upper section of the instrument, and the greater chance for loss or gain during the numerous manipulations involved in this method of testing. The high results by the ammonium-bromide method have been already explained (p. 34) as in all probability due, in part at least, to action of the nonvolatile gangue on the reagent; and the failure to find positive evidence of oxygen in the gases evolved on heating the mineral without flux may be taken to indicate that the excess of nitrogen found by the ammonium-bromide method is wholly due to the chemical action of the gangue matter on the ammonium bromide, and not even in part to a basic mercury salt.

MERCỤRY.

Mercury. was determined in several ways, almost always in connection with one of the nitrogen determinations already described, in order to spare valuable material.

1. As mercury, by ignition with sodium carbonate or as in organic combustions. The mercury was obtained as such in the drawn-out end of the combustion or ignition tube nearest the outlet or in an attached Peligot tube, gold leaf being used to prevent loss. The end of the tube was cut off and weighed with its contents; most of the mercury was then poured out, the rest volatilized in an air current, and the tube and gold reweighed. Most of the determinations of the table were made in this way.

2. As mercury by electrolysis from sodium-sulphide solution. This method was employed but a few times for total mercury, but frequently for partial determinations that are not in the table, the temperature being about $70^{\circ}$, the current about 0.1 ampere, and the cathode a platinum plate of about 27.5 square centimeters total surface. The solutions obtained in the nitrogen determinations by sodium sulphide, after boiling out the ammonia, were not used for total mercury, because the frequent separation of mercury in the metallic state necessitated a double determination with accompanying greater liability to error.

3. As the sulphide. The solutions of the mineral in ammonium bromide, a method that was at first employed for obtaining the nitrogen as ammonia, were acidified by hydrochloric acid and precipitated by hydrogen sulphide, and the resulting mercuric sulphide was weighed, after washing with alcohol and extracting free sulphur by carbon disulphide in the manner recommended by Treadwell. 
These results were in part higher than by any other method, possibly because of incomplete extraction of free sulphur. When checked by electrolysis; they were once or twice found to be high. Analyses by this method are shown under 9 and 10 of the table, page 41. Their average, however, is in all probability nearer the truth than those by method 1, and is in close agreement with the third result of analysis 8 (86.18), which was obtained by electrolysis and is regarded as very reliable.

A very small amount of the mercury is present, probably as calomel, in the gangue. The third test of analysis 8 showed about 0.16 per cent of mercury left as chloride on solution of the mineral in hydrochloric acid. That it is from the gangue is likely, since this was found, when tested separately, to afford a sublimate of calomel, and the earthy gangue generally blackens on exposure to vapors of hydrogen sulphide, whereas the kleinite is more resistant toward that reagent. The rest of the mercury is in the mercuric state.

CHLORINE AND SULPHUR.

The results for chlorine and sulphur that were obtained after decomposition of the mineral by heat in presence of sodium carbonate at atmospheric pressure are the most trustworthy. The methods of determination need no description.

For the deep-yellow to orange crystals the chlorine values are all close to 7.3 per cent, rather over than below, calculated to the gangue-free mineral. The few lower values belong to experiments in which there was observed loss of chlorine by volatilization.

The greater variation among the chlorine results for the lightyellow crystals and for those of the sulphate radicle throughout the series is evident, but it is not at all probable that any marked diversity of composition is thereby indicated, unless it be among the light-colored crystals themselves. The $\mathrm{SO}_{4}$ determinations are probably simply less accurate than those for chlorine. But the determinations on light-colored material show variations that may be real, though it is to be noted (perhaps owing to the small amounts used for the tests) that a serious analytical error must have been incurred in analysis 12, for the figures given represent duplicates on the same sample.

The sublimates that were obtained on heating the mineral without retainer were several times analyzed, but more with a view to learning something about the changes then taking place under different conditions of treatment than to getting accurate figures for the total of their constituents, and the results do not find place in the table, though it is upon them that some of the statements made in foregoing pages were in part based. 
GANGUE, WATER (HYDROGEN?).

The original gangue was doubtless hydrous, but that reported in the analyses represents the part that was not volatile on ignition, and therefore was anhydrous.

The water determinations, as before said, are far from being as consistent and satisfactory as it seemed they ought to be. Most of them were made by heating the mineral powder in a current of dry air with sodium carbonate, taking the precaution not to heat rapidly and to use a plug of gold leaf before the absorption tube. Other experiments were made in a similar way, but without sodium carbonate and with the expenditure of much more time, for with even moderately rapid heating it was found impossible to prevent some slight mechanical carrying over of mercury compounds, and there was danger of a little $\mathrm{SO}_{2}$ counting as water. The length of time consumed in these last tests militated against their accuracy, but the gains of the absorption tube were sometimes checked against the losses of the ignition tube. At temperatures below that at which the first trace of sublimate other than water was wont to appear the losses and gains were, as a rule, almost identical. When the brown color of the powder had changed to nearly white, the losses equalled the gains of the absorption tube, plus the nitrogen, and when phosphorus pentoxide was placed in the tube the loss was practically equivalent to the nitrogen content only.

But it was also observed that when the loss was ascertained by heating in an open porcelain crucible, at a temperature below that at which any indication of sublimate should appear, the weight of the crucible after cooling in a desiccator indicated far less than had been shown by the gain of the absorption tube in the other experiments. In fact, after some hours in the desiccator the original weight of the sample might be regained. Additional water would then be visibly given off on heating this powder in a small tube. The partially dehydrated mineral seems then to possess an extraordinary attractive power for water, like that of some zeolites and other minerals, but the original color is not restored as the result of this reabsorption.

The expulsion of the water does not seem to take place at a fixed temperature, but to persist in decreasing amount so long as any chloro-nitrogen compound remains; yet it has not been proved that any such relation exists as might be gathered from the last statement. About half the water, roughly, comes off below $100^{\circ}$ when the mineral is heated by itself.

As already said, the water comes, no doubt, in part from the gangue. To test this point, the gangue left undissolved by ammonium bromide was washed with water, alcohol, and ether, dried at room temperature, then over sulphuric acid, and finally ignited. On 0.0135 gram of the 
unignited product, representing 2.7 per cent of the kleinite, there was produced an ignition loss of 0.002 gram, or 0.4 per cent of the mineral. Some of this, but not all, may have resulted from hydration effected by the action of the ammonium bromide. But that there is no general relation between the water and the gangue is indicated by the table of analyses if the water values are nearly correct, since some of those with least gangue show most water. It is practically certain that the greater part of the water was derived from the mercury mineral itself. This is the more credible, since an artificial hydrous compound, $\mathrm{NHg}_{2} \mathrm{Cl} . x \mathrm{H}_{2} \mathrm{O}$, is known, extremely similar in its behavior to kleinite at and below $100^{\circ}$. In it the water is said to vary between one-half and one molecule. The artificial preparation mentioned on page 33 afforded 1.6 per cent water, or a little less than one-half molecule, when tested in the same manner as the kleinite.

In order to learn if there might be hydrogen in the mineral in addition to that given off as water on direct ignition, two combustions were made with copper oxide, preceded in the tube by lead chromate and a roll of copper. The result (analysis 5) was no increase of water above that obtained with sodium carbonate. Furthermore, no trace of ammonia was afforded by decomposition of the mineral with sodium carbonate or lime. These two facts seem to show that the mineral contains no hydrogen other than as water or as hydroxyl. The results for water by different methods, the last three only fractional, are tabulated below, figured on gangue-free material. They need to be checked on larger amounts of pure mineral:

Percentage of water in kleinite as determined in different ways.

\begin{tabular}{|c|c||c|c||c|c|}
\hline $\begin{array}{c}\text { Analysis } \\
\text { No. }\end{array}$ & $\begin{array}{c}\mathrm{By}_{2} \\
\mathrm{Na}_{2} \mathrm{CO}_{3} .\end{array}$ & $\begin{array}{c}\text { Analysis } \\
\text { No. }\end{array}$ & $\begin{array}{c}\text { By com- } \\
\text { bustion. }\end{array}$ & $\begin{array}{c}\text { Analysis } \\
\text { No. }\end{array}$ & By heat only. \\
\cline { 2 - 4 } 2 & 0.49 & $5 \mathrm{a}$ & 1.14 & 7 & 1.20 in $\mathrm{CO}_{2}$. \\
3 & 0.76 & $5 \mathrm{~b}$ & 1.13 & $5 \mathrm{~b}$ & 0.88 at $260^{\circ}$ (air). \\
$3 \mathrm{a}$ & 1.06 & & & 6 & 0.91 at $160^{\circ}$ (air). \\
$8 \mathrm{~b}$ & 1.19 & & & 1.03 at $175^{\circ}-205^{\circ}$. \\
11 & 1.29 & & & \\
\hline
\end{tabular}

The evidence of all the tests except 2 and 3 is that those two must be low and that the general average for water might properly be raised a little by omitting them. This is the more likely from the fact that 3 and $3 \mathrm{a}$ represent the same sample. Accurate water determinations under the given conditions are most difficult to secure.

ANALYSES.

The various quantitative data obtained for kleinite are shown in the following table: 
Analyses of kleinite.

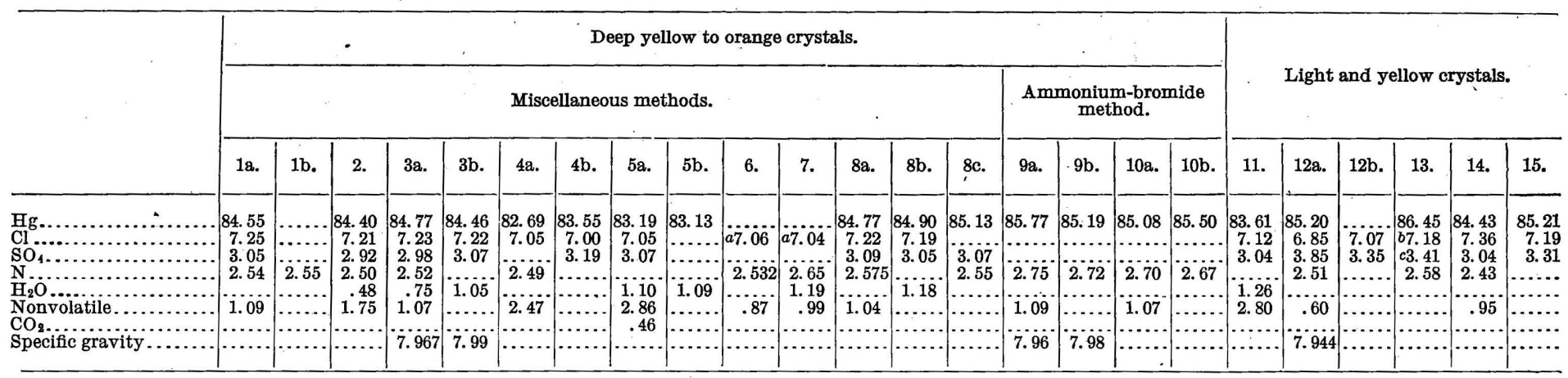

SAME CALCULATED TO SUBSTANCE FREE FROM GANGUE.

\begin{tabular}{|c|c|c|c|c|c|c|c|c|c|c|c|c|c|c|c|c|c|c|c|c|c|c|c|c|}
\hline 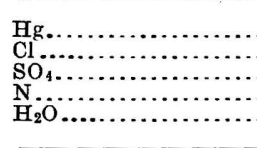 & $\begin{array}{l}85.48 \\
7.33 \\
3.08 \\
2.56 \\
\ldots \ldots\end{array}$ & \begin{tabular}{|c|}
$\ldots \ldots$. \\
$\cdots \cdots$ \\
\hdashline 2.57 \\
$\cdots \cdots$
\end{tabular} & $\begin{array}{c}85.90 \\
7.34 \\
2.97 \\
2.545 \\
.49\end{array} \mid$ & $\begin{array}{r}85.69 \\
7.31 \\
3.01 \\
2.55 \\
.76\end{array}$ & $\mid \begin{array}{r}85.37 \\
7.30 \\
3.10 \\
\hdashline 1.06\end{array}$ & \begin{tabular}{c}
84.78 \\
7.23 \\
\hdashline 2.55 \\
$\cdots$
\end{tabular} & $\begin{array}{c}85.67 \\
7.18 \\
3.27 \\
\cdots \cdots\end{array}$ & \begin{tabular}{r}
86.05 \\
7.29 \\
3.17 \\
\hdashline 1.14 \\
1.14 \\
\end{tabular} & \begin{tabular}{|c}
85.99 \\
$\cdots \cdots$ \\
\hdashline$\ldots \ldots$ \\
\hdashline 1.13 \\
1.13
\end{tabular} & \begin{tabular}{l}
7.12 \\
\hdashline .55 \\
2.55
\end{tabular} & \begin{tabular}{c}
$7 \% 13$ \\
\hdashline 2.67 \\
1.20
\end{tabular} & $\begin{array}{r}85.66 \\
7.28 \\
3.12 \\
2.60 \\
\ldots \ldots\end{array} \mid$ & 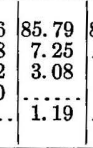 & \begin{tabular}{c}
86.18 \\
\hdashline 3.10 \\
2.57 \\
$\cdots \cdots$
\end{tabular} & \begin{tabular}{|c|c}
86.72 \\
$\cdots \cdots$ \\
\hdashline 2.78 \\
2.7 \\
\end{tabular} & $\begin{array}{l}86.13 \\
\ldots \ldots\end{array}$ & $\because 2.74$ & $\mid$\begin{tabular}{l}
86.42 \\
$\cdots \cdots$ \\
\hdashline 2.70 \\
$\cdots \cdots$
\end{tabular} & $\begin{array}{c}86.02 \\
7.33 \\
3.13 \\
1.29\end{array}$ & \begin{tabular}{|c|c|}
85.71 \\
6 \\
6.89 \\
3.87 \\
2.53 \\
.$\ldots \ldots$ \\
.$\ldots$.
\end{tabular} & $\begin{array}{c}7.11 \\
3.37 \\
\cdots\end{array}$ & $\begin{array}{l}\cdots \cdots \\
\cdots \cdots \\
\cdots \cdots \\
\cdots \cdots \\
\cdots \cdots\end{array}$ & $\begin{array}{r}85.24 \\
7.43 \\
3.07 \\
2.45 \\
\cdots \cdots . .\end{array}$ & $\begin{array}{c}\ldots \ldots . . \\
\cdots \cdots \\
\cdots \cdots \\
\cdots \cdots \\
\cdots \cdots \\
\end{array}$ \\
\hline
\end{tabular}


DISCUSSION OF ANALYSES.

The average composition of the gangue-free kleinite, as represented by the analyses of the deeper-colored crystals, is given below, together with the atomic ratio.

Average composition and atomic ratio for deeper-colored kleinite.

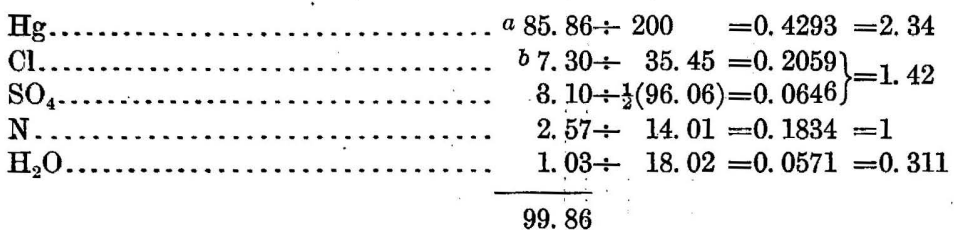

99.86

The general average for mercury is certainly low, for reasons already set forth. The true value is at least 86 , but the difference thereby introduced in the ratio is insignificant and may be neglected. To include the values for the light-yellow crystals would affect the ratio but little, and as those values in themselves are perhaps less trustworthy than those for the deeper-colored crystals they are omitted. The molecular value for water is of little probable worth.

The ratio shows at once that there is far too little nitrogen for a general formula of the type $\mathrm{NHg}_{2} \mathrm{X}$, in which $\mathrm{X}$ represents $\mathrm{Cl}$ and $\mathrm{SO}_{4}$. It is even insufficient for the chlorine alone in such a formula. The trace of calomel present and derived from the gangue (p. 38) is not enough to affect the above ratio materially. A chloro-sulphate is not known among the artificial mercury-ammonium compounds, and it seems not improbable that the mineral may be a mixture of the chlorine compound, $\mathrm{NHg}_{2} \mathrm{Cl}$, with one or more other salts of mercury. The simplest assumption is that one of these is mercuric chloride. If so, the residual ratio leads to a basic sulphate of mercury for the other, as shown by the following calculation, in which the $\mathrm{SO}_{4}$ is given its proper value as a bivalent radicle:

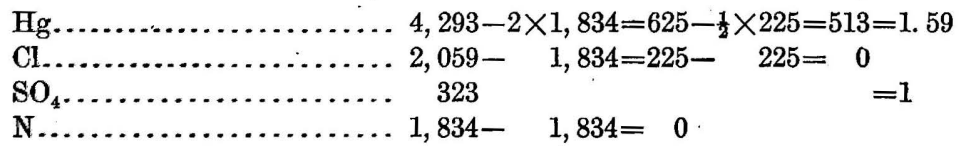

An important objection to the assumption of admixed mercuric chloride is the solubility of this salt in water, though it is conceivable that it might be held in a condition of solid solution. To the assumption of a basic salt in addition there is the objection that no oxygen was found in the gaseous product of decomposition when the mineral was heated by itself so slowly as to prevent breaking up of the $\mathrm{SO}_{4}$ group. It must be admitted, though, that the tests on this latter point were not so decisive as could be wished; a little oxygen given 
off from such a combination might conceivably act on some of the already sublimed mercury or calomel, especially if in an active state, and thus escape collection in the pump, but no evidence of any such action on the sublimate was seen. The reaction with ammonium bromide would probably afford a positive indication of the presence of a basic salt if enough of the mineral absolutely free from gangue matter could be secured to afford a series of quantitative tests on this point.

If the mineral is a mixture of the bodies suggested, or of others, it would perhaps be necessary to assume a case of solid solution that would be remarkable in view of the very considerable combined percentage of the bodies that would have to be regarded as the solutes. The absence of a uniformly extinguishing field under the polarizing microscope when sections are examined at ordinary temperatures, and the uniformity of the same field above $130^{\circ}$, is indicative that the temperature of formation of the mineral was a relatively high one, and that it is crystallographically at least unstable below a certain point.

It is regrettable that the long labor has resulted in nothing more definite than the fixing of the mineral as the first naturally occurring member of the so-called mercury-ammonium compounds, and the refutation of the views of Professor Sachs that have already been referred to. The question as to the structure of these mercuryammonium bodies, whether they belong to one or other of the several types that have been suggested for them, is outside the scope of this investigation.

\section{CRYSTALLOGRAPHY.}

The crystallography of kleinite has been fully described by Sachs. ${ }^{a}$ The crystals are hexagonal and show essentially only the simple forms. The suggestion of Moses, induced by the measurements of some very poor crystals, that the crystals might have a lower symmetry, has not been substantiated. The following description applies to the crystals measured by the writer and is in entire accord with the earlier description by Sachs.

FORMS AND VALUE OF $C$ AXIS.

The crystals of kleinite are very simple in their combinations, consisting of the base, pyramid, and the two prisms, $a$ and $m$. On only one crystal were any additional faces noted, namely two faces of a second pyramid. The forms present are: $c\{0001\}, m\{10 \overline{1} 0\}, a\{11 \overline{2} 0\}$, $p\{10 \overline{1} 1\}$, and $x\{10 \overline{1} 2\}$.

The base is invariably dull and generally gives no reflection. On some natural faces there may be seen concentric markings. Cleavage 
faces are fairly bright, but are all uneven and give a multitude of signals extending through a number of degrees.

The prism $m\{10 \overrightarrow{10}\}$ is large and bright, but rarely plane, many faces being uneven and especially rounded into oscillatory combination with the unit pyramid. This is especially true of the short crystals. The prism faces are striated horizontally. On crystal No. $1, m \wedge m$ was measured as $61^{\circ} 11^{\prime}-61^{\circ} 25^{\prime}$; on crystal No. 2 , as $58^{\circ} 50^{\prime}-60^{\circ} 41^{\prime}$; on crystal No. 3 , as $59^{\circ} 48^{\prime}-60^{\circ} 26^{\prime}$.

The prism $a\{11 \overline{2} 0\}$ is invariably a very narrow face, often so narrow as to be hardly discernible. It is probably present on all the crystals, but on account of its minuteness is not shown in most of the accompanying figures. Crystal No. 1 gave $a \wedge m, 29^{\circ} 10^{\prime}-29^{\circ} 56^{\prime}$; crystal No. $2,28^{\circ} 54^{\prime}-30^{\circ} 58^{\prime}$; crystal No. $3,29^{\circ} 30^{\prime}-30^{\circ} 39^{\prime}$.

The pyramid $p\{10 \overline{1} 1\}$, while present on all the crystals, varies considerably in size, even on the same crystal. The faces were mostly bright, but rounded, and some were horizontally striated. For the measurements see below.

The pyramid $x\{10 \overline{1} 2\}$ was noted on only one crystal, on which two adjacent faces occur, narrow but broader than line faces. They were smaller than the faces of $\{10 \overline{1} 1\}$ and gave poor reflections.

$$
\left.\begin{array}{l}
\text { Meas. } 10 \overline{1} 0 \wedge 10 \overline{1} 2=46^{\circ} 11^{\prime} \\
\text { Meas. } 01 \overline{1} 0 \wedge 01 \overline{1} 2=45^{\circ} 43^{\prime}
\end{array}\right\} \text { Calc. }=46^{\circ} 09^{\prime} .
$$

The following table gives the values of $\rho$ observed for $p\{10 \overline{1} 1\}$ :

Values of $\rho$ for $p\{1011\}$.

\begin{tabular}{|c|c|c|c|c|c|c|}
\hline Cryst. 1. & Cryst. 2. & Cryst. 3. & Cryst. 7: & Cryst. 8. & Cryst. 10. & Cryst. 12. \\
\hline $\begin{array}{cc}\circ & \prime \\
61 & 45 \\
63 & 45 \\
64 & 15\end{array}$ & $\begin{array}{cc}\circ & \prime \\
62 & 03 \\
62 & 30 \\
62 & 30\end{array}$ & $\begin{array}{cc}\circ & , \\
62 & 50 \\
62 & 39 \\
62 & 34 \\
62 & 29 \\
62 & 40\end{array}$ & $\begin{array}{cc}\circ & \text { ' } \\
61 & 37 \\
62 & 02 \\
62 & 23 \\
63 & 20\end{array}$ & $\begin{array}{cc}\circ & \prime \\
61 & 34 \\
61 & 45 \\
61 & 38 \\
62 & 59 \\
61 & 59 \\
62 & 09\end{array}$ & $\begin{array}{cc}\circ & \prime \\
63 & 20 \\
62 & 46 \\
62 & 43 \\
62 & 42 \\
61 & 56\end{array}$ & $\begin{array}{cc}\circ & \prime \\
62 & 47 \\
62 & 41 \\
62 & 46\end{array}$ \\
\hline$a 63 \quad 15$ & $a 62 \quad 21$ & $\begin{array}{lll}a & 62 & 38\end{array}$ & $a 62 \quad 21$ & $a_{62} \quad 01$ & $\begin{array}{lll}a & 62 & 41\end{array}$ & $\begin{array}{ll}a & 62 \quad 45\end{array}$ \\
\hline
\end{tabular}

a Average.

Bringing these values together we have, as the average of 29 measurements, $62^{\circ} 31^{\prime}$.

The general average differs only $1^{\prime}$ from the value obtained by Sachs, namely, $62^{\circ} 30^{\prime}$. We may therefore take $62^{\circ} 30 \frac{1}{2}^{\prime}$ as the correct value, which gives $c^{\prime}=1.6642$. A single minute makes a variation in this value of 0.0012 . 
Table of forms and coordinate angles for kleinite.

[Hexagonal; $\left.\mathrm{c}=1.6642 ; \mathrm{p}_{0}=1.9217.\right]$

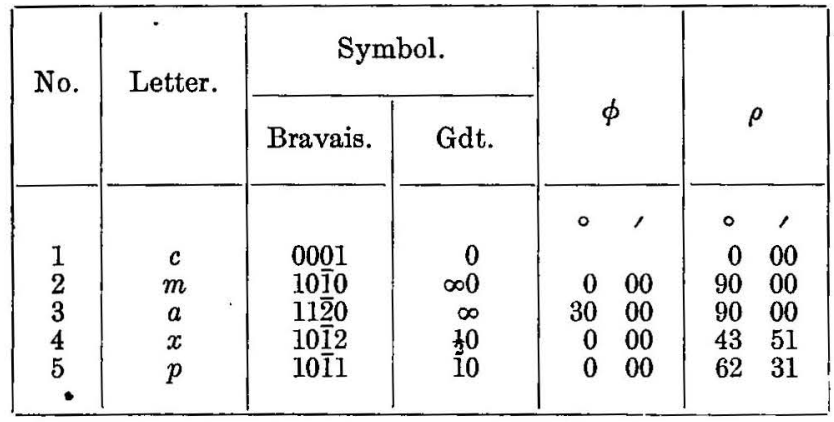

HABIT.

The crystals are usually short prismatic, from two to three times as long as thick. On these prismatic crystals the pyramid faces are either small or relatively large, while on many the six faces of the pyramid are very unequally developed. Figures 4, 5, and 6 show the variations in the habit caused by the pyramid faces. In figure 4 the pyramids are very narrow and, as shown in the drawing, generally fairly uniform in size. In figure 5 the pyramids are of large size and here many of the $a$ faces are about as broad as shown,

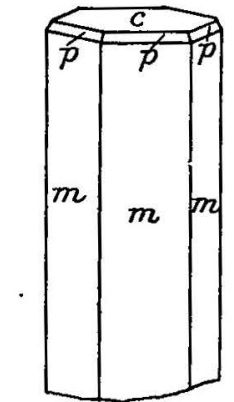

FTgURE 4.-Kleinite, short prismatic habit, with uniform development of the very narrow pyramids: $c\{0001\}, m\{10 \overline{1} n\}, p\{10 \overline{1} 1\}$.

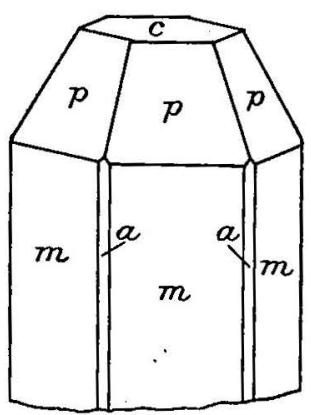

FIGURE 5.-Kleinite, short prismatic habit, with large development of the pyramid faces: $c\{0001\}, m\{10 \overline{1} 0\}, a\{11 \overline{1} 0\}, p\{10 \overline{1} 1\}$.

though elsewhere they are the merest line faces. Figure 6 shows a crystal on which the pyramid faces are very unequally developed. The line faces of $a$ are not shown in figures. 4 and 6, though they are probably present on every crystal.

A second habit shows crystals of approximately equal diameter in all directions. The prism faces are much shorter and the general shape of such crystals is seen in figure 7. The prism faces are more rounded than on crystals of the first habit and no accurate measurements could be made. 


\section{SUMMARY.}

Kleinite is hexagonal, $c=1.6642$, with five forms. Cleavage, good parallel to $\{0001\}$ and imperfect parallel to $\{10 \overline{1} 0\}$. Brittle. Occurs as single crystals, rarely over 1 millimeter in length, and as aggregates. Luster, adamantine to greasy on bright surfaces. Original color probably bright yellow for the most part, but grading to nearly colorless exceptionally. The bright-yellow crystals are peculiarly prone to darken almost to orange in daylight, but regain their original color very soon in the dark. Color of powder, sulphur yellow. Density as determined, about 7.98, but probably over 8 for absolutely pure material. Hardness, apparently slightly over 3.5. Not radioactive. Optically a basal section shows double refraction, but on heating to about $130^{\circ}$ becomes singly refracting, being uniaxial, positive. On cooling, the section reverts very slowly, several years being necessary for the change. This indicates dimorphism and a temperature of formation of above $130^{\circ}$.

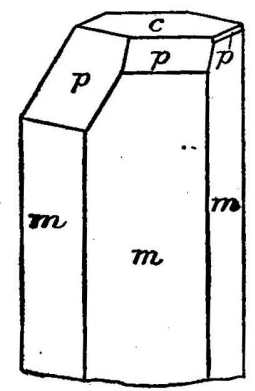

FIGURE 6.-Kleinite, short prismatic habit, with unequal development of the pyramid faces: $c\{0001\}, m\{10 \overline{1} 0\}, p\{10 \overline{1} 1\}$.

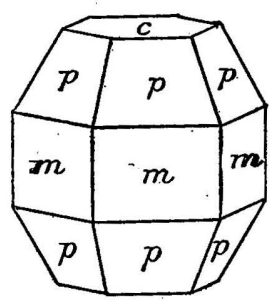

FIGURE 7.-Kleinite, equidimensional habit: $c\{0001\}, m\{10 \overline{1} 0\}, p\{10 \overline{1} 1\}$.

In the closed tube water first appears, the mineral darkens, then mercury and calomel sublimates form, followed at a much higher temperature by a sublimate of mercury sulphates. Most of the nitrogen escapes during the formation of the calomel. No ammonia is formed. A trace of free chlorine is given off at the higher temperature (much in vacuo). This seems to be due to secondary reactions. Sometimes a little sulphur dioxide is noticeable. Soluble in warm hydrochloric and nitric acids without separation of calomel; in sodium sulphide and ammonium bromide with liberation of ammonia. Fixed alkalies do not liberate ammonia, even at boiling heat. Hydrogen sulphide blackens, ammonia does not. No positive evidence could be gained as to the presence of more hydrogen than that afforded as water or of more oxygen than that in the water and $\mathrm{SO}_{4}$ radicle, but there is some doubtful evidence in favor of a little basic oxygen. The analytical methods are discussed and the results for nitrogen by several methods (including direct gas-volumetric) 
are tabulated. No certain difference could be detected in the composition of the orange and the light-yellow crystals. No positive conclusion is reached as to the molecular constitution of the mineral, which may possibly be a mixture of mercury-ammonium chloride, $\mathrm{NHg}_{2} \mathrm{Cl}$, in great preponderance, with an oxychloride and a sulphate or oxysulphate of mercury.

\section{MONTROYDITE.}

FORMS.

Montroydite may be said to occur under two broad aspects: (1) As distinct individual crystals of macroscopic size, usually found separate, and (2) as aggregates of minute crystals or crystalline masses. Each of these divisions is again subdivided into several groups, as follows:

1a. As long red prismatic crystals, commonly between 1 and 2 centimeters long and usually less than 1 millimeter thick.

1b. As equidimensional crystals a few millimeters thick.

1c. As flattened and striated distorted crystals several millimeters across.

$2 a$. As brown to orange worm-like masses consisting of minute prismatic crystals.

$2 b$. As aggregations of small spheres, usually 1 millimeter in diameter, but becoming cylindrical in shape and grading into $2 a$ and $2 d$.

2c. As hollow pipe stems and also irregularly shaped masses consisting usually of minute prismatic crystals.

2d. Âs hollow, irregular, spherical masses, resembling bubbles and made up of crystalline montroydite, usually of a dark-brown color. In these hollows or geodes are found large red prismatic crystals (1a) and also drusy coatings of dark-colored minute prismatic crystals.

$2 e$. As irregular dark-red masses showing on the surface large areas belonging to one crystal face, but no distinct crystals.

$2 f$. As a nearly parallel stratified layer of dark-colored crystalline material often mixed with some of the other phases.

$2 g$. As a powdery material of a brilliant light-orange color, and consisting of minute crystals.

Even though ten divisions are indicated above, it is not always easy to refer a given specimen to one of them, for many of the different phases are intimately mixed and also show varying gradations. The colors are also not characteristic, since they largely depend on the size of the outside layer of montroydite crystals. In the large crystals it is a deep red, but as they decrease in size the color becomes orange and brown, and often has a decided yellowish tint, especially in crystals that are so minute that one receives the effect of transmitted as well as reflected light. In very thin crystals the transmitted light is pale yellow, while in the larger ones it is of deep orange 
shades. The more massive phases of montroydite often have a dark color, and the presence of greenish terlinguaite intimately mixed with some of the montroydite further affects the resultant color. It is believed, however, that the foregoing subdivisions cover all the essential forms, and that a description of any particular specimen of montroydite may be referred to one or more of them.

Each of the ten divisions will now be taken up and described in some detail.

1a. The long, red, prismatic crystals reach a maximum length of about $2 \frac{1}{2}$ centimeters, such long ones, however, being rare. Many reach a length of 2 centimeters, while $1 \frac{1}{2}$ centimeters is common. They are rarely over 1 millimeter thick, and usually a little less. The crystals are not all uniform in their thickness, many bulging out, and a little farther along resuming their ordinary thickness. These bulgings, usually only a few millimeters long, are often terminated by steep forms. Most of the crystals are found singly, though occasionally more or less parallel groups are seen. The crystals are usually terminated only at one end, the other extremity tapering down to a point, and it is usually the terminated end by which they are attached, the tapering end projecting freely into space. They are not, however, uniformly attached to the matrix by one end, many being attached by the side or by another montroydite crystal, which in turn is also attached by the side. There they are more apt to be doubly terminated than where the crystal is attached by one extremity. Though some of them are united directly to the calcite crystals, most of the long needles spring from a layer of crystalline montroydite, which rests on the calcite. Some of the crystals are accurately in parallel position, either joined symmetrically so that the resulting group is no longer than the crystals themselves or else so joined that the resulting group is several times as long as a crystal. No case was observed, however, in which two or more of these long crystals were so placed that their $c$ axes actually coincided; they were always joined by a face in the prism zone. In color they are red, often a dark red with some orange, and sometimes showing a bluish iridescence, which may, however, be due to the effect of laboratory gases and not an inherent property of the mineral. Many of the crystals are covered with a greenish coating of what appears to be some mercury mineral; a satisfactory determination of it could not be made, though it seems to be largely terlinguaite. It seems remarkable that this coating is invariably nearer the end, tapering to a point; in fact, in many crystals it covers the entire point, and from there reaches to within a few millimeters of the other broader and often terminated end.

But the most curious and interesting feature of these large crystals is their flexibility. Many are found bent and torsioned, and straight crystals can be artificially distorted at will. They are apparently 


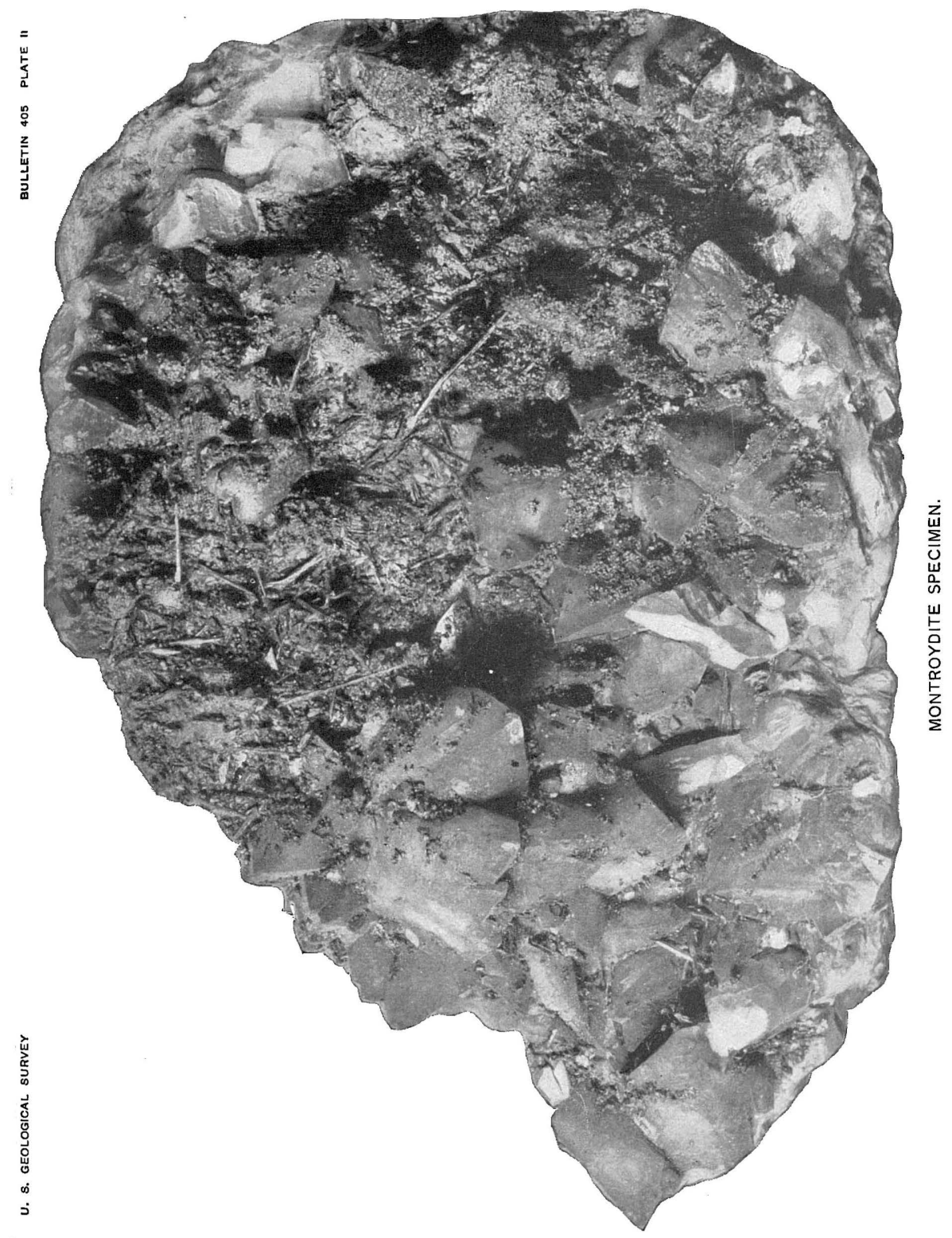



very inelastic, for after being bent no tendency to resume their original shape could be detected. Their flexibility is so great that most of the long crystals were bent and twisted when they reached us. The mineral has a perfect cleavage parallel to the brachypinacoid, $b\{010\}$, and when a crystal is crushed it breaks into numerous platy cleavage pieces. Many of these have a corrugated appearance on the cleavage surface similar to that which may be produced on stibnite. Some of the naturally bent crystals have developed this cleavage, and in consequence part of the crystal is frayed out into a number of plates all joined at one end, while others which are bent and torsioned show no sign of cleavage. The same effect can be produced artificially; either the crystals can be bent without showing any sign of fraying or cleaving, or the one crystal may be separated into numerous thin plates. (See further under "Physical properties," p. 52.) Crystals of this phase are shown in Plate III, and in the figures in the part of this paper devoted to the crystallography of the mineral (pp. 74 to 82 ).

1b. The equidimensional crystals are abundant, being found with the long crystals of $1 a$ and also as groups by themselves. Though mostly single, they are in some specimens grouped irregularly together, or a number are in parallel position, either attached by various points of the crystals or else, though rarely, so placed in parallel position that their $c$ axes coincide. Scepter crystals, in which one of the equidimensional crystals is attached to the top of a long prismatic one in parallel position, are also found. (See fig. 21, p. 82, illustrating such a crystal.) While these short crystals are found on the mass of crystalline montroydite from which the long prismatic crystals project, many of them also are directly attached to the large scalenohedral calcite crystals. These can be very well seen on part of the large specimen illustrated in Plate II, which also shows the long prismatic crystals $(1 a)$ as well as some of the other phases which will be referred to later.

Between these two extremes in habit, all gradations in size may be observed, the crystals becoming longer and thinner. Such a series is shown in row $a$ of Plate III, where those at the left show the equidimensional crystals up to a few millimeters thick while the long prismatic ones are shown on the right. In these latter, the tapering end is pointing upward while the broader and terminated end is at the bottom. The second figure (on the left) in row $b$ shows a scepter crystal which is illustrated in clinographic projection in figure 21. The remaining crystals (except the first one-see below) show some of the naturally bent prisms, which are also further illustrated under $f$.

1c. The curious flat distorted crystals are rather rare and always imperfect, all that were seen being terminated on both sides by 4494-Bull. $405-09-4$ 
cleavage faces of $\{010\}$. They are very striated and uneven and diffcult to orient correctly, but it is believed that the one described and illustrated on page 82 (fig. 22) is correctly shown. Such a crystal is shown in the first figure on the left in row $b$, Plate III. Some of them are several millimeters across but few as much as a millimeter thick.

$2 a$. The brown to orange wormlike masses are rather common and many are over a centimeter in length, with a thickness of about a millimeter. In color they vary from a rather dark brownish red to a light brown, many being nearly brownish yellow, depending on the fineness of texture of the outside crystal layer. A few are covered with a dark grayish mineral, apparently the same as that on the long prismatic crystals ( $1 a$ ). If one of these wormlike masses is complete, both ends are closed with the same material that forms the outside layer on the sides. When these masses are broken it is usually seen that they are cylinders partly filled with porous dark brown to red crystalline montroydite, many with a minute hollow canal in the center, but some completely filled. Rarely they are hollow, the diameter of the hollow canal being at least half the diameter of the entire mass. In those mostly filled with the porous crystalline montroydite, three concentric colors are to be seen. The innermost mass is red, that surrounding it is a dark brown or dark red, sometimes appearing nearly black, while the outside rim has the light yellow-brown color of the entire mass. Sometimes distinct small crystals can be seen in the interior porous mass, but most of it is a crystalline aggregate. The outside coating, generally very thin, of a light yellow-brown, is composed of a feltlike mass of minute prismatic crystals, so fine as to rub off like flour on the fingers. A series of illustrations of these wormlike masses can be seen in row $c$, Plate III, while $h$, same plate, shows one of these attached to a mass of crystalline montroydite.

$2 b$. The small spheres are similar to the above-described wormlike masses in every way except in shape. There are so many of these spherical masses that show no tendency to form elongated groups and thus pass into $2 a$ that one seems justified in classing them separately. When such spherical groups become elongated in some directions they generally grade into the forms of $2 c$ rather than $2 a$.

It is a great rarity to see these spheres directly associated with the wormlike masses, though they are commonly found with the other forms, such as $2 c, 2 d, 2 e$, and $2 f$. When one is broken, the interior is seen to be composed of a dark-colored crystalline mass of montroydite, from which the outer shell of light-colored prismatic crystals radiates, forming a bristling sphere. Some of these prismatic crystals are extremely thin compared with their length, which probably never exceeds 0.5 millimeter, being almost hairlike, and the ratio of their 


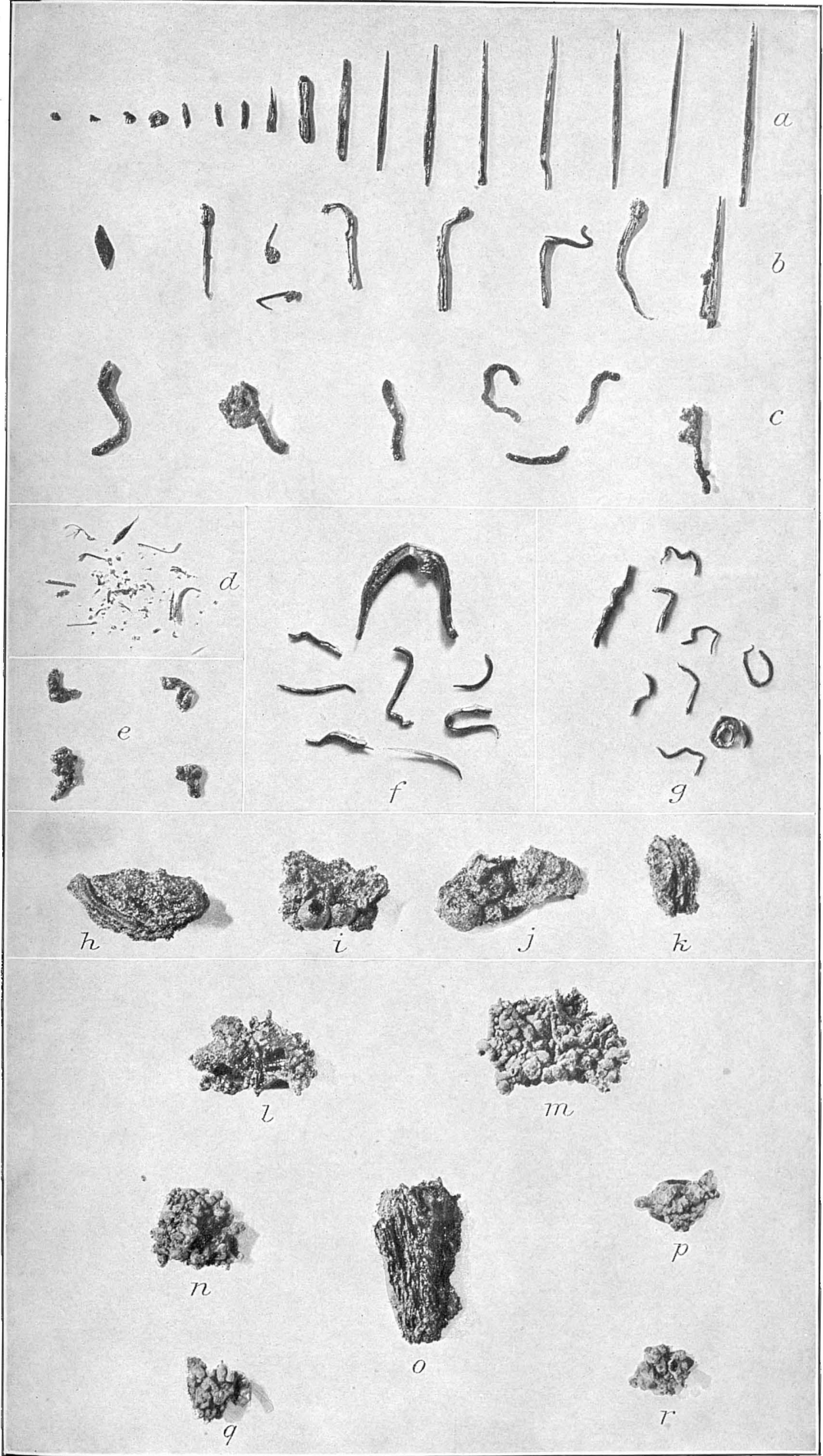

MONTROYDITE FORMS. 

length to thickness is doubtless very much greater than that of the longest of the large red prismatic crystals of $1 a$. Spheres in which the bristling crystals are so very thin as described are almost light-yellow in color, and are shown in $i, j, n, q, r$, Plate III.

$2 c$. The hollow pipe-stem structure is rare on the specimens at hand, many of the groupings of minute light-colored crystals being very irregular and undefinable as to their shape. Some are partly hollow, and others are filled with crystalline material. While many such groupings are light-brown, some are rather dark, lacking the outer envelope of the velvety minute crystals. Some specimens referred to this type consist of hollow cylindrical masses, from both the outside and inside of which radiate a large number of the small minute prismatic crystals. Forms described by Moses, in which the supporting column is mercury and has the "velvety incrustation of orange-red needles" projecting from it, were not found by us. Some illustrations of specimens referred to here are shown in $l, m, n, p$, $q, r$, Plate IIT.

$2 d$. The large bubble-like masses are rather common and are found implanted on the crystalline masses of montroydite, especially the form $2 f$, and also between the large scalenohedral calcites, where these bubbles attain a large size. A smaller bubble on $2 f$, broken open to show the hollow interior, is shown in $i$, Plate III, while several others appear in Plate II, one over a centimeter across being well shown in the central upper part. In color they are very dark, appearing almost black, and are smooth with a dull luster. While the smaller ones are nearly spherical the larger ones tend to be more irregular in shape and many appear as if made of several fused together. On breaking a number of these open it was found that they were all hollow; they thus differ markedly from the forms already described, in which the center is filled with crystalline montroydite. The inside walls of these bubbles are covered with a drusy coating of the minute dark-red colored crystals, $1 b$, and rarely with the light-colored prismatic crystals which in the other forms are on the outside. The appearance of these bubbles very much resembles that of geodes. A number of them have in addition numerous large, red, prismatic crystals, $1 a$, running through the interior space and of a length nearly equal to the diameter of the bubble. A number of these bubbles have considerable terlinguaite inside, this mineral, generally mixed with the montroydite, forming an aggregate of crystallized material in which the individual crystals are usually not very distinct.

$2 e$. The irregular masses which show large crystal faces, but no distinct crystals, are rather abundant. They have a dark-red color and often a resinous appearance, reminding one very much of darkred sphalerite. The crystal faces, some of them several millimeters 
across, though generally much smaller, are always striated and uneven. Some of these masses are hollow, others more or less filled with dark-red crystalline matter. Group e, Plate III, shows four of these forms, though the photograph does not bring out the structure well.

$2 f$. The stratified form is present in the largest quantity and contains mixed with it examples of nearly all the other forms. The large mass on the large specimen, a part of which is shown in Plate II, is slightly over 2 centimeters thick and more than a decimeter across. Its structure is not well shown in this plate, as this shows a top view looking down on the mass, but $k$ and $o$, Plate III, show the stratified appearance. The layers are generally very thin and are separated from each other by spaces much higher than the thickness of each individual layer. While in general fairly parallel, in detail they are not so, at one place the layers running down to meet each other, and elsewhere two parallel ones being joined by a third slanting between them. No individual layers can be traced for any distance, since they become broken up and very irregular in shape. They are of a dark reddish-brown color and are composed of crystalline montroydite in which are embedded distinct crystals, either long or short, and usually dark-red, and also variously shaped masses of the light-brown, minute prismatic crystals. Considerable terlinguaite is mixed with this montroydite, so much at times as to give the whole mass a greenish color. Short, minute, dark-red crystals (1b) are rather abundant here. So far we have not found any metallic mercury mixed with this stratified material.

$2 g$. The powdery material is placed in a separate class, as it was particularly noticed on a specimen where prismatic red crystals constituted the only other form of montroydite. It is the specimen on which montroydite (with terlinguaite) is found associated with calomel, the matrix being the pink earthy mass, which is here highly impregnated with calomel. The specimen when received was of an exceedingly brilliant light-orange color, the unusual lightness being due probably to the associated powdery yellowish terlinguaite, as well as to the minuteness of the montroydite crystals. After the terlinguaite had changed its yellow color to a dark greenish gray, the brilliant color of the specimen entirely disappeared.

\section{PHYSICAL PROPERTIES.}

COHESION, ETC.

The cleavage is perfect parallel to the brachypinacoid $b\{010\}$, and is obtained with the greatest ease. Sometimes when a crystal is being bent it will give at a certain point and form a sharply angular $\mathrm{V}$-shaped mass, when the cleavage will cause the crystal to 
separate into numerous plates parallel to the brachypinacoid. $\mathrm{Nu}-$ merous parallel straight lines on the brachypinacoid $\{010\}$, normal to the prism edges, are caused by a steplike structure on the cleavage piece. The presence of these numerous parallel lines seems to indicate that the basal pinacoid $\{001\}$ is a gliding plane. But its development is very slight, as we were not able to produce artificially a plane surface parallel to $\{001\}$; neither could any such surface be detected on any of the crystals. It may be mentioned here that the base $\{001\}$ has not been observed as a form for montroydite. Indications of a cleavage oblique to the length, as mentioned by Moses, were not seen on any of the crystals.

\section{FLEXIBILITY.}

The crystals are somewhat brittle, in that they may be broken into masses of irregular shape, but it is very difficult to do so on account of the excellent cleavage. Attempts to crush the mineral almost always result in forming numerous cleavage plates. The mineral is sectile, since a thin piece may be cut off with a knife, the separated piece curling as is usual with a sectile substance.

As far as qualitative tests show, the mineral is not elastic, but is flexible. In fact, as already shown, its flexibility is developed to a wonderful extent. It is possible to bend a crystal into a circle without its showing the least sign of breaking or cleaving. There does not seem to be any tendency on the part of the mineral to resume its original position, though no accurate experiments were made to prove this. The bending force must be applied normal to the cleavage face, that is, parallel to the $b$ axis, when the crystal will bend in the zone (010): (001). If the force be applied in some other direction the crystals will usually break, though not always. Moreover, measurements of some of the crystals naturally bent have shown that not only have they been bent in the zone (010): (001), that is, in one direction, but they have also been twisted, so that they were flexible in at least two directions. One crystal that was naturally twisted as well as bent, without showing under the microscope any indication of breakage or cleavage, was measured and shown to have been bent and twisted by at least two forces. Attempts to twist a crystal artificially were not very successful, as the mineral usually cleaved into numerous plates.

Plate III shows some crystals ( $g$ ) of montroydite that were originally straight, but have been bent into various shapes to illustrate the flexibility of the mineral, as well as some others $(f)$ that were bent when received by us.

In directions other than that normal to the cleavage the crystals are fairly rigid, and, if not allowed to turn so that the stress may be applied in a direction normal to the cleavage, will either break 
irregularly or cleave into numerous plates when a sufficient force is applied. Plate III, $d$, shows the result of applying to a crystal a sufficient force in a direction not normal to the cleavage. In breaking there formed numerous small pieces (result of brittleness) and also numerous platy masses (result of cleavage). These last as a secondary effect are often bent, as can be seen in several of the pieces.

The flexibility shown by these crystals is not the effect of translation. Translation may be said to have taken place when "the particles have evidently slipped without change in orientation . . . there is no change in the direction of the optic axis" (for ice, e. g.). ${ }^{a}$ If we assume the bending of a montroydite crystal to be the effect of translation, then, as each unit has simply slipped or moved parallel to itself, the resultant structure must have the same optic relation that obtained before bending, and the entire crystal will extinguish at the same time. But these bent crystals of montroydite do not show such extinction. The direction of extinction in such a bent crystal is always parallel to the edges of the crystal, and this extinction direction has therefore been bent with the crystal.

Moses gives the hardness as less than 2, but no trouble was experienced in scratching gypsum with montroydite. Its hardness is therefore placed between 2 and 3.

DENSITYY.

The specific gravity was not determined by the writers, as they were unable to obtain any quantity of montroydite sufficiently free from mercury for the purpose. A determination on an amount of less than a gram can have but an approximate value, and it was found that almost all the montroydite contained inclusions of mercury, which would of course cause a material plus error. The value was also not determined by Moses, and therefore remains an unknown quantity.

LUSTER, COLOR, ETC.

The luster is very vitreous and often inclines to adamantine, as with all of these mercury minerals. No indications of greasy luster were seen.

The large crystals are in color a red, resembling that of some massive realgar and also vanadinite. It is a deep red with some brown in it. The smaller crystals are more of a dark orange or brownishred, while the very minute ones, such as form the irregular-shaped masses or worms, are decidedly brown. Some of the more massive crystalline forms of montroydite are very dark, nearly black, though this may possibly be a secondary effect due to laboratory gases. In transmitted light the thicker crystals are of a beautiful deep orangered, slightly pleochroic, in some directions tending more toward a 
reddish, normal to this tending to a yellowish shade. In thinner crystals the color becomes orange and in very thin plates is pale yellow, in which no pleochroism can be detected. The streak is yellow-brown, with no indication of any red color.

OPTICAL PROPERTIES.

Unfortunately it was not possible to obtain any data of value in regard to the optical constants. None of the crystals possess any natural prismatic edges that are suitable for a determination of the indices of refraction, and the flexibility of the mineral with its perfect cleavage prevents the preparation of artificial prisms. The mineral has parallel extinction and is slightly pleochroic in thick sections. The cleavage face seems to show the emergence of a bisectrix with a very large optic angle (much larger than $90^{\circ}$, even in oil). The trace of the axial plane is vertical, and therefore the axial plane would be parallel to (100) with bisectrices emerging on (001) and (010), probably $B_{\mathrm{x}_{0} \perp}(010)$. It was not found feasible to measure any axial angle. Attempts were made to measure the indices of refraction by the method of the Duc de Chaulnes, using the microscope, but no concordant results were obtained, though the values were always considerably above 2 .

\section{CHEMISTRY:}

Montroydite is completely volatile without fusing, yielding in a closed tube a sublimate of mercury only.

Since the oxygen as given for montroydite in the paper by Moses was assumed by difference, it seemed desirable to make a gas-volumetric determination of it by dissociating the mineral in vacuo in a tube with a plug of gold leaf near the exit, attached to a Töpler pump, collecting the gaseous product, measuring its volume, and testing it as to its chemical behavior. The gas contained nothing absorbable by caustic alkali and was wholly absorbed by yellow phosphorus. Hence it was pure oxygen, and the test confirmed the supposition of Moses. Analysis of 0.2213 gram of the prismatic needles gave the following results:

Analysis of montroydite compared with theoretical composition.

\begin{tabular}{|r|r|r|}
\hline & Theory. & Found. \\
\hline Hg..... & $\begin{array}{r}92.59 \\
7.41\end{array}$ & $\begin{array}{r}a 92.74 \\
b 7.49\end{array}$ \\
\cline { 2 - 2 } & 100.00 & 100.23 \\
\hline
\end{tabular}

$a$ Weighed as metal.

$b$ Calculated from the volume. 


\section{CRYSTALLOGRAPHY.}

GENERAL DESCRIPTION.

The crystallography of montroydite was so well described by Moses that only such additional and more accurate data as can naturally be obtained from a larger quantity and better material than was at his disposal are here presented. The results obtained by Moses were deduced from the measurement of a single crystal, which showed the mineral to be orthorhombic with 11 forms. The orientation chosen by Moses could not be improved upon, and is therefore retained.

Twenty-four crystals were measured by the writer, and many more were carefully examined with a hand lens; but it is believed that all the essential features of the crystallography of montroydite are embodied in the 24 crystals selected and measured. The result of this more extensive work has naturally increased the number of forms for montroydite. In addition to the 11 forms described by Moses, 45 new ones were measured, increasing the number to 56 . The better crystals also allowed a more accurate determination of the crystal elements, which, however, show only a slight variation from the values obtained by Moses. The size of the crystals measured is shown in the following table, the smaller values (less than 1 millimeter) being only approximate:

Habit and dimensions of montroydite crystals.

\begin{tabular}{|c|c|c|}
\hline $\begin{array}{l}\text { Crystal } \\
\text { No. }\end{array}$ & 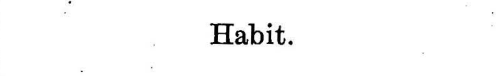 & Dimensions (millimeters). \\
\hline $\begin{aligned} & 1-. \\
& 5 \ldots \ldots \\
& 6 \ldots \\
& 7 \ldots \\
& 8 \ldots \\
& 9 \ldots \\
& 10 \ldots \\
& 11 \ldots \\
& 12 \ldots \\
& 13 \ldots \\
& 14 \ldots \\
& 15 \ldots \\
& 16 \ldots \\
& 17 \ldots \\
& 18 \ldots \\
& 19 \ldots \\
& 20 \ldots \\
& 21 \ldots \\
& 22 \ldots \\
& 23 \ldots \\
& 24 \ldots\end{aligned}$ & 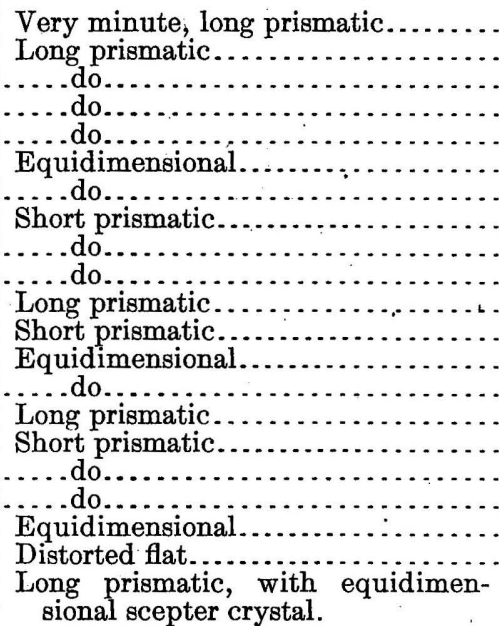 & $\begin{array}{l}\text { Less than } 1 \mathrm{~mm} \text {. long. } \\
3 \text { by } \frac{1}{4} \text { by } \frac{1}{3} . \\
1 \text { by } \frac{1}{5} \text { by } \frac{1}{5} . \\
1 \text { by } \frac{1}{5} \text { by } \frac{1}{5} . \\
14 \text { by } 1 \text { by } 1 . \\
1 \frac{1}{2} \text { by } 1 \frac{1}{2} \text { by } 1 . \\
2 \text { by } 1 \frac{1}{2} \text { by } 1 \frac{1}{2} . \\
1 \text { by } \frac{1}{2} \text { by } \frac{1}{3} . \\
3 \text { by } 2 \text { by } 2 . \\
2 \text { by } 1 \text { by } 1 . \\
4 \text { by } \frac{1}{3} \text { by } \frac{1}{3} . \\
3 \text { by } 1 \text { by } 1 . \\
2 \text { by } 1 \frac{1}{2} \text { by } 1 \frac{1}{2} . \\
1 \frac{1}{2} \text { by } 1 \frac{1}{2} \text { by } 1 \frac{1}{2} . \\
4 \text { by } \frac{1}{4} \text { by } \frac{1}{4} . \\
3 \frac{1}{2} \text { by } 1 \text { by } 1 . \\
3 \text { by } 1 \text { by } 1 . \\
3 \text { by } 1 \text { by } \frac{1}{2} . \\
1 \frac{1}{2} \text { by } 1 \text { by } 1 . \\
4 \text { by } 1 \frac{1}{2} \text { by } 1 \frac{1}{3} . \\
12 \text { by } 1 \frac{1}{2} \text { by } \frac{2}{3} .\end{array}$ \\
\hline
\end{tabular}


CALCULATION OF ELEMENTS.

In the calculation of the axial elements, values for $p_{\mathrm{o}}$ are obtained from the measurements on the macrodomes, while values for $q_{0}$ are obtained from measurements of the brachydomes. From the pyramids values for both $p_{o}$ and $q_{o}$ are obtained. The best measurements of the unit prism faces gave the following values:

Measurements of $\phi$ for unit prism, montroydite.

\begin{tabular}{|c|c|c|}
\hline $\begin{array}{l}\text { Excellent } \\
\text { reflection. }\end{array}$ & Good reflection. & Fair reflection. \\
\hline \begin{tabular}{cc}
$\circ$ & \multicolumn{1}{c}{} \\
57 & 28 \\
29 \\
27 \\
29 \\
29 \\
33 \\
25 \\
27 \\
30 \\
26 \\
25 \\
31 \\
27 \\
29 \\
28 \\
34
\end{tabular} & $\begin{array}{cc}\circ & \prime \\
5626 \\
27 \\
27 \\
27 \\
30 \\
26 \\
26 \\
28 \\
30 \\
32 \\
31\end{array}$ & $\begin{array}{cc}\circ & 1 \\
57 & 27 \\
31 \\
25 \\
27 \\
27 \\
27 \\
27 \\
32 \\
\\
29\end{array}$ \\
\hline Av. 5728.5 . & Av. 5728.6 & Av. 5728.1 \\
\hline
\end{tabular}

The average of all with due weight according to quality of reflection gives:

$$
\begin{aligned}
\phi & =57^{\circ} 28.5^{\prime} . \\
a & =.63768 .
\end{aligned}
$$

This value is verified by measurement of the unit pyramids, the $\phi$ angle of which is the same as the $\phi$ angle for the unit prism, the following values for $\phi$ being obtained:

\begin{tabular}{|c|c|c|}
\hline Form. & $\begin{array}{l}\text { No. of } \\
\text { measure- } \\
\text { ments. }\end{array}$ & $\begin{array}{l}\text { Average } \\
\text { value. }\end{array}$ \\
\hline 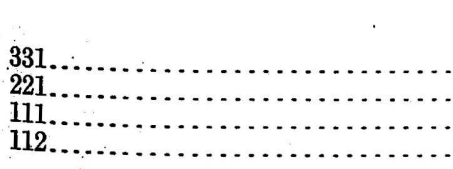 & $\begin{array}{l}11 \\
13 \\
16 \\
14\end{array}$ & $\begin{array}{rr}\circ \quad & \\
57 & 29 \\
26 \\
31 \\
28\end{array}$ \\
\hline Average $\ldots \ldots \ldots$ & 54 & 5728.6 \\
\hline
\end{tabular}

Measurements of $\phi$ for unit pyramids, montroydite. 
In calculating $p_{\mathrm{o}}$ and $q_{\mathrm{o}}$ from the different pyramids, a value is used for $\phi$ which is the average of the measurements and that obtained by calculation from $\phi(110)=57^{\circ} 28.5^{\prime}$, for in this way a better value can be obtained, since the final result will be the average of a greater number of measurements.

The value used for the $\phi$ angle for the unit pyramids is $57^{\circ} 28.5^{\prime}$.

Values of $\phi$ angle for pyramids used in calculation of elements, montroydite.

Pyramids of zone (130):(001):

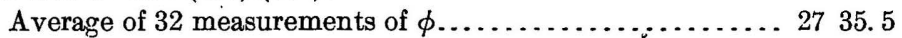

Calculated from $\phi(110)=57^{\circ} 28.5^{\prime} \ldots \ldots \ldots \ldots \ldots \ldots \ldots \ldots .2735 .9$

Value used in the calculation..................... $\overline{2735.7}$

Pyramids of zone (120):(001):

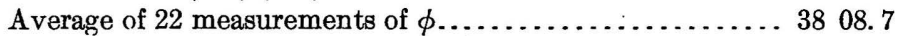

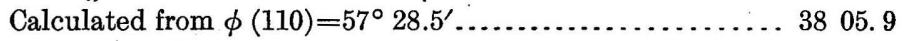

Value used in the calculation.......................

Pyramids of zone (210):(001):

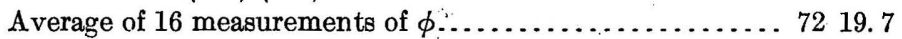

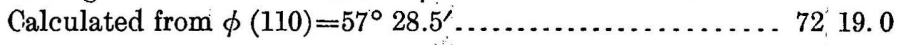

Value used in the calculation.................... $\overline{7219.4}$

Pyramids of zone (310):(001):

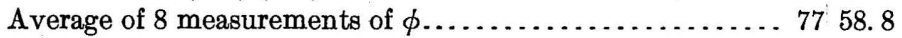

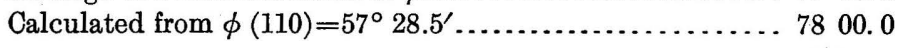

Value used in the calculation..................... $\overline{7759.4}$

Calculation of $p_{0}$ and $q_{0}$, montroydite crystals.

\begin{tabular}{|c|c|c|c|c|c|}
\hline \multirow{2}{*}{ Form. } & \multirow{2}{*}{$\begin{array}{c}\text { No. of } \\
\text { measure- } \\
\text { ments. }\end{array}$} & \multicolumn{2}{|c|}{ Angle. } & \multicolumn{2}{|c|}{ Value. } \\
\hline & & $\phi$ & $\rho$ & $p_{\mathrm{o}}$ & $q_{\mathrm{o}}$ \\
\hline & & $0 \quad 1$ & $\circ \quad y$ & & \\
\hline 012 & 28 & 000 & 3055.0 & & 1. 1978 \\
\hline 023 & 10 & 000 & $\begin{array}{ll}38 & 40.5\end{array}$ & & 1.2006 \\
\hline 102 & 14 & 9000 & $\begin{array}{ll}43 & 12.7\end{array}$ & 1. 8789 & \\
\hline 101 & 23 & 9000 & 6159.5 & 1. 8801 & ... \\
\hline 302 & 9 & 9000 & 7027.1 & 1. 8778 & ....... \\
\hline 201 & 14 & 9000 & $\begin{array}{lll}75 & 02.9\end{array}$ & 1.8723 & \\
\hline 301 & 21 & 9000 & 7957.7 & 1. 8831 & \\
\hline 112 & 23 & 5728.5 & $\begin{array}{lll}48 & 04.6\end{array}$ & 1.8780 & 1. 1975 \\
\hline 111 & 54 & 5728.5 & $\begin{array}{lll}65 & 49.3\end{array}$ & 1. 8781 & 1. 1976 \\
\hline 221 & 32 & 5728.5 & $77 \quad 20.4$ & 1.8767 & 1. 1967 \\
\hline 331 & 31 & 5728.5 & 8129.2 & 1. 8775 & 1. 1972 \\
\hline 133 & 6 & 2735.7 & 5330.5 & 1. 8785 & 1. 1981 \\
\hline 132 & 25 & 2735.7 & $\begin{array}{lll}63 & 47.1\end{array}$ & 1.8816 & 1. 2000 \\
\hline 122 & 24 & $\begin{array}{lll}38 & 07.3\end{array}$ & $56 \quad 45.0$ & 1. 8832 & 1. 1999 \\
\hline 211 & 18 & $72 \quad 19.4$ & 75 43. 9 & 1. 8731 & 1. 1940 \\
\hline 311 & 9 & 7759.4 & 8007.3 & 1. 8724 & 1. 1951 \\
\hline
\end{tabular}


The average of 303 measurements of $p_{0}$ is 1.8788 ; the average of 260 measurements of $q_{\mathrm{o}}$ is 1.1977 . The elements for montroydite are therefore:

$$
\begin{aligned}
a & =.6375 \\
c & =1.1977 \\
(010):(110) & =57^{\circ} 29^{\prime} \\
(001):(011) & =50^{\circ} 08^{\prime} \\
(001):(101) & =61^{\circ} 59^{\prime}
\end{aligned}
$$

Comparison of measured angles with those calculated from the foregoing values.

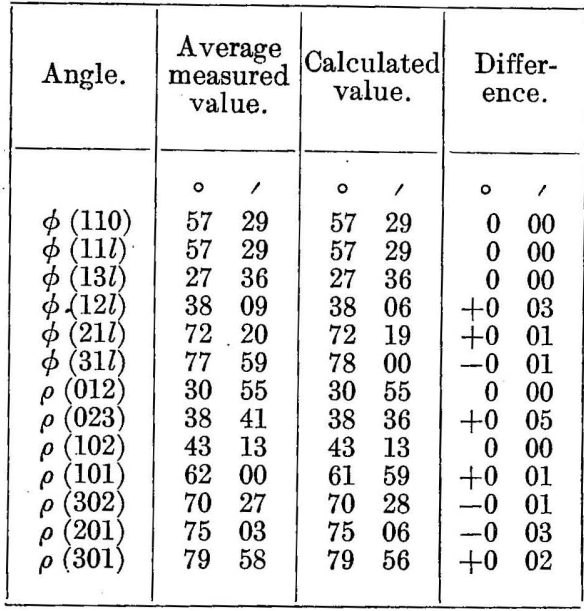

The values obtained by Moses, namely, $a=0.63797$ and $c=1.1931$, are very close to the above.

FORMS AND ANGLES.

Eleven forms were determined by Moses, all of which were found by the writer and all of which are common forms for montroydite. In addition to these 11 forms, 45 new ones were found, making a total of 56 for the mineral. ${ }^{a}$

The 11 forms found by Moses are:

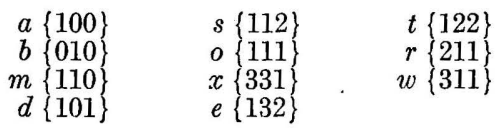

The new forms can be seen in the following table, which gives all the forms for montroydite, their letters and the average of the measured angles compared with those calculated from the elements derived by the writer. The new forms are starred.

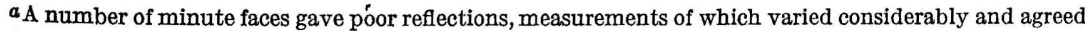
only approximately for the forms $\{356\},\{214\},\{212\},\{423\}$, and $\{312\}$. These can not, however, be classed oven as doubtful, as their characters were too uncertain. 
Forms and angles on montroydite crystals.

\begin{tabular}{|c|c|c|c|c|c|c|c|}
\hline \multirow{2}{*}{ No. } & \multirow{2}{*}{$\begin{array}{l}\text { Let. } \\
\text { ter. }\end{array}$} & \multicolumn{2}{|c|}{ Symbol. } & \multicolumn{2}{|c|}{ Measured. } & \multicolumn{2}{|c|}{ Calculated. } \\
\hline & & Gdt. & Miller. & $\phi$ & $\rho$ & $\phi$ & $\rho$ \\
\hline $\begin{array}{l}1 \\
2 \\
3 \\
4 \\
5\end{array}$ & $\begin{array}{r}a \\
b \\
* l \\
* h \\
* k\end{array}$ & $\begin{array}{c}\infty 0 \\
0 \infty 0 \\
\infty 10 \\
\infty 2 \\
\infty \frac{5}{3}\end{array}$ & $\begin{array}{r}100 \\
010 \\
1.10 .0 \\
120 \\
350\end{array}$ & \begin{tabular}{rc}
$\circ$ & \multicolumn{1}{c}{} \\
90 & 00 \\
0 & 00 \\
8 & 52 \\
37 & 58 \\
43 & 36
\end{tabular} & $\begin{array}{ll}\circ & . \\
90 & 00 \\
90 & 00 \\
90 & 00 \\
90 & 00 \\
90 & 00\end{array}$ & $\begin{array}{rc}\circ & \\
90 & 00 \\
0 & 00 \\
8 & 55 \\
38 & 06 \\
43 & 17\end{array}$ & $\begin{array}{ll}\circ & , \\
90 & 00 \\
90 & 00 \\
90 & 00 \\
90 & 00 \\
90 & 00\end{array}$ \\
\hline $\begin{array}{r}6 \\
7 \\
8 \\
9 \\
10\end{array}$ & $\begin{array}{l}{ }^{*} C \\
m \\
{ }^{*} f \\
{ }^{*} \xi \\
{ }^{*} j\end{array}$ & $\begin{array}{l}\infty \frac{3}{2} \\
\infty \\
3 \\
\frac{3}{2} \infty \\
3 \infty \\
4 \infty\end{array}$ & $\begin{array}{l}230 \\
110 \\
320 \\
310 \\
410\end{array}$ & $\begin{array}{ll}46 & 13 \\
57 & 29 \\
66 & 29 \\
77 & 50 \\
80 & 56\end{array}$ & $\begin{array}{ll}90 & 00 \\
90 & 00 \\
90 & 00 \\
90 & 00 \\
90 & 00\end{array}$ & $\begin{array}{ll}46 & 17 \\
57 & 29 \\
66 & 59 \\
78 & 00 \\
80 & 57\end{array}$ & $\begin{array}{ll}90 & 00 \\
90 & 00 \\
90 & 00 \\
90 & 00 \\
90 & 00\end{array}$ \\
\hline $\begin{array}{l}11 \\
12 \\
13 \\
14 \\
15\end{array}$ & $\begin{array}{l}* \Phi \\
* v \\
* v \\
* y \\
{ }^{*} K \\
{ }^{*} z\end{array}$ & $\begin{array}{r}5 \infty \\
0 \frac{1}{2} \\
0 \frac{2}{3} \\
0 \frac{4}{5} \\
01\end{array}$ & $\begin{array}{l}510 \\
012 \\
023 \\
045 \\
011\end{array}$ & $\begin{array}{rr}82 & 34 \\
0 & 00 \\
0 & 00 \\
0 & 00 \\
0 & 00\end{array}$ & $\begin{array}{ll}90 & 00 \\
30 & 55 \\
38 & 41 \\
43 & 22 \\
50 & 31\end{array}$ & $\begin{array}{rr}82 & 44 \\
0 & 00 \\
0 & 00 \\
0 & 00 \\
0 & 00\end{array}$ & $\begin{array}{ll}90 & 00 \\
30 & 55 \\
38 & 36 \\
43 & 47 \\
50 & 08\end{array}$ \\
\hline $\begin{array}{l}16 \\
17 \\
18 \\
19 \\
20\end{array}$ & $\begin{array}{l}{ }^{*} G \\
{ }^{*} L \\
{ }^{*} \beta \\
{ }^{*} E \\
{ }^{*} g\end{array}$ & $\begin{array}{l}03 \\
02 \\
02 \\
06 \\
\frac{1}{3} 0 \\
\frac{1}{2} 0\end{array}$ & $\begin{array}{l}032 \\
021 \\
061 \\
103 \\
102\end{array}$ & $\begin{array}{rr}0 & 00 \\
0 & 00 \\
0 & 00 \\
90 & 00 \\
90 & 00\end{array}$ & $\begin{array}{ll}60 & 57 \\
67 & 46 \\
81 & 56 \\
31 & 31 \\
43 & 13\end{array}$ & $\begin{array}{rr}0 & 00 \\
0 & 00 \\
0 & 00 \\
.90 & 00 \\
90 & 00\end{array}$ & $\begin{array}{ll}60 & 54 \\
67 & 20 \\
82 & 05 \\
32 & 04 \\
43 & 13\end{array}$ \\
\hline $\begin{array}{l}21 \\
22 \\
23 \\
24 \\
25\end{array}$ & $\begin{array}{l}{ }^{*} M \\
d \\
{ }^{*} n \\
{ }^{*} q \\
{ }^{*} \mu\end{array}$ & $\begin{array}{l}\frac{2}{3} 0 \\
10 \\
30 \\
20 \\
20 \\
30\end{array}$ & $\begin{array}{l}203 \\
101 \\
302 \\
201 \\
301\end{array}$ & $\begin{array}{ll}90 & 00 \\
90 & 00 \\
90 & 00 \\
90 & 00 \\
90 & 00\end{array}$ & $\begin{array}{ll}51 & 51 \\
62 & 00 \\
70 & 27 \\
75 & 03 \\
79 & 58\end{array}$ & $\begin{array}{ll}90 & 00 \\
90 & 00 \\
90 & 00 \\
90 & 00 \\
90 & 00\end{array}$ & $\begin{array}{ll}51 & 24 \\
61 & 59 \\
70 & 28 \\
75 & 06 \\
79 & 56\end{array}$ \\
\hline $\begin{array}{l}26 \\
27 \\
28 \\
29 \\
30\end{array}$ & $\begin{array}{l}{ }^{*} \alpha \\
{ }^{*} \zeta \\
e \\
{ }^{*} N \\
{ }^{*} Z\end{array}$ & $\begin{array}{l}\frac{1}{3} 1 \\
\frac{2}{5} \frac{6}{5} \\
\frac{1}{2} \frac{3}{2} \\
\frac{2}{3} \\
\frac{1}{2} \frac{7}{6}\end{array}$ & $\begin{array}{l}133 \\
265 \\
132 \\
263 \\
376\end{array}$ & $\begin{array}{ll}27 & 30 \\
27 & 39 \\
27 & 37 \\
28 & 05 \\
33 & 38\end{array}$ & $\begin{array}{ll}53 & 31 \\
59 & 22 \\
63 & 47 . \\
69 & 15 \\
59 & 21\end{array}$ & $\begin{array}{ll}27 & 36 \\
27 & 36 \\
27 & 36 \\
27 & 36 \\
33 & 55\end{array}$ & $\begin{array}{ll}53 & 30 \\
58 & 21 \\
63 & 45 \\
69 & 42 \\
59 & 18\end{array}$ \\
\hline $\begin{array}{l}31 \\
32 \\
33 \\
34 \\
35\end{array}$ & $\begin{array}{l}\quad t \\
* O \\
* Q \\
* S \\
* R\end{array}$ & $\begin{array}{l}\frac{1}{2} 1 \\
\frac{24}{3} \\
\frac{2}{3} \\
\frac{2}{9} \frac{1}{3} \\
1 \frac{3}{2} \\
\frac{1}{2} \frac{2}{3}\end{array}$ & $\begin{array}{l}122 \\
243 \\
239 \\
232 \\
346\end{array}$ & $\begin{array}{ll}38 & 09 \\
38 & 55 \\
46 & 58 \\
47 & 05 \\
49 & 32\end{array}$ & $\begin{array}{ll}56 & 45 \\
64 & 13 \\
29 & 32 \\
68 & 59 \\
51 & 14\end{array}$ & $\begin{array}{ll}38 & 06 \\
38 & 06 \\
46 & 17 \\
46 & 17 \\
49 & 38\end{array}$ & $\begin{array}{ll}56 & 42 \\
63 & 46 \\
30 & 01 \\
68 & 58 \\
50 & 57\end{array}$ \\
\hline $\begin{array}{l}36 \\
37 \\
38 \\
39 \\
40\end{array}$ & $\begin{array}{l}{ }^{*} U \\
{ }^{*} A \\
{ }^{*} B \\
s \\
{ }^{*} D\end{array}$ & $\begin{array}{l}\frac{3}{41} \\
\frac{1}{4} \\
\frac{1}{3} \\
\frac{1}{2} \\
\frac{2}{3}\end{array}$ & $\begin{array}{l}344 \\
114 \\
113 \\
112 \\
223\end{array}$ & $\begin{array}{ll}50 & 14 \\
57 & 36 \\
57 & 38 \\
57 & 29 \\
57 & 37\end{array}$ & $\begin{array}{ll}61 & 10 \\
29 & 06 \\
35 & 49 \\
48 & 05 \\
55 & 15\end{array}$ & $\begin{array}{ll}49 & 38 \\
57 & 29 \\
57 & 29 \\
57 & 29 \\
57 & 29\end{array}$ & $\begin{array}{ll}61 & 36 \\
29 & 07 \\
36 & 36 \\
48 & 05 \\
56 & 03\end{array}$ \\
\hline $\begin{array}{l}41 \\
42 \\
43 \\
44 \\
45\end{array}$ & $\begin{array}{r}*^{o} \\
x \\
x \\
* \delta \\
* V\end{array}$ & $\begin{array}{r}1 \\
2 \\
3 \\
5 \\
\frac{1}{2} \frac{2}{5}\end{array}$ & $\begin{array}{r}111 \\
221 \\
331 \\
551 \\
5.4 .10\end{array}$ & $\begin{array}{ll}57 & 29 \\
57 & 29 \\
57 & 29 \\
57 & 30 \\
62 & 33\end{array}$ & $\begin{array}{ll}65 & 49 \\
77 & 20 \\
81 & 29 \\
84 & 38 \\
47 & 08\end{array}$ & $\begin{array}{ll}57 & 29 \\
57 & 29 \\
57 & 29 \\
57 & 29 \\
62 & 59\end{array}$ & $\begin{array}{ll}65 & 50 \\
77 & 21 \\
81 & 29 \\
84 & 52 \\
46 & 32\end{array}$ \\
\hline $\begin{array}{l}46 \\
47 \\
48 \\
49 \\
50\end{array}$ & $\begin{array}{l}{ }^{*} \gamma \\
{ }^{*} P \\
{ }^{*} \pi \\
r \\
{ }^{*} \phi\end{array}$ & $\begin{array}{l}\frac{5}{2} 2 \\
\frac{1}{3} \frac{1}{3} \\
13 \\
21 \\
3 \frac{3}{2}\end{array}$ & $\begin{array}{l}542 \\
326 \\
323 \\
211 \\
632\end{array}$ & $\begin{array}{ll}62 & 40 \\
66 & 22 \\
66 & 46 \\
72 & 20 \\
71 & 43\end{array}$ & $\begin{array}{ll}80 & 22 \\
45 & 42 \\
63 & 53 \\
75 & 44 \\
80 & 23\end{array}$ & $\begin{array}{ll}62 & 59 \\
66 & 58 \\
66 & 58 \\
72 & 19 \\
72 & 19\end{array}$ & $\begin{array}{ll}79 & 16 \\
45 & 34 \\
63 & 54 \\
75 & 46 \\
80 & 24\end{array}$ \\
\hline
\end{tabular}


Forms and angles on montroydite crystals-Continued.

\begin{tabular}{|c|c|c|c|c|c|c|c|}
\hline \multirow{2}{*}{ No. } & \multirow{2}{*}{$\begin{array}{l}\text { Luet- } \\
\text { ter. }\end{array}$} & \multicolumn{2}{|c|}{ Symbol. } & \multicolumn{2}{|c|}{ Measured. } & \multicolumn{2}{|c|}{ Calrulated. } \\
\hline & & Gdt. & Miller. & $\phi$ & $\rho$ & $\phi$ & $\rho$ \\
\hline $\begin{array}{l}5 \\
59 \\
52 \\
53 \\
54 \\
55 \\
56\end{array}$ & $\begin{array}{l}* \rho \\
* \lambda \\
* \lambda \\
{ }^{*} w \\
* W \\
* \omega\end{array}$ & $\begin{array}{r}\frac{7}{13} \frac{3}{18} \\
\frac{3}{7} \frac{1}{7} \\
1 \frac{1}{3} \\
31 \\
41 \\
\frac{5}{6} \frac{1}{12}\end{array}$ & $\begin{array}{r}7.3 .13 \\
317 \\
313 \\
311 \\
411 \\
10.1 .12\end{array}$ & $\begin{array}{ll}\circ & \prime \\
74 & 29 \\
78 & 26 \\
78 & 22 \\
77 & 59 \\
80 & 47 \\
86 & 21\end{array}$ & $\begin{array}{lc}\circ & , \\
46 & 29 \\
39 & 52 \\
63 & 00 \\
80 & 07 \\
82 & 45 \\
57 & 21\end{array}$ & $\begin{array}{lc}\circ & \prime \\
74 & 43 \\
78 & 00 \\
78 & 00 \\
78 & 00 \\
80 & 57 \\
86 & 21\end{array}$ & $\begin{array}{lc}\circ & , \\
46 & 22 \\
39 & 27 \\
62 & 29 \\
80 & 09 \\
82 & 31 \\
57 & 28\end{array}$ \\
\hline
\end{tabular}

The following pages give a more detailed description of the forms observed on montroydite. For convenience they have been divided into three groups: (a) The common forms, which include those that were observed 10 or more times and, excepting $\{10.1 .12\}$, were noticed on 8 or more crystals; (b) those that were measured less than 10 times but at least 3 times; and (c) those that were found only once or twice. This last group constitutes the class of rare forms. The number of forms in each of these groups was: Common forms (a), 22; less common forms (b), 18; rare forms (c), 16; making the total number of forms 56.

DESCRIPTION OF COMMON FORMS.

The following table shows the measurements with the occurrence of the common forms, except $a, b$, and $m,{ }^{a}$ for which the measurements are not given.

Measurements of common forms on montroydite crystals.

\begin{tabular}{|c|c|c|c|c|c|c|c|c|c|c|c|}
\hline \multirow{2}{*}{ } & \multirow{2}{*}{ 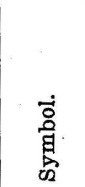 } & \multirow{2}{*}{ 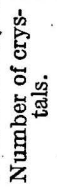 } & \multirow{2}{*}{ 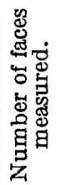 } & \multicolumn{2}{|c|}{ Measured. } & \multicolumn{2}{|c|}{ Calculated. } & \multicolumn{2}{|c|}{$\begin{array}{l}\text { Number } \\
\text { measured } \\
\text { within } 5^{\prime} \text {. }\end{array}$} & \multicolumn{2}{|c|}{ Limits of measurement. } \\
\hline & & & & $\phi$ & $\rho$ & $\phi$ & $\rho$ & $\phi$ & $\rho$ & $\phi$ & $\rho$ \\
\hline $\begin{array}{l}* v \\
* y \\
* z \\
* g \\
d\end{array}$ & $\begin{array}{l}012 \\
023 \\
011 \\
102 \\
101\end{array}$ & $\begin{array}{l}18 \\
11 \\
10 \\
15 \\
23\end{array}$ & $\begin{array}{l}39 \\
17 \\
12 \\
24 \\
45\end{array}$ & \begin{tabular}{rc}
$\circ$ & \multicolumn{1}{c}{} \\
0 & 00 \\
0 & 00 \\
0 & 00 \\
90 & 00 \\
90 & 00
\end{tabular} & $\begin{array}{cc}\circ & \prime \\
30 & 55 \\
38 & 41 \\
50 & 31 \\
43 & 13 \\
62 & 00\end{array}$ & $\begin{array}{rc}\circ & 1 \\
0 & 00 \\
0 & 00 \\
0 & 00 \\
90 & 00 \\
90 & 00\end{array}$ & \begin{tabular}{cc}
$\circ$ & \multicolumn{1}{c}{} \\
30 & 55 \\
38 & 36 \\
50 & 08 \\
43 & 13 \\
61 & 59
\end{tabular} & & $\begin{array}{r}21 \\
2 \\
1 \\
11 \\
30\end{array}$ & 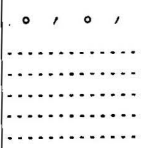 & \begin{tabular}{cccc}
$\circ$ & \multicolumn{1}{c}{$\circ^{\prime}$} & $\prime$ \\
30 & $48-31$ & 00 \\
38 & $22-39$ & 00 \\
48 & $45-51$ & 56 \\
42 & $59-43$ & 48 \\
61 & $28-62$ & 06
\end{tabular} \\
\hline $\begin{array}{l}* n \\
*^{*} q \\
*_{u} u \\
*_{a} \\
e\end{array}$ & $\begin{array}{l}302 \\
201 \\
301 \\
133 \\
132\end{array}$ & $\begin{array}{r}8 \\
13 \\
14 \\
10 \\
16\end{array}$ & $\begin{array}{l}10 \\
21 \\
46 \\
12 \\
33\end{array}$ & $\begin{array}{ll}90 & 00 \\
90 & 00 \\
90 & 00 \\
27 & 30 \\
27 & 37\end{array}$ & $\begin{array}{rr}70 & 27 \\
75 & 03 \\
79 & 58 \\
53 & 31 \\
63 & 47\end{array}$ & $\begin{array}{ll}90 & 00 \\
90 & 00 \\
90 & 00 \\
27 & 36 \\
27 & 36\end{array}$ & $\begin{array}{ll}70 & 28 \\
75 & 06 \\
79 & 56 \\
53 & 30 \\
63 & 45\end{array}$ & $\begin{array}{c}3 \\
11\end{array}$ & $\begin{array}{r}6 \\
8 \\
15 \\
4 \\
12\end{array}$ & $\begin{array}{llll}27 & 03-28 & 48 \\
27 & 20-28 & 20\end{array}$ & $\begin{array}{llll}70 & 08-70 & 41 \\
74 & 47-75 & 38 \\
79 & 48-80 & 21 \\
52 & 58-54 & 22 \\
63 & 05-64 & 30\end{array}$ \\
\hline $\begin{array}{r}t \\
s \\
0 \\
* i \\
x\end{array}$ & $\begin{array}{l}122 \\
112 \\
111 \\
221 \\
331\end{array}$ & $\begin{array}{l}20 \\
22 \\
23 \\
21 \\
17\end{array}$ & $\begin{array}{l}45 \\
72 \\
84 \\
48 \\
52\end{array}$ & $\begin{array}{ll}38 & 09 \\
57 & 29 \\
57 & 29 \\
57 & 29 \\
57 & 29\end{array}$ & $\begin{array}{ll}56 & 45 \\
48 & 05 \\
65 & 49 \\
77 & 20 \\
81 & 29\end{array}$ & $\begin{array}{ll}38 & 06 \\
57 & 29 \\
57 & 29 \\
57 & 29 \\
57 & 29\end{array}$ & $\begin{array}{ll}56 & 42 \\
48 & 05 \\
65 & 50 \\
77 & 21 \\
81 & 29\end{array}$ & & $\begin{array}{l}13 \\
24 \\
40 \\
21 \\
24\end{array}$ & 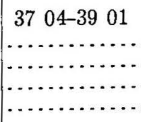 & $\begin{array}{llll}56 & 14-57 & 53 \\
47 & 44-48 & 46 \\
65 & 30-66 & 00 \\
77 & 01-78 & 18 \\
80 & 31-81 & 54\end{array}$ \\
\hline $\begin{array}{l}*_{p}^{r} \\
w \\
*_{\omega}\end{array}$ & $\begin{array}{r}211 \\
7.3 .13 \\
311 \\
10.1 .12\end{array}$ & $\begin{array}{r}16 \\
9 \\
8 \\
4\end{array}$ & $\begin{array}{l}24 \\
19 \\
13 \\
11\end{array}$ & $\begin{array}{ll}72 & 20 \\
74 & 29 \\
77 & 59 \\
86 & 21\end{array}$ & $\begin{array}{ll}75 & 44 \\
46 & 29 \\
80 & 07 \\
57 & 21\end{array}$ & $\begin{array}{ll}72 & 19 \\
74 & 43 \\
78 & 00 \\
86 & 21\end{array}$ & $\begin{array}{ll}75 & 46 \\
46 & 22 \\
80 & 09 \\
57 & 28\end{array}$ & $\begin{array}{r}11 \\
8 \\
3 \\
1\end{array}$ & $\begin{array}{r}10 \\
8 \\
6 \\
3\end{array}$ & $\begin{array}{lll}71 & 31-72 & 41 \\
73 & 19-75 & 48 \\
77 & 43-78 & 39 \\
85 & 00-86 & 56\end{array}$ & $\begin{array}{lll}75 & 15-75 & 57 \\
45 & 46-47 & 23 \\
79 & 50-80 & 25 \\
56 & 55-57 & 58\end{array}$ \\
\hline
\end{tabular}


The two pinacoids $a\{100\}$ and $b\{010\}$, together with the prism $m\{110\}$, are among the most prominent forms of montroydite. It is owing to their frequent development as large faces that the crystals have a prismatic habit. In general these three faces are about equaliy developed on all the crystals. On some of those of an equidimensional habit the orthopinacoid is slightly larger than the other two forms. It was not distinctly noticed that any of these faces were vertically striated, though parallel growth and combinations with other faces in this zone tend to partly develop an appearance of vertical striation. Very rarely the brachypinacoid is horizontally striated just below the brachydomes. Some of these faces, especially the orthopinacoid, have irregular depressions or cavities on their surface.

$v\{012\}$ is usually a large face, long and narrow. It is the most prominent of the brachydomes and as such has its effect in determining the habit of the crystal. It is striated horizontally, as is in fact the entire zone of brachydomes.

$y\{023\}$. - This form, though second in size of the brachydomes, is usually minute to small, sometimes almost a line face, and very rarely fairly large.

$z\{011\}$. - The unit brachydome is poorly developed as either a minute or a line face. The reflections were particularly poor and the measurements of this form showed considerable variation.

$g\{102\}$.-Contrary to the corresponding brachydome, $v\{012\}$, this orthodome invariably occurs as a small or minute face. It is triangular in shape and is horizontally striated.

$d\{101\}$. - The unit orthodome is one of the most dominant forms for montroydite. It forms large faces on the prismatic crystals and is the largest form on the equidimensional ones, then determining the habit of these crystals. It is characteristically striated vertically or else has inverted V-shaped markings.

$n\{302\}$. - This dome is present as line faces, and not in as many places as most of the other common forms.

$q\{201\}$.-This form, while present on many crystals, is almost invariably a line face between $\{101\}$ and $\{301\}$, or more rarely between $\{301\}$ and $\{302\}$.

$u\{301\}$.-This form is a characteristic one for the mineral, being usually present as broad faces. These are narrow and long in the stout crystals and have an oblong shape in the prismatic ones. On one crystal the form was partly striated vertically, though it is characteristically very even and highly polished, giving good reflections. $\alpha\{133\}$.-This pyramid is present as minute to small faces, being usually very subordinate in size. 
$e\{132\}$.-This form is also a subordinate one in size, the faces being minute or line faces.

$t\{122\}$.-Though generally small, in some'crystals minute, this pyramid is rarely absent, being present in 20 crystals. It is usually striated parallel to the intersection of the faces in the zone (010): (102).

$s\{112\}$. - This form is a very important one for montroydite, being present on every terminated crystal that was measured except one. In size it varies from small to medium and is, in fact, the largest pyramid for the mineral. It is striated, usually in two directions, in the zone (001):(110) and (010): (102).

$o\{111\}$.-Also a principal form but generally subordinate in size to $s\{112\}$. It is present on all the terminated crystals examined. It is striated usually in two directions in the zones (001):(110) and (010) : (101), though a third direction of striæ has been observed in the zone (100): (011).

$i\{221\}$.-This form is present as minute or narrow faces on almost all the crystals, and attains a large size on none.

$x\{331\}$.-This pyramid shows considerable variation in size, being usually minute or small, in some places a line face, and but rarely a relatively large face.

$r\{211\}$. - This form is generally small or minute.

$w\{311\}$. - This form occurs either as a minute face or a line face and is one of the least common of the chief forms of montroydite.

$\rho\{7.3 .13\}$. -An interesting form, as it occurs repeatedly on numerous crystals. (See measurements on next page.) In size it is generally a fairly large face, rarely smaller to minute. The indices are somewhat complex and unique, but, as the measurements show, they are the correct ones. The form is near to the simple one $\{214\}$, but still too far removed therefrom to be in any way referable to it. It is of interest to note that the simple form $\{214\}$ has not been found for the mineral. The form is usually striated nearly in the zone (010): (102). All the measurements for this form are shown in the following table: 
Occurrence and measurements of the form $\rho\{7.3 .13\}$ (new) on montroydite crystals.

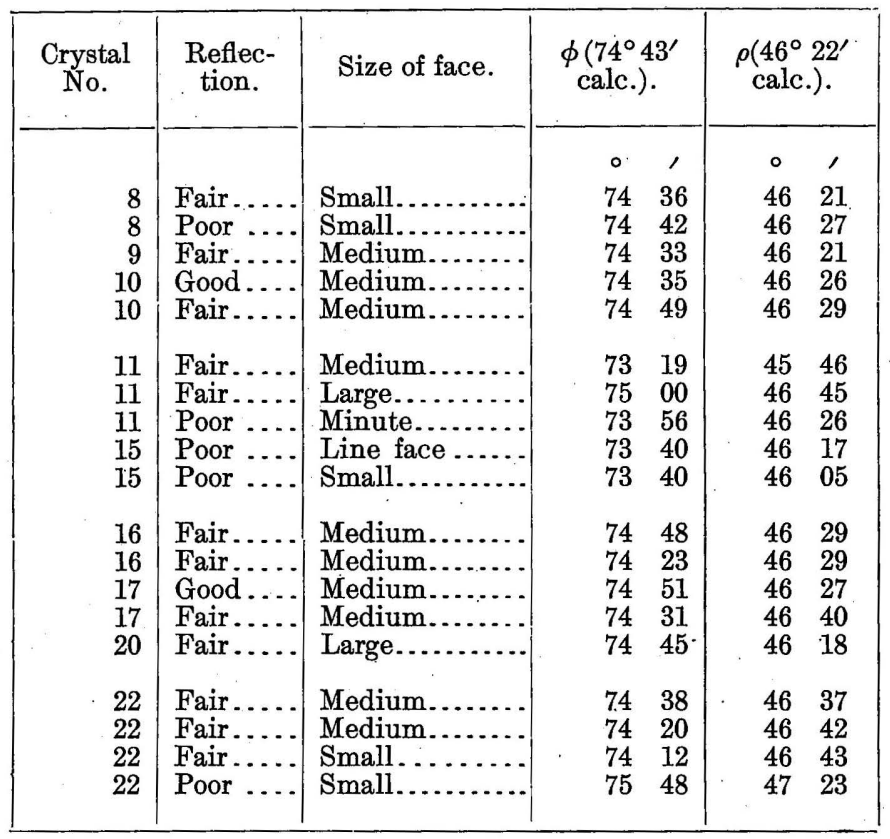

$\omega\{10.1 .12\}$. - The size of this form varies from a line face to one of small size, yet larger than many of the other forms. It is near to the unit dome $\{101\}$ and lies in the zone $\{7.3 .13\}:\{101\}$.

Occurrence and measurements of the form $\omega\{10.1 .12\}$ (new) on montroydite crystals.

\begin{tabular}{|c|c|c|c|c|c|}
\hline $\begin{array}{l}\text { Crystal } \\
\text { No. }\end{array}$ & $\begin{array}{c}\text { Reflec- } \\
\text { tion. }\end{array}$ & Size of face. & 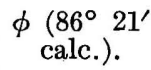 & $\begin{array}{l}\rho\left(57^{\circ}\right. \\
\text { calc. }\end{array}$ & )$^{28^{\prime}}$ \\
\hline $\begin{array}{l}11 \\
11 \\
17 \\
17 \\
17 \\
17 \\
20 \\
22 \\
22 \\
22 \\
22\end{array}$ & $\begin{array}{l}\text { Poor.... } \\
\text { Poor.... } \\
\text { Fair .... } \\
\text { Poor.... } \\
\text { Fair .... } \\
\text { Fair .... } \\
\text { Poor.... } \\
\text { Poor.... } \\
\text { Poor.... } \\
\text { Fair.... } \\
\text { Poor.... }\end{array}$ & $\begin{array}{l}\text { Line face..... } \\
\text { Line face..... } \\
\text { Line face.... } \\
\text { Line face..... } \\
\text { Medium..... } \\
\text { Medium..... } \\
\text { Small ....... } \\
\text { Line face..... } \\
\text { Line face..... } \\
\text { Line face..... } \\
\text { Small . . . }\end{array}$ & $\begin{array}{cc}\circ & \prime \\
86 & 22 \\
85 & 28 \\
86 & 34 \\
86 & 56 \\
86 & 50 \\
85 & 02 \\
85 & 00 \\
86 & 36 \\
86 & 55 \\
86 & 38 \\
87 & 28\end{array}$ & $\begin{array}{c}\circ \\
57 \\
57 \\
56 \\
57 \\
57 \\
57 \\
57 \\
57 \\
-57 \\
57 \\
57\end{array}$ & $\begin{array}{l}\prime \\
28 \\
29 \\
55 \\
18 \\
58 \\
11 \\
10 \\
21 \\
21 \\
25 \\
12\end{array}$ \\
\hline
\end{tabular}

The vicinal form $\{44.1 .48\}$ usually occurs with $\{10.1 .12\}$ and is commonly much larger than it, being present as large faces, most of which give a good signal. However, the complex indices permit the form to be classed only as vicinal. 
DESCRIPTION OF LESS COMMON FORMS.

In the following table are given all the measurements, with descriptions, of those forms which were measured less than 10 times but more than twice, all being new forms. They constitute with the common forms the essential form system of montroydite.

Occurrence and measurements of less common forms on montroydite crystals.

[Bold-faced figures show calculated values.]

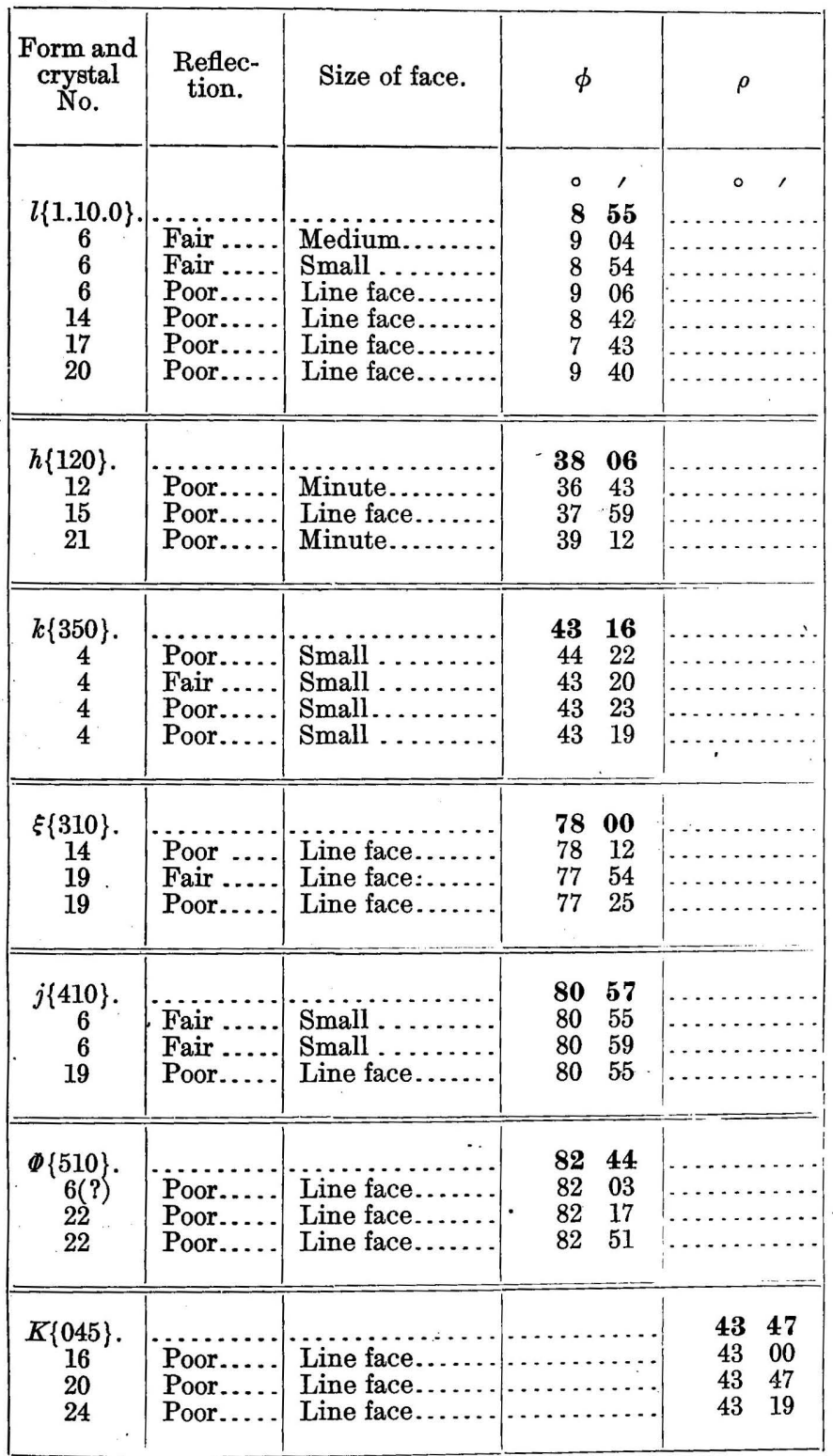

4494-Bull. $405-09-5$ 
Occurrence and measurements of less common forms on montroydite crystals-Continued.

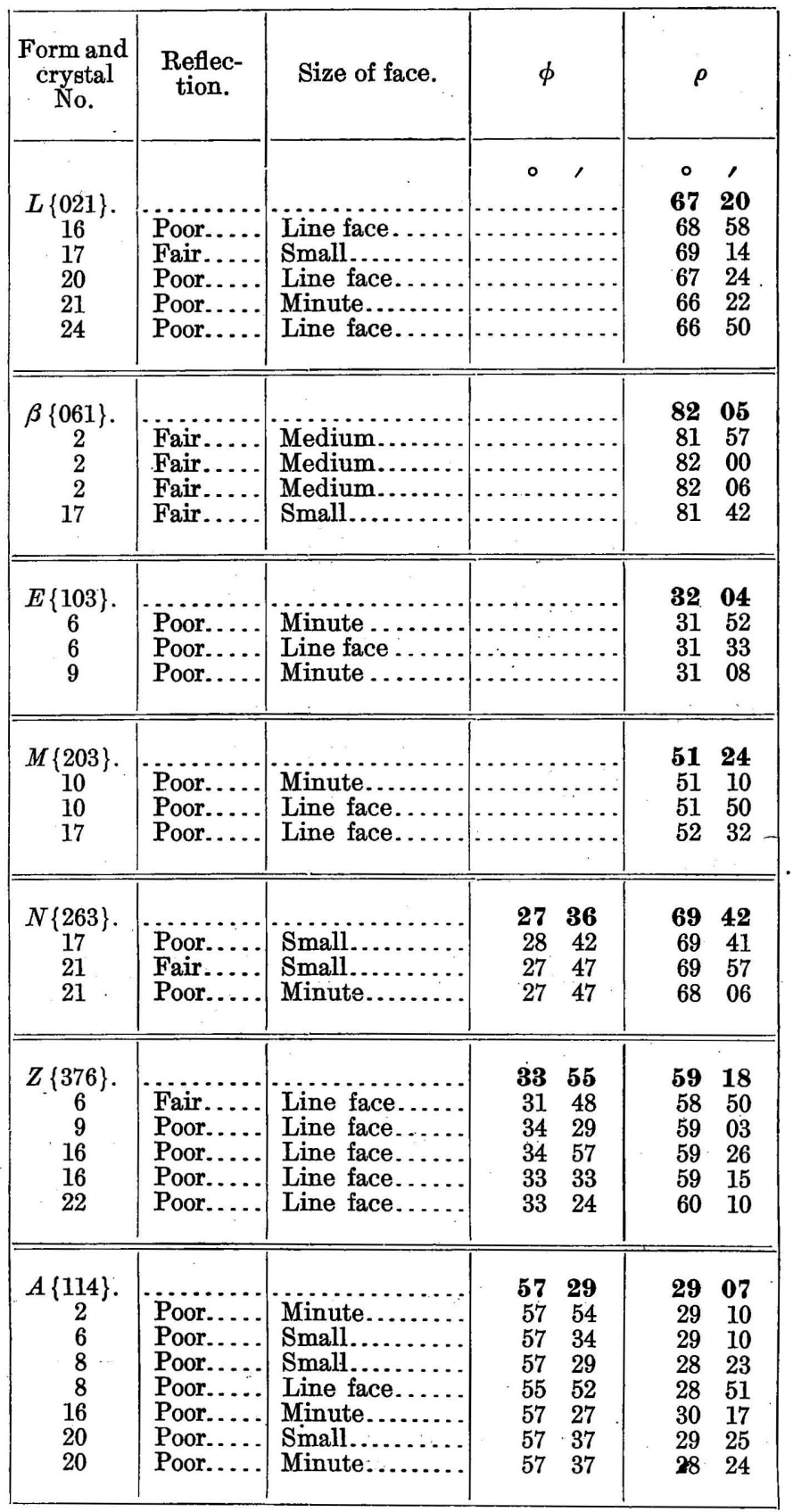


Occurrence and measurements of less common forms on montroydite crystals-Continued.

\begin{tabular}{|c|c|c|c|c|c|c|}
\hline $\begin{array}{l}\text { Form and } \\
\text { crystal } \\
\text {.No. }\end{array}$ & $\begin{array}{l}\text { Reflec- } \\
\text { tion. }\end{array}$ & Size of face. & $\phi$ & & $\rho$ & \\
\hline$B\{113\}$. & $\begin{array}{l}\text { Poor... } \\
\text { Poor... } \\
\text { Poor... }\end{array}$ & $\begin{array}{l}\text { Minute........ } \\
\text { Minute....... } \\
\text { Line face.... }\end{array}$ & $\begin{array}{cc}\circ & 1 \\
\mathbf{5 7} & \mathbf{2} \\
57 & 5 \\
57 & 3 \\
57 & 2\end{array}$ & $\begin{array}{l}\prime \\
\mathbf{2 9} \\
54 \\
33 \\
28\end{array}$ & $\begin{array}{c}\circ \\
\mathbf{3 6} \\
35 \\
38 \\
33\end{array}$ & $\begin{array}{l}\text { 36 } \\
\text { 36 } \\
21 \\
51\end{array}$ \\
\hline $\begin{array}{c}D\{223\} . \\
6 \\
6 \\
8 \\
12 \\
18 \\
22\end{array}$ & $\begin{array}{l}\text { Poor.... } \\
\text { Poor.... } \\
\text { Poor... } \\
\text { Poor... } \\
\text { Poor... . } \\
\text { Poor.... }\end{array}$ & $\begin{array}{l}\text { Line face } . . . \\
\text { Line face .... } \\
\text { Line face.... } \\
\text { Line face.... } \\
\text { Minute....... } \\
\text { Small........ }\end{array}$ & $\begin{array}{ll}\mathbf{5 7} & \mathbf{2} \\
57 & 3 \\
57 & 3 \\
57 & 2 \\
57 & 2 \\
56 & 0 \\
57 & 2\end{array}$ & $\begin{array}{l}29 \\
37 \\
37 \\
29 \\
27 \\
07 \\
28\end{array}$ & $\begin{array}{c}\mathbf{5 6} \\
55 \\
55 \\
55 \\
54 \\
54 \\
55\end{array}$ & $\begin{array}{l}\mathbf{0 3} \\
50 \\
56 \\
51 \\
10 \\
19 \\
25\end{array}$ \\
\hline $\begin{array}{c}\delta\{551\} . \\
2(?) \\
9 \\
20 \\
22\end{array}$ & $\begin{array}{l}\text { Poor.... } \\
\text { Poor..... } \\
\text { Poor.... } \\
\text { Poor.... }\end{array}$ & $\begin{array}{l}\text { Minute..... } \\
\text { Line face.... } \\
\text { Line face.... } \\
\text { Line face.... }\end{array}$ & $\begin{array}{ll}\mathbf{5 7} & \mathbf{2} \\
54 & 3 \\
57 & 2 \\
57 & 3 \\
57 & 2\end{array}$ & $\begin{array}{l}29 \\
34 \\
26 \\
35 \\
28\end{array}$ & $\begin{array}{l}84 \\
84 \\
85 \\
85 \\
84\end{array}$ & $\begin{array}{l}\mathbf{5 2} \\
00 \\
03 \\
16 \\
14\end{array}$ \\
\hline $\begin{array}{c}P\{326\} . \\
6 \\
6 \\
6 \\
8 \\
17 \\
22 \\
24\end{array}$ & $\begin{array}{l}\text { Poor.... } \\
\text { Poor.... } \\
\text { Fair.... } \\
\text { Poor.... } \\
\text { Poor.... } \\
\text { Poor.... } \\
\text { Poor.... }\end{array}$ & $\begin{array}{l}\text { Minute...... } \\
\text { Small........ } \\
\text { Small....... } \\
\text { Line face..... } \\
\text { Line face.... } \\
\text { Minute...... } \\
\text { Line face.... }\end{array}$ & $\begin{array}{rr}\mathbf{6 6} & \mathbf{5} \\
66 & 3 \\
63 & 5 \\
67 & 4 \\
64 & 3 \\
67 & 5 \\
67 & 0 \\
66 & .4\end{array}$ & $\begin{array}{l}58 \\
30 \\
59 \\
49 \\
37 \\
50 \\
06 \\
40\end{array}$ & $\begin{array}{l}45 \\
45 \\
45 \\
45 \\
46 \\
47 \\
44 \\
45\end{array}$ & $\begin{array}{l}34 \\
54 \\
14 \\
19 \\
05 \\
52 \\
20 \\
12\end{array}$ \\
\hline $\begin{array}{c}\{44.1 .48\} a \\
17 \\
18 \\
22 \\
22 \\
22 \\
22\end{array}$ & $\begin{array}{l}\text { Fair... } \\
\text { Poor.... } \\
\text { Good... } \\
\text { Fair.... } \\
\text { Poor... . } \\
\text { Poor.... }\end{array}$ & $\begin{array}{l}\text { Small } \\
\text { Minute........ } \\
\text { Medium..... } \\
\text { Medium..... } \\
\text { Small........ } \\
\text { Small......... }\end{array}$ & $\begin{array}{ll}\mathbf{8 9} & \mathbf{1} \\
88 & 4 \\
88 & 1 \\
89 & 1 \\
89 & 1 \\
89 & 0 \\
89 & 0\end{array}$ & $\begin{array}{l}10 \\
45 \\
15 \\
10 \\
17 \\
04 \\
09\end{array}$ & $\begin{array}{l}\mathbf{5 9} \\
59 \\
59 \\
59 \\
59 \\
59 \\
59\end{array}$ & $\begin{array}{r}46 \\
40 \\
53 \\
46 \\
49 \\
47 \\
48\end{array}$ \\
\hline
\end{tabular}

a Vicinal form. This form lies nearly in the zone $\{7.3 .13\}:\{101\}$, which has the zone symbol [121]:

$$
\begin{array}{r}
12 \overline{1} \\
44.1 .48 \\
\hline \Sigma+=46 \\
\Sigma-=48
\end{array}
$$

The one face giving a good reflection agrees exactly in angles with the calculated values. 
DESCRIPTION OF RARE FORMS.

The following table gives all the measurements for each of the rare forms:

Occurrence and measurements of rare forms, montroydite crystals.

\begin{tabular}{|c|c|c|c|c|c|c|c|c|}
\hline \multirow{2}{*}{$\begin{array}{l}\text { Let- } \\
\text { ter. }\end{array}$} & \multirow{2}{*}{ Symbol. } & \multirow{2}{*}{ 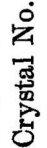 } & \multirow{2}{*}{$\begin{array}{l}\text { Reflec- } \\
\text { tion. }\end{array}$} & \multirow{2}{*}{ Size of face. } & \multicolumn{2}{|c|}{ Measured. } & \multicolumn{2}{|c|}{ Calculated. } \\
\hline & & & & & $\phi$ & $\rho$ & $\phi$ & $\rho$ \\
\hline $\begin{array}{l}C \\
f \\
f \\
G \\
G \\
\zeta \\
\zeta \\
\delta \\
Q \\
S \\
R \\
R \\
M \\
V \\
V \\
r \\
\pi \\
\phi \\
\phi \\
\lambda \\
\Delta \\
W \\
W\end{array}$ & $\begin{array}{r}230 \\
320 \\
320 \\
032 \\
032 \\
265 \\
265 \\
a \\
a 43 \\
239 \\
232 \\
346 \\
346 \\
344 \\
5.4 .10 \\
5.4 .10 \\
b 542 \\
323 \\
632 \\
632 \\
317 \\
313 \\
c 411 \\
c 411\end{array}$ & $\begin{array}{r}21 \\
6 \\
6 \\
6 \\
6 \\
21 \\
21 \\
17 \\
17 \\
22 \\
6 \\
11 \\
11 \\
3 \\
15 \\
21 \\
6 \\
22 \\
24 \\
17 \\
12 \\
18 \\
18\end{array}$ & $\begin{array}{l}\text { Poor... } \\
\text { Poor... } \\
\text { Poor... } \\
\text { Poor... } \\
\text { Poor... } \\
\text { Poor... } \\
\text { Poor... } \\
\text { Poor... } \\
\text { Poor... } \\
\text { Poor... } \\
\text { Poor... } \\
\text { Poor... } \\
\text { Poor... } \\
\text { Poor... } \\
\text { Poor... } \\
\text { Poor... } \\
\text { Fair... } \\
\text { Poor... } \\
\text { Poor... } \\
\text { Fair... } \\
\text { Poor... } \\
\text { Poor... } \\
\text { Poor... }\end{array}$ & 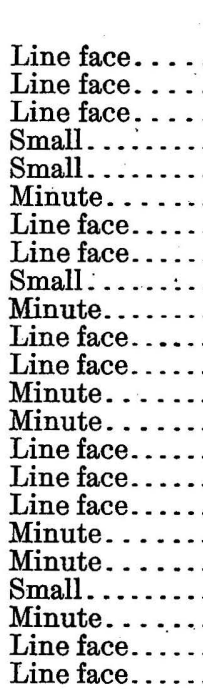 & \begin{tabular}{rc}
\multicolumn{1}{c}{$\circ$} & $\prime$ \\
46 & 13 \\
66 & 45 \\
66 & 12 \\
0 & 00 \\
0 & 00 \\
27 & 41 \\
27 & 37 \\
38 & 55 \\
46 & 58 \\
47 & 05 \\
48 & 55 \\
50 & 09 \\
50 & 14 \\
62 & 26 \\
62 & 40 \\
62 & 40 \\
66 & 46 \\
71 & 26 \\
72 & 00 \\
78 & 26 \\
78 & 22 \\
81 & 31 \\
80 & 02
\end{tabular} & $\begin{array}{ll}\circ & \prime \\
90 & 00 \\
90 & 00 \\
90 & 00 \\
62 & 02 \\
59 & 52 \\
59 & 22 \\
59 & 22 \\
64 & 13 \\
29 & 32 \\
68 & 59 \\
50 & 59 \\
51 & 29 \\
61 & 10 \\
47 & 33 \\
46 & 42 \\
80 & 22 \\
63 & 53 \\
80 & 57 \\
79 & 49 \\
39 & 52 \\
63 & 00 \\
82 & 51 \\
82 & 39\end{array}$ & $\begin{array}{rr}\circ & 1 \\
46 & 17 \\
66 & 58 \\
66 & 58 \\
0 & 00 \\
0 & 00 \\
27 & 36 \\
27 & 36 \\
38 & 06 \\
46 & 17 \\
46 & 17 \\
49 & 38 \\
49 & 38 \\
49 & 38 \\
62 & 59 \\
62 & 59 \\
62 & 59 \\
66 & 58 \\
72 & 19 \\
72 & 19 \\
78 & 00 \\
78 & 00 \\
80 & 57 \\
80 & 57\end{array}$ & $\begin{array}{ll}\circ & \text { ' } \\
90 & 00 \\
90 & 00 \\
90 & 00 \\
60 & 54 \\
60 & 54 \\
58 & 21 \\
58 & 21 \\
63 & 46 \\
30 & 01 \\
68 & 58 \\
50 & 57 \\
50 & 57 \\
61 & 36 \\
46 & 32 \\
46 & 32 \\
79 & 16 \\
63 & 54 \\
80 & 24 \\
80 & 24 \\
39 & 27 \\
62 & 29 \\
82 & 31 \\
82 & 31\end{array}$ \\
\hline
\end{tabular}

$a$ The face lies in the zone with $\{263\}$ and $\{010\}$

$b$ This form lies in the zone of and between $\{211\}$ and $\{331\}$.

$c$ Two line faces between $\{301\}$ and $\{110\}$, and $\{301\}$ and $\{110\}$.

SUMMARY OF FORMS.

The forms for montroydite may conveniently be repeated here at the close of the foregoing descriptions:

(a) Common forms.

$\begin{array}{rrr}a(100) & n(302) & i(221) \\ b(010) & q(301) & x(331) \\ m(110) . & u(301) & r(211) \\ v(012) & \alpha(133) & \rho(7.3 .13) \\ y(023) & e(132) & w(311) \\ z(011) & t(122) & \omega(10.1 .12) \\ g(102) & s(112) & \\ d(101) & o(111) & \end{array}$


(b) Less common forms.

$l(1.10 .0)$
$h(120)$
$k(350)$
$\xi(310)$
$j(410)$
$\Phi(510)$

$C(230)$

$f(320)$

$G(032)$

$\zeta(265)$

$O(243)$

$Q(239)$

$K(045)$
$L(021)$
$\beta(061)$
$E(103)$
$M(203)$
$N(263)$

(c) Rare forms.

$$
\begin{array}{r}
S(232) \\
R(346) \\
M(344) \\
V(5.4 .10) \\
r(542) \\
\pi(323)
\end{array}
$$

$Z(376)$

$A(114)$

$B(113)$

$D(223)$

$\delta(551)$

$P(326)$

\begin{tabular}{|c|c|c|c|c|c|c|c|c|c|c|c|}
\hline \multirow{3}{*}{ Form. } & \multicolumn{10}{|c|}{ Prism zone (No. 1)a; symbol, $\frac{h}{k}$. } & \multirow{3}{*}{$\begin{array}{c}a \\
100\end{array}$} \\
\hline & $\{b$ & $l$ & $h$ & $k$ & $C$ & $m$ & $f$ & $\xi$ & $j$ & $\emptyset$ & \\
\hline & $\{010$ & 1. 10.0 & 120 & 350 & 230 & 110 & 320 & 310 & 410 & 510 & \\
\hline & 0 & $1 / 10$ & $1 / 2$ & $3 / 5$ & $2 / 3$ & 1 & $3 / 2$ & 3 & 4 & 5 & $\infty$ \\
\hline & 0 & $(1 / 10)$ & . $1 / 2$ & $(3 / 5)$ & $2 / 3$ & 1 & $3 / 2$ & . 3 & (4) & (5) & $\infty$ \\
\hline
\end{tabular}

$W(411)$

DISCUSSION OF FORMS.

The two forms $\{130\}$ and $\{210\}$ are lacking to make the series $N_{3}$ complete. Four forms are extra. One of them, 3/5 or $\{350\}$, is interesting, as it was noticed on only one crystal (No. 4), on which, however, all four faces of the form occur. The crystal is broken at both ends, and $a, b, k$, and $m$ are the only forms present. The three other extra forms, $\{1.10 .0\},\{410\}$, and $\{510\}$ are well established, all occurring on more than one crystal. As these four forms do not belong to the normal series $N_{3}$, special attention is called to them by the discussion, but a due consideration of all facts shows that there is no reason for excluding or considering any of them as doubtful. The conclusion then follows that this prism zone is somewhat disturbed, and it is to be specially noticed that most of the forms causing this disturbance are nearest to the forms with the simplest indices in the entire zone. Thus $\{1.10 .0\}$ is nearest $\{010\} ;\{410\}$ and $\{510\}$ are nearest $\{100\}$. The form $\{350\}$ is not closest to the next simplest form, which would be $\{110\}$, but it is next to $\{120\}$, which is also a simple form. This zone therefore supports the statement; which is verified by the further discussions, that the forms which do not fit in the normal series--that is, those which cause a disturbance in an otherwise normal zone-are usually nearest to the forms with simplest indices. 


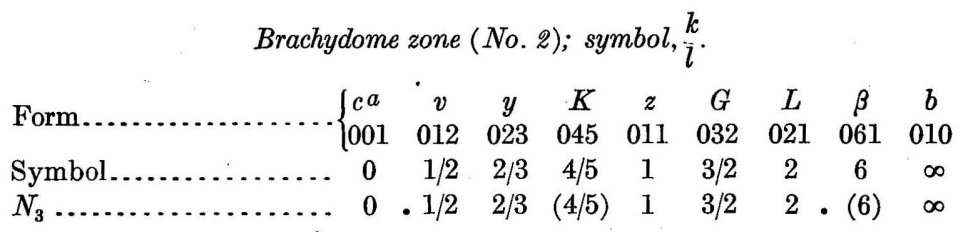

Here again we have two extra forms, $\{045\}$ and $\{061\}$, both of which are well established. These extra forms also are nearest the normal forms with simplest indices; thus $\{045\}$ is nearest $\{011\}$ and $\{061\}$ is nearest $\{010\}$.

$$
\text { Macrodome zone (No. 3); symbol, } \frac{h}{l} \text {. }
$$

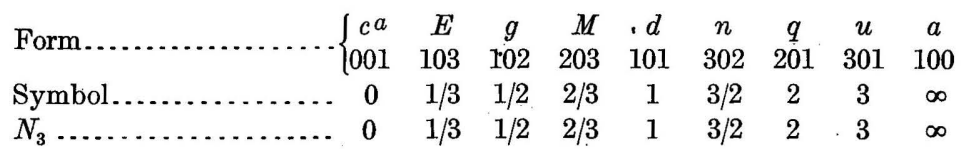

This zone is entirely normal, there being neither missing, ${ }^{a}$ extra, nor disagreeing forms. It may be remarked that most of the nonaccordances for montroydite crystals are instances of either missing or extra forms; very few are disagreements with the members of the normal series.

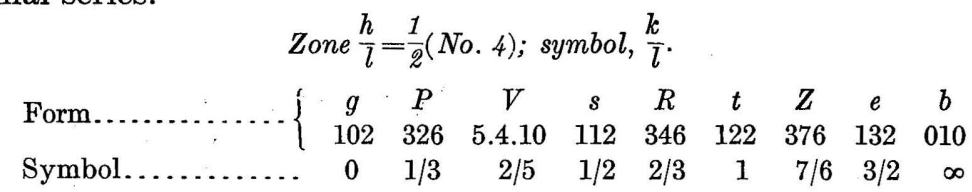

Dividing the series at 1 , and letting $v$ in any row represent the member in the preceding line, we have:

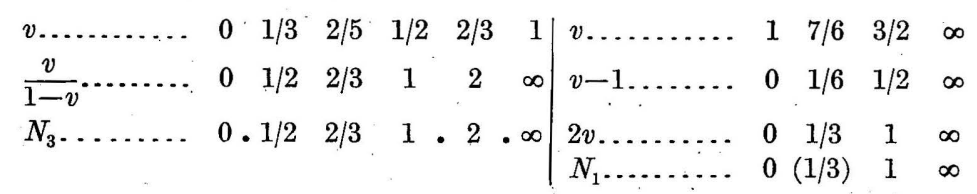

In the first division, the zone is normal. In the second, only $1 / 3$ or $\{376\}$ is extra.

$$
\text { Zone } \frac{h}{l}=\frac{2}{3}(\text { No. } 5) ; \text { symbol, } \frac{k}{l} \text {. }
$$

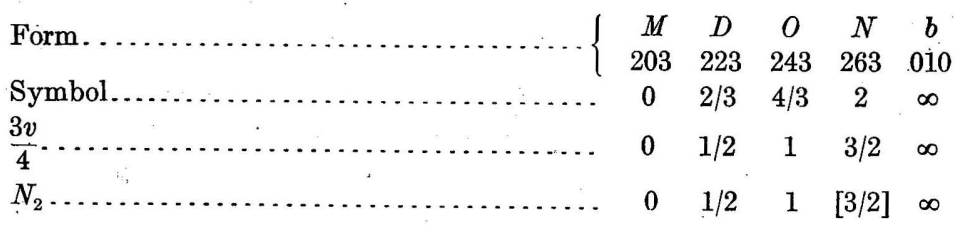

We would expect 2 in place of $3 / 2$, which would give the form $\{483\}$, but $\{263\}$ are the correct symbols.

$a$ The form $c\{001\}$ is not present on these crystals, but is here introduced in order to simplify the discussion. 


$$
\text { Zone } \frac{h}{l}=1(\text { No. } 6) ; \text { symbol, } \frac{k}{l} \text {. }
$$

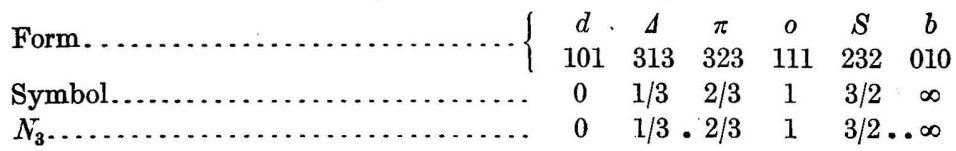

The zone is normal, though incomplete.

$$
\text { Zone } \frac{h}{l}=3(\text { No. } 7) \text {; symbol, } \frac{k}{h} \text {. }
$$

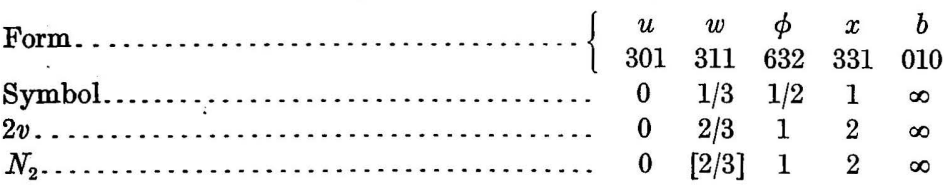

The form $2 / 3$ or $\{311\}$ is a common one for montroydite.

\begin{tabular}{|c|c|c|c|c|c|c|c|c|c|}
\hline & $z$ & $\alpha$ & $t$ & $U$ & $o$ & $r$ & $w$ & $W$ & $a$ \\
\hline & 011 & 133 & 122 & 344 & 111 & 211 & 311 & 411 & 100 \\
\hline Symbol.. & 0 & $1 / 3$ & $1 / 2$ & $3 / 4$ & 1 & 2 & 3 & 4 & $\infty$ \\
\hline (n... & 0 & $1 / 3$ & $1 / 2$ & {$[3 / 4]$} & 1 & 2 & 3 & (4) & \\
\hline
\end{tabular}

$$
\text { Zone } \frac{k}{l}=1 \text { (No. 8); symbol, } \frac{h}{l} \text {. }
$$

In place of $3 / 4$, we would expect $2 / 3$ or $\{233\}$. Measurements show that $\{344\}$ are the correct indices. $W\{411\}$ is extra. Both forms, however, are well established.

Note again that $3 / 4$ or $\{344\}$ is nearest 1 or $\{111\}$ and 4 or $\{411\}$ is nearest to $\infty$ or $\{100\}$.

$$
\text { Zone } \frac{k}{l}=2(\text { No. } 9) ; \text { symbol, } \frac{h}{l} \text {. }
$$

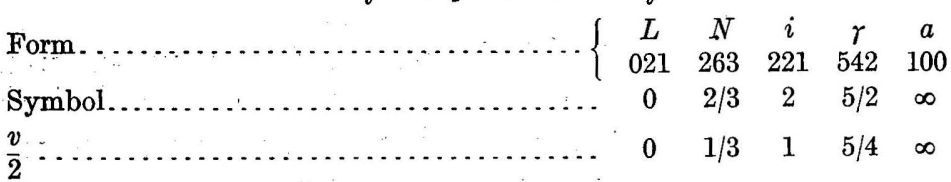

This zone is abnormal. Of these forms, $\gamma\{542\}$ should be confirmed.

$$
\begin{aligned}
& \text { Pyramid zone } \frac{h}{k}=1 \text { (No. 10); symbol, } \frac{h}{l} \text {. } \\
& \text { Form.......... }\left\{\begin{array}{cccccccccc}
c & A & B & s & D & o & i & x & \delta & m \\
001 & 114 & 113 & 112 & 223 & 111 & 221 & 331 & 551 & 110
\end{array}\right. \\
& \begin{array}{lllllllllll}
\text { Symbol........... } & 0 & 1 / 4 & 1 / 3 & 1 / 2 & 2 / 3 & 1 & 2 & 3 & 5 & \infty
\end{array} \\
& \begin{array}{llllllllllll}
N_{3} \ldots \ldots \ldots \ldots \ldots & 0 & (1 / 4) & 1 / 3 & 1 / 2 & 2 / 3 & 1 & 2 & 3 & (5) & \infty
\end{array}
\end{aligned}
$$

The two forms $\{114\}$ and $\{551\}$ are extra, but both are well established. Again note that both are nearest the simplest forms.

$$
\text { Zone (201):(021) (No. 11); symbol, } \frac{h}{l} \text {. }
$$

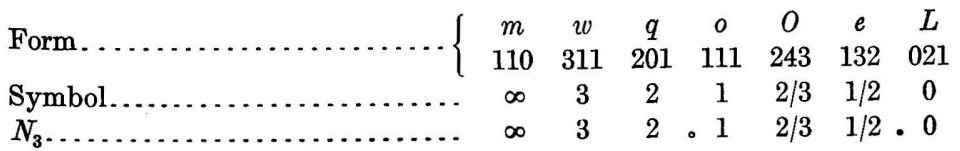

The zone is normal. 
Zone (102):(011) (No. 12); symbol, $\frac{h}{l}$.

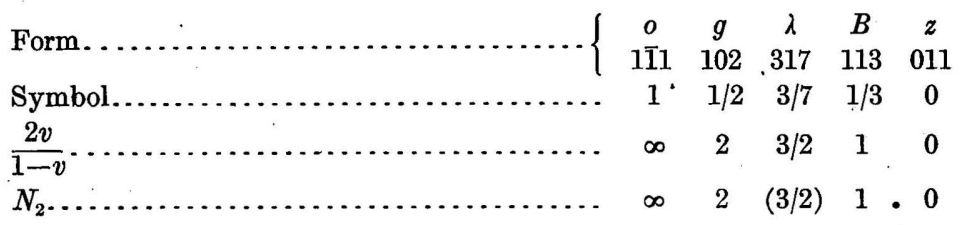

Zone (001):(130) (No. 13); symbol, $\frac{h}{l}$.

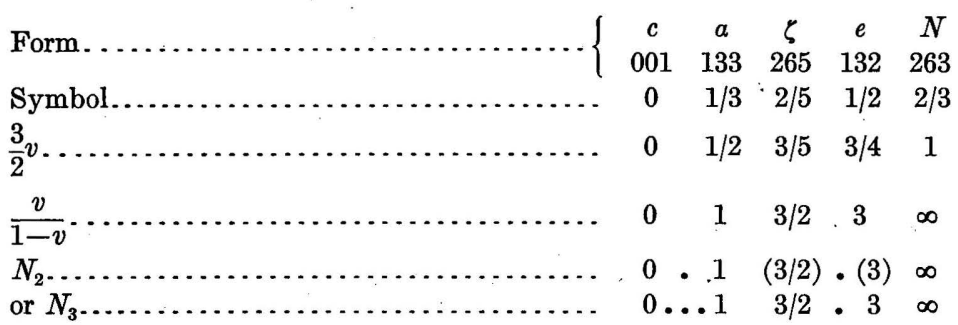

Zone (012):(101) (No. 14); symbol, $\frac{h}{l}$.

\begin{tabular}{|c|c|c|c|c|c|c|c|}
\hline Form.... & $v$ & $B$ & $\rho$ & $\omega$ & $d$ & $w$ & $\overline{-}$ \\
\hline & 012 & 113 & 7.3.13 & 10.1.12 & 101 & $3 \overline{11} 1$ & $(2 \overline{1} 0)$ \\
\hline Syn & 0 & $1 / 3$ & $7 / 13$ & $5 / 6$ & 1 & 3 & $\infty$ \\
\hline$N_{3}$. & 0 & $1 / 3$ & {$[7 / 13]$} & $(5 / 6)$ & 1. & . 3 & $\infty$ \\
\hline
\end{tabular}

The form $\{7.3 .13\}$ takes the place of the simpler form $\{214\}$, which was not observed on these crystals. The form $\{10.1 .12\}$ is extra, being very close to $\{101\}$. Both forms partake of a vicinal character, though they are included in the list of established forms on account of their relatively large size, good reflections, and frequent occurrence.

The following forms are extra to the normal series, and attention is again called to the fact that most of these extra forms, or forms which cause a disturbance in the otherwise normal series, are very close to the forms with simplest indices:

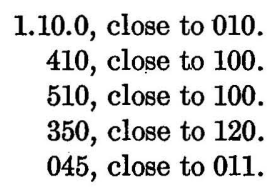

061 , close to 010 .
411 , close to 100.
114 , close to 001 .
551 , close to 110 .
344 , close to 111.

The following pyramids, which do not fit in well with the normal series, are not so close to simple forms:

376 , near 122 .

263 , near 121. 
Combinations of forms on montroydite crystals.

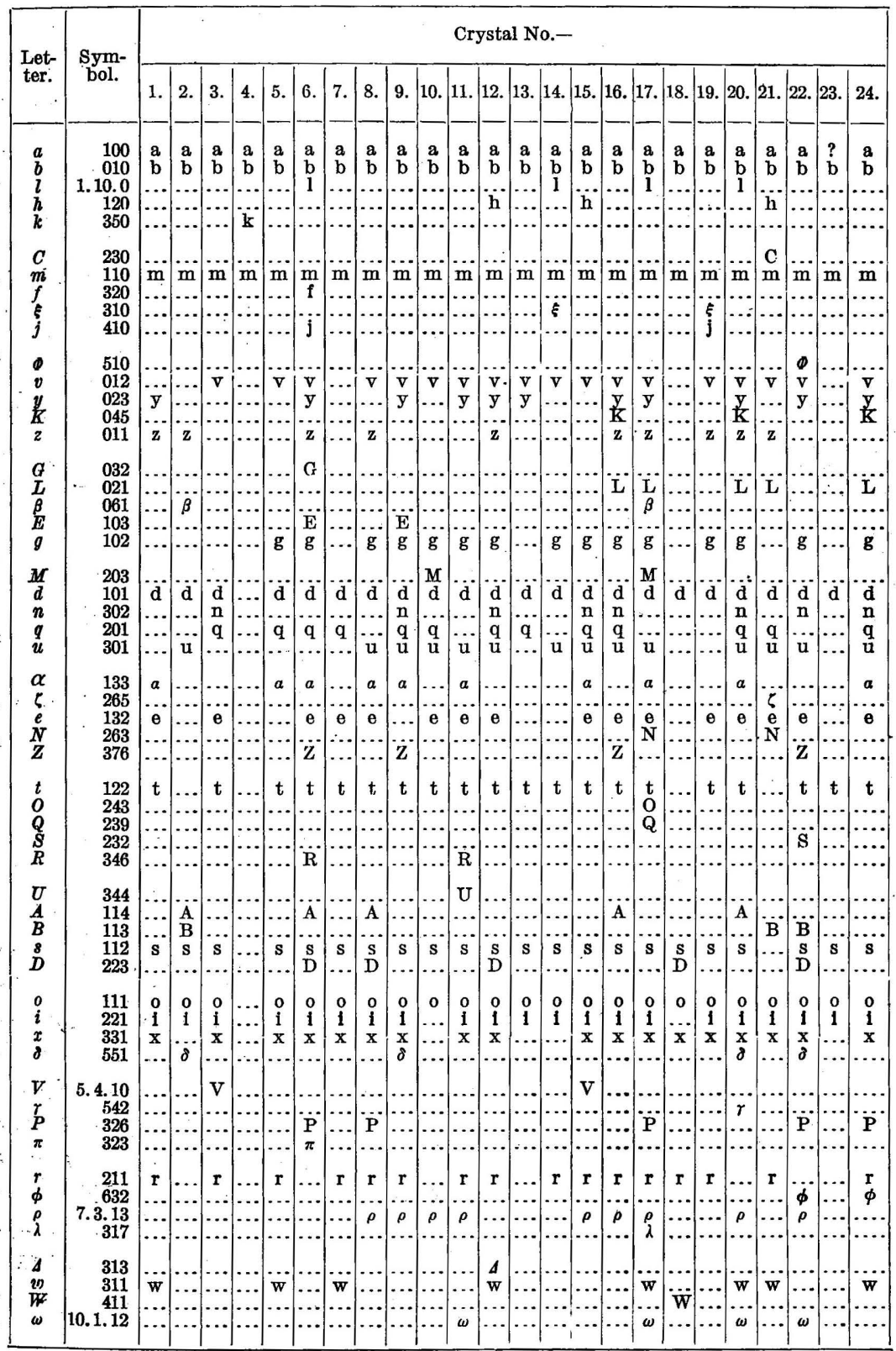


zONAL RELATIONS, STRIATIONS, AND GNOMONIC PROJECTION OF FORMS.

As can be seen by the discussion of the forms just given, montroydite crystals are very symmetrical, all of the forms found lying in well-developed zones, many of which show but a very slight disturbance. Intimately connected with these zone directions are the striations, which are well developed on some crystals. In all, six directions or zones of striations were noticed on these crystals. They are given below, in approximately the order of the great-

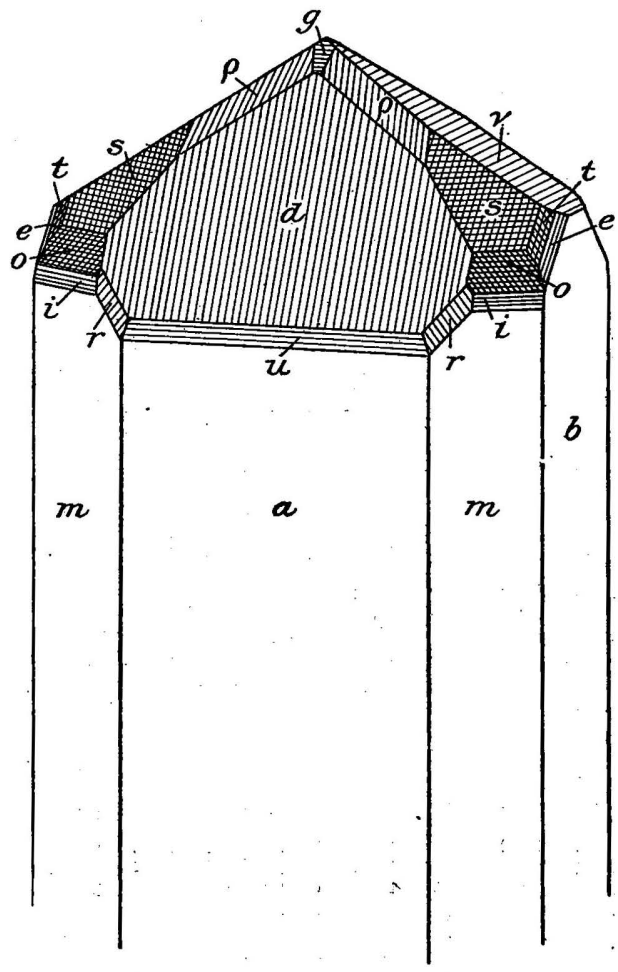

FiguRe 8.-Montroydite crystal showing striations. est development of the striæ.

(1) Zone (001) : (010). The clinodomes are all striated, but particularly the lower part of the prominent dome $v\{012\}$, which is usually present on these crystals as a large face. Between the lower end of $v$ and $b\{010\}$, a rounded striated surface often takes the place of distinct faces, though it has been possible to establish the presence of six domes between $v$ and $b$, namely: $y\{023\}, \quad K\{045\}$, $z\{011\}, G\{032\}, L\{021\}$, and $\beta\{061\}$.

(2) Zone (102):(112): (010). This zone of pyramids almost always contains striated faces. The form $\rho\{7.3 .13\}$ is almost in this zone, but, as can be seen on the crystals by means of the striæ, it is a little out. Two narrow faces of the zone $(102):$ (010) lie between (102) and (112), namely, $P(326)$ and $V(5.4 .10)$, while between (112) and (010) are the two prominent forms $t\{122\}$ and $e\{132\}$, with the less common $R\{346\}$ and $Z\{376\}$. It is in this zone that the form approximating to $\{356\}$ and shown in figure 17 lies.

(3) Zone (001) : (110), . The zone of unit pyramids is usually striated, there being thus two directions of striæ on $s\{112\}$, both of which are often well developed. A number of forms occur in this zone as line faces, $A\{114\}, B\{113\}, D\{223\}, \delta\{551\}$ and often $x\{331\}$, and less commonly $i\{221\}$, the faces of this last form usually being broader than line faces. The horizontal striæ only extend to the prisms, these last not showing any striation at all. 


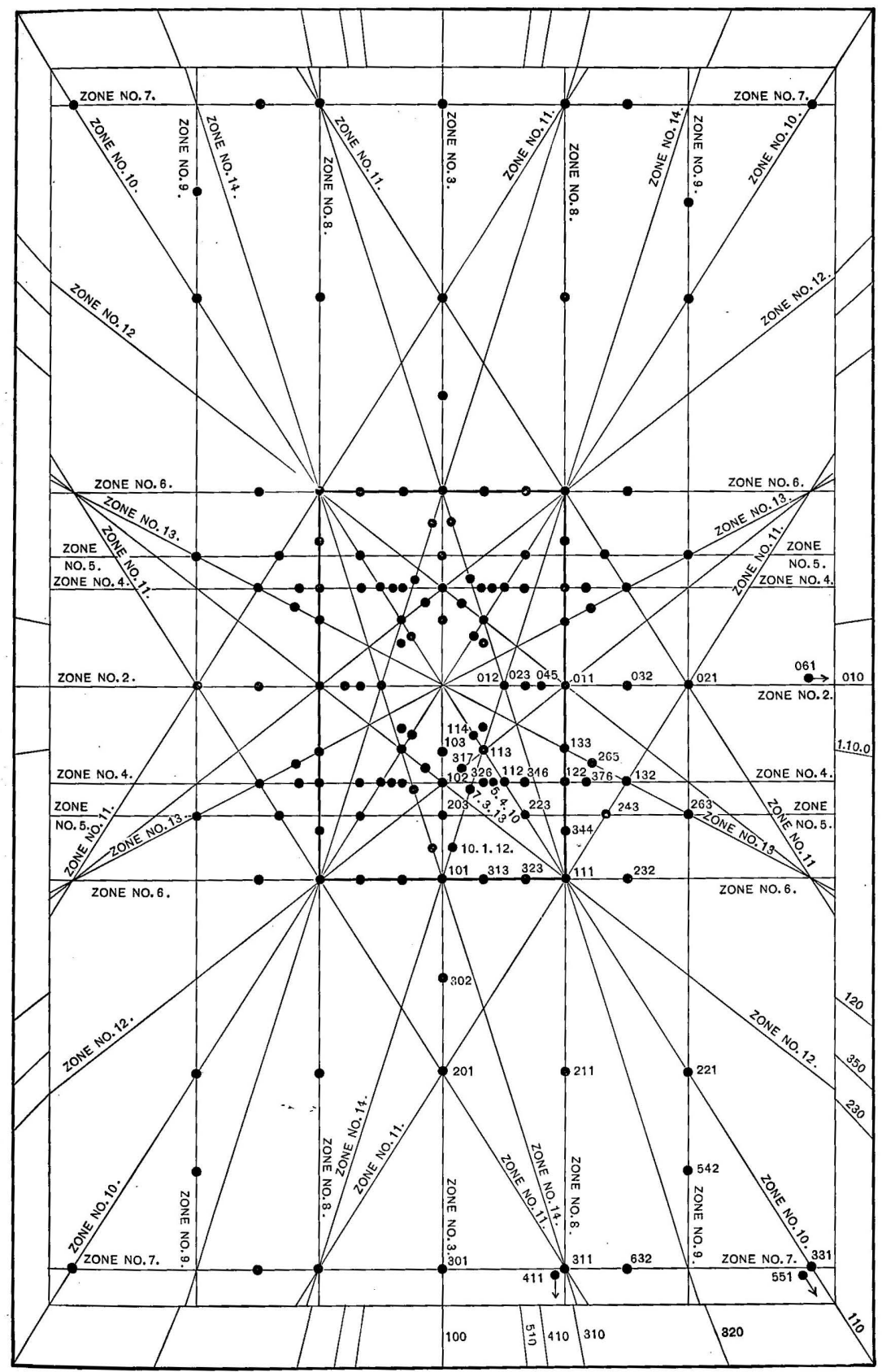

GNOMONIC PROJECTION OF MONTROYDITE FORMS. 

(4) Zone (211): (111) : (011). In this zone the striæ are not very prominently developed, usually showing best on $\{211\}$ and $\{122\}$. The faces of $\{122\}$ are often strongly striated in two directions, resulting in a rhombic grating effect. $\{111\}$ also, at times, shows the two directions of striations on the same face. The other forms in this striated zone are $\{411\},\{311\},\{344\},\{133\}$ with $\{100\}$ and $\{011\}$, these last, however, not showing the striations.

(5) Zone (001): (100). The orthodome zone is striated, but the only large form in it $\{101\}$ is not striated parallel to the dome intersections but normal thereto, namely in the zone (101): (010). There is therefore a break in the orthodome striæ, the faces between (101) and (001) and between (101) and (100) being striated parallel to the intersections. The faces between (101) and (001), namely, $E(103), g(102)$, $M(203)$ are much more striated (especially $g$ ) than the remaining domes below (101), namely, $n(302)$, $q(201)$, and $u(301)$.

(6) Zone (101):(010). This is the last zone in which distinct striations were seen, and these were highly developed only in the one form $\{101\}$, the faces of which are very commonly strongly striated. Other forms in this zone are the line faces $\Delta\{313\}$, $\pi\{323\}, S\{232\}$ and the unit pyramid $o\{111\}$.

The six directions of striations here described are shown on the crystal illustrated in figure 8 , which shows the forms $a\{100\}, b\{010\}, m\{110\}, v\{012\}$, $q\{102\}, d\{101\}, u\{301\}, \rho\{7.3 .13\}, s\{112\}, o\{111\}$, $i\{221\}, t\{122\}, e\{132\}, r\{211\}$.

The form system of montroydite is shown in gnomonic projection in Plate IV, which well shows the distribution of the faces in zones, and also shows the symmetrical development of the mineral. The absence of the base is a rather unusual feature.

\section{HABIT.}

In habit montroydite varies between two extremes, long prismatic (fig. 9), the crystals not infrequently nearly 20 millimeters long and not more than 1 millimeter thick, to nearly equidiametral (fig. 20), averaging from 1 to 2 millimeters thick. All gradations can be found between these two extremes. As the crystals become longer in the direction of the vertical axis they decrease in thickness, so that the long prismatic ones are thinner than the short equidiametral ones.

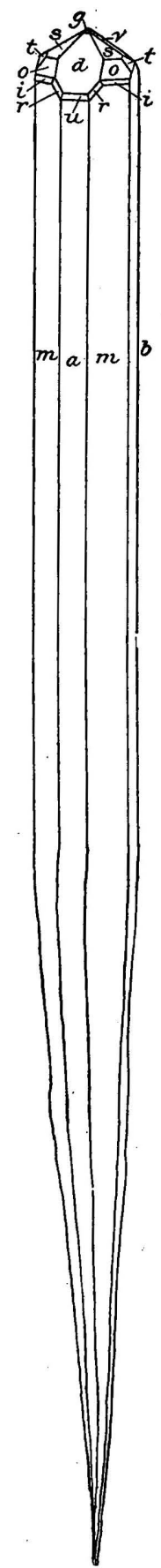

Tigure 9.-Montroydite crystal: $b\{010\}$, $a\{100\}, m\{110\}, v\{012\}$, $g\{102\}, d\{101\}, u\{301\}$ $s\{112\}, o\{111\}, i\{221\}$, $t\{122\}, r\{211\}$. 
Some of the long prismatic crystals bulge out at a certain point so that they are several times the usual thickness, decreasing to the normal thickness again a little farther along. Many of these long crystals are terminated at one end only, the other tapering down almost to a point (fig. 9). They are generally attached by the terminated end, the pointed end sticking out from the matrix. They are also often attached on the side, or a number of crystals are grouped irregularly together, many having both ends developed. Most, if not all, of the short equidiametral crystals are, however, doubly terminated, and these as well as the short prismatic ones (many of which are also doubly terminated) show that the mineral is holohedral in its crystal-

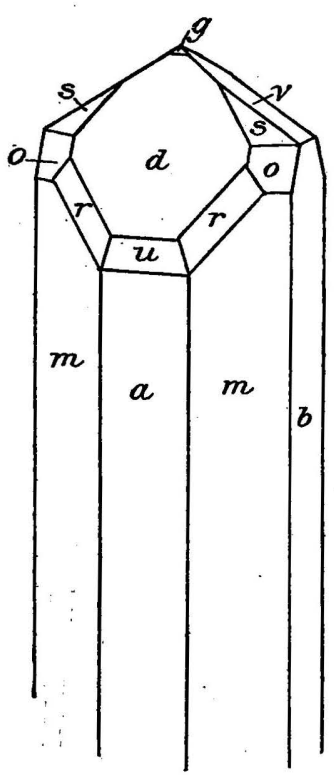

FIGURE 10.-Montroyditecrystal 14: $b\{010\}$ $a\{100\}, m\{110\}, v\{012\}, g\{102\}, d\{101\}$ $u\{301\}, s\{112\}, o\{111\}, r\{211\}$.

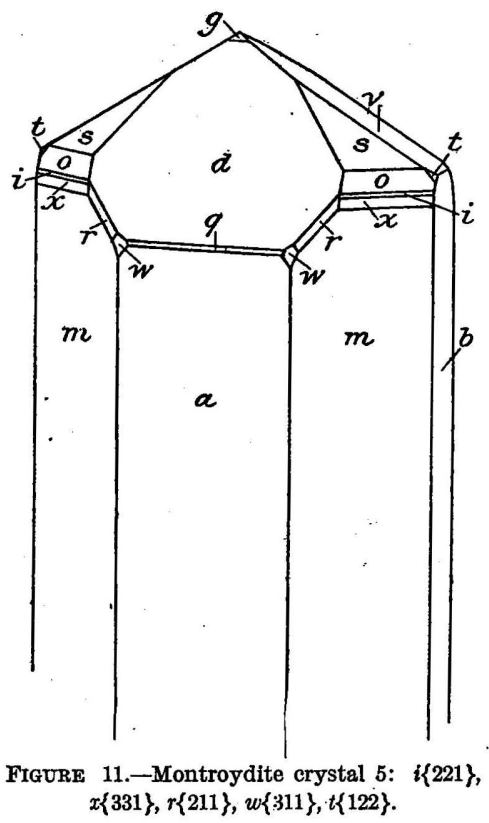

lographical development. Parallel intergrowths of a number of the equidiametral crystals are not uncommon and scepter intergrowths (one equidiametral crystal fastened in a parallel position to a long prismatic one) are also found (fig. 21).

A number of curiously distorted crystals also occur, their distortion being the result of unequal development of the different faces of the same forms. They have mostly a tabular habit, being flattened parallel to one face (fig. 22).

The crystals may then conveniently be grouped into three habits, as follows:

(a) Long prismatic, about 1 by 20 millimeters.

(b) Small equidimensional, about 2 by 2 millimeters.

(c) Flattened distorted crystals, rather thin and several millimeters ácross. 
In the following description of the crystals they will be described in the order of their habit, commencing with the long prismatic

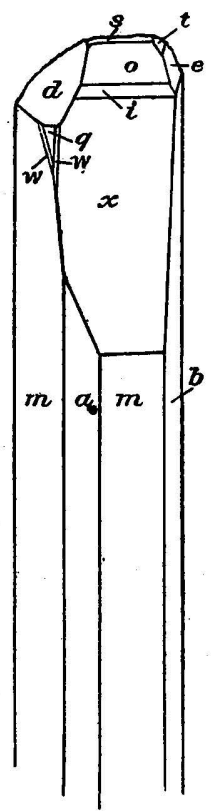

FTGURE 12.-Montroydite crystal 7: $q\{201\}, x\{331\}, w\{311\}$.

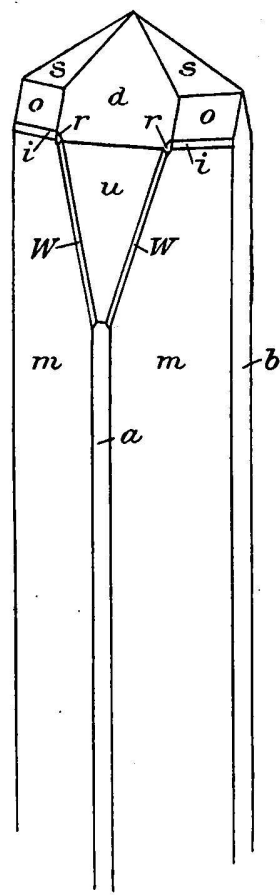

FIGURE 13.-Montroydite crystal 18: $u\{301\}, W\{411\}$.

crystals and gradually approaching the smaller equidimensional ones. Several characteristics of the crystal development go hand in hand with this change in habit, as some forms have large faces on the

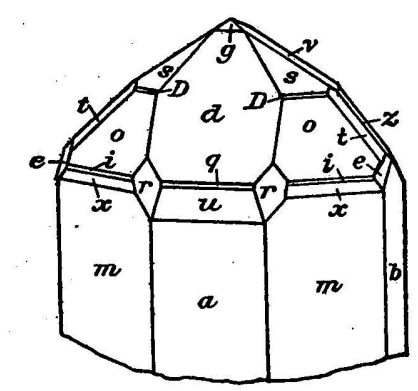

FTGURE 14.-Montroydite crystal 12: $q\{201\}$, $z\{011\}, D\{223\}, t\{122\}, e\{132\}, r\{211\}$.

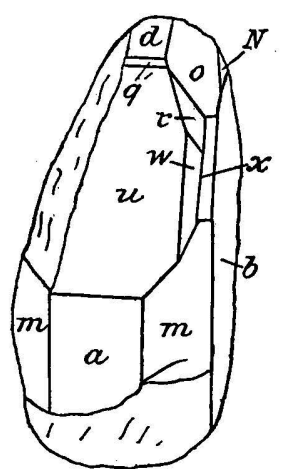

FIGURE 15.-Montroydite crystal 21: $q\{201\}, x\{331\}, w\{311\}, N\{263\}$.

one habit and are poorly represented or else entirely absent on the other. In passing from the first to the second habit, the orthopinacoid 


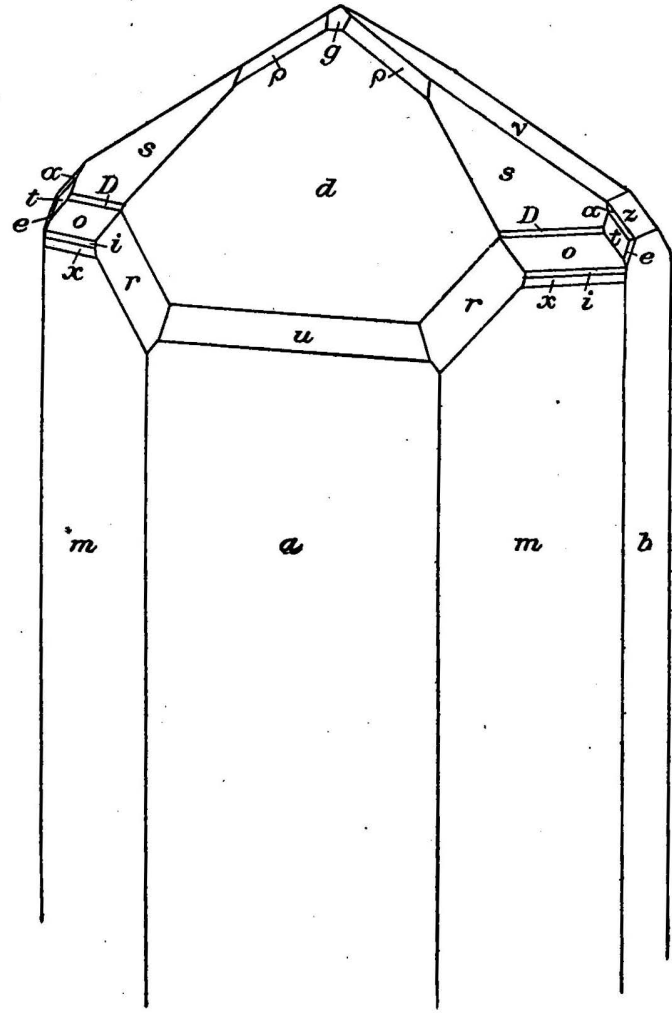

FIGURE 16.-Montroydite crystal 8: $z\{011\}, D\{223\}, a\{133\}$, $t\{122\}, e\{132\}, \rho\{7.3 .13\}$. gradually changes from a vertical line face to a large face of the same diameter in the two directions, and finally to a horizontal line face.

DESCRIPTION OF CRYSTALS.

The long prismatic habit is shown by the majority of all the crystals we have seen, and is shown in figure 9, which does not represent any particular crystal measured, but gives their general appearance.

Except as otherwise stated, the illustrations of montroydite crystals are drawn in ideal development, as the crystals are usually fairly symmetrical, and such drawings show the symmetry better than a true draw-

ing, where the deviation from ideal symmetry is but slight.

Crystal 14 (fig. 10) shows a development of faces not uncommon on these long crystals. All three forms in the prism zone $a b m$, are well developed, being nearly equal in size, and they necessarily determine the habit. The dome $d\{101\}$ is the dominant terminal form, while $v\{012\}, s\{112\}$, $o\{111\}, \quad r\{211\}, \quad$ and $u\{301\}$ are present as small faces. The minute dome $g\{102\}$ and the large faces of $r\{211\}$ are characteristic of these long prismatic crystals.

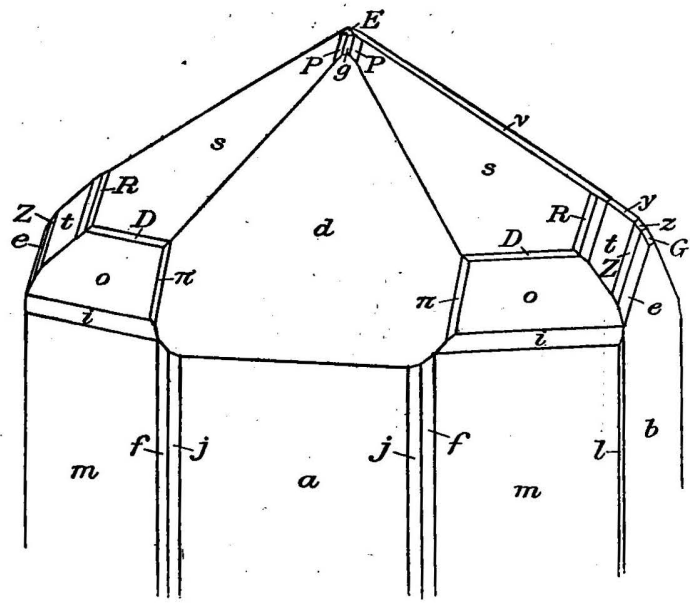

FIGURE 17.-Montroydite crystal $6: l\{1.10 .0\}, f\{320\}, j\{410\}$, $E\{103\}, P\{326\}, R\{346\},-\{356\}, Z\{376\}, \pi\{323\}, y\{023\}, z\{011\}$, $G\{032\}, D\{223\}$. 
Crystal 5 (fig. 11) shows a somewhat richer combination, though of the same general type as the preceding. The four pyramids, $s\{112\}, o\{111\}, i\{221\}$, and $x\{331\}$, commonly occur together, being usually of the relative sizes shown in figure 11. Small faces of $t\{122\}$ are present, and $e\{132\}$, though not shown in this figure, often occurs with $t\{122\}$, these two being the only forms present in this zone between $s\{112\}$ and $b\{010\}$, though on the equidimensional crystals this zone is much richer in forms.

Crystal 7 (fig. 12) shows an actual drawing of the combination as seen on the crystal. The termination is incomplete, but the very large development of $x\{331\}$ gives it an unusual appearance. Moses noted the large size of the $x$ faces on the crystal he measured, though this is a rather unusual feature for montroydite. The form $e\{132\}$ is here shown for the first time.

On crystal 18 (fig. 13) the $a$ faces are much narrower than either $b$ or $m$, and approach the character of line faces. The form $u\{301\}$ equals that of $d\{101\}$ in its development, and this crystal shows the two faces of $W\{411\}$, as line faces between $u$ and $m$. This form was not noticed on any other crystal.

Crystal 12 (fig. 14) shows a richer combination, with line faces of $D\{223\}$. Two faces were present, and though the measurements agree more closely with

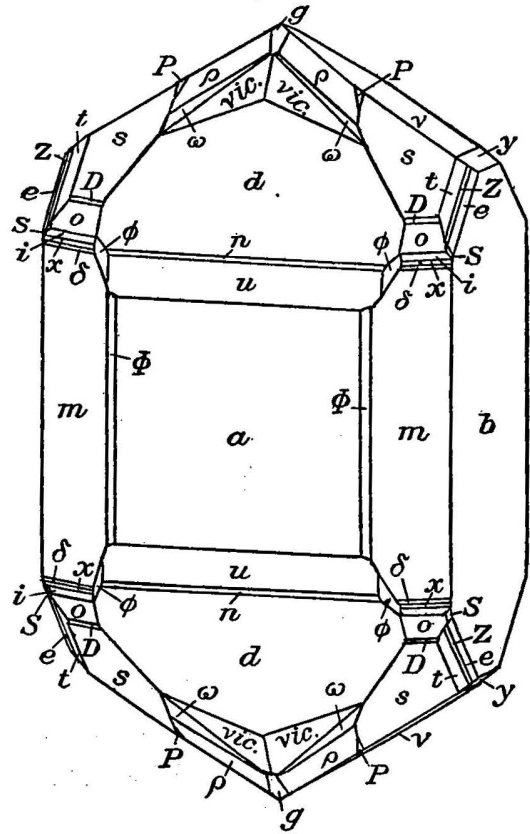

FIGURE 18.-Montroyditecrystal 22: $\Phi\{510\}, y\{023\}$, $n\{302\}, D\{223\}, \delta\{551\}, \phi\{632\}, S\{232\}, Z\{376\}$, $\rho\{7.3 .13\}, \omega\{10.1 .12\}$, vic. $\{44.1 .48\}, P\{326\}$. $\{335\}$, a form not elsewhere observed, they are referred to $\{223\}$.

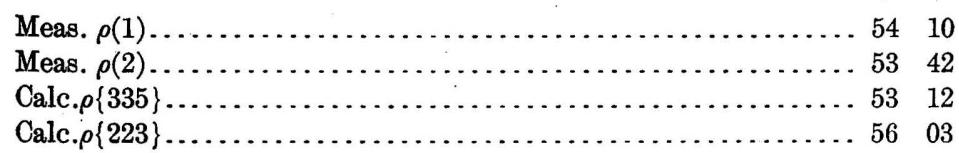

A long narrow face of $z\{011\}$ is present, and $t\{122\}$, between it and $o\{111\}$, is also long and narrow.

Crystal 21 (fig. 15) is incomplete, and, like crystal 18 (fig. 13), shows a large development of $u\{301\}$. Many other forms, not shown in figure 15, are present as minute faces. The figure shows a small face of $N\{263\}$, a form also present on crystal 17. On crystal 21 the form is accompanied by a vicinal form, measurement of which gave values very close to those for $\{263\}$. 
Measurements of $N\{263\}$ and vicinal form, montroydite.

\begin{tabular}{|c|c|c|}
\hline . & $\phi$ & $\rho$ \\
\hline & ० & $\circ$ \\
\hline Calc. $\{263\} \ldots \ldots \ldots \ldots$ & $27 \quad 36$ & 69 \\
\hline Meas................... & $\begin{array}{ll}27 & 47 \\
27 & \end{array}$ & $\begin{array}{l}69 \\
68\end{array} .57$ \\
\hline
\end{tabular}

The form $r\{542\}$, present once on this crystal, forms a line face between $\{211\}$ and $\{331\}$. A narrow line face, in zone $\{112\},\{010\}$,

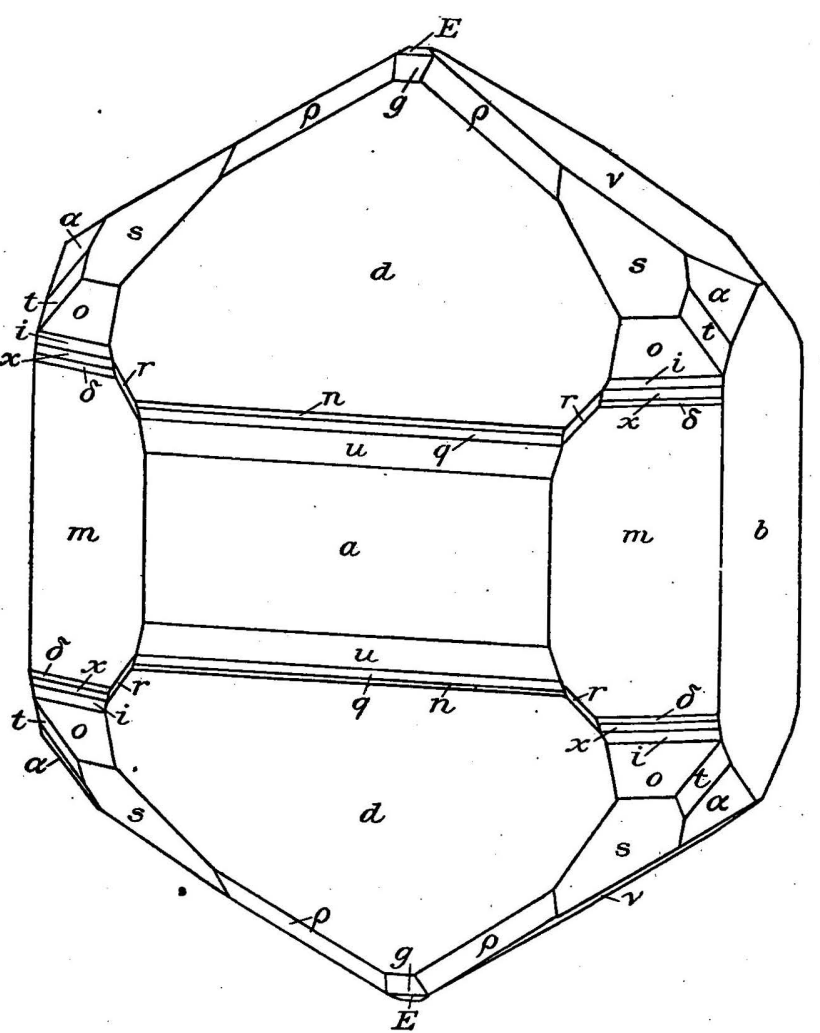

FIqURE 19.-Montroydite crystal 9: $E\{103\}, n\{302\}, q\{201\}, \delta\{551\}, \rho\{7.3 .13\}, \alpha\{133\}$.

approximating to $\{356\}$, is present, but the measurement varied too widely from the calculated value for its reference to that form. A similar narrow face, near $\{356\}$, occurs on crystal 6 and is shown in figure 17 , though the measurement here was also at variance. 
Measurements of form near $\{356\}$, montroydite.

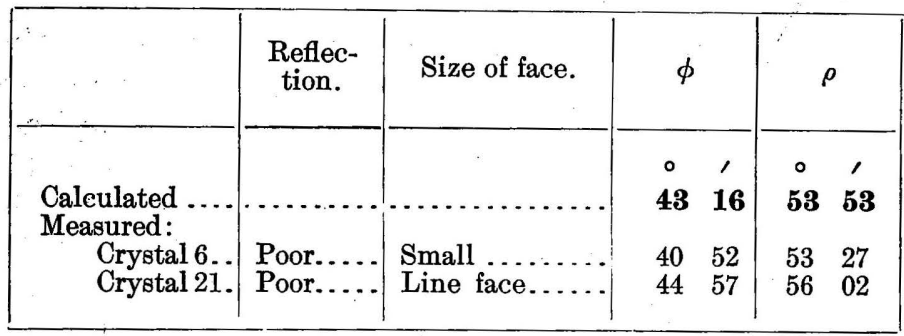

Crystal 8 (fig. 16) shows in addition to the forms already shown small faces of $\rho\{7.3 .13\}$, this form being usually absent on these long prismatic crystals, though very characteristic on the equidimensional ones. Small faces of $\alpha\{133\}$ and $D\{223\}$ are also shown. Two minute line faces of $A\{114\}$ are present, though not shown on the figure.

Crystal 6 (fig. 17) shows the chief forms of this small but very rich crystal. In habít it occupies an intermediate position, being short prismatic and already showing the characteristics of the equidimensional crystals." The number of brachydomes present is unusual, including, besides $v\{012\}$, the forms $y\{023\}$,

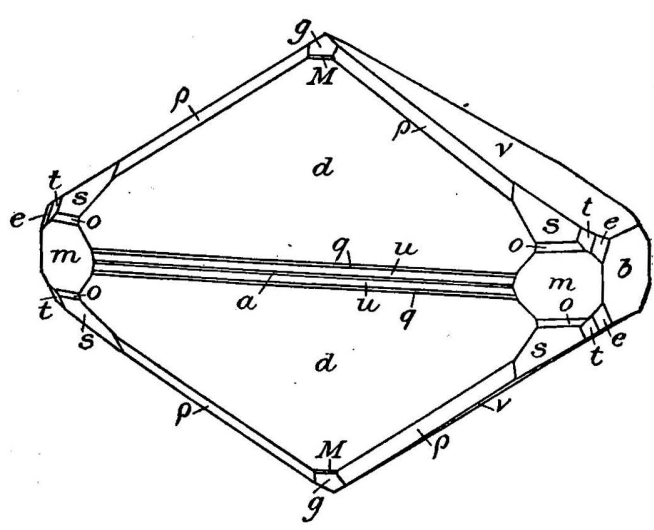

FIGURE 20.-Montroydite crystal 10: $M\{203\}, q\{201\}, \alpha\{7.3 .13\}$. $z\{011\}$, and $G\{032\}$. The prism zone is also rich in forms, $a, b, m$, $l\{1.10 .0\}, f\{320\}$, and $j\{410\}$ being shown in figure 17 , while in addition faces of $h\{120\}, \Phi\{510\}$, and $C\{230\}$ are present. Besides $d\{101\}$ and $g\{102\}$, there are two small line faces of $E\{103\}$. The zone $s\{112\}, b\{010\}$, is rich in faces, $P\{326\}, R\{346\},-\{356\}, t\{122\}$, $Z\{376\}$, and $e\{132\}$ being present, besides $g, s$, and $b$. The form $\pi\{323\}$, between $d\{101\}$ and $o\{111\}$, is present but once, and only on this crystal.

Crystal 22 (fig. 18) is short prismatic, nearly equidimensional, with a rich combination of forms. The form $\rho\{7.3 .13\}$ is well developed, the zone $s\{112\}, b\{010\}$, is rich in forms, $r\{211\}$ is absent, and in addition the form $\omega\{10.1 .12\}$ and the vicinal form $\{44.1 .48\}$ are well developed. Two faces of $\Phi\{510\}$ are present, besides $a, b, m$ in the prism zone. The pyramid zone, $c m$, shows $s\{112\}, D\{223\}, o\{111\}$, $i\{221\}, x\{331\}, \delta\{551\}$, and $B\{113\}$, the latter not shown in the figure. Small faces of the rare pyramids $S\{232\}$ and $\phi\{632\}$ are also 4494-Bull. 405-09-6 


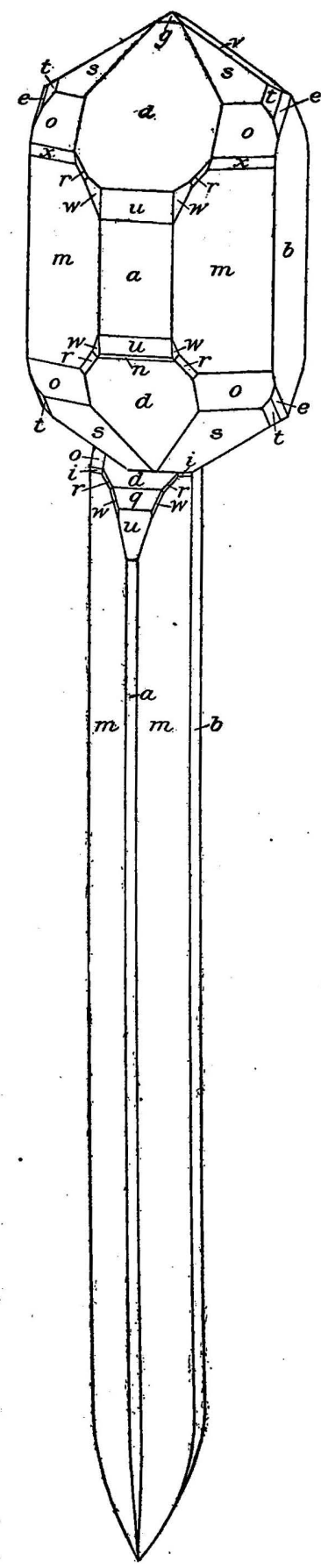

Figure 21.-Montroydite, scepter crystal (No. 24): $q\{201\}, n\{302\}$, $w\{311\}$. shown in the figure, $S$ occurring only on this crystal, while $\phi$ was observed on one other. The large faces of $\{44.1 .48\}$ are rather unusual, for while vicinal forms are not rare they elsewhere occur as very narrow or line faces.

Crystal 9 (fig. 19) shows the second habit well - the equidimensional one. Another feature of crystals of this habit is well brought out in figure 19, namely, the number of forms in the orthodome zone, there being shown $E\{103\}, g\{102\}, d\{101\}, n\{302\}, q\{201\}$, and $u\{301\}$, besides $a\{100\}$. Two small faces of $r\{211\}$ are present, this form being rather unusual for crystals of this habit, and the single face of $\alpha\{133\}$ is much larger than usual.

Crystal 10 (fig. 20) shows the extreme development of the equidimensional habit, the crystal being somewhat longer in the direction of the $b$ axis than in the vertical direction. In crystals of this type the $a$ face is often the merest line. The development of the orthodome zone, mentioned in the case of

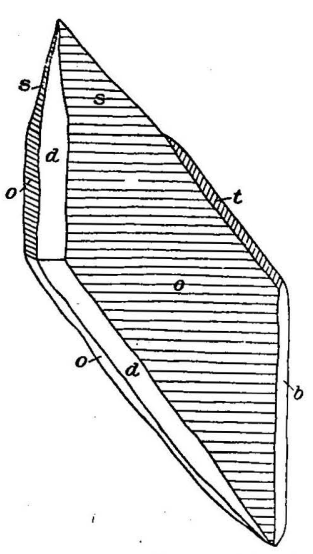

FIgURE 22.-Montroydite, distorted crystal (No. 23): $d\{101\}, s\{112\}, o\{111\},\{\{122\}$. the previous crystals, is here again well shown. The lower end of the clinodome zone is very much striated, making it impossible to determine any forms that may be present here. The long narrow faces of $\rho\{7.3 .13\}$, striated and grading into $s\{112\}$, are very characteristic.

Crystal 24 (fig. 21) shows a scepter crystal, one of the second habit being perched in strictly parallel position on a long one of the first habit. Several such instances were noted, as well as others where two or more nearly equidimensional crystals were joined together in parallel position. In this latter arrangement, one crystal was always slightly 
more prismatic than the other, no instance being observed where the two crystals superimposed in parallel position had exactly the same habit.

Crystal 23 (fig. 22) shows about the appearance of the peculiar distorted crystals of habit 3 . They are so rounded and striated that their correct orientation is very difficult to determine, but it is believed that figure 22 shows the proper position of this crystal.

\section{TERLINGUAITE.}

FORMS.

Terlinguaite occurs in three forms, as distinct crystals, as a crystalline crust, and as a yellow powder.

1. As distinct crystals terlinguaite occurs on many of the specimens, often resting on or growing out of a crystalline mass (2), though often also resting directly on calcite. The crystals are usually several millimeters long, the largest one measuring 16 by 4 by 4 millimeters, and some of the imperfect crystals showing faces over a centimeter broad. The individual crystals show a number of habits, which are described on pages 126-132, and illustrated in figures 23 to 31 . They may be grouped under the three general headings given below:

(a) Equidimensional, small and very rich in faces:

(b) Elongated in one direction (usually the $b$ axis), and then often striated.

(c) Tabular to some form (mostly $a\{100\}$ ).

2. As a crystalline crust terlinguaite is found usually intimately associated with montroydite and forming a greenish mass which often contains a considerable quantity of well-crystallized material.

3. The mineral is frequently found as a yellow powder which changes to a gray or greenish color after exposure to light. Of the powdery forms in which these minerals occur it is, perhaps, the most abundant, coloring not only the pink earthy gangue but also the layer of coarse calcite.

\section{PHYSICAL PROPERTIES.}

COHESION, ETC.

The cleavage of terlinguaite is perfect and is parallel to the rear unit orthodome $u\{\overline{101}\}$ in the orientation chosen by the writer, or to the dome $\{\overline{1} 03\}$ in the orientation of Moses. No indication of any other cleavage was seen, and not only is this perfect cleavage easy to obtain but almost all (if not all) of the faces of $\{\overline{1} 01\}$ present on the crystals measured are cleavage faces. It was not found possible to so orient the crystals as to make the cleavage 
parallel to either the base or the orthopinacoid and at the same time to preserve the simplicity of the indices of the 134 forms. For a discussion of this point see part of the section on crystallography (p. 132).

The mineral is brittle, breaking with an uneven fracture, and is neither elastic nor plastic. Though described by Moses as brittle or subsectile, no indication of sectility was observed, the crystals invariably cutting to a powder. Terlinguaite thus shows marked differences in these properties from montroydite.

The hardness was found to be between 2 and 3, as given by Moses.

DENSITY.

The density was not determined by us, as so much of the mineral contains included mercury. Two determinations by Moses gave 8.728 and $8.723 .{ }^{a}$

LUSTER, COLOR, ETC.

The luster is adamantine and sometimes very brilliant. Rarely there is a faint indication of a greasy luster.

Much confusion seems to exist as to the original color of terlinguatie before it has been exposed to light. Moses writes of it as "sulphuryellow with a slightly greenish tinge, very slowly darkening on exposure to an olive green," and that "the most convenient distinctions [from eglestonite] are the yellow color and the very slow change of color to olive green as compared to the brownish color and rapid change to black with eglestonite." But H. W. Turner (p. 259 of the paper by Moses) is quoted in a statement implying that the original color is yellow-green, and Mr. Hartley, in reply to our inquiry, wrote that the terlinguaite crystals were green before they were touched by sunlight, but that most of the terlinguaite occurs as a yellow powder changing to green. The crystals which were measured over two years ago and have lain since that time in the dark are decidedly more sulphur-yellow than green, but unfortunately, not knowing of this apparent confusion in regard to their color, the authors then took no note of their exact shade. It may be possible that terlinguaite, if sulphur-yellow originally and turned green by exposure to light, returns to its yellow color after considerable lapse of time if kept in the dark. At any rate, we have specimens that show a greenish or dark yellowish-green color as well as the sulphur-yellow, and the color of the mineral must be so described as to include both the sulphur-yellow and the greenish or light olive-green colors. Sometimes brown crystals are seen, and occasionally the green and brown

$a$ This inclosed mercury, so characteristic of all these minerals except kleinite, renders the few values given by Moses more or less doubtful. 
colors appear in the same crystal. When brown they are difficult to distinguish at sight from eglestonite in one of its transitional color stages. Some of our earthy specimens that were yellow at first turned greenish on exposure, and presumably contained terlinguaite. Beautiful spots of emerald-green reflected light appear when the crystals are examined with a lens as they occur on the specimen. If at times originally. yellow the mineral is not in that state always distinguishable from kleinite, and perhaps not from eglestonite or even from the orangered form of montroydite. The color of terlinguaite may then be defined as sulphur-yellow, olive-green of varying shades, and brown, of which the sulphur-yellow probably changes to the olive-green. In transmitted light the colors are olive-green, becoming in thin sections very pale. There is a slight pleochroism, in one direction of a greenish, and normal thereto of a yellowish, shade. The streak is yellow, turning greenish-gray on exposure. The crystals, if bounded by parallel faces, are transparent, though the large number of faces usually present makes the crystals translucent.

OPTICAL PROPERTIES.

The extinction was measured on the clinopinacoid, the angle being determined by Klein's Universal Drehapparat fastened to a microscope, with the mineral immersed in monobromnaphthalene. The crystal fragment was so turned that the clinopinacoid was parallel to the stage of the microscope. Extinction measured with regard to direction of edge $(010):(\overline{101})$ is, to left, $39^{\circ}$, to right, $51^{\circ}$. Therefore one extinction direction (on (010)) is inclined $7^{\circ}$ to the rear from the vertical axis, while the other direction emerges nearly normal to the $a$ face (100) or exactly $83^{\circ}$ down in front of the vertical axis. This is for daylight. The faces on this section were determined by the following measurements on the two-circle goniometer:

\begin{tabular}{|c|c|c|}
\hline Cleavage. & $\begin{array}{c}\text { Measure- } \\
\text { ments. }\end{array}$ & $\begin{array}{c}\text { Calcula- } \\
\text { tion. }\end{array}$ \\
\hline & $\circ$, & $\circ$, \\
$(100):(10 \overline{1}) \ldots \ldots$. & 4407 & 4404 \\
$(010):(10 \overline{1}) \ldots \ldots .$. & 9000 & 9000 \\
\hline
\end{tabular}

On another crystal fragment a section was ground down approximately parallel to $a(100)$. This showed the emergence of a bisectrix, and the trace of the axial plane was parallel to the striations on the $a(100)$ face. As these striations are parallel to the $b$ axis, the orientation of the axial plane for terlinguaite is as follows: Axial 
plane nearly parallel with a plane containing the $a$ and $b$ axis but inclined $7^{\circ}$ up in front. The axial angle in air is very large. The above-stated determinations could not be verified on other crystals, so that some hesitancy is felt about advancing them as perfectly correct. Should some future determinations be at variance with them this doubt should be borne in mind. The indices of refraction could not be measured, though approximate determinations with the microscope gave values considerably greater than 2 .

\section{CHEMISTRY.}

PYROGNOSTIC BEHAVIOR.

The effect of heating terlinguaite crystals in a closed tube differs somewhat, according as this is done slowly or quickly. When quickly done there is violent decrepitation, continuing until the mineral has volatilized, the mineral turning red-brown or almost vermilion in color, and much of the resulting powder being projected up onto the sublimate of calomel and mercury above the assay. Eventually there is complete volatilization of the remaining mercuric oxide, but if the heating is stopped before the end, the oxide on cooling is orange-yellow. When the heating is very slowly done, decrepitation is hardly to be noticed. With the first burst of sublimation there appears a little mercury, but then only calomel so long as there is any chlorine left in the residue. Sometimes at the last, when the flame is removed, brilliant short red needles of mercuric oxide form on the warm glass by recombination of some of the mercury vapor and oxygen.

If the heating is done in vacuo the color changes of the crystals as the heat increases are most marked, these being, after the first appearance of a sublimate, red, black (without loss of luster), redbrown, orange-brown (orange, cold), and dull. Before the crystals become completely orange-brown some faces are olive-greenish. When the crystals are orange-brown the only visible sublimate is calomel, and no trace of oxygen has been evolved. The residue now seems to be mercuric oxide. When it decomposes partial recombination of its constituents occurs, to judge from the deposition on the warm glass near by of a slight orange-brown sublimate.

BEHAVIOR TOWARD REAGENTS.

Hydrogen sulphide blackens a crystal of terlinguaite at once, ammonia only after some time. Both tests serve to distinguish the mineral from kleinite and the second from eglestonite, which is at once blackened by ammonia. Hydrochloric and nitric acids readily decompose the mineral, with separation of calomel. The hydrochloric acid filtrate yields much divalent mercury. Cold dilute 
acetic acid slowly decomposes the mineral in powder form, also with separation of calomel, and in the filtrate hydrochloric acid produces no further precipitate, or but a very faint one, showing the absence in the original substance of univalent mercury in combination with oxygen. Hereby is afforded a decisive chemical test to distinguish terlinguaite from eglestonite, which, under similar conditions, yields a further heavy precipitate of calomel with hydrochloric acid. This test, coupled with the first showing of calomel when the mineral is decomposed, shows that terlinguaite is a mercuric-mercurous compound.

\section{QUANTITATIVE COMPOSITION.}

The empirical formula of Moses $\left(\mathrm{Hg}_{2} \mathrm{ClO}\right)$ was confirmed by the following analyses, in which the supposed oxygen was measured directly and found to be wholly absorbed by phosphorus. The crystals, while very fine, are seldom procurable entirely free from attached or imbedded globules of mercury.

Analyses of terlinguaite.

\begin{tabular}{|c|c|c|c|}
\hline & 1 , & 2. & 3. \\
\hline \multirow{4}{*}{$\begin{array}{l}\mathrm{Hg} \ldots \ldots \\
\mathrm{Cl} \ldots \ldots \\
\mathrm{O} \ldots . . \\
\text { Nonvolatile... }\end{array}$} & \multirow[t]{2}{*}{88.92} & \multirow[t]{2}{*}{86.73} & $\begin{array}{r}a 85.65 \\
7.58\end{array}$ \\
\hline & & & 3. 63 \\
\hline & \multirow[t]{2}{*}{ None. } & \multirow[t]{2}{*}{1.79} & 3.14 \\
\hline & & & 100.00 \\
\hline
\end{tabular}

Analyses of terlinguaite calculated to gangue-free basis.

\begin{tabular}{|c|c|c|c|c|c|}
\hline . & 1. & 2. & 3. & Ratio of 3 & $\begin{array}{l}\text { Theory } \\
\left(\mathrm{Hg}_{2} \mathrm{ClO}\right)\end{array}$ \\
\hline 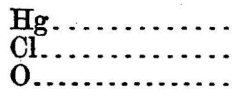 & $\begin{array}{c}88.92 \\
\cdots . . .\end{array}$ & $\begin{array}{c}88.31 \\
\cdots \ldots . .\end{array}$ & $\begin{array}{r}b 88.61 \\
7.83 \\
3.75\end{array}$ & $\begin{array}{l}2.00 \\
1.00 \\
1.06\end{array}$ & $\begin{array}{r}88.65 \\
7.85 \\
3.50\end{array}$ \\
\hline & & & 100.19 & & 100.00 \\
\hline
\end{tabular}

$a$ Difference.

$b$ Mean of 1 and 2.

1. Weight, 0.2502 gram. Selected crystals free from nonvolatile matter, but with a little native mercury imbedded. Mercury weighed as sulphide after solution of the mineral in hydrochloric acid aided by a little bromine, removal of the excess of bromine by just enough sulphur dioxide, and precipitation by hydrogen sulphide.

2. Weight, 0.2072 gram. Crystals free from native mercury. Dissolved in sodium sulphide, wherein about 22 per cent of mercury separated in the free state with gangue. These were easy to separate. The rest of the mercury was obtained from the alkaline solution by electrolysis, as described under kleinite:(p.37).

3. Welght, 0.1052 gram. Crystals containing a little montroydite and free mercury. Volatilized in a tube attached to pump, using gold leaf to retain mercury vapor. The chlorine was extracted from the sublimate by caustic alkali and determined as usual. The gas collected showed no contraction when treated with caustic alkali and was wholly absorbed by phosphorus. 
The high oxygen found in analysis 3 is due probably more to error in measuring so small a volume as 2.67 cubic centimeters $\left(0^{\circ}\right.$ and 760 $\mathrm{mm}$.) than to the little montroydite that was present.

The only artificial mercuric-mercurous oxychloride hitherto prepared $^{a}$ has the empirical formula of terlinguaite. It was made by heating with water at $180^{\circ}$ equivalent weights of mercuric oxide and calomel, but its system of crystallization was not ascertained.

\section{CRYSTALLOGRAPHY.}

GENERAL DESCRIPTION.

The fundamentals of the crystallography of terlinguaite were determined by Moses and but slight changes have been made in them. The orientation chosen by him has been retained, as it gives the simplest indices and shows the geometric relations of the various forms very well. The only disadvantage is that the perfect cleavage of the mineral is parallel to the unit negative dome $\{\overline{1} 01\}$, but, as described in detail further on, it was not found possible to so orient the crystals as to make the cleavage a pinacoidal form and at the same time retain the simplicity of the forms. That terlinguaite possesses a rich form system was already shown by Moses's measurements of but four minute crystals, showing the presence of 32 forms. This number the writer has been able to extend by about a hundred forms, for the greater part simple in their indices and lying in welldeveloped zones. It was found that the indices of Moses could be much simplified by multiplying the first (in the Millerian form) by 3; thus $h . k . l$ becomes $3 h . k$. $l$. Both of these are given under the form description; so that they may be better compared with the results of Moses, and also to illustrate how much simpler the forms are in their new indices. For reference, the indices in the form given by Moses are referred to as $\mathrm{M}_{1}$, those in the new form as $\mathrm{M}_{2}$. In the later tables, only the form finally adopted, namely $\mathrm{M}_{2}$, is given. A few forms of Moses, with very high and vicinal indices, have been much simplified, and, in one case, two of his forms have been united into one. As the best orientation could not be determined until all the crystals had been measured and determined, the new elements were calculated on the basis of the former indices, namely, $\mathrm{M}_{1}$, but the discussion of the forms is carried out in the orientation finally chosen and put forward in this paper as the most suitable one for terlinguaite, namely, $\mathrm{M}_{2}$ : Therefore, $h . k . l\left(\mathrm{M}_{1}\right)=3 h . k . l\left(\mathrm{M}_{2}\right)$.

Though not particularly large, the crystals are exceedingly rich in forms, many of the faces being very minute. It would have been utterly impossible to completely determine the various forms without the two-circle goniometer. 
The following table shows the number of determined forms and faces on the twelve crystals measured, all doubtful and vicinal ones being excluded:

Number of forms and faces on twelve terlinguaite crystals.

\begin{tabular}{|r|r|r|r|r|r|}
\hline $\begin{array}{c}\text { Crystal } \\
\text { No.- }\end{array}$ & Forms. & Faces. & $\begin{array}{c}\text { Crystal } \\
\text { No.- }\end{array}$ & Forms. & Faces. \\
\cline { 1 - 2 } 1 & 54 & 86 & 7 & 52 & \\
\hline 2 & 32 & 48 & 8 & 51 & 58 \\
3 & 41 & 59 & 9 & 67 & 80 \\
4 & 41 & 55 & 10 & 45 & 53 \\
5 & 38 & 43 & 11 & 64 & 96 \\
6 & 87 & 174 & 12 & 39 & 48 \\
\hline
\end{tabular}

The sizes of the twelve (often incomplete) crystals measured are shown below:

Dimensions of terlinguaite crystals.

\begin{tabular}{|c|c|}
\hline Crystal No.- & Dimensions (millimeters). \\
\hline $\begin{array}{r}1 \\
2 \\
3 \\
4 \\
5 \\
6 \\
7 \\
8 \\
9 \\
10 \\
11 \\
12\end{array}$ & $\begin{array}{l}2 \frac{1}{2} \text { by } 1 \frac{1}{2} \text { by } 1 \frac{1}{2} . \\
1 \text { by } 1 \text { by } \frac{1}{2} . \\
2 \frac{1}{4} \text { by } 1 \frac{1}{2} \text { by } \frac{1}{2} . \\
2 \frac{1}{4} \text { by } 1 \text { by } \frac{1}{2} . \\
2 \text { by } \frac{3}{4} \text { by } \frac{1}{2} . \\
15 \text { by } 1 \frac{3}{4} \text { by } 1 \frac{3}{4} . \\
2 \frac{1}{4} \text { by } 1 \frac{1}{2} \text { by } \frac{3}{4} . \\
3 \frac{1}{4} \text { by } 2 \text { by } 1 \frac{3}{4} . \\
2 \text { by } 1 \frac{1}{2} \text { by } 1 . \\
1 \frac{1}{2} \text { by } 1 \frac{1}{2} \text { by } \frac{3}{4} . \\
2 \text { by } 1 \frac{1}{2} \text { by } 1 \frac{1}{4} . \\
1 \frac{1}{2} \text { by } 1 \frac{1}{2} \text { by } \frac{1}{2} .\end{array}$ \\
\hline
\end{tabular}

CALCULATION OF ELEMENTS.

On account of the large number of faces present which give good reflections, a new set of values were calculated for the crystallographical elements. The two-circle goniometer is beautifully adapted for the determination of the crystallographical elements of a mineral, as each reading may or may not be directly used, according as to whether or not it gave a good reflection. As there are so many faces and forms on the terlinguaite crystals measured, a fairly exact value may be obtained.

For the determination of the angle $\beta$, there are three means at hand, namely (1) direct measurement, or, what is practically the same thing, taking the complement of the $\rho$ measurement on the basal pinacoid; (2) the $\phi$ reading of all faces in the zone (001): (010), if the crystal is set up with the clinopinacoid polar; and (3) obtaining 
the $\cot \beta\left(=e^{\prime}\right)$ from measurements of the clinodomes, since $\sin \phi \tan$ $\rho=x$ and $x^{\prime}=e^{\prime}=\cot \beta$ for clinodomes.

Using only the measurements of such faces as gave good signals, the following results were obtained:

The angle $\beta$ measured directly on terlinguaite crystals. .

\begin{tabular}{|c|c|c|c|c|c|}
\hline $\begin{array}{l}\text { Crystal } \\
\text { No.- }\end{array}$ & Reflection. & Angle. & $\begin{array}{c}\text { Crystal } \\
\text { No.- }\end{array}$ & Reflection. & Angle. \\
\hline \multirow[t]{2}{*}{$\begin{array}{l}1 \\
1 \\
2 \\
2 \\
3 \\
4 \\
4 \\
4 \\
6\end{array}$} & \multirow[t]{2}{*}{$\begin{array}{l}\text { Excellent.... } \\
\text { Good ......... } \\
\text { Good........ } \\
\text { Fair.......... } \\
\text { Good ........ } \\
\text { Excellent... } \\
\text { Good ......... } \\
\text { Excellent... }\end{array}$} & \multirow[t]{2}{*}{$\begin{array}{cc}\circ \quad \\
7423 \\
22 \\
22 \\
22 \\
24 \\
25 \\
23 \\
23\end{array}$} & \multirow[t]{2}{*}{$\begin{array}{r}6 \\
6 \\
6 \\
9 \\
10 \\
11 \\
\\
\text { Average }\end{array}$} & \multirow[t]{2}{*}{$\begin{array}{l}\text { Excellent..... } \\
\text { Fair.......... } \\
\text { Fair........... } \\
\text { Fair........... } \\
\text { Excellent.... } \\
\text { Excellent.... }\end{array}$} & $\begin{array}{lc}\circ & \prime \\
74 & 23 \\
21 \\
25 \\
\quad 23 \\
23 \\
23 \\
23\end{array}$ \\
\hline & & & & & 7422.8 \\
\hline
\end{tabular}

From this average is obtained $e^{\prime}=0.27957$.

In the crystals adjusted by using orthodomes as the prisms and setting the clinopinacoid as pole, the $\phi$ angle for any form in the zone $(001):(010)$ is the same as the complement of $\beta$. The following are the $\phi$ angles for such clinodomes as are present on those parts of crystal 6 that were set up in this position.

Measurements of $\phi$ angle on clinodomes of terlinguaite crystal No. 6 .

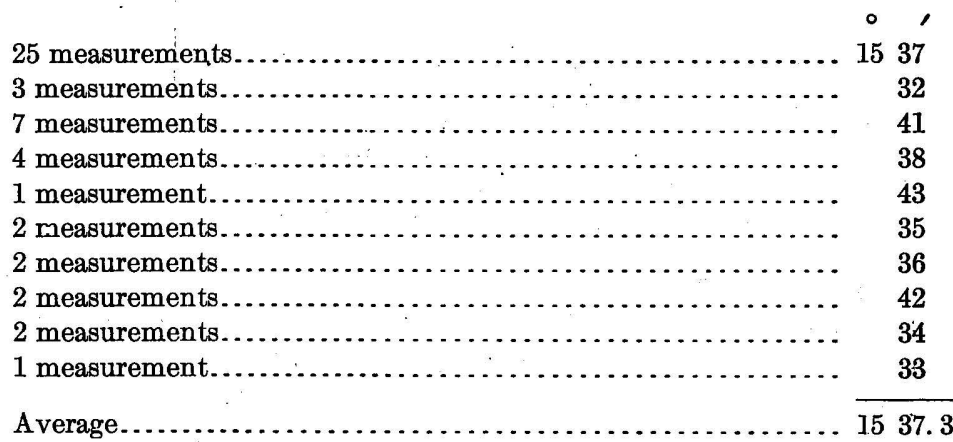

Or, if $\phi=15^{\circ} 37.3^{\prime}, \beta=74^{\circ} 22.7^{\prime}$, and hence is obtained $e^{\prime}=$ 0.27962 . 
The values for $e^{\prime}$ obtained from the direct measurements of the clinodomes, the crystal being adjusted polar, are as follows:

Values of $e^{\prime}$ obtained from measurements of clinodomes, terlinguaite crystals.

\begin{tabular}{|r|r||r|r|}
\hline $\begin{array}{c}\text { Number of } \\
\text { measure- } \\
\text { ments. }\end{array}$ & Value. & $\begin{array}{r}\text { Number of } \\
\text { measure- } \\
\text { ments. }\end{array}$ & Value. \\
\hline & 0.2793 & 1 & \\
\hline 5 & .2790 & 1 & 0.2794 \\
10 & .2805 & 1 & .2807 \\
1 & .2798 & 2 & .2796 \\
1 & .2789 & 2 & .2799 \\
1 & .2801 & 7 & .2802 \\
6 & .2776 & 4 & .2787 \\
1 & .2774 & 3 & .2813 \\
1 & .2795 & 5 & .2797 \\
3 & .2803 & 58 & Av. .27965 \\
2 & .2806 & 58 \\
1 & & & \\
\hline
\end{tabular}

The values obtained for $e^{\prime}$ are then:

From $\beta$ measured directly (14 measurements)............ 0.27957

From $\phi$ angle of clinodomes $\left(90^{\circ}-\beta\right)(49$ measurements $) \ldots \ldots \ldots \quad .27962$

From clinodomes $(58$ measurements) $\ldots \ldots \ldots \ldots \ldots \ldots \ldots \ldots \ldots . .27965$

Average (121 measurements) .............................. $\overline{.2796}$

Hence $e^{\prime}=0.2796 ; \beta=74^{\circ} 22^{\prime} 40^{\prime \prime}+$, or $74^{\circ} 23^{\prime}$.

For the determination of $p_{0}^{\prime}$ or $q_{0}^{\prime}$, the average measurements were used for each of the forms of which at least three faces gave concordant measurements, and only such measurements were used as agreed closely with the general average. From the pyramids and clinodomes, the values for $q_{0}^{\prime}$ were obtained; from the pyramids and orthodomes and prisms (using the value of $q_{0}^{\prime}$ obtained and the equation $p_{0}^{\prime}=\frac{\dot{k}}{h} q^{\prime}{ }_{0} \tan \phi$ ), the values for ${p^{\prime}}_{0}$ were obtained. 
The values are as follows:

Values of $p_{0}^{\prime}$ and $q_{0}^{\prime}$, terlinguaite crystals.

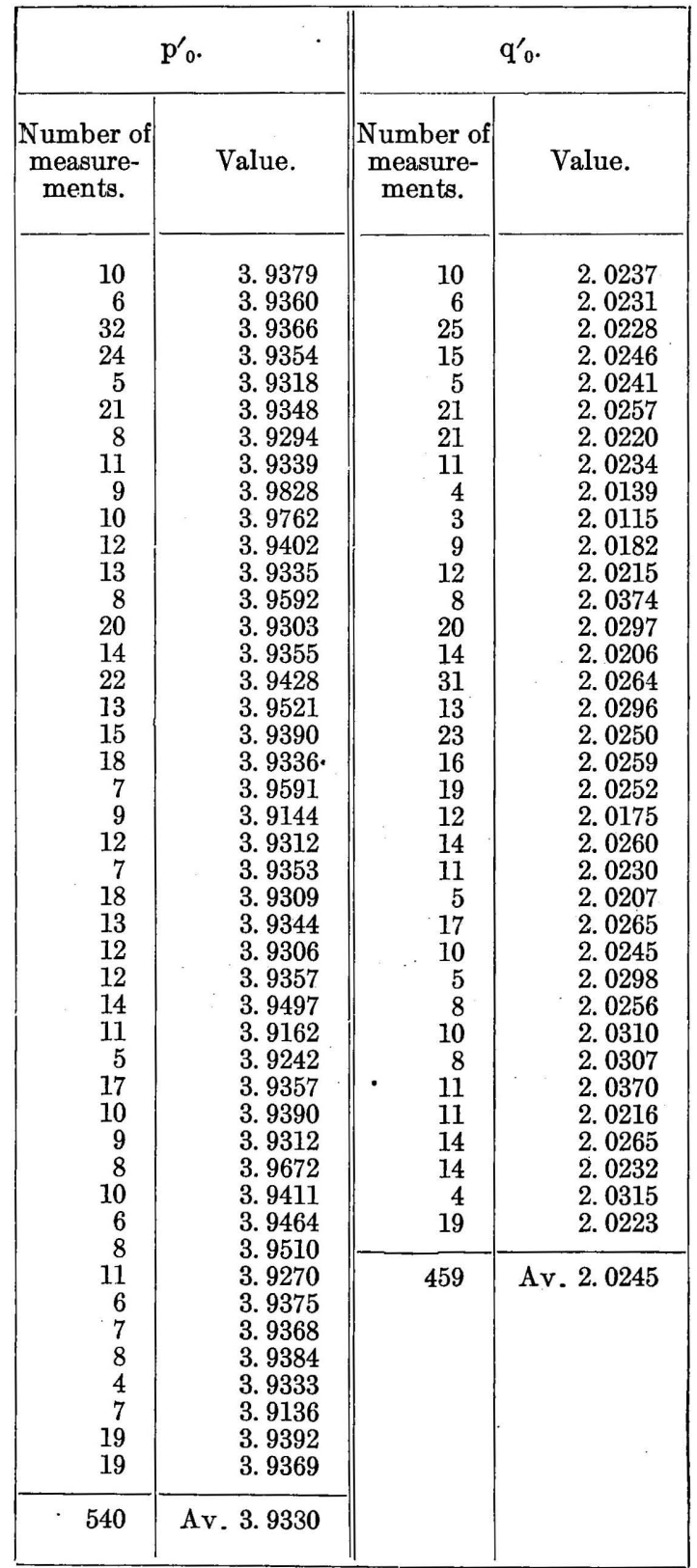

The elements for terlinguaite then become:

$$
\begin{array}{ll}
p^{\prime}{ }_{0}=3.9380 & a=.5338 \\
{q^{\prime}}^{\prime}=2.0245 & c=2.0245 \\
e^{\prime}=.2796 & \beta=74^{\circ} 23^{\prime}
\end{array}
$$


The values obtained by Moses, based on a much smaller number of measurements, are very close to the above. His values are: $a: b: c=.5306: 1: 2.0335, \beta=74^{\circ} 16^{\prime}$.

These constants are based on the orientation of Moses. Therefore, on changing the elements from the position $\mathrm{M}_{1}$, we obtain the following as the correct orientation $\mathrm{M}_{2}$ :

$$
\begin{array}{ll}
p_{0}^{\prime}=1.3127 & a=1.6050 \\
q_{0}^{\prime}=2.0245 & c=2.0245 \\
e^{\prime}=.2796 & \beta=74^{\circ} 23^{\prime}
\end{array}
$$

FORMS AND ANGLES.

The complete list of 134 established forms is shown in the table below, which gives the two orientations $M_{1}$ and $M_{2}$, the letters for

\begin{tabular}{|c|c|c|c|c|c|c|c|c|c|c|c|}
\hline \multirow{2}{*}{ No. } & \multirow{2}{*}{ Letter. } & \multicolumn{2}{|c|}{ Symbol. } & \multicolumn{4}{|c|}{ Measured. } & \multicolumn{4}{|c|}{ Calculated. } \\
\hline & & $\mathrm{M}_{1}$ & $\mathrm{M}_{2}$ & 9 & & $\rho$ & & $\phi$ & & & $o$ \\
\hline $\begin{array}{l}1 \\
2 \\
3 \\
4 \\
5\end{array}$ & $\begin{array}{l}c \\
b \\
a \\
* j \\
*_{u}\end{array}$ & $\begin{array}{l}001 \\
010 \\
100 \\
160 \\
290\end{array}$ & $\begin{array}{l}001 \\
010 \\
100 \\
120 \\
230\end{array}$ & $\begin{array}{r}90 \\
0 \\
90 \\
17 \\
23\end{array}$ & $\begin{array}{c}\prime \\
00 \\
00 \\
00 \\
58 \\
28\end{array}$ & $\begin{array}{c}\circ \\
15 \\
90 \\
90 \\
90 \\
90\end{array}$ & $\begin{array}{c}\prime \\
37 \\
00 \\
00 \\
00 \\
00\end{array}$ & $\begin{array}{r}\circ \\
90 \\
0 \\
90 \\
17 \\
23\end{array}$ & $\begin{array}{c}\prime \\
00 \\
00 \\
00 \\
58 \\
23\end{array}$ & $\begin{array}{c}\circ \\
15 \\
90 \\
90 \\
90 \\
90\end{array}$ & $\begin{array}{c}\prime \\
37 \\
00 \\
00 \\
00 \\
00\end{array}$ \\
\hline $\begin{array}{r}6 \\
7 \\
8 \\
9 \\
10\end{array}$ & $\begin{array}{c}m \\
{ }^{*} B \\
\delta \\
{ }^{*} \mathfrak{1 1} \\
{ }_{j}^{\prime}\end{array}$ & $\begin{array}{l}130 \\
120 \\
230 \\
560 \\
890\end{array}$ & $\begin{array}{l}110 \\
320 \\
210 \\
520 \\
830\end{array}$ & $\begin{array}{l}32 \\
44 \\
52 \\
58 \\
60\end{array}$ & $\begin{array}{l}57 \\
11 \\
21 \\
21 \\
10\end{array}$ & $\begin{array}{l}90 \\
90 \\
90 \\
90 \\
90\end{array}$ & $\begin{array}{l}00 \\
00 \\
00 \\
00 \\
00\end{array}$ & $\begin{array}{l}32 \\
44 \\
52 \\
58 \\
59\end{array}$ & $\begin{array}{l}58 \\
12 \\
22 \\
20 \\
58\end{array}$ & $\begin{array}{l}90 \\
90 \\
90 \\
90 \\
90\end{array}$ & $\begin{array}{l}00 \\
00 \\
00 \\
00 \\
00\end{array}$ \\
\hline $\begin{array}{l}11 \\
12 \\
13 \\
14 \\
15\end{array}$ & $\begin{array}{c}{ }^{*} \mathbf{z} \\
{ }^{*} D \\
d \\
{ }^{*} \mathbf{t} \\
{ }^{*} \mathbf{g}\end{array}$ & $\begin{array}{l}210 \\
031 \\
011 \\
045 \\
035\end{array}$ & $\begin{array}{l}610 \\
031 \\
011 \\
045 \\
035\end{array}$ & $\begin{array}{r}76 \\
2 \\
7 \\
9 \\
13\end{array}$ & $\begin{array}{l}20 \\
38 \\
52 \\
46 \\
32\end{array}$ & $\begin{array}{l}90 \\
80 \\
63 \\
58 \\
50\end{array}$ & $\begin{array}{l}00 \\
39 \\
56 \\
51 \\
04\end{array}$ & $\begin{array}{r}75 \\
2 \\
7 \\
9 \\
12\end{array}$ & $\begin{array}{l}35 \\
38 \\
52 \\
48 \\
58\end{array}$ & $\begin{array}{l}90 \\
80 \\
63 \\
58 \\
51\end{array}$ & $\begin{array}{l}00 \\
40 \\
56 \\
41 \\
16\end{array}$ \\
\hline $\begin{array}{l}16 \\
17 \\
18 \\
19 \\
20\end{array}$ & $\begin{array}{l}{ }^{*} \mathfrak{h} \\
*_{\mathfrak{a}} \\
{ }^{*} \mathfrak{k} \\
f \\
h\end{array}$ & $\begin{array}{l}012 \\
049 \\
025 \\
013 \\
015\end{array}$ & $\begin{array}{l}012 \\
049 \\
025 \\
013 \\
015\end{array}$ & $\begin{array}{l}15 \\
17 \\
19 \\
22 \\
34\end{array}$ & $\begin{array}{l}24 \\
23 \\
33 \\
31 \\
36\end{array}$ & $\begin{array}{l}46 \\
43 \\
39 \\
36 \\
26\end{array}$ & $\begin{array}{l}34 \\
04 \\
53 \\
10 \\
12\end{array}$ & $\begin{array}{l}15 \\
17 \\
19 \\
22 \\
34\end{array}$ & $\begin{array}{l}26 \\
15 \\
03 \\
30 \\
37\end{array}$ & $\begin{array}{l}46 \\
43 \\
40 \\
36 \\
26\end{array}$ & $\begin{array}{l}24 \\
18 \\
35 \\
09 \\
12\end{array}$ \\
\hline $\begin{array}{l}21 \\
22 \\
23 \\
24 \\
25\end{array}$ & $\begin{array}{l}*_{\mathfrak{l}} \\
*_{\mathfrak{i t}} \\
*_{\mathfrak{n}} \\
*_{\mathfrak{k}} \\
*_{\mathfrak{j}}\end{array}$ & $\begin{array}{r}017 \\
1.0 .15 \\
1.0 .12 \\
109 \\
108\end{array}$ & $\begin{array}{l}017 \\
105 \\
104 \\
103 \\
308\end{array}$ & $\begin{array}{l}44 \\
90 \\
90 \\
90 \\
90\end{array}$ & $\begin{array}{l}17 \\
00 \\
00 \\
00 \\
00\end{array}$ & $\begin{array}{l}21 \\
28 \\
32 \\
35 \\
37\end{array}$ & $\begin{array}{l}56 \\
28 \\
02 \\
24 \\
29\end{array}$ & $\begin{array}{l}44 \\
90 \\
90 \\
90 \\
90\end{array}$ & $\begin{array}{l}01 \\
00 \\
00 \\
00 \\
00\end{array}$ & $\begin{array}{l}21 \\
28 \\
31 \\
35 \\
37\end{array}$ & $\begin{array}{l}55 \\
28 \\
18 \\
39 \\
40\end{array}$ \\
\hline $\begin{array}{l}26 \\
27 \\
28 \\
29 \\
30\end{array}$ & $\begin{array}{c}t \\
*_{1} \\
*_{2 y} \\
y \\
*^{*}\end{array}$ & $\begin{array}{l}106 \\
209 \\
104 \\
103 \\
409\end{array}$ & $\begin{array}{r}102 \\
\cdot 203 \\
304 \\
101 \\
403\end{array}$ & $\begin{array}{l}90 \\
90 \\
90 \\
90 \\
90\end{array}$ & $\begin{array}{l}00 \\
00 \\
00 \\
00 \\
00\end{array}$ & $\begin{array}{l}43 \\
49 \\
51 \\
57 \\
63\end{array}$ & $\begin{array}{l}05 \\
03 \\
40 \\
59 \\
50\end{array}$ & $\begin{array}{l}90 \\
90 \\
90 \\
90 \\
90\end{array}$ & $\begin{array}{l}00 \\
00 \\
00 \\
00 \\
00\end{array}$ & $\begin{array}{l}43 \\
49 \\
51 \\
57 \\
63\end{array}$ & $\begin{array}{l}06 \\
07 \\
39 \\
52 \\
46\end{array}$ \\
\hline
\end{tabular}
the forms and the average of the measured angles compared with the calculated values. All doubtful and vicinal forms are excluded. These latter are shown together on page 108. Forms marked with a star are new.

Forms and angles on terlinguaite crystals. 
Forms and angles on terlinguaite crystals—Continued.

\begin{tabular}{|c|c|c|c|c|c|c|c|c|c|c|c|}
\hline \multirow{2}{*}{ No. } & \multirow{2}{*}{ Letter. } & \multicolumn{2}{|c|}{ Symbol. } & \multicolumn{4}{|c|}{ Measured. } & \multicolumn{4}{|c|}{ Calculated. } \\
\hline & & $\mathrm{M}_{1}$ & $\mathrm{M}_{2}$ & \multicolumn{2}{|l|}{$\phi$} & \multicolumn{2}{|l|}{$\rho$} & \multicolumn{2}{|l|}{$\phi$} & \multicolumn{2}{|c|}{$\rho$} \\
\hline & & & & 。 & & $\circ$ & & $\circ$ & , & 。 & , \\
\hline 31 & ${ }^{*} F$ & 509 & 503 & 90 & 00 & 67 & 47 & 90 & 00 & 67 & 56 \\
\hline 32 & $w$ & 101 & 301 & & 00 & 76 & 17 & 90 & 00 & 76 & 40 \\
\hline 33 & ${ }^{*} G$ & 403 & 401 & & 00 & 79 & 12 & 90 & 00 & 79 & 45 \\
\hline 34 & $*_{\eta}$ & 301 & 901 & & 00 & 85 & 19 & 90 & 00 & 85 & 16 \\
\hline 35 & $*_{k}$ & 401 & 12.0 .1 & 90 & 00 & 86 & 34 & 90 & 00 & 86 & 26 \\
\hline 36 & ${ }^{*} M$ & 1. 0.21 & $\overline{1} 07$ & 90 & 00 & 4 & 58 & 90 & 00 & 5 & 16 \\
\hline 37 & ${ }^{*} L$ & 1. 0.12 & 104 & 90 & 00 & 2 & 40 & 90 & 00 & 2 & 13 \\
\hline 38 & *组 & 109 & 103 & 90 & 00 & 8 & 47 & 90 & 00 & 8 & 59 \\
\hline 39 & $n$ & 106 & $\overline{1} 02$ & 90 & 00 & 20 & 35 & 90 & 00 & 20 & 39 \\
\hline 40 & $*_{x}$ & $\overline{1} 05$ & $\overline{3} 05$ & 90 & 00 & 26 & 50 & 90 & 00 & 26 & 56 \\
\hline 41 & ${ }^{*} N$ & $\overline{2} 09$ & $\overline{2} 03$ & 90 & 00 & 30 & 45 & 90 & 00 & 30 & 47 \\
\hline 42 & ${ }^{*} \mathbf{y}$ & $-\overline{104}$ & $\underline{3} 04$ & 90 & 00 & 35 & 14 & 90 & 00 & 35 & 11 \\
\hline 43 & ${ }^{*} R$ & $\overline{4} .0 .15$ & 405 & 90 & 00 & 37 & 36 & 90 & 00 & 37 & 37 \\
\hline 44 & $u$ & 103 & 101 & 90 & 00 & 45 & 52 & 90 & 00 & 45 & 56 \\
\hline 45 & ${ }^{*} \Pi$. & $\overline{2} 05$ & $\overline{6} 05$ & 90 & 00 & 52 & 25 & 90 & 00 & 52 & 20 \\
\hline 46 & ${ }^{* P}$ & $\overline{4} 09$ & $\overline{4} 03$ & 90 & 00 & 55 & .46 & 90 & 00 & 55 & 47 \\
\hline 47 & ${ }^{*} Q$ & 102 & $\underline{\overline{3}} 02$ & 90 & 00 & 59 & 21 & 90 & 00 & 59 & 23 \\
\hline 48 & *蛋 & 509 & $\underline{5} 03$ & 90 & 00 & 62 & 24 & 90 & 00 & 62 & 21 \\
\hline 49 & $x$ & $\overline{2} 03$ & $\overline{2} 01$ & 90 & 00 & 66 & 52 & 90 & 00 & 66 & 55 \\
\hline 50 & **it & 506 & 502 & 90 & 00 & 71 & 19 & 90 & 00 & 71 & 35 \\
\hline 51 & $z$ & $\overline{1} 01$ & $\overline{3} 01$ & 90 & 00 & 74 & 41 & 90 & 00 & 74 & 43 \\
\hline 52 & ${ }^{*} S$ & 403 & 401 & 90 & 00 & 79 & 01 & 90 & 00 & 78 & 38 \\
\hline 53 & ${ }^{*} \theta$ & 503 & $\underline{\overline{5}} 01$ & 90 & 00 & 81 & 09 & 90 & 0 & 80 & 58 \\
\hline 54 & ${ }^{*} z$ & 703 & -701 & 90 & 00 & 83 & 54 & 90 & 00 & 83 & 36 \\
\hline 55 & * $\mathfrak{I}$ & $\overline{4} 01$ & $\overline{12} .0 .1$ & 90 & 00 & 86 & 32 & 90 & 00 & 86 & 18 \\
\hline 56 & ${ }^{*} r$ & 117 & 317. & 71 & 57 & 41 & 54 & 71 & 03 & 41 & 41 \\
\hline 57 & & 111 & 311 & 64 & 2 & 77 & 56 & 64 & 2 & 77 & 56 \\
\hline 58 & ${ }^{*} U$ & 1. 1.11 & $\overline{3} .1 .11$ & 23 & 32 & 11 & 16 & 23 & 0 & 11 & 19 \\
\hline 59 & $* V$ & 119 & 319 & 35 & 21 & 15 & 19 & 35 & 05 & 15 & 22 \\
\hline 60 & $q$ & $\overline{115}$ & $\overline{3} 15$ & 51 & 32 & 32 & 59 & 51 & 27 & 33 & 01 \\
\hline 61 & $a$ & $\overline{1} 13$ & $\overline{3} 13$ & 56. & 55 & 50 & 56 & 56 & 51 & 50 & 59 \\
\hline 62 & & & $\overline{3} 11$ & & 06 & 76 & 3 & 61 & & 76 & 33 \\
\hline 63 & *(B) & 1. 30.30 & 1. 10.10 & 11 & 30 & 64 & 10 & 11 & $2 \varepsilon$ & 64 & 10 \\
\hline 64 & $*_{\tau}$ & 1. 24.24 & 188 & 12 & 24 & 64 & 12 & 12 & 25 & 64 & 15 \\
\hline 65 & & 1. 18.18 & 166 & 13 & 30 & 64 & 37 & 13 & 10 & 64 & 23 \\
\hline 66 & $*_{\mathrm{n}}$ & 1. 15.15 & 155 & 14 & 55 & 64 & 32 & & 00 & & 30 \\
\hline 67 & & 1. 12.12 & 144 & 16 & 43 & 64 & 40 & 16 & 43 & 64 & 41 \\
\hline 68 & ${ }^{*} \cdot \varepsilon$ & 199 & 13 & 19 & 31 & 65 & 01 & 19 & 30 & 65 & 02 \\
\hline 69 & $* \boldsymbol{Z}$ & 166 & 122 & 24 & 48 & 65 & 51 & 24 & 49 & 65 & 51 \\
\hline 70 & $v$ & 155 & 355 & & & & & 27 & 48 & 66 & 24 \\
\hline & $* Y$ & 299 & 233 & & 40 & & 46 & & 42 & & 47 \\
\hline 72 & 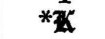 & 144 & 344 & 31 & 56 & 67 & 21 & 31 & 59 & 67 & 16 \\
\hline 73 & $p$ & 133 & 11 & 38 & 09 & 68 & 47 & 38 & 11 & 68 & 47 \\
\hline 74 & & 499 & 433 & 45 & 03 & 70 & 35 & 45 & 00 & 70 & 45 \\
\hline 75 & & 122 & 322 & 47 & 59 & 71 & 41 & 48 & 00 & 71 & 43 \\
\hline & * & 599 & 533 & & 35 & & & 50 & 38 & 72 & 36 \\
\hline 77 & $i$ & 233 & 211 & 55 & 07 & 74 & 13 & 55 & 08 & 74 & 14 \\
\hline 78 & $*$ (1) & & 411 & 69 & 55 & 80 & 20 & 69 & 54 & 80 & 22 \\
\hline 79 & $*_{\sigma}$ & 1. 15.15 & 155 & 0 & 29 & 63 & 34 & 0 & 29 & 63 & 43 \\
\hline 80 & ${ }^{*} \phi$ & 1. 12.12 & 144 & 1 & 29 & 63 & 39 & 1 & 22 & 63 & 43 \\
\hline
\end{tabular}


Forms and angles on terlinguaite crystals-Continued.

\begin{tabular}{|c|c|c|c|c|c|c|c|c|c|c|c|}
\hline \multirow{2}{*}{ No. } & \multirow{2}{*}{ Letter. } & \multicolumn{2}{|c|}{ Symbol. } & \multicolumn{4}{|c|}{ Measured. } & \multicolumn{4}{|c|}{ Calculated. } \\
\hline & & $\mathrm{M}_{1}$ & $\mathrm{M}_{2}$ & $\phi$ & & $\rho$ & & $\phi$ & & & \\
\hline $\begin{array}{l}81 \\
82 \\
83 \\
84 \\
85\end{array}$ & $\begin{array}{l}* X \\
* \pi \\
* y \\
* 4 \\
* \omega \\
* \Delta\end{array}$ & $\begin{array}{r}\overline{1} 99 \\
\overline{2} .15 .15 \\
\overline{1} 66 \\
\overline{1} 55 \\
\overline{2} 99\end{array}$ & $\begin{array}{l}\overline{1} 33 \\
\overline{2} 55 \\
\overline{1} 22 \\
\overline{3} 55 \\
\overline{2} 33\end{array}$ & $\begin{array}{r}\circ \\
4 \\
7 \\
10 \\
14 \\
16\end{array}$ & $\begin{array}{l}\prime \\
35 \\
15 \\
34 \\
31 \\
23\end{array}$ & $\begin{array}{c}\circ \\
63 \\
64 \\
64 \\
64 \\
64\end{array}$ & $\begin{array}{l}\prime \\
46 \\
03 \\
04 \\
25 \\
37\end{array}$ & $\begin{array}{r}\circ \\
4 \\
6 \\
10 \\
14 \\
16\end{array}$ & $\begin{array}{l}\prime \\
28 \\
55 \\
33 \\
05 \\
23\end{array}$ & $\begin{array}{c}\circ \\
63 \\
63 \\
64 \\
64 \\
64\end{array}$ & $\begin{array}{l}\prime \\
47 \\
53 \\
06 \\
24 \\
39\end{array}$ \\
\hline $\begin{array}{l}86 \\
87 \\
88 \\
89 \\
90\end{array}$ & $\begin{array}{c}* \Gamma \\
* 7 \\
e \\
l \\
l_{7}^{*}\end{array}$ & $\begin{array}{l}\overline{1} 44 \\
\overline{2} 77 \\
133 \\
\overline{4} 99 \\
122\end{array}$ & $\begin{array}{l}\overline{3} 44 \\
\overline{6} 77 \\
\overline{1} 11 \\
\overline{4} 33 \\
\overline{3} 22\end{array}$ & $\begin{array}{l}19 \\
21 \\
26 \\
36 \\
40\end{array}$ & $\begin{array}{l}13 \\
45 \\
55 \\
01 \\
05\end{array}$ & $\begin{array}{l}65 \\
65 \\
66 \\
68 \\
69\end{array}$ & $\begin{array}{l}08 \\
27 \\
17 \\
11 \\
22\end{array}$ & $\begin{array}{l}19 \\
22 \\
27 \\
36 \\
39\end{array}$ & $\begin{array}{l}12 \\
40 \\
02 \\
00 \\
51\end{array}$ & $\begin{array}{l}65 \\
65 \\
66 \\
68 \\
69\end{array}$ & $\begin{array}{l}00 \\
30 \\
15 \\
13 \\
14\end{array}$ \\
\hline $\begin{array}{l}91 \\
92 \\
93 \\
94 \\
95\end{array}$ & $\begin{array}{c}g \\
* g \\
r \\
* \varpi \\
* q\end{array}$ & $\begin{array}{l}\overline{2} 33 \\
\overline{5} 66 \\
433 \\
126 \\
128\end{array}$ & $\begin{array}{l}\overline{2} 11 \\
\overline{5} 22 \\
\overline{4} 11 \\
326 \\
328\end{array}$ & $\begin{array}{l}49 \\
56 \\
67 \\
54 \\
56\end{array}$ & $\begin{array}{l}13 \\
08 \\
52 \\
00 \\
31\end{array}$ & $\begin{array}{l}72 \\
74 \\
79 \\
48 \\
43\end{array}$ & $\begin{array}{l}08 \\
40 \\
29 \\
57 \\
33\end{array}$ & $\begin{array}{l}49 \\
55 \\
67 \\
54 \\
56\end{array}$ & $\begin{array}{l}12 \\
57 \\
50 \\
09 \\
45\end{array}$ & $\begin{array}{l}72 \\
74 \\
79 \\
49 \\
42\end{array}$ & $\begin{array}{l}07 \\
32 \\
27 \\
03 \\
43\end{array}$ \\
\hline $\begin{array}{r}96 \\
97 \\
98 \\
99 \\
100\end{array}$ & $\begin{array}{c}k \\
\pi \\
* 1 \text { H } \\
* 0 \\
\lambda\end{array}$ & $\begin{array}{r}134 \\
136 \\
137 \\
139 \\
1.3 .15\end{array}$ & $\begin{array}{l}334 \\
112 \\
337 \\
113 \\
115\end{array}$ & $\begin{array}{l}42 \\
44 \\
46 \\
53\end{array}$ & $\begin{array}{l}40 \\
08 \\
42 \\
15\end{array}$ & $\begin{array}{l}53 \\
50 \\
44 \\
34\end{array}$ & $\begin{array}{l}59 \\
21 \\
34 \\
05\end{array}$ & $\begin{array}{l}39 \\
42 \\
44 \\
46 \\
53\end{array}$ & $\begin{array}{l}47 \\
45 \\
09 \\
44 \\
15\end{array}$ & $\begin{array}{l}63 \\
54 \\
50 \\
44 \\
34\end{array}$ & $\begin{array}{l}09 \\
02 \\
25 \\
33 \\
05\end{array}$ \\
\hline $\begin{array}{l}101 \\
102 \\
103 \\
104 \\
105\end{array}$ & $\begin{array}{l}* 8 \\
* 2 \\
* * \\
* \emptyset \\
* 4\end{array}$ & $\begin{array}{r}1.4 .14 \\
1.6 .12 \\
1.6 .18 \\
1.6 .24 \\
193\end{array}$ & $\begin{array}{r}\text { 3. } 14 \\
124 \\
126 \\
128 \\
131\end{array}$ & $\begin{array}{l}43 \\
30 \\
36 \\
41 \\
14\end{array}$ & $\begin{array}{l}56 \\
56 \\
32 \\
18 \\
19\end{array}$ & $\begin{array}{l}39 \\
49 \\
40 \\
33 \\
81\end{array}$ & $\begin{array}{l}12 \\
45 \\
06 \\
59 \\
07\end{array}$ & $\begin{array}{l}44 \\
30 \\
36 \\
41 \\
14\end{array}$ & $\begin{array}{l}07 \\
59 \\
27 \\
14 \\
41\end{array}$ & $\begin{array}{l}38 \\
49 \\
40 \\
33 \\
80\end{array}$ & $\begin{array}{l}52 \\
44 \\
00 \\
56 \\
57\end{array}$ \\
\hline $\begin{array}{l}106 \\
107 \\
108 \\
109 \\
110\end{array}$ & $\begin{array}{l}{ }^{*} W \\
* \theta \\
* T \\
* * 1 \\
* z\end{array}$ & $\begin{array}{r}232 \\
236 \\
239 \\
2.3 .15 \\
124\end{array}$ & $\begin{array}{l}632 \\
212 \\
213 \\
215 \\
\overline{3} 24\end{array}$ & $\begin{array}{l}55 \\
57 \\
59 \\
62 \\
34\end{array}$ & $\begin{array}{l}01 \\
38 \\
38 \\
01 \\
57\end{array}$ & $\begin{array}{l}78 \\
61 \\
53 \\
42 \\
50\end{array}$ & $\begin{array}{l}52 \\
54 \\
15 \\
07 \\
59\end{array}$ & $\begin{array}{l}54 \\
57 \\
59 \\
63 \\
34\end{array}$ & $\begin{array}{l}15 \\
32 \\
42 \\
17 \\
51\end{array}$ & $\begin{array}{l}79 \\
62 \\
53 \\
42 \\
50\end{array}$ & $\begin{array}{l}07 \\
04 \\
13 \\
00 \\
58\end{array}$ \\
\hline $\begin{array}{l}111 \\
112 \\
113 \\
114 \\
115\end{array}$ & $\begin{array}{l}{ }^{*} \Xi \\
{ }^{*} \rho \\
{ }^{*} H \\
{ }^{*} \\
{ }_{l}\end{array}$ & $\begin{array}{r}\overline{1} 34 \\
\overline{1399} \\
\overline{1} .3 .12 \\
\overline{1} .3 .15 \\
\overline{1} .6 .12\end{array}$ & $\begin{array}{l}\overline{3} 34 \\
\overline{1} 13 \\
114 \\
\overline{1} 15 \\
\overline{1} 24\end{array}$ & $\begin{array}{r}26 \\
13 \\
5 \\
2 \\
2\end{array}$ & $\begin{array}{l}15 \\
15 \\
21 \\
23 \\
40\end{array}$ & $\begin{array}{l}59 \\
34 \\
26 \\
22 \\
45\end{array}$ & $\begin{array}{l}33 \\
49 \\
00 \\
11 \\
26\end{array}$ & $\begin{array}{r}24 \\
13 \\
5 \\
2 \\
2\end{array}$ & $\begin{array}{l}54 \\
11 \\
29 \\
25 \\
45\end{array}$ & $\begin{array}{l}59 \\
34 \\
26 \\
22 \\
45\end{array}$ & $\begin{array}{l}09 \\
44 \\
57 \\
04 \\
23\end{array}$ \\
\hline $\begin{array}{l}116 \\
117 \\
118 \\
119 \\
120\end{array}$ & $\begin{array}{l}{ }^{*} I \\
{ }^{*} J \\
{ }^{*} K \\
{ }^{*} \mu \\
{ }^{*} \mathrm{mt}\end{array}$ & $\begin{array}{r}\overline{193} \\
\overline{2} .1 .15 \\
\overline{2} 31 \\
\overline{2} 32 \\
\overline{2} 35\end{array}$ & $\begin{array}{r}\overline{131} \\
\overline{6} .15 \\
\overline{6} 31 \\
\overline{6} 32 \\
\overline{6} 35\end{array}$ & $\begin{array}{r}9 \\
61 \\
51 \\
50 \\
46\end{array}$ & $\begin{array}{l}38 \\
55 \\
26 \\
20 \\
56\end{array}$ & $\begin{array}{l}80 \\
15 \\
84 \\
77 \\
60\end{array}$ & $\begin{array}{l}46 \\
46 \\
14 \\
33 \\
42\end{array}$ & $\begin{array}{r}9 \\
61 \\
51 \\
50 \\
46\end{array}$ & $\begin{array}{l}39 \\
12 \\
18 \\
18 \\
47\end{array}$ & $\begin{array}{l}80 \\
15 \\
84 \\
78 \\
60\end{array}$ & $\begin{array}{l}47 \\
39 \\
07 \\
07 \\
35\end{array}$ \\
\hline $\begin{array}{l}121 \\
122 \\
123 \\
124 \\
125\end{array}$ & $\begin{array}{l}* \Omega \\
* \xi \\
* t \\
* u \\
* A\end{array}$ & $\begin{array}{r}\overline{2} 36 \\
\overline{2} 39 \\
\overline{2} .3 .15 \\
\overline{2} .3 .18 \\
\overline{2} .3 .21\end{array}$ & $\begin{array}{l}\overline{2} 12 \\
\overline{2} 13 \\
\overline{2} 15 \\
\overline{2} 16 \\
\overline{2} 17\end{array}$ & $\begin{array}{l}45 \\
41 \\
31 \\
24 \\
17\end{array}$ & $\begin{array}{l}44 \\
27 \\
11 \\
54 \\
52\end{array}$ & $\begin{array}{l}55 \\
41 \\
25 \\
19 \\
16\end{array}$ & $\begin{array}{l}21 \\
58 \\
21 \\
52 \\
53\end{array}$ & $\begin{array}{l}45 \\
41 \\
31 \\
25 \\
18\end{array}$ & $\begin{array}{l}35 \\
26 \\
14 \\
05 \\
16\end{array}$ & $\begin{array}{l}55 \\
41 \\
25 \\
20 \\
16\end{array}$ & $\begin{array}{l}20 \\
59 \\
20 \\
26 \\
56\end{array}$ \\
\hline $\begin{array}{l}126 \\
127 \\
128 \\
129 \\
130\end{array}$ & $\begin{array}{l}{ }^{*} C \\
{ }^{*} \text { 面 } \\
{ }^{*} \text { A } \\
\text { *正 } \\
{ }^{*} E\end{array}$ & $\begin{array}{r}\overline{439} \\
\overline{4} .3 .15 \\
\overline{4} .3 .33 \\
\overline{4} .9 .15 \\
\overline{5} 39\end{array}$ & $\begin{array}{r}\overline{4} 13 \\
\overline{4} 15 \\
\overline{4} .1 .11 \\
\overline{4} 35 \\
\overline{5} 13\end{array}$ & $\begin{array}{l}65 \\
62 \\
47 \\
32 \\
70\end{array}$ & $\begin{array}{l}22 \\
26 \\
21 \\
37 \\
29\end{array}$ & $\begin{array}{l}58 \\
41 \\
15 \\
55 \\
63\end{array}$ & $\begin{array}{l}17 \\
06 \\
07 \\
17 \\
41\end{array}$ & $\begin{array}{l}65 \\
62 \\
47 \\
33 \\
70\end{array}$ & $\begin{array}{l}21 \\
17 \\
03 \\
20 \\
31\end{array}$ & $\begin{array}{l}58 \\
41 \\
15 \\
55 \\
63\end{array}$ & $\begin{array}{l}17 \\
03 \\
07 \\
29 \\
45\end{array}$ \\
\hline $\begin{array}{l}131 \\
132 \\
133 \\
134\end{array}$ & 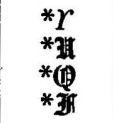 & $\begin{array}{l}\overline{5} .3 .15 \\
\overline{5} .3 .27 \\
\overline{5} .6 .12 \\
\overline{8} .3 .12\end{array}$ & $\begin{array}{l}\overline{5} 15 \\
\overline{5} 19 \\
\overline{5} 24 \\
\overline{8} 14\end{array}$ & $\begin{array}{l}68 \\
63 \\
53 \\
77\end{array}$ & $\begin{array}{l}30 \\
39 \\
19 \\
42\end{array}$ & $\begin{array}{l}47 \\
26 \\
59 \\
67\end{array}$ & $\begin{array}{l}57 \\
35 \\
31 \\
30\end{array}$ & $\begin{array}{l}68 \\
63 \\
53 \\
77\end{array}$ & $\begin{array}{l}36 \\
21 \\
22 \\
48\end{array}$ & $\begin{array}{l}47 \\
26 \\
59 \\
67\end{array}$ & $\begin{array}{l}59 \\
38 \\
29 \\
20\end{array}$ \\
\hline
\end{tabular}


As with montroydite, the forms of terlinguaite are divided into three classes, according to their prominence. In the first class are the common forms which are present on most of the crystals measured, and probably would have been found on all had the crystals been complete.

DESCRIPTION OF COMMON FORMS.

Moses described two domes, $m\{\overline{5} 08\}$ and $x\{\overline{7} .0 .10\}$, which have been combined into the simpler form $x\{\overline{2} 03\}$. Neither $\{\overline{5} 08\}$ nor $\{\overline{7} .0 .10\}$ was found by the writer. Both these forms were described as large faces, and as the form system of terlinguaite shows that most of its forms have simple indices it seems improbable that "large faces" would have such complex symbols as were ascribed to $m$ and $x$. These symbols become still more complex and also decidedly vicinal if they be changed from the orientation $\mathrm{M}_{1}$ (as given above) to the correct one $\mathrm{M}_{2}$, which results in simplifying the symbols of the different forms. The two forms then become $m\{\overline{1} \overline{5} .0 .8\}$ and $x\{\overline{21} .0 .10\}$, which are decidedly vicinal to $\{\overline{2} 01\} \mathrm{M}_{2}$ or $\{\overline{2} 03\} \mathrm{M}_{1}$. The form $\{\overline{2} 01\} \mathbf{M}_{2}$, not noted by Moses, is a common form for terlinguaite, and is present on many crystals. The letter $x$ is retained for this simpler form, while $m$ is placed with the unit prism where it belongs. Five other forms have had their indices changed to simpler ones, as some of the symbols given by Moses are very complex and vicinal.

$r\{11.25 .25\}$ as given by Moses becomes $\{33.25 .25\}$ when changed to the simpler orientation. This form reduces to $\{499\} M_{1}$ or $\{433\} M_{2}$, and in fact the angles measured by Moses agree better with the simpler form than they do with the complex one. The form is a prominent one, occurring on six crystals.

Angle values for $r\{433\} M_{2}$.

\begin{tabular}{|c|c|c|}
\hline & $\phi$ & $\rho$ \\
\hline & $\circ$ & $\circ$ \\
\hline $\begin{array}{l}\text { Meas. by Moses........ } \\
\text { Calc. }\{433\} \mathrm{M}_{2} \ldots \ldots \ldots .\end{array}$ & $\begin{array}{ll}45 & 08 \\
45 & 00\end{array}$ & $\begin{array}{ll}70 & 58 \\
70 & 45\end{array}$ \\
\hline
\end{tabular}

$i\{7.11 .11\}$ becomes $\{21.11 .11\}$ in the better orientation. This reduces to $\{233\} \mathrm{M}_{1}$ or $\{211\} \mathrm{M}_{2}$.

Angle values for $i\{211\} M_{2}$.

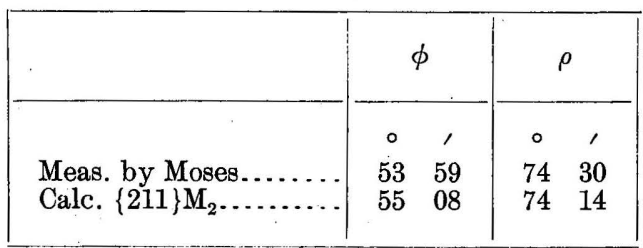


The form is a prominent one, being present on nine crystals.

$l\{\overline{1} 1.25 .25\}$ as given by Moses becomes in $\mathrm{M}_{2}\{\overline{33} .25 .25\}$, which reduces to $\{\overline{4} 99\} M_{1}$ or $\left\{\overline{4}_{33}\right\} \mathbf{M}_{2}$. This form is described as a large striated face, and as found by the writer is a prominent form for this mineral, being seen on eight crystals.

Angle values for $l\{\overline{4} 33\} M_{2}$.

\begin{tabular}{|c|c|c|}
\hline & $\phi$ & $\rho$ \\
\hline $\begin{array}{l}\text { Meas. by Moses } \\
\text { Calc. }\left\{\frac{433\} M_{2} .}{}\right.\end{array}$ & $\begin{array}{cc}\circ & 1 \\
36 & 12 \\
36 & 00\end{array}$ & $\begin{array}{cc}\circ & 1 \\
68 & 22 \\
68 & 13\end{array}$ \\
\hline
\end{tabular}

$g\{\overline{1} \overline{3} .20 .20\}$ as given by Moses becomes $\{\overline{3} \overline{9} .20 .20\}$ in $\mathrm{M}_{2}$, which plainly shows that the correct symbol is $\{\overline{2} 33\} \mathrm{M}_{1}$ or $\{\overline{2} 11\} \mathrm{M}_{2}$. The form, as illustrated by Moses, is the largest pyramid fące on the crystal, and as such would hardly have the symbol $\{\overline{39} .20 .20\}$.

Angle values for $g\{\bar{Q} 11\} M_{2}$.

\begin{tabular}{|c|c|c|}
\hline & $\phi$ & $\rho$ \\
\hline & $\circ$ & $\circ$ \\
\hline $\begin{array}{l}\text { Meas. by Moses......... } \\
\text { Calc. }\{211\} M_{2} \ldots \ldots \ldots\end{array}$ & $\begin{array}{ll}48 & 37 \\
49 & 12\end{array}$ & $\begin{array}{ll}72 & 02 \\
72 & 07\end{array}$ \\
\hline
\end{tabular}

It is a prominent form, 22 faces having been measured by the writer. $\gamma\{\overline{9} 77\}$ as given by Moses becomes $\{\overline{2} \overline{7} .7 .7\} \mathrm{M}_{2}$, which reduces to $\{\overline{4} 33\} \mathbf{M}_{1}$ or $\{\overline{4} 11\} \mathbf{M}_{2}$. It is also described as a prominent form for the mineral, and was noticed on 11 crystals.

Angle values for $r\{\overline{4} 11\} M_{2}$.

\begin{tabular}{|c|c|c|c|}
\hline & $\phi$ & \multicolumn{2}{|c|}{$\rho$} \\
\hline & $\circ$ & $\circ$ & , \\
\hline Meas. by Moses.... . . . . & 67 & 79 & 28 \\
\hline Calc. $\{411\} M_{2} \ldots \ldots \ldots$ & $67 \quad 50$ & 79 & 27 \\
\hline
\end{tabular}

The first table below, giving the most common forms, shows only such as were measured at least 10 times - that is, at least 10 different faces of the form were seen on the 12 crystals measured.

4494-Bull. 405-09-7 
MERCURY MINERALS FROM TERLINGUA, TEXAS.

Measurements of common forms on terlinguaite rrystals.

\begin{tabular}{|c|c|c|c|c|c|c|c|c|c|c|c|c|}
\hline \multirow[t]{2}{*}{$\begin{array}{l}\text { Let- } \\
\text { ter. }\end{array}$} & \multicolumn{2}{|c|}{ Symbol. } & \multirow{2}{*}{ 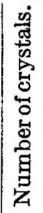 } & \multirow{2}{*}{ 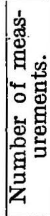 } & \multicolumn{2}{|c|}{$\begin{array}{l}\text { A verage meas- } \\
\text { ured. }\end{array}$} & \multicolumn{2}{|c|}{ Calculated. } & \multicolumn{2}{|c|}{$\begin{array}{c}\text { Number } \\
\text { meas:- } \\
\text { ured } \\
\text { within } \\
5^{\prime} .\end{array}$} & \multicolumn{2}{|c|}{ Limits of measurement. } \\
\hline & $\mathbf{M}_{1}$ & $\mathbf{M}_{2}$ & & & $\phi$ & $\rho$ & $\phi$ & $\rho$ & $\phi$ & $\rho^{\circ}$ & $\phi$ & $\rho$ \\
\hline $\begin{array}{r}*_{j} \\
m \\
*_{\delta} \\
* D \\
d\end{array}$ & $\begin{array}{l}160 \\
130 \\
230 \\
031 \\
011\end{array}$ & $\begin{array}{l}120 \\
110 \\
210 \\
031 \\
011\end{array}$ & $\begin{array}{r}10 \\
10 \\
10 \\
8 \\
12\end{array}$ & $\begin{array}{l}21 \\
19 \\
17 \\
13 \\
23\end{array}$ & \begin{tabular}{rc}
\multicolumn{1}{c}{} &, \\
17 & 58 \\
32 & 57 \\
52 & 31 \\
2 & 38 \\
7 & 52
\end{tabular} & $\begin{array}{cc}\circ & , \\
90 & 00 \\
90 & 00 \\
90 & 00 \\
80 & 39 \\
63 & 56\end{array}$ & \begin{tabular}{rc}
$\circ$ & \multicolumn{1}{c}{} \\
17 & 58 \\
32 & 58 \\
52 & 22 \\
2 & 38 \\
7 & 52
\end{tabular} & $\begin{array}{cc}\circ & , \\
90 & 00 \\
90 & 00 \\
90 & 00 \\
80 & 40 \\
63 & 56\end{array}$ & $\begin{array}{r}14 \\
11 \\
7 \\
10 \\
15\end{array}$ & $\begin{array}{c}\cdots . \\
\cdots \\
\cdots 9 \\
17\end{array}$ & $\begin{array}{rcc}\circ & \\
17 & 31-18 & 43 \\
32 & 48-33 & 16 \\
52 & 10-52 & 57 \\
2 & 22-2 & 48 \\
7 & 23-8 & 03\end{array}$ & 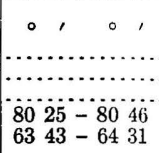 \\
\hline $\begin{array}{r}f \\
h \\
* t \\
* L \\
n\end{array}$ & $\begin{array}{r}013 \\
015 \\
106 \\
\text { I. } 0.12 \\
\overline{1} 06\end{array}$ & $\begin{array}{l}013 \\
015 \\
102 \\
\overline{1} 04 \\
\overline{1} 02\end{array}$ & $\begin{array}{r}8 \\
10 \\
10 \\
9 \\
11\end{array}$ & $\begin{array}{l}16 \\
19 \\
19 \\
10 \\
13\end{array}$ & $\begin{array}{ll}22 & 31 \\
34 & 36 \\
90 & 00 \\
90 & 00 \\
90 & 00\end{array}$ & $\begin{array}{rr}36 & 10 \\
26 & 12 \\
43 & 05 \\
2 & 40 \\
20 & 35\end{array}$ & $\begin{array}{ll}22 & 30 \\
34 & 37 \\
90 & 00 \\
90 & 00 \\
90 & 00\end{array}$ & $\begin{array}{rr}36 & 09 \\
26 & 12 \\
43 & 06 \\
2 & 13 \\
20 & 39\end{array}$ & $\begin{array}{r}7 \\
6 \\
\cdots . . \\
\cdots \\
\cdots .\end{array}$ & $\begin{array}{r}10 \\
11 \\
15 \\
1 \\
7\end{array}$ & 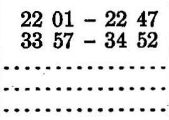 & 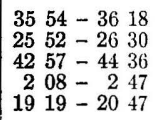 \\
\hline $\begin{array}{r}u \\
* Q \\
*_{x} \\
s \\
a\end{array}$ & $\begin{array}{l}\overline{1} 03 \\
\overline{1} 02 \\
\overline{2} 03 \\
111 \\
\overline{1} 113\end{array}$ & $\begin{array}{l}\overline{1} 01 \\
\overline{3} 02 \\
\overline{2} 01 \\
311 \\
\overline{3} 13\end{array}$ & $\begin{array}{r}11 \\
10 \\
10 \\
9 \\
9\end{array}$ & $\begin{array}{l}18 \\
13 \\
12 \\
10 \\
12\end{array}$ & $\begin{array}{ll}90 & 00 \\
90 & 00 \\
90 & 00 \\
64 & 22 \\
56 & 55\end{array}$ & $\begin{array}{ll}45 & 52 \\
59 & 21 \\
66 & 52 \\
77 & 56 \\
50 & 56\end{array}$ & $\begin{array}{ll}90 & 00 \\
90 & 00 \\
90 & 00 \\
64 & 22 \\
56 & 51\end{array}$ & $\begin{array}{ll}45 & 56 \\
59 & 23 \\
66 & 55 \\
77 & 56 \\
50 & 59\end{array}$ & $\begin{array}{l}\cdots \\
\cdots \\
\cdots 7 \\
6\end{array}$ & $\begin{array}{l}9 \\
6 \\
6 \\
9 \\
4\end{array}$ & $\begin{array}{l}6415-6434 \\
5644-5821\end{array}$ & $\begin{array}{lll}45 & 38-46 & 35 \\
59 & 06-59 & 31 \\
66 & 16-67 & 06 \\
77 & 49-78 & 00 \\
50 & 28-51 & 11\end{array}$ \\
\hline $\begin{array}{r}i \\
*_{\varepsilon} \\
* Z \\
p \\
i\end{array}$ & $\begin{array}{l}111 \\
199 \\
166 \\
133 \\
233\end{array}$ & $\begin{array}{l}\overline{3} 11 \\
133 \\
122 \\
111 \\
211\end{array}$ & $\begin{array}{r}10 \\
10 \\
11 \\
12 \\
9\end{array}$ & $\begin{array}{l}14 \\
15 \\
15 \\
23 \\
11\end{array}$ & $\begin{array}{ll}61 & 06 \\
19 & 31 \\
24 & 48 \\
38 & 09 \\
55 & 07\end{array}$ & $\begin{array}{ll}76 & 35 \\
65 & 01 \\
65 & 51 \\
68 & 47 \\
74 & 13\end{array}$ & $\begin{array}{ll}61 & 02 \\
19 & 30 \\
24 & 49 \\
38 & 11 \\
55 & 08\end{array}$ & $\begin{array}{ll}76 & 33 \\
65 & 02 \\
65 & 51 \\
68 & 47 \\
74 & 14\end{array}$ & $\begin{array}{r}10 \\
10 \\
5 \\
9 \\
5\end{array}$ & $\begin{array}{r}8 \\
11 \\
8 \\
14 \\
7\end{array}$ & $\begin{array}{llll}60 & 58-61 & 18 \\
18 & 06 & -19 & 42 \\
24 & 21 & -25 & 13 \\
36 & 25 & -38 & 29 \\
54 & 58 & -55 & 22\end{array}$ & $\begin{array}{lll}76 & 23-76 & 56 \\
64 & 44-65 & 10 \\
65 & 26-65 & 57 \\
67 & 46-68 & 54 \\
74 & 03-74 & 24\end{array}$ \\
\hline $\begin{array}{r}* X \\
* \psi \\
* y \\
e \\
l\end{array}$ & $\begin{array}{l}\overline{1} 99 \\
\mathbf{1} 66 \\
\overline{2} 99 \\
\overline{1} 33 \\
\overline{4} 99\end{array}$ & $\begin{array}{l}\overline{1} 33 \\
\overline{1} 22 \\
\overline{2} 33 \\
\overline{1} 11 \\
\overline{4} 33\end{array}$ & $\begin{array}{r}7 \\
10 \\
8 \\
10 . \\
8\end{array}$ & $\begin{array}{l}10 \\
12 \\
13 \\
20 \\
14\end{array}$ & 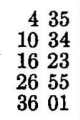 & $\begin{array}{ll}63 & 46 \\
64 & 04 \\
64 & 37 \\
66 & 17 \\
68 & 11\end{array}$ & $\begin{array}{rl}4 & 28 \\
10 & 33 \\
16 & 23 \\
27 & 02 \\
36 & 00\end{array}$ & $\begin{array}{ll}63 & 47 \\
64 & 06 \\
64 & 39 \\
66 & 15 \\
68 & 13\end{array}$ & $\begin{array}{l}1 \\
4 \\
4 \\
9 \\
8\end{array}$ & $\begin{array}{r}6 \\
4 \\
6 \\
10 \\
9\end{array}$ & $\begin{array}{r}408-451 \\
1006-1055 \\
1600-1635 \\
2631=2756 \\
3554-3622\end{array}$ & 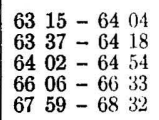 \\
\hline $\begin{array}{r}g \\
\gamma \\
\pi \\
\pi \\
\lambda\end{array}$ & $\begin{array}{r}\overline{2} 33 \\
\overline{433} \\
136 \\
139 \\
1.3 .15\end{array}$ & $\begin{array}{l}\overline{2} 11 \\
411 \\
112 \\
113 \\
115\end{array}$ & $\begin{array}{r}11 \\
10 \\
8 \\
11 \\
6\end{array}$ & $\begin{array}{l}22 \\
14 \\
11 \\
17 \\
10\end{array}$ & $\begin{array}{ll}49 & 13 \\
67 & 52 \\
42 & 40 \\
46 & 42 \\
53 & 15\end{array}$ & $\begin{array}{ll}72 & 08 \\
79 & 29 \\
53 & 59 \\
44 & 34 \\
34 & 05\end{array}$ & $\begin{array}{ll}49 & 12 \\
67 & 50 \\
42 & 45 \\
46 & 44 \\
53 & 15\end{array}$ & $\begin{array}{ll}72 & 07 \\
79 & 27 \\
54 & 02 \\
44 & 33 \\
34 & 05\end{array}$ & $\begin{array}{r}12 \\
4 \\
6 \\
10 \\
4\end{array}$ & $\begin{array}{l}9 \\
6 \\
6 \\
9 \\
7\end{array}$ & $\begin{array}{lll}48 & 51-49 & 38 \\
67 & 39-68 & 08 \\
42 & 33-42 & 48 \\
46 & 29-46 & 54 \\
52 & 45-53 & 57\end{array}$ & 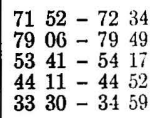 \\
\hline $\begin{array}{r}* T \\
\beta \\
* I \\
* A\end{array}$ & $\begin{array}{r}239 \\
\overline{1} .315 \\
\overline{1} 93 \\
\overline{2} .3 .21\end{array}$ & $\begin{array}{l}213 \\
\overline{1} 15 \\
\frac{1}{2} 31 \\
217\end{array}$ & $\begin{array}{l}7 \\
9 \\
6 \\
6\end{array}$ & $\begin{array}{l}10 \\
12 \\
12 \\
14\end{array}$ & $\begin{array}{rr}59 & 38 \\
2 & 23 \\
9 & 38 \\
17 & 52\end{array}$ & $\begin{array}{ll}53 & 15 \\
22 & 11 \\
80 & 46 \\
16 & 53\end{array}$ & $\begin{array}{rl}59 & 42 \\
2 & 25 \\
9 & 39 \\
18 & 16\end{array}$ & $\begin{array}{ll}53 & 13 \\
22 & 04 \\
80 & 47 \\
16 & 56\end{array}$ & $\begin{array}{l}6 \\
3 \\
7 \\
0\end{array}$ & $\begin{array}{l}4 \\
5 \\
6 \\
6\end{array}$ & $\begin{array}{rrrr}58 & 58-60 & 11 \\
1 & 02-3 & 52 \\
9 & 26-11 & 24 \\
15 & 52-20 & 04\end{array}$ & $\begin{array}{lll}52 & 41-53 & 28 \\
21 & 23-23 & 51 \\
79 & 11-80 & 53 \\
16 & 10-17 & 14\end{array}$ \\
\hline
\end{tabular}

DESCRIPTION OF LESS COMMON FORMS.

In the following table are given the data for the forms that showed less than 10 faces but more than 2. . With these, however, are included the measurements of those forms determined by Moses, to which he gave rather complex symbols. 
Occurrence and measurements of less common forms on terlinguaite crystals.

[Bold-faced figures show calculated values. Stars indicate new forms.]

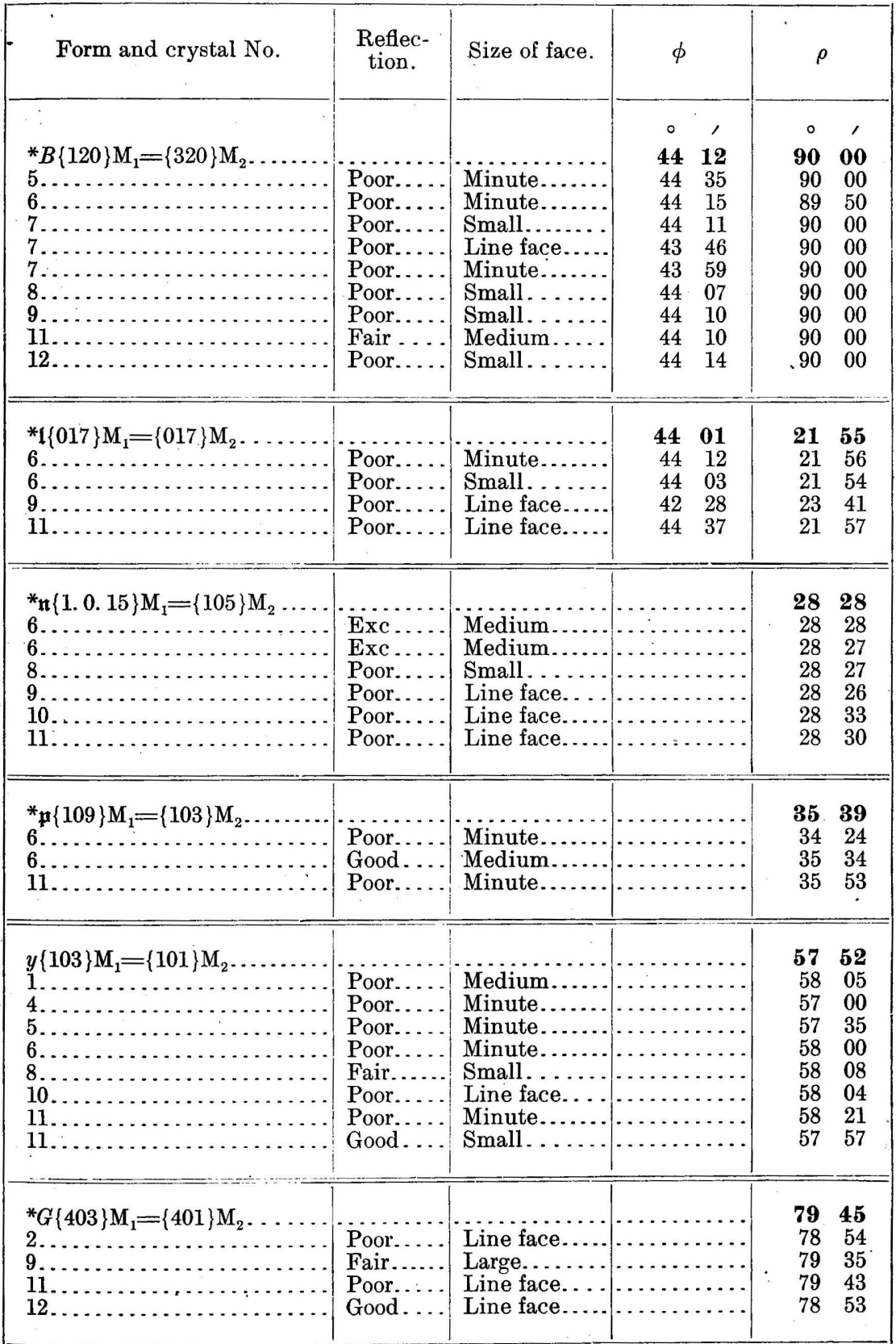


Occurrence and measurements of less common forms on terlinguaite crystals-Continued.

\begin{tabular}{|c|c|c|c|c|c|}
\hline Form and crystal No. & $\begin{array}{c}\text { Reflec- } \\
\text { tion. }\end{array}$ & Size of face. & $\phi$ & $\rho$ & \\
\hline 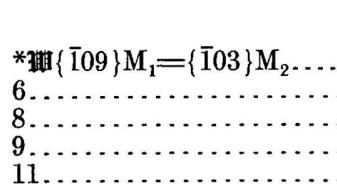 & $\begin{array}{l}\text { Poor... } \\
\text { Poor... } \\
\text { Poor... } \\
\text { Poor... }\end{array}$ & $\begin{array}{l}\text { Line face... } \\
\text { Small..... } \\
\text { Line face... } \\
\text { Minute.... }\end{array}$ & 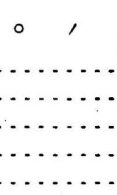 & $\begin{array}{l}\circ \\
8 \\
8 \\
8 \\
8 \\
8\end{array}$ & $\begin{array}{l}1 \\
\mathbf{5 9} \\
46 \\
54 \\
32 \\
55\end{array}$ \\
\hline 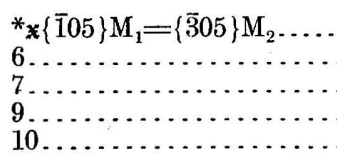 & $\begin{array}{l}\text { Poor... } \\
\text { Poor... } \\
\text { Poor... } \\
\text { Poor... }\end{array}$ & $\begin{array}{l}\text { Minute...... } \\
\text { Minute...... } \\
\text { Line face... } \\
\text { Line face... }\end{array}$ & & $\begin{array}{l}\mathbf{2 6} \\
26 \\
26 \\
26 \\
26\end{array}$ & $\begin{array}{l}\mathbf{5 6} \\
44 \\
54 \\
44 \\
38\end{array}$ \\
\hline 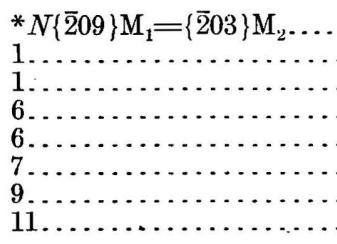 & $\begin{array}{l}\text { Good.. } \\
\text { Poor... } \\
\text { Poor... } \\
\text { Poor... } \\
\text { Fair.... } \\
\text { Good.. } \\
\text { Poor... }\end{array}$ & $\begin{array}{l}\text { Medium..... } \\
\text { Medium ..... } \\
\text { Line face.... } \\
\text { Line face... } \\
\text { Small...... } \\
\text { Small........ } \\
\text { Line face.... }\end{array}$ & & $\begin{array}{r}30 \\
30 \\
30 \\
30 \\
30 \\
31 \\
30 \\
30\end{array}$ & $\begin{array}{l}47 \\
36 \\
45 \\
45 \\
48 \\
05 \\
41 \\
42\end{array}$ \\
\hline 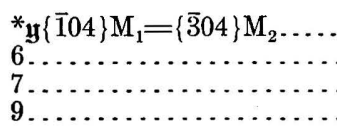 & $\begin{array}{l}\text { Poor... } \\
\text { Poor... } \\
\text { Poor... }\end{array}$ & $\begin{array}{l}\text { Minute.... } \\
\text { Small. .... } \\
\text { Line face... }\end{array}$ & & $\begin{array}{r}35 \\
35 \\
35 \\
35\end{array}$ & $\begin{array}{l}\mathbf{1 1} \\
09 \\
09 \\
04\end{array}$ \\
\hline $\begin{array}{l}{ }^{*} \Pi\{\overline{2} 05\} \mathrm{M}_{1}=\left\{\overline{6}_{05}\right\} \mathrm{M}_{2} \ldots \\
4 \ldots \\
6 \ldots \\
9 \ldots \ldots\end{array}$ & $\begin{array}{l}\text { Poor... } \\
\text { Fair.... } \\
\text { Good... } \\
\text { Poor... }\end{array}$ & $\begin{array}{l}\text { Line face... } \\
\text { Line face... } \\
\text { Line face... } \\
\text { Minute..... }\end{array}$ & & $\begin{array}{l}\mathbf{5 2} \\
52 \\
53 \\
52 \\
51\end{array}$ & $\begin{array}{l}\mathbf{2 0} \\
14 \\
08 \\
19 \\
26\end{array}$ \\
\hline $\begin{array}{l}{ }^{*} P\{\overline{4} 09\} \mathrm{M}_{1}=\{\overline{4} 03\} \mathrm{M}_{2} \ldots \\
1 \ldots \ldots+\cdots \\
6 \ldots \ldots+\cdots \\
10 \ldots \cdots \cdots\end{array}$ & $\begin{array}{l}\text { Poor... } \\
\text { Poor.... } \\
\text { Poor.... }\end{array}$ & $\begin{array}{l}\text { Line face... } \\
\text { Minute..... } \\
\text { Line face... }\end{array}$ & & $\begin{array}{r}\mathbf{5 5} \\
55 \\
55 \\
55\end{array}$ & $\begin{array}{l}47 \\
44 \\
45 \\
50\end{array}$ \\
\hline 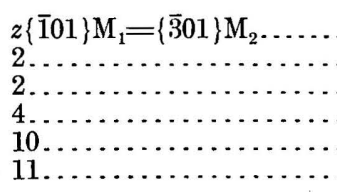 & $\begin{array}{l}\text { Fair.... } \\
\text { Fair..... } \\
\text { Fair.... } \\
\text { Pooor.... } \\
\text { Poor.... }\end{array}$ & $\begin{array}{l}\text { Minute...... } \\
\text { Minute...... } \\
\text { Minute..... } \\
\text { Small..... } \\
\text { Minute...... }\end{array}$ & & $\begin{array}{l}74 \\
74 \\
74 \\
74 \\
73 \\
75\end{array}$ & $\begin{array}{l}43 \\
49 \\
53 \\
37 \\
11 \\
34\end{array}$ \\
\hline 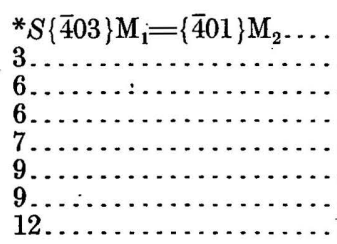 & $\begin{array}{l}\text { Poor.... } \\
\text { Poor.... } \\
\text { Fair.... } \\
\text { Poor.... } \\
\text { Fair..... } \\
\text { Fair.... } \\
\text { Good... }\end{array}$ & $\begin{array}{l}\text { Line face... } \\
\text { Minute..... } \\
\text { Small..... } \\
\text { Medium.... } \\
\text { Line face... } \\
\text { Small. . . . } \\
\text { Small. . . . }\end{array}$ & & $\begin{array}{l}78 \\
77 \\
78 \\
78 \\
78 \\
79 \\
79 \\
78\end{array}$ & $\begin{array}{l}38 \\
56 \\
51 \\
33 \\
39 \\
45 \\
45 \\
53\end{array}$ \\
\hline
\end{tabular}


Occurrence and measurements of less common forms on terlinguaite crystals—Continued.

\begin{tabular}{|c|c|c|c|c|c|c|}
\hline Form and crystal No. & $\begin{array}{l}\text { Reflec- } \\
\text { tion. }\end{array}$ & Size of face. & $\phi$ & & $\rho$ & \\
\hline 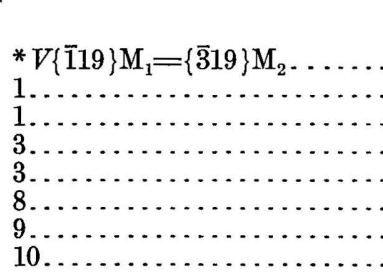 & $\begin{array}{l}\text { Poor.... } \\
\text { Fair..... } \\
\text { Poor.... } \\
\text { Fair..... } \\
\text { Poor.... } \\
\text { Poor.... } \\
\text { Good... }\end{array}$ & $\begin{array}{l}\text { Minute....... } \\
\text { Minute........ } \\
\text { Small....... } \\
\text { Line face..... } \\
\text { Line face..... } \\
\text { Line face..... } \\
\text { Medium...... }\end{array}$ & $\begin{array}{cc}\circ & \\
\mathbf{3 5} & \mathbf{0} \\
33 & 5 \\
34 & \vdots \\
36 & \\
35 & \\
36 & \\
35 & \\
34 & \end{array}$ & $\begin{array}{l}1 \\
\mathbf{0 5} \\
59 \\
56 \\
26 \\
42 \\
52 \\
09 \\
25\end{array}$ & $\begin{array}{l}\circ \\
\mathbf{1 5} \\
15 \\
15 \\
15 \\
15 \\
15 \\
15 \\
15\end{array}$ & $\begin{array}{l}\prime \\
\mathbf{2 2} \\
14 \\
21 \\
02 \\
20 \\
40 \\
24 \\
11\end{array}$ \\
\hline 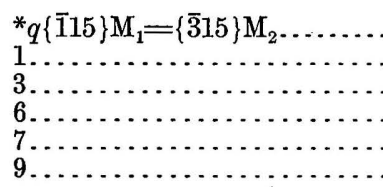 & $\begin{array}{l}\text { Fair..... } \\
\text { Fair..... } \\
\text { Poor.... } \\
\text { Poor.... } \\
\text { Poor.... }\end{array}$ & $\begin{array}{l}\text { Small } . . . . \\
\text { Small . . . . } \\
\text { Small. . . . } \\
\text { Minute..... } \\
\text { Minute...... }\end{array}$ & $\begin{array}{l}\mathbf{5 1} \\
51 \\
51 \\
51 \\
51 \\
51\end{array}$ & $\begin{array}{l}27 \\
25 \\
35 \\
33 \\
30 \\
39\end{array}$ & $\begin{array}{r}33 \\
32 \\
32 \\
32 \\
33 \\
33\end{array}$ & $\begin{array}{l}\mathbf{0 1} \\
59 \\
56 \\
59 \\
01 \\
00\end{array}$ \\
\hline $\begin{array}{l}{ }^{*}\left(\mathfrak{G}\{1.30 .30\} \mathrm{M}_{1}=\{1.10 .10\} \mathrm{M}_{2}\right. \\
6 \ldots \ldots \\
6 \ldots \ldots \ldots \\
6 \ldots \ldots \ldots \ldots \\
7 \ldots \ldots \ldots \ldots\end{array}$ & $\begin{array}{l}\text { Poor.... } \\
\text { Poor... } \\
\text { Poor... } \\
\text { Poor... }\end{array}$ & $\begin{array}{l}\text { Line face... } \\
\text { Line face.... } \\
\text { Line face.... } \\
\text { Line face.... }\end{array}$ & $\begin{array}{l}11 \\
11 \\
11 \\
11 \\
11\end{array}$ & $\begin{array}{l}28 \\
33 \\
35 \\
14 \\
36\end{array}$ & $\begin{array}{l}\mathbf{6 4} \\
64 \\
64 \\
63 \\
64\end{array}$ & $\begin{array}{l}\mathbf{1 0} \\
09 \\
06 \\
53 \\
27\end{array}$ \\
\hline 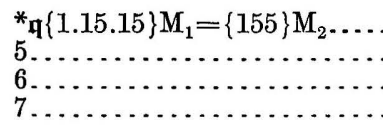 & $\begin{array}{l}\text { Fair..... } \\
\text { Poor.... } \\
\text { Poor.... }\end{array}$ & $\begin{array}{l}\text { Line face.... } \\
\text { Line face.... } \\
\text { Line face.... }\end{array}$ & $\begin{array}{l}15 \\
15 \\
14 \\
15\end{array}$ & $\begin{array}{l}\mathbf{0 0} \\
03 \\
12 \\
22\end{array}$ & $\begin{array}{l}\mathbf{6 4} \\
64 \\
64 \\
64\end{array}$ & $\begin{array}{r}\mathbf{3 0} \\
30 \\
27 \\
42\end{array}$ \\
\hline $\begin{array}{l}{ }^{*}{ }_{1}\{1.12 .12\} \mathrm{M}_{1}=\{144\} \mathrm{M}_{2} \ldots \\
6{ }_{6} \ldots \\
6 \ldots \\
6 \ldots \ldots \\
6 \ldots \ldots \\
11 \ldots \ldots\end{array}$ & $\begin{array}{l}\text { Good... } \\
\text { Fair.... } \\
\text { Fair..... } \\
\text { Fair.... } \\
\text { Poor... } \\
\text { Poor.... }\end{array}$ & $\begin{array}{l}\text { Medium ..... } \\
\text { Medium ..... } \\
\text { Small......... } \\
\text { Small........ } \\
\text { Line face.... } \\
\text { Small ........ }\end{array}$ & $\begin{array}{l}16 \\
16 \\
16 \\
16 \\
16 \\
16 \\
17\end{array}$ & $\begin{array}{l}43 \\
46 \\
43 \\
41 \\
44 \\
39 \\
01\end{array}$ & $\begin{array}{l}64 \\
64 \\
64 \\
64 \\
64 \\
64 \\
64\end{array}$ & $\begin{array}{l}\mathbf{4 1} \\
34 \\
42 \\
46 \\
37 \\
40 \\
45\end{array}$ \\
\hline $\begin{array}{l}{ }^{*} Y\{299\} \mathrm{M}_{1}=\{233\} \mathrm{M}_{2} \ldots \\
1 \\
1 \\
3 \\
4 \\
6 \ldots \\
6 \ldots \\
12 \ldots\end{array}$ & $\begin{array}{l}\text { Poor.... } \\
\text { Exc .... } \\
\text { Fair..... } \\
\text { Poor.... } \\
\text { Poor.... } \\
\text { Poor.... }\end{array}$ & $\begin{array}{l}\text { Minute...... } \\
\text { Minute...... } \\
\text { Minute....... } \\
\text { Minute...... } \\
\text { Minute...... } \\
\text { Line face.... }\end{array}$ & $\begin{array}{r}\mathbf{2 9} \\
29 \\
29 \\
29 \\
29 \\
29 \\
29\end{array}$ & $\begin{array}{l}\mathbf{4 2} \\
11 \\
41 \\
43 \\
40 \\
30 \\
25\end{array}$ & $\begin{array}{l}\mathbf{6 6} \\
66 \\
66 \\
66 \\
66 \\
66 \\
66\end{array}$ & $\begin{array}{l}\mathbf{4 7} \\
50 \\
51 \\
44 \\
46 \\
33 \\
36\end{array}$ \\
\hline 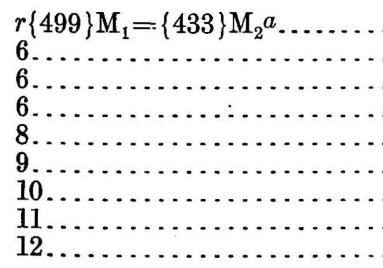 & $\begin{array}{l}\text { Poor.... } \\
\text { Poor.... } \\
\text { Fair..... } \\
\text { Fair..... } \\
\text { Poor... } \\
\text { Poor.... } \\
\text { Poor.... } \\
\text { Fair..... }\end{array}$ & $\begin{array}{l}\text { Minute...... } \\
\text { Minute..... } \\
\text { Minute...... } \\
\text { Small........ } \\
\text { Line face.... } \\
\text { Line face.... } \\
\text { Line face.... } \\
\text { Small......... }\end{array}$ & $\begin{array}{l}45 \\
44 \\
44 \\
45 \\
45 \\
44 \\
43 \\
43 \\
45\end{array}$ & $\begin{array}{l}\text { 00 } \\
47 \\
57 \\
03 \\
11 \\
59 \\
40 \\
37 \\
07\end{array}$ & $\begin{array}{l}70 \\
69 \\
70 \\
70 \\
70 \\
70 \\
70 \\
70 \\
70\end{array}$ & $\begin{array}{l}\mathbf{4 5} \\
52 \\
52 \\
39 \\
40 \\
46 \\
16 \\
20 \\
42\end{array}$ \\
\hline
\end{tabular}

$a$ Given as $\{11.25 .25\} \mathrm{M}_{1}=\{33.25 .25\} \mathrm{M}_{2}$ by Moses. 
Occurrence and measurements of less common forms on terlinguaite crystals-Continued.

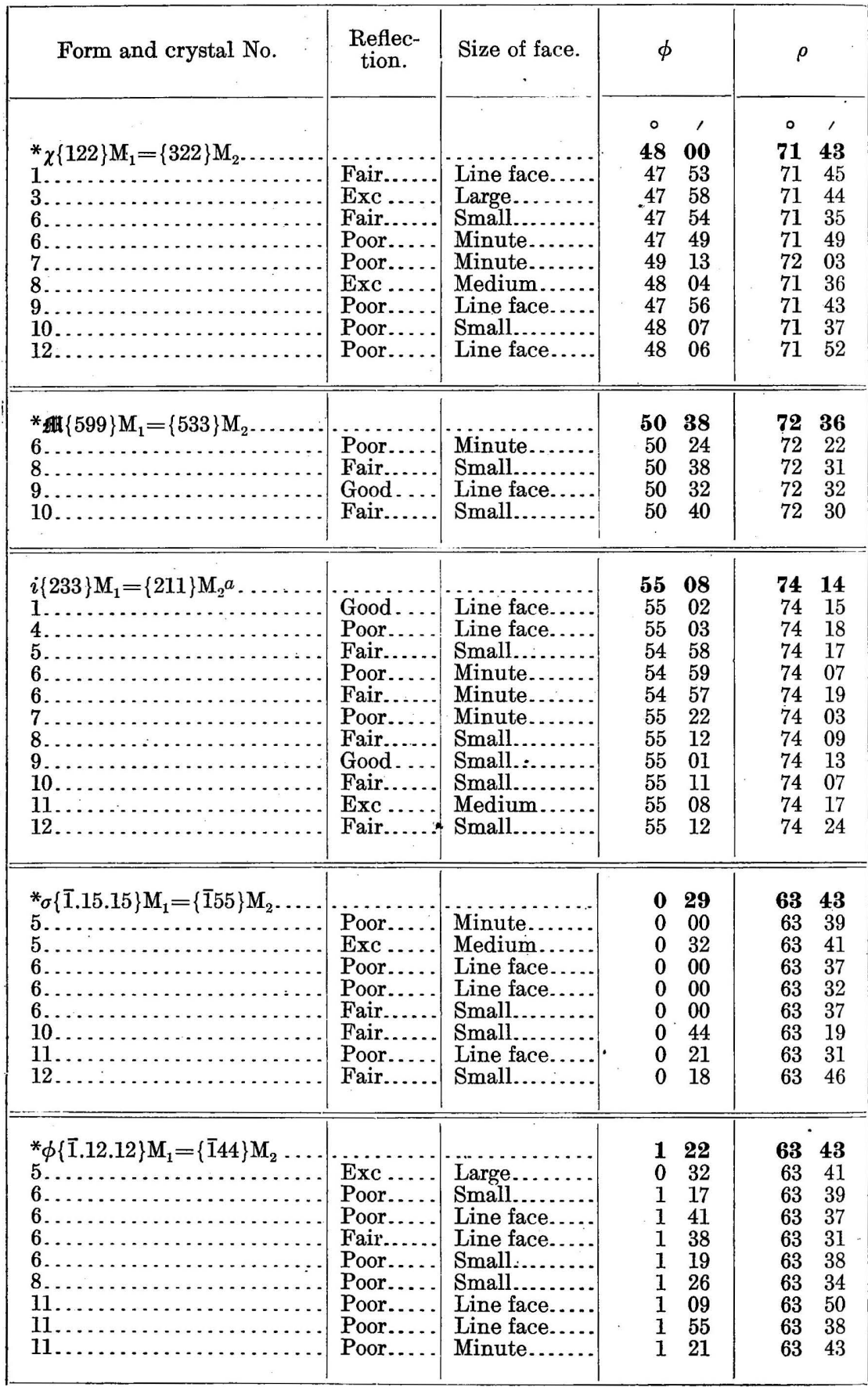


Occurrence and measurements of less common forms on terlinguaite crystals-Continued.

\begin{tabular}{|c|c|c|c|c|c|}
\hline Form and crystal No. & $\begin{array}{l}\text { Reflec- } \\
\text { tion. }\end{array}$ & Size of face. & $\phi$ & $\rho$ & \\
\hline 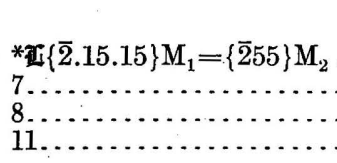 & $\begin{array}{l}\text { Poor.... } \\
\text { Good... } \\
\text { Poor.... }\end{array}$ & $\begin{array}{l}\text { Minute....... } \\
\text { Medium..... } \\
\text { Line face.... }\end{array}$ & $\begin{array}{lc}\circ & \prime \\
\mathbf{6} & \mathbf{5 5} \\
7 & 19 \\
7 & 41 \\
6 & 46\end{array}$ & $\begin{array}{c}\circ \\
\mathbf{6 3} \\
64 \\
64 \\
64\end{array}$ & $\begin{array}{l}\prime \\
\mathbf{5 3} \\
11 \\
01 \\
00\end{array}$ \\
\hline 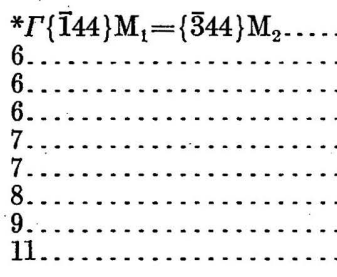 & $\begin{array}{l}\text { Fair..... } \\
\text { Poor.... } \\
\text { Fair.... } \\
\text { Exc .... } \\
\text { Exc .... } \\
\text { Fair.... } \\
\text { Fair..... } \\
\text { Poor.... }\end{array}$ & $\begin{array}{l}\text { Small........ } \\
\text { Minute...... } \\
\text { Small........ } \\
\text { Medium..... } \\
\text { Large........ } \\
\text { Small........ } \\
\text { Small........ } \\
\text { Minute...... }\end{array}$ & $\begin{array}{ll}\mathbf{1 9} & \mathbf{1 2} \\
19 & 14 \\
19 & 23 \\
19 & 03 \\
19 & 12 \\
19 & 17 \\
19 & 16 \\
19 & 18 \\
19 & 02\end{array}$ & $\begin{array}{l}65 \\
64 \\
65 \\
65 \\
64 \\
65 \\
65 \\
65 \\
65\end{array}$ & $\begin{array}{l}\text { 00 } \\
58 \\
17 \\
02 \\
59 \\
07 \\
14 \\
02 \\
00\end{array}$ \\
\hline 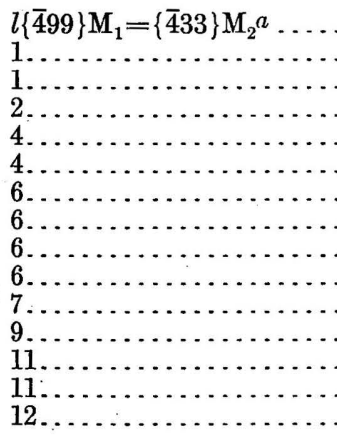 & $\begin{array}{l}\text { Poor.... } \\
\text { Poor.... } \\
\text { Poor.... } \\
\text { Poor.... } \\
\text { Good... } \\
\text { Poor.... } \\
\text { Poor.... } \\
\text { Poor.... } \\
\text { Poor.... } \\
\text { Poor.... } \\
\text { Fair.... } \\
\text { Fair..... } \\
\text { Poor.... } \\
\text { Poor.... }\end{array}$ & $\begin{array}{l}\text { Line face.... } \\
\text { Line face.... } \\
\text { Line face... } \\
\text { Medium..... } \\
\text { Line face.... } \\
\text { Line face.... } \\
\text { Line face.... } \\
\text { Line face.... } \\
\text { Minute...... } \\
\text { Minute...... } \\
\text { Medium..... } \\
\text { Medium..... } \\
\text { Minute...... } \\
\text { Line face.... }\end{array}$ & $\begin{array}{ll}\mathbf{3 6} & \mathbf{0 0} \\
36 & 04 \\
35 & 39 \\
35 & 57 \\
35 & 57 \\
35 & 54 \\
36 & 18 \\
36 & 06 \\
35 & 05 \\
35 & 58 \\
36 & 22 \\
36 & 05 \\
36 & 01 \\
35 & 59 \\
34 & 31\end{array}$ & $\begin{array}{l}\mathbf{6 8} \\
68 \\
67 \\
68 \\
68 \\
68 \\
67 \\
68 \\
68 \\
68 \\
68 \\
68 \\
68 \\
67 \\
67\end{array}$ & $\begin{array}{l}\mathbf{1 3} \\
09 \\
53 \\
18 \\
10 \\
10 \\
51 \\
11 \\
12 \\
16 \\
32 \\
18 \\
16 \\
59 \\
34\end{array}$ \\
\hline 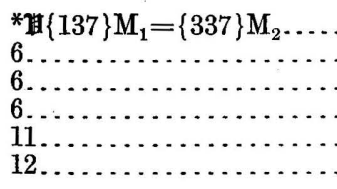 & $\begin{array}{l}\text { Fair..... } \\
\text { Poor.... } \\
\text { Good... } \\
\text { Poor.... } \\
\text { Poor... }\end{array}$ & $\begin{array}{l}\text { Small } \\
\text { Minute........ } \\
\text { Small ......... } \\
\text { Line face.... } \\
\text { Line face.... }\end{array}$ & $\begin{array}{ll}\mathbf{4 4} & \mathbf{0 9} \\
44 & 11 \\
44 & 06 \\
44 & 06 \\
44 & 06 \\
44 & 09\end{array}$ & $\begin{array}{l}\mathbf{5 0} \\
50 \\
50 \\
50 \\
50 \\
50\end{array}$ & $\begin{array}{l}25 \\
22 \\
08 \\
23 \\
31 \\
14\end{array}$ \\
\hline $\begin{array}{l}{ }^{*} \Sigma\{1.6 .12\} \mathrm{M}_{1}=\{124\} \mathrm{M}_{2} . \\
1 \\
3 \\
5 \\
5 \\
6 \\
6 \\
6 \\
6 \\
6 \\
11 \\
11\end{array}$ & $\begin{array}{l}\text { Exc .... } \\
\text { Exc ..... } \\
\text { Good... } \\
\text { Exc .... } \\
\text { Exc .... } \\
\text { Good... } \\
\text { Exc .... } \\
\text { Poor.... } \\
\text { Good... }\end{array}$ & $\begin{array}{l}\text { Minute...... } \\
\text { Medium..... } \\
\text { Medium..... } \\
\text { Large....... } \\
\text { Medium..... } \\
\text { Large........ } \\
\text { Large....... } \\
\text { Medium.... } \\
\text { Medium..... }\end{array}$ & $\begin{array}{rr}\mathbf{3 0} & \mathbf{5 9} \\
31 & 06 \\
30 & -55 \\
30 & 50 \\
30 & 46 \\
30 & 52 \\
30 & 57 \\
31 & 05 \\
30 & 55 \\
30 & 56\end{array}$ & $\begin{array}{l}\mathbf{4 9} \\
49 \\
49 \\
49 \\
49 \\
49 \\
49 \\
49 \\
49 \\
49\end{array}$ & $\begin{array}{l}\mathbf{4 4} \\
45 \\
46 \\
45 \\
43 \\
45 \\
50 \\
44 \\
54 \\
45\end{array}$ \\
\hline
\end{tabular}


Occurrence and measurements of less common forms on terlinguaite crystals-Continued.

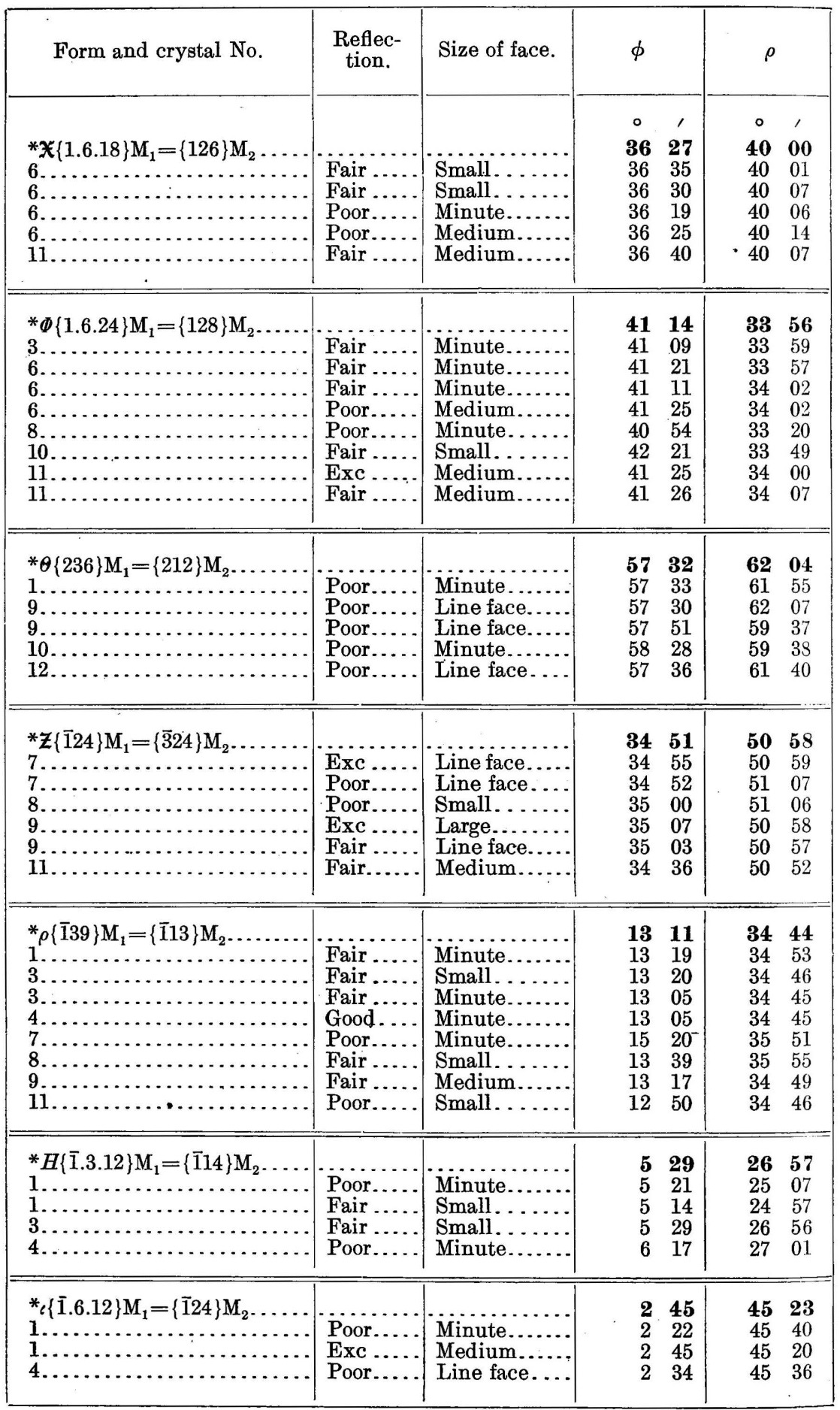


Occurrence and measurements of less common forms on terlinguaite crystals-Continued.

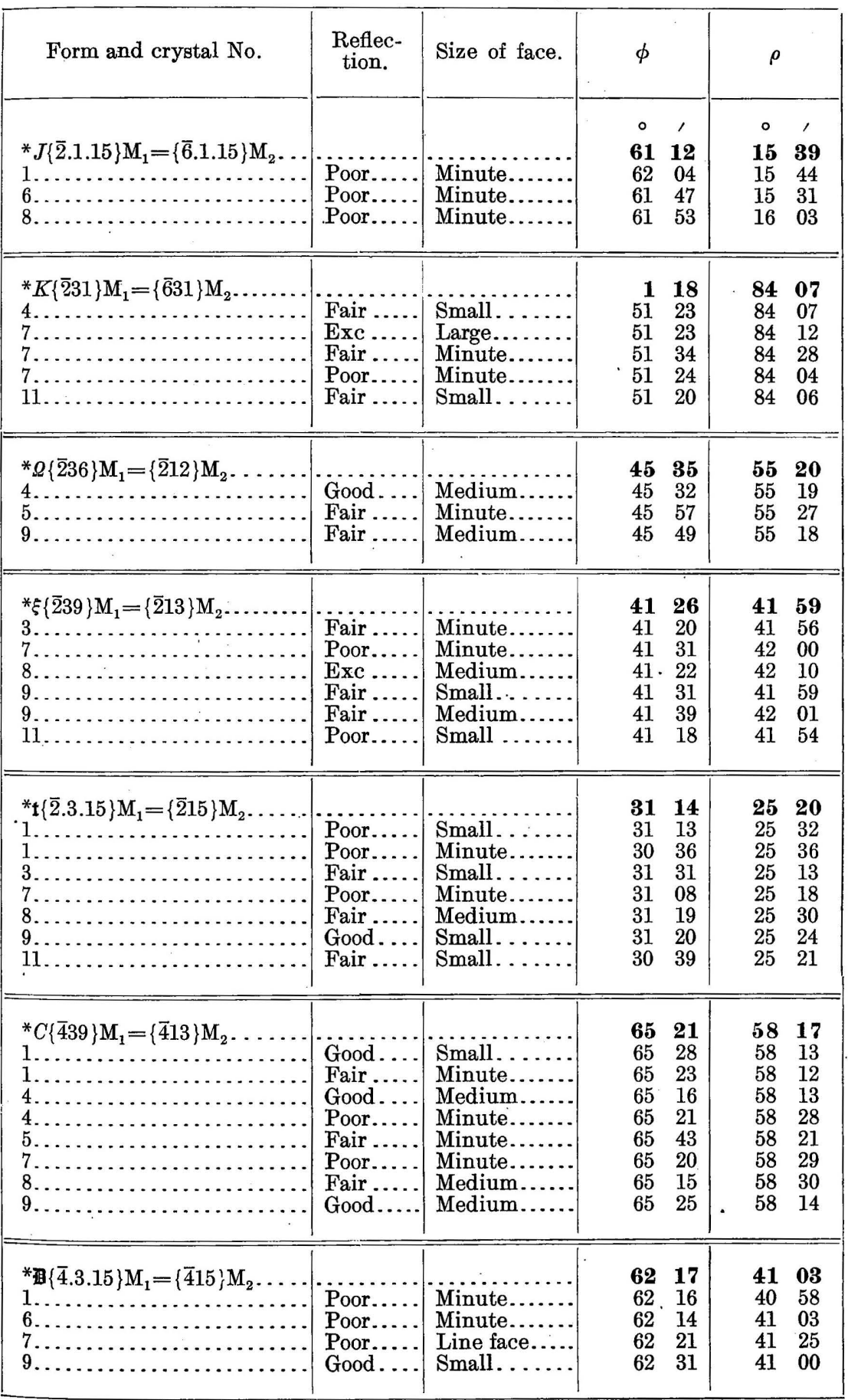


Occurrence and measurements of less common forms on terlinguaite crystals—Continued.

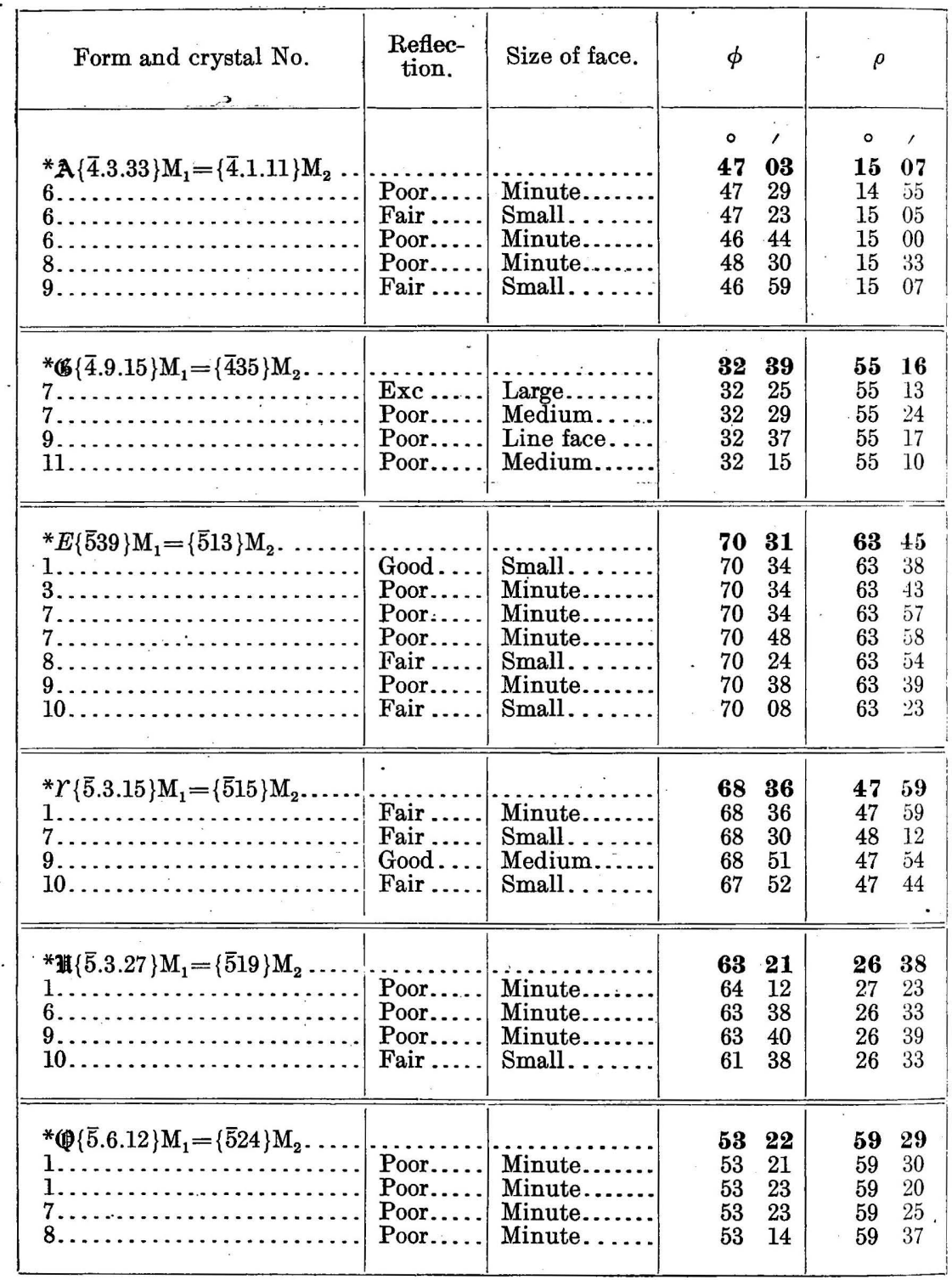


DESCRIPTION OF RARE FORMS.

Finally, the following table shows the rare forms, such as occurred only once or twice:

Occurrence and measurements of rare forms (all new), terlinguaite crystals.

\begin{tabular}{|c|c|c|c|c|c|c|c|c|c|}
\hline \multirow{2}{*}{ Letter. } & \multicolumn{2}{|c|}{ Symbol. } & \multirow{2}{*}{$\begin{array}{c}\text { Crys- } \\
\text { tal } \\
\text { No. }\end{array}$} & \multirow{2}{*}{$\begin{array}{l}\text { Reflec- } \\
\text { tion. }\end{array}$} & \multirow{2}{*}{ Size of face. } & \multicolumn{2}{|c|}{ Measured. } & \multicolumn{2}{|c|}{ Calculated. } \\
\hline & $\mathrm{M}_{1}$. & $\mathbf{M}_{2}$. & & & & $\phi$ & $\rho$ & $\phi$ & $\rho$ \\
\hline $\begin{array}{l}\mathfrak{b} \\
\mathfrak{w} \\
\mathfrak{i} \\
\mathbf{p} \\
\mathbf{f}\end{array}$ & $\begin{array}{l}290 \\
560 \\
890 \\
210 \\
045\end{array}$ & $\begin{array}{l}230 \\
520 \\
830 \\
610 \\
045\end{array}$ & $\begin{array}{l}1 \\
4 \\
9 \\
2 \\
6\end{array}$ & $\begin{array}{l}\text { Poor.... } \\
\text { Good.... } \\
\text { Poor.... } \\
\text { Poor.... } \\
\text { Poor.... }\end{array}$ & $\begin{array}{l}\text { Minute........ } \\
\text { Small........ } \\
\text { Small........ } \\
\text { Minute........ } \\
\text { Line face...... }\end{array}$ & $\begin{array}{rl}\circ & , \\
23 & 28 \\
58 & 21 \\
60 & 10 \\
76 & 20 \\
9 & 46\end{array}$ & $\begin{array}{cc}\circ & \prime \\
90 & 00 \\
90 & 00 \\
90 & 00 \\
90 & 00 \\
58 & 51\end{array}$ & $\begin{array}{rc}\circ & \prime \\
23 & 23 \\
58 & 20 \\
59 & 58 \\
75 & 35 \\
9 & 48\end{array}$ & $\begin{array}{cc}\circ & 1 \\
90 & 00 \\
90 & 00 \\
90 & 00 \\
90 & 00 \\
58 & 41\end{array}$ \\
\hline $\begin{array}{l}\mathbf{g} \\
\mathbf{g} \\
\mathbf{h} \\
\mathbf{a} \\
\mathbf{a}\end{array}$ & $\begin{array}{l}035 \\
035 \\
012 \\
049 \\
049\end{array}$ & $\begin{array}{l}035 \\
035 \\
012 \\
049 \\
049\end{array}$ & $\begin{array}{l}6 \\
6 \\
6 \\
6 \\
6\end{array}$ & $\begin{array}{l}\text { Poor.... } \\
\text { Fair..... } \\
\text { Fair..... } \\
\text { Fair.... } \\
\text { Poor.... }\end{array}$ & $\begin{array}{l}\text { Line face... . . } \\
\text { Minute.... . . } \\
\text { Minute....... } \\
\text { Minute........ } \\
\text { Minute........ }\end{array}$ & $\begin{array}{ll}13 & 04 \\
13 & 46 \\
15 & 24 \\
17 & 23 \\
16 & 46\end{array}$ & $\begin{array}{ll}50 & 56 \\
49 & 38 \\
46 & 34 \\
43 & 04 \\
44 & 08\end{array}$ & $\begin{array}{ll}12 & 58 \\
12 & 58 \\
15 & 26 \\
17 & 15 \\
17 & 15\end{array}$ & $\begin{array}{ll}51 & 16 \\
51 & 16 \\
46 & 24 \\
43 & 18 \\
43 & 18\end{array}$ \\
\hline $\begin{array}{l}\mathbf{b} \\
\mathbf{n} \\
\mathbf{n} \\
3 \\
\mathbf{r}\end{array}$ & $\begin{array}{r}025 \\
1.0 .12 \\
1.0 .12 \\
108 \\
209\end{array}$ & $\begin{array}{l}025 \\
104 \\
104 \\
308 \\
203\end{array}$ & $\begin{array}{r}6 \\
6 \\
11 \\
11 \\
2\end{array}$ & $\begin{array}{l}\text { Poor .... } \\
\text { Good.... } \\
\text { Poor.... } \\
\text { Poor .... } \\
\text { Poor.... }\end{array}$ & $\begin{array}{l}\text { Minute....... } \\
\text { Small........ } \\
\text { Small........ } \\
\text { Minute........ } \\
\text { Line face..... }\end{array}$ & $\begin{array}{rl}19 & 33 \\
0 & 00 \\
0 & 00 \\
0 & 00 \\
0 & 00\end{array}$ & $\begin{array}{ll}39 & 53 \\
32 & 49 \\
31 & 15 \\
37 & 29 \\
48 & 21\end{array}$ & $\begin{array}{rl}19 & 03 \\
0 & 00 \\
0 & 00 \\
0 & 00 \\
0 & 00\end{array}$ & $\begin{array}{ll}40 & 35 \\
31 & 18 \\
31 & 18 \\
37 & 40 \\
49 & 07\end{array}$ \\
\hline $\begin{array}{l}\mathbf{r} \\
\text { 亲 } \\
\mathbf{2} \\
\mathbf{a} \\
\mathbf{n}\end{array}$ & $\begin{array}{l}209 \\
104 \\
104 \\
409 \\
409\end{array}$ & $\begin{array}{l}203 \\
304 \\
304 \\
403 \\
403\end{array}$ & $\begin{array}{r}9 \\
2 \\
11 \\
10 \\
11\end{array}$ & $\begin{array}{l}\text { Fair..... } \\
\text { Poor.... } \\
\text { Poor.... } \\
\text { Poor.... } \\
\text { Poor.... }\end{array}$ & $\begin{array}{l}\text { Small......... } \\
\text { Line face...... } \\
\text { Small........ } \\
\text { Minute........ } \\
\text { Minute........ }\end{array}$ & $\begin{array}{ll}0 & 00 \\
0 & 00 \\
0 & 00 \\
0 & 00 \\
0 & 00\end{array}$ & $\begin{array}{ll}49 & 03 \\
51 & 58 \\
51 & 22 \\
63 & 47 \\
63 & 53\end{array}$ & $\begin{array}{ll}0 & 00 \\
0 & 00 \\
0 & 00 \\
0 & 00 \\
0 & 00\end{array}$ & $\begin{array}{ll}49 & 07 \\
51 & 39 \\
51 & 39 \\
63 & 46 \\
63 & 46\end{array}$ \\
\hline $\begin{array}{l}F \\
F \\
W \\
W \\
\eta\end{array}$ & $\begin{array}{l}509 \\
509 \\
101 \\
101 \\
301\end{array}$ & $\begin{array}{l}503 \\
503 \\
301 \\
301 \\
901\end{array}$ & $\begin{array}{r}1 \\
1 \\
6 \\
11 \\
8\end{array}$ & $\begin{array}{l}\text { Poor.... } \\
\text { Poor.... } \\
\text { Poor.... } \\
\text { Poor.... } \\
\text { Good.... }\end{array}$ & $\begin{array}{l}\text { Small ......... } \\
\text { Line face...... } \\
\text { Minute........ } \\
\text { Line face...... } \\
\text { Medium....... }\end{array}$ & $\begin{array}{ll}0 & 00 \\
0 & 00 \\
0 & 00 \\
0 & 00 \\
0 & 00\end{array}$ & $\begin{array}{ll}67 & 49 \\
67 & 44 \\
76 & 54 \\
75 & 40 \\
85 & 27\end{array}$ & $\begin{array}{ll}0 & 00 \\
0 & 00 \\
0 & 00 \\
0 & 00 \\
0 & 00\end{array}$ & $\begin{array}{ll}67 & 56 \\
67 & 56 \\
76 & 40 \\
76 & 40 \\
85 & 16\end{array}$ \\
\hline$\stackrel{\substack{n \\
M}}{R}$ & $\begin{array}{r}301 \\
401 \\
\overline{1} .0 .21 \\
\overline{4} .0 .15 \\
\overline{5} 09\end{array}$ & $\begin{array}{r}901 \\
12.0 .1 \\
\overline{107} \\
\overline{4} 05 \\
\overline{5} 03\end{array}$ & $\begin{array}{r}10 \\
6 \\
3 \\
7 \\
7\end{array}$ & $\begin{array}{l}\text { Poor.... } \\
\text { Poor.... } \\
\text { Poor.... } \\
\text { Poor.... } \\
\text { Fair..... }\end{array}$ & $\begin{array}{l}\text { Line face... ... } \\
\text { Minute....... } \\
\text { Minute....... } \\
\text { I.ine face... . . } \\
\text { Minute........ }\end{array}$ & $\begin{array}{ll}0 & 00 \\
0 & 00 \\
0 & 00 \\
0 & 00 \\
0 & 00\end{array}$ & $\begin{array}{rr}84 & 56 \\
86 & 34 \\
4 & 58 \\
37 & 36 \\
62 & 16\end{array}$ & $\begin{array}{ll}0 & 00 \\
0 & 00 \\
0 & 00 \\
0 & 00 \\
0 & 00\end{array}$ & $\begin{array}{rl}85 & 16 \\
86 & 26 \\
5 & 16 \\
37 & 37 \\
62 & 21\end{array}$ \\
\hline 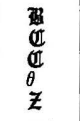 & $\begin{array}{l}\overline{5} 09 \\
\overline{5} 06 \\
\overline{5} 06 \\
\overline{5} 03 \\
\overline{7} 03\end{array}$ & $\begin{array}{l}\overline{5} 03 \\
\overline{5} 02 \\
\overline{5} 02 \\
\overline{5} 01 \\
\overline{7} 01\end{array}$ & $\begin{array}{r}12 \\
6 \\
10 \\
7 \\
2\end{array}$ & $\begin{array}{l}\text { Exe ..... } \\
\text { Poor.... } \\
\text { Poor ..... } \\
\text { Poor.... } \\
\text { Poor.... }\end{array}$ & $\begin{array}{l}\text { Small......... } \\
\text { Minute........ } \\
\text { Line face..... } \\
\text { Line face..... } \\
\text { Line face...... }\end{array}$ & $\begin{array}{ll}0 & 00 \\
0 & 00 \\
0 & 00 \\
0 & 00 \\
0 & 00\end{array}$ & $\begin{array}{ll}62 & 28 \\
71 & 28 \\
71 & 10 \\
81 & 09 \\
83 & 54\end{array}$ & $\begin{array}{ll}0 & 00 \\
0 & 00 \\
0 & 00 \\
0 & 00 \\
0 & 00\end{array}$ & $\begin{array}{ll}62 & 21 \\
71 & 35 \\
71 & 35 \\
80 & 58 \\
83 & 36\end{array}$ \\
\hline $\begin{array}{l}\underset{J}{1} \\
\stackrel{1}{U} \\
U \\
6\end{array}$ & $\begin{array}{r}\overline{401} \\
117 \\
\overline{1} .1 .11 \\
\overline{1} .1 .11 \\
1.24 .24\end{array}$ & \begin{tabular}{|r}
$\mathbf{1 2} .0 .1$ \\
317 \\
$\overline{3} .1 .11$ \\
$\overline{3} .1 .11$ \\
188
\end{tabular} & $\begin{array}{r}9 \\
11 \\
1 \\
1 \\
5\end{array}$ & $\begin{array}{l}\text { Poor .... } \\
\text { Poor.... } \\
\text { Poor.... } \\
\text { Fair..... } \\
\text { Fair..... }\end{array}$ & $\begin{array}{l}\text { Minute....... } \\
\text { Line face... } \\
\text { Line face..... } \\
\text { Minute....... } \\
\text { Line face...... }\end{array}$ & $\begin{array}{rr}0 & 00 \\
71 & 57 \\
24 & 26 \\
23 & 05 \\
12 & 24\end{array}$ & 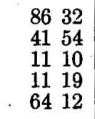 & $\begin{array}{rr}0 & 00 \\
71 & 03 \\
23 & 05 \\
23 & 05 \\
12 & 25\end{array}$ & $\begin{array}{ll}86 & 18 \\
41 & 41 \\
11 & 19 \\
11 & 19 \\
64 & 15\end{array}$ \\
\hline $\begin{array}{l}\text { 戛 } \\
\mathbf{2} \\
\mathbf{6} \\
\mathbf{6} \\
\omega\end{array}$ & $\begin{array}{r}1.18 .18 \\
144 \\
433 \\
433 \\
\square 55\end{array}$ & $\begin{array}{l}166 \\
344 \\
411 \\
411 \\
\overline{355}\end{array}$ & $\begin{array}{r}7 \\
6 \\
6 \\
10 \\
4\end{array}$ & $\begin{array}{l}\text { Poor .... } \\
\text { Poor .... } \\
\text { Poor.... } \\
\text { Poor.... } \\
\text { Good.... }\end{array}$ & $\begin{array}{l}\text { Line face..... } \\
\text { Minute....... } \\
\text { Line face...... } \\
\text { Small........ } \\
\text { Medium....... }\end{array}$ & $\begin{array}{ll}13 & 30 \\
31 & 56 \\
69 & 56 \\
69 & 54 \\
14 & 02\end{array}$ & $\begin{array}{ll}64 & 37 \\
67 & 21 \\
80 & 23 \\
80 & 17 \\
64 & 24\end{array}$ & $\begin{array}{ll}13 & 10 \\
31 & 59 \\
69 & 54 \\
69 & 54 \\
14 & 05\end{array}$ & $\begin{array}{ll}64 & 23 \\
67 & 16 \\
80 & 22 \\
80 & 22 \\
64 & 24\end{array}$ \\
\hline 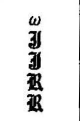 & $\begin{array}{l}\overline{1} 55 \\
\overline{2} 77 \\
\overline{2} 77 \\
\overline{1} 22 \\
\overline{1} 22\end{array}$ & $\begin{array}{l}\overline{3} 55 \\
677 \\
\overline{6} 77 \\
\overline{3} 22 \\
\overline{3} 22\end{array}$ & $\begin{array}{l}6 \\
1 \\
7 \\
5 \\
8\end{array}$ & $\begin{array}{l}\text { Fair..... } \\
\text { Poor.... } \\
\text { Poor ..... } \\
\text { Fair..... } \\
\text { Fair..... }\end{array}$ & $\begin{array}{l}\text { Small........ } \\
\text { Minute........ } \\
\text { Minute....... } \\
\text { Minute........ } \\
\text { Minute........ }\end{array}$ & $\begin{array}{ll}15 & 14 \\
21 & 03 \\
22 & 27 \\
40 & 05 \\
38 & 08\end{array}$ & $\begin{array}{ll}64 & 27 \\
65 & 19 \\
65 & 34 \\
69 & 22 \\
68 & 39\end{array}$ & $\begin{array}{ll}14 & 05 \\
22 & 40 \\
22 & 40 \\
39 & 51 \\
39 & 51\end{array}$ & $\begin{array}{ll}64 & 24 \\
65 & 30 \\
65 & 30 \\
69 & 14 \\
69 & 14\end{array}$ \\
\hline 甠 & $\begin{array}{l}566 \\
126 \\
126 \\
128 \\
193\end{array}$ & $\begin{array}{l}\overline{5} 22 \\
326 \\
326 \\
328 \\
131\end{array}$ & $\begin{array}{r}6 \\
6 \\
11 \\
10 \\
1\end{array}$ & $\begin{array}{l}\text { Poor.... } \\
\text { Good.... } \\
\text { Poor.... } \\
\text { Poor..... } \\
\text { Poor.... }\end{array}$ & $\begin{array}{l}\text { Minute........ } \\
\text { Small......... } \\
\text { Line face...... } \\
\text { Small......... } \\
\text { Minute........ }\end{array}$ & $\begin{array}{ll}56 & 08 \\
54 & 17 \\
53 & 08 \\
56 & 31 \\
14 & 03\end{array}$ & $\begin{array}{ll}74 & 40 \\
49 & 09 \\
48 & 21 \\
43 & 33 \\
81 & 16\end{array}$ & $\begin{array}{ll}55 & 57 \\
54 & 09 \\
54 & 09 \\
56 & 45 \\
14 & 41\end{array}$ & $\begin{array}{ll}74 & 32 \\
49 & 03 \\
49 & 03 \\
42 & 43 \\
80 & 57\end{array}$ \\
\hline $\begin{array}{l}\stackrel{A}{W} \\
\underset{8}{3} \\
\underset{8}{8}\end{array}$ & $\begin{array}{r}193 \\
232 \\
2.3 .15 \\
2.3 .15 \\
1.4 .14\end{array}$ & $\begin{array}{r}131 \\
632 \\
215 \\
215 \\
3.4 .14\end{array}$ & $\begin{array}{l}1 \\
3 \\
6 \\
6 \\
6\end{array}$ & $\begin{array}{l}\text { Poor.... } \\
\text { Good.... } \\
\text { Poor.... } \\
\text { Poor.... } \\
\text { Poor.... }\end{array}$ & $\begin{array}{l}\text { Minute........ } \\
\text { Minute....... } \\
\text { Small........ } \\
\text { Small........ } \\
\text { Line face...... }\end{array}$ & $\begin{array}{ll}14 & 35 \\
55 & 01 \\
61 & 40 \\
62 & 21 \\
43 & 51\end{array}$ & $\begin{array}{ll}80 & 57 \\
78 & 52 \\
42 & 07 \\
42 & 06 \\
39 & 16\end{array}$ & $\begin{array}{ll}14 & 41 \\
54 & 15 \\
63 & 17 \\
63 & 17 \\
44 & 07\end{array}$ & $\begin{array}{ll}80 & 57 \\
79 & 07 \\
42 & 00 \\
42 & 00 \\
38 & 52\end{array}$ \\
\hline $\begin{array}{l}\stackrel{8}{g} \\
\mu \\
\mathfrak{m} \\
\mathfrak{m}\end{array}$ & $\begin{array}{r}1.4 .14 \\
\overline{1} 34 \\
\overline{2} 32 \\
\overline{2} 35 \\
\overline{2} 35\end{array}$ & \begin{tabular}{|c}
3.4 .14 \\
$\overline{3} 34$ \\
$\overline{6} 32$ \\
$\overline{6} 35$ \\
$\overline{6} 35$
\end{tabular} & $\begin{array}{l}6 \\
6 \\
7 \\
4 \\
5\end{array}$ & $\begin{array}{l}\text { Poor.... } \\
\text { Poor.... } \\
\text { Poor.... } \\
\text { Poor.... } \\
\text { Fair..... }\end{array}$ & $\begin{array}{l}\text { Line face... . . } \\
\text { Minute........ } \\
\text { Line face..... } \\
\text { Line face...... } \\
\text { Minute........ }\end{array}$ & $\begin{array}{ll}44 & 00 \\
26 & 15 \\
50 & 20 \\
46 & 29 \\
47 & 09\end{array}$ & $\begin{array}{ll}39 & 07 \\
59 & 33 \\
77 & 33 \\
60 & 41 \\
60 & 42\end{array}$ & $\begin{array}{ll}44 & 07 \\
24 & 54 \\
50 & 18 \\
46 & 47 \\
46 & 47\end{array}$ & $\begin{array}{ll}38 & 52 \\
59 & 03 \\
78 & 07 \\
60 & 35 \\
60 & 35\end{array}$ \\
\hline$\underset{\mathbb{3}}{\mathbf{4}}$ & $\begin{array}{l}\overline{\mathbf{2}} .3 .18 \\
\overline{\mathbf{8}} . \mathbf{3 . 1 2}\end{array}$ & $\begin{array}{l}\overline{2} 16 \\
\overline{8} 14\end{array}$ & $\begin{array}{r}11 \\
2\end{array}$ & $\begin{array}{l}\text { Poor .... } \\
\text { Poor.... }\end{array}$ & $\begin{array}{l}\text { Ijine face....... } \\
\text { Minute....... }\end{array}$ & $\begin{array}{ll}24 & 54 \\
77 & 42\end{array}$ & $\begin{array}{cc}19 & 52 \\
67 & 30 \\
\end{array}$ & $\begin{array}{ll}25 & 05 \\
77 & 48\end{array}$ & $\begin{array}{l}2026 \\
6720\end{array}$ \\
\hline
\end{tabular}


DOUBTFUL AND VICINAL FORMS.

Below is given a list of nine doubtful forms, some of them vicinal. As, however, the reflections, though poor, could be measured with fair accuracy, the measurements are given for the different forms. Some of them show the vicinal form of the indices better when transformed into new orientations.

$\{029\} \mathrm{M}_{1}$ or $\{029\} \mathrm{M}_{2}$ : This dome was observed but once, as a minute face, on crystal 6 . The measured angles vary considerably from the values calculated for $\{029\}$, but agree well with those calculated for the more complex symbol $\{0.3 .13\}$.

Angle values for $\{029\} M_{2}$.

\begin{tabular}{|c|c|c|}
\hline . & $\phi$ & $\rho$ \\
\hline & $\circ$ & .1 \\
\hline Measured $\ldots \ldots \ldots \ldots$ & $30 \quad 50$ & $28 \quad 37$ \\
\hline Calculated for $\{029\} \ldots \ldots$ & 3151 & $27 \cdot 54$ \\
\hline Calculated for $\{0.3 .13\} \ldots$ & $30 \quad 54$ & $28 \quad 34$ \\
\hline
\end{tabular}

The symbol $\{0.3 .13\}$ is a rather unusual one, however, and the number 13 does not occur in any other form of terlinguaite. The form is therefore referred to $\{029\}$ and classed as doubtful.

$\{503\} \mathrm{M}_{1}$ or $\{501\} \mathrm{M}_{2}$ is probably the correct symbol for a form measured on four faces, on as many different crystals, but the measurements gave such varying results, that, until better verified, the form is classed as doubtful.

Occurrence and measurements of $\{503\} M_{1}$ or $\{501\} M_{2}$.

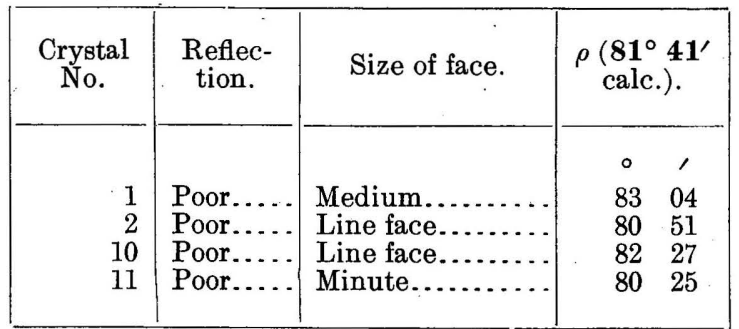

$\{\overline{1} 3.0 .36\} \mathrm{M}_{1}$ or $\{\overline{13} .0 .12\} \mathrm{M}_{2}$ is a form doubtless best considered as vicinal to $\{\overline{1} 01\} \mathbf{M}_{2}$. It was noticed twice on crystal 6 with the following measurements:

Calculated $(\rho)$ $\circ$

Measured (1) $\begin{array}{ll}48 & 48\end{array}$

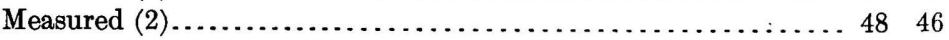

$\{114\} \mathrm{M}_{1}$ or $\{314\} \mathrm{M}_{2}$ occurs on three crystals, on two accompanied by a vicinal form. The measurements of the different faces 
vary considerably, and they are therefore grouped together under this one head, and the form is considered as doubtful.

Occurrence and measurements of $\{114\} M_{1}$ or $\{314\} M_{2}$.

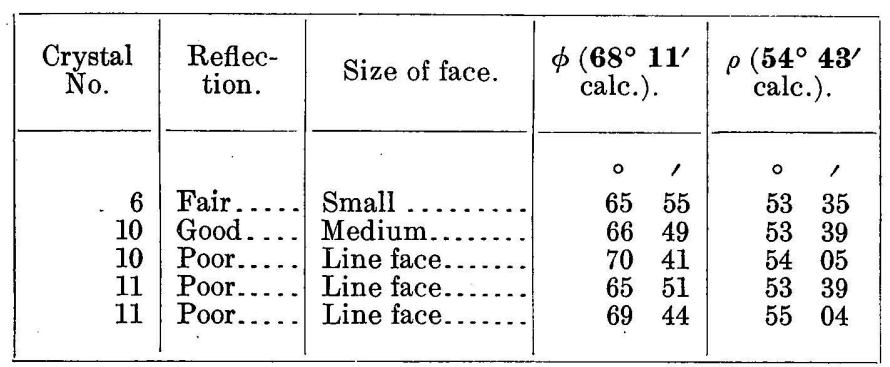

$\{477\} \mathrm{M}_{1}$ or $\{12.7 .7\} \mathrm{M}_{2}$ occurs twice on two crystals, the measurements showing almost identical values, which, however, are not very close to the calculated.

Occurrence and measurements of $\{477\} M_{1}$ or $\{12.7 .7\} M_{2}$.

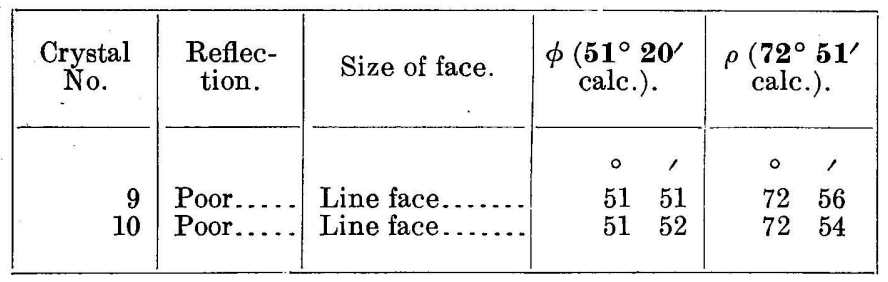

$\{533\} M_{1}$ or $\{511\} M_{2}$ was observed once as a minute face, the measured and calculated angles not agreeing well. The face is present on crystal 1 and gave a poor reflection.

Angle values of $\{593\} M_{1}$ or $\{511\} M_{2}$.

\begin{tabular}{|c|c|c|c|}
\hline & $\phi$ & $\rho$ & \\
\hline & $\circ \quad$, & & , \\
\hline Calculated............. & $73 \quad 00$ & 82 & 01 \\
\hline Measured ............ & $73 \quad 04$ & 81 & 07 \\
\hline
\end{tabular}

$\{\overline{5} 08\} \mathrm{M}_{1}$ or $\{\overline{1} \overline{5} .0 .8\} \mathrm{M}_{2}$, and $\{\overline{7} .0 .10\} \mathrm{M}_{1}$ or $\{\overline{2} \overline{1} .0 .10\} \mathrm{M}_{2}$, both given by Moses, are considered vicinal to $\{\overline{2} 03\}$, to which the letter $x$ has been assigned. Moses describes $\{\overline{7} .0 .10\}$ as occurring twice, once as a striation and the second time as a large face (shown in his fig. 3). The latter is undoubtedly $\{\overline{2} 03\}$, which form is not given by Moses. A line face was observed by the writer on crystal 2, measurement of which placed it near the form $\{\overline{5} 08\}$, but it is considered vicinal. $\{\overline{3} .2 .18\} \mathrm{M}_{1}$ or $\{\overline{9} .2 .18\} \mathrm{M}_{2}$ was observed twice on crystal 1 , as minute faces giving fair.reflections. 
Angle values of $\{3.2 .18\} M_{1}$ or $\{9.2 .18\} M_{2}$.

\begin{tabular}{|c|c|c|c|}
\hline & $\phi$ & $\rho$ & \\
\hline & $\circ$ & $\circ$ & , \\
\hline Calculated... & $59 \quad 10$ & 23 & 42 \\
\hline Measured (1). . & $59 \quad 04$ & 23 & 39 \\
\hline Measured (2)... & $\begin{array}{ll}60 & 20\end{array}$ & 24 & 24 \\
\hline
\end{tabular}

$\{\overline{9} .8 .18\} \mathrm{M}_{1}$ or $\{\overline{2} \overline{7} .7 .18\} \mathrm{M}_{2}$ was also noted twice, on two crystals, Nos. 1 and 3 , giving poor reflections.

Angle values of $\{\overline{9} .8 .18\} M_{1}$ or $\{\overline{2} \overline{\%} .7 .18\} M_{\dot{2}}$.

\begin{tabular}{|c|c|c|}
\hline & $\phi$ & $\rho$ \\
\hline $\begin{array}{l}\text { Calculated } \ldots \ldots \ldots \\
\text { Measured }(1) \ldots \ldots \\
\text { Measured }(3) \ldots \ldots \ldots\end{array}$ & $\begin{array}{cc}\circ & , \\
61 & 58 \\
62 & 11 \\
62 & 34\end{array}$ & $\begin{array}{cc}\circ & , \\
62 & 25 \\
62 & 14 \\
61 & 35\end{array}$ \\
\hline
\end{tabular}

DISCUSSION OF FORMS.

Prism zone (No: 1); a symbol, $\frac{h}{k}$.

\begin{tabular}{|c|c|c|c|c|c|c|c|c|c|c|}
\hline & $b$ & $j$ & $\mathbf{u}$ & $m$ & $B$ & $\zeta$ & $\mathfrak{w} \mathbf{w}$ & $\grave{\mathbf{a}}$ & E & $a$ \\
\hline & & 120 & 230 & 110 & 320 & 210 & 520 & 830 & 610 & 100 \\
\hline Symbol. & 0 & $1 / 2$ & $2 / 3$ & 1 & $3 / 2$ & 2 & $5 / 2$ & $8 / 3$ & 6 & $\infty$ \\
\hline$N_{3}$. & 0 & $1 / 2$ & $2 / 3$ & 1 & $3 / 2$ & 2 & $(5 / 2)$ & {$[8 / 3]$} & (6) & $\infty$ \\
\hline
\end{tabular}

In place of $8 / 3$ we should expect 3 or $\{310\}$. The measurement shows, however, that $\{830\}$ is the correct symbol:

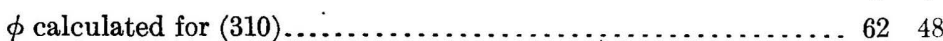

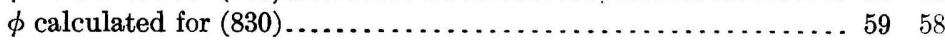

$\phi$ measured .......................................... $60 \quad 10$

Two other forms are extra. The last three forms show the following characteristics:

$\{520\}$ occurs once; small face; good reflection; $\Delta b=01^{\prime}$.

$\{830\}$ occurs once; small face; poor reflection; $\Delta=12^{\prime}$.

$\{610\}$ occurs once; minute face; poor reflection; $\Delta=45^{\prime}$.

The angles between the nearest forms for $\{610\}$ are: $(100):(610)=$ $14^{\circ} 25^{\prime}$; and $(830):(610)=15^{\circ} 37^{\prime}$; so that $\{610\}$ must be taken as the correct symbol. The face occurred in the prism zone with $\zeta, m, j, b, j^{\prime}, \zeta^{\prime}$.

All three forms are considered as established, the zone showing a marked disturbance in the vicinity of the orthopinacoid, it being 
again noted that the extra forms are nearest the form with the simplest indices, namely, $\{100\}$.

$$
\text { Clinodome zone (No. 2); symbol, } \frac{k}{l} \text {. }
$$

Form......... $\left\{\begin{array}{ccccccccccccc}c & \mathfrak{l} & h & - & f & \mathbf{b} & \mathfrak{a} & \mathfrak{h} & \mathfrak{g} & \mathfrak{f} & d & D & b \\ 001 & 017 & 015 & 029 & 013 & 025 & 049 & 012 & 035 & 045 & 011 & 031 & 010\end{array}\right.$ $\begin{array}{lllllllllllllll}\text { Symbol....... } & 0 & 1 / 7 & 1 / 5 & 2 / 9 & 1 / 3 & 2 / 5 & 4 / 9 & 1 / 2 & 3 / 5 & 4 / 5 & 1 & 3 & \infty\end{array}$

Dividing the series at $1 / 3$, and letting $v$ in any row represent the member in the preceding row:

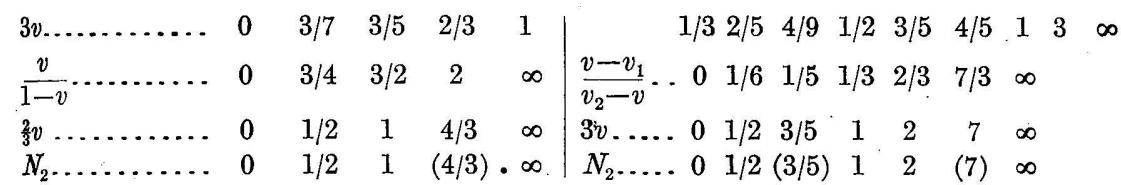

$\{029\},\{049\}$, and $\{045\}$ do not fit in, all three being extra.

$\{029\}$ occurs once as a minute face, $\Delta_{\phi}=1^{\circ} 01^{\prime} ; A_{\rho}=0^{\circ} 43^{\prime}$. The form is doubtful. (See p. 108.)

$\{049\}$ occurs twice as minute faces. The best measurement agrees fairly closely with the calculated angles..$\{045\}$ occurs once as a line face, $\Delta_{\phi}=02^{\prime} ; \Delta_{\rho}=10^{\prime}$. The agreement between the measured and calculated angles is good for these two forms, so that both are considered as established. The two forms $\{049\}$ and $\{045\}$, which cause a disturbance in the otherwise normal series (the doubtful form $\{029\}$ being excluded), are near to the simple forms $\{012\}$ and $\{011\}$.

$$
\text { Positive orthodome zone (No. 3a); symbol, } \frac{h}{l} \text {. }
$$

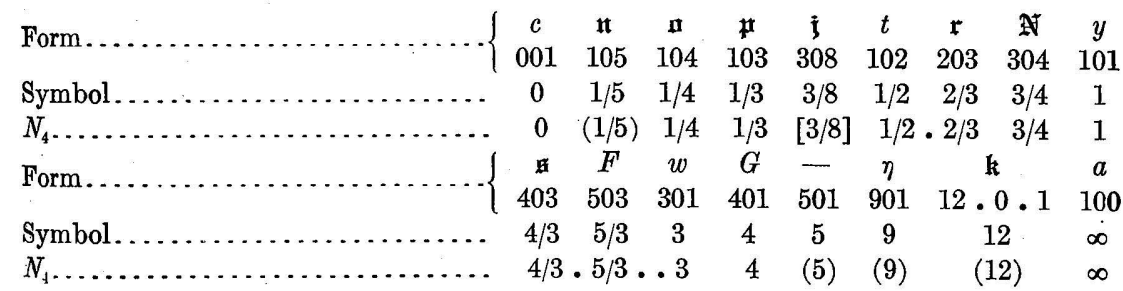

In place of $3 / 8$ we would expect $2 / 5$, but the measured angles agree better with $3 / 8$.

$\left.\begin{array}{lll}\text { Calculated......... } & 3 / 8=37^{\circ} & 40^{\prime} \\ \text { Calculated........ } & 2 / 5=38 & 49\end{array}\right\}$ Measured......... $37^{\circ} \quad 29^{\prime}$

Dividing the series at 1 and considering the first part:

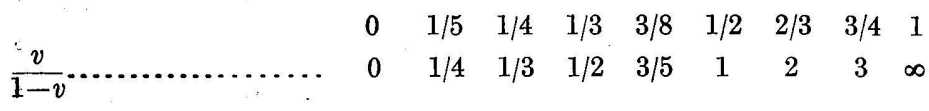

Dividing again at 1 :

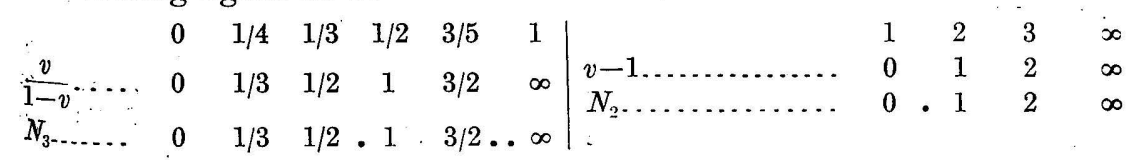

The first part of the entire zone from $\{001\}$ to $\{101\}$ is normal. 
The second part of the original series gives:

\begin{tabular}{|c|c|c|c|c|c|c|c|}
\hline & $14 / 3$ & $5 / 3$ & 3 & 4 & 5 & 9 & 12 \\
\hline$v-1 \ldots \ldots$ & $0 \quad 1 / 3$ & $2 / 3$ & 2 & 3 & 4 & 8 & 11 \\
\hline$N_{3} \ldots \ldots \ldots \ldots \ldots \ldots \ldots$ & $1 / 3$ & $2 / 3$. & 2 & 3 & $(4)$ & (8) & (11) \\
\hline$\frac{v}{2} \ldots \ldots \ldots \ldots \ldots$ & & & 1 & $3 / 2$ & 2 & 4 & $11 / 2$ \\
\hline$v-1 \ldots \ldots \ldots$ & & & 0 & $1 / 2$ & 1 & 3 & $9 / 2$ \\
\hline$N_{2} \ldots$ & & & 0 & $1 / 2$ & 1 & - (3) & $(9 / 2)$ \\
\hline
\end{tabular}

The form 3 or $\{901\}$ does not fit in. In its place we would expect $\{701\}$. The measurements show, however, that $\{901\}$ is the correct symbol:

Calculated $\{901\}$

Calculated $\{701\}$

Measured (1) 8527

Measured (2) 8456

The form must therefore be considered as established.

$\{12.0 .1\}$ is extra. It occurred but once as a minute face; $A=8^{\prime}$. $\{501\}$, though fitting well in the series, must be classed as doubtful for the present. The form is present on four crystals, but the angles vary considerably, $\triangle$ amounting to $+1^{\circ} 23^{\prime},-1^{\circ} 50^{\prime},+0^{\circ} 46^{\prime}$, and $-1^{\circ} 16^{\prime}$. (See p. 108 for angles.) It is possible that more forms than one are here grouped under $\{501\}$.

The zone shows the results of disturbance near the orthopinacoid in the presence of $\{901\}$ and $\{12.0 .1\}$, which do not fit into the normal series.

$$
\text { Negative orthodome zone (No. } 3 b) \text {; symbol, }-\frac{h}{l} \text {. }
$$

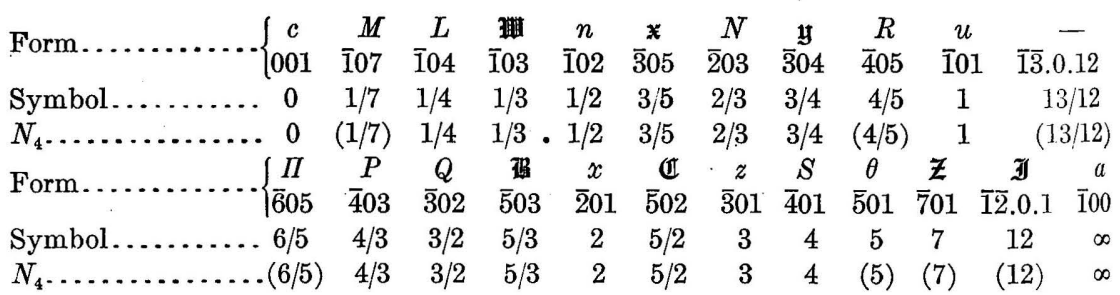

The only missing number is $2 / 5$; otherwise the series is complete for $N_{4}$. As a whole, the zone is nearly normal, several extra forms being present.

Dividing the series at 1 and considering only the first part:

$\begin{array}{ccccccccccc}v & 0 & 1 / 7 & 1 / 4 & 1 / 3 & 1 / 2 & 3 / 5 & 2 / 3 & 3 / 4 & 4 / 5 & 1 \\ 1-v \ldots \ldots \ldots \ldots \ldots \ldots \ldots & 0 & 1 / 6 & 1 / 3 & 1 / 2 & 1 & 3 / 2 & 2 & 3 & 4 & \infty \\ N_{3} \ldots \ldots \ldots \ldots \ldots \ldots \ldots \ldots & 0 & (1 / 6) & 1 / 3 & 1 / 2 & .1 & 3 / 2 & 2 & 3 & (4) & \infty\end{array}$

Again dividing at 1:

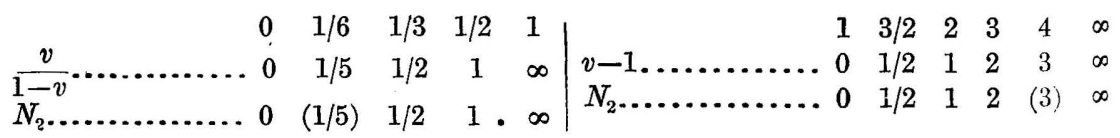


These results show that neither $(1 / 5)$ representing $\{\overline{1} 07\}$ nor $(4 / 5)$ pepresenting $\{\overline{4} 05\}$ fit into the normal series, and that no benefit results in further reducing the series $N_{3}$.

$\{\tilde{1} 07\}$ occurs but once, as a minute face; $\Delta=18^{\prime}$.

$\{\overline{4} 05\}$ occurs but once, as a line face; $\Delta=01^{\prime}$.

Both forms are considered as established. Here again these extra forms in an otherwise normal series are nearest the end members with simplest indices, $\{001\}$ and $\{\overline{1} 01\}$.

Considering now the second portion of the original series:

\begin{tabular}{|c|c|c|c|c|c|c|c|c|c|c|c|c|}
\hline & $13 / 1$ & $6 / 5$ & 4 & $3 / 2$ & $5 / 3$ & 2 & $5 / 2$ & 3 & 4 & 5 & 7 & 12 \\
\hline 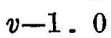 & $1 / 1$ & 1 & & $1 / 2$ & $2 / 3$ & & $3 / 2$ & 2 & 3 & & & \\
\hline & $(1 / 12)$ & $(1 / 5$ & $1 / 3$ & $1 / 2$ & $2 / 3$ & 1 & $3 / 2$ & 2 & 3 & (4) & (6) & (11) \\
\hline
\end{tabular}

Dividing the series at 1 we have:

\begin{tabular}{|c|c|c|c|c|c|c|c|c|c|c|c|c|c|}
\hline & $1 / 12$ & $1 / 5$ & $1 / 3$ & $1 / 2$ & $2 / 3$ & 1 & 1 & $3 / 2$ & 2 & 3 & 4 & 6 & 11 \\
\hline$\frac{v}{-y} \cdot 0$ & $1 / 11$ & $1 / 4$ & $1 / 2$ & 1 & 2 & $\infty$ & $v-1 \ldots 0$ & $1 / 2$ & 1 & 2 & 3 & 5 & 10 \\
\hline 0 & $(1 / 11)$ & $(1 / 4)$ & $1 / 2$ & 1 & 2 & $\infty$ & $N_{2} \ldots \ldots 0$ & $1 / 2$ & 1 & 2 & (3) & (5) & (10) \\
\hline
\end{tabular}

These results show that (13/12), (6/5), (5), (7), and (12) do not fit into the normal series, a result obtained also by a consideration of the series $N_{3}$.

$\{\overline{6} 05\}$ is a well-established form, occurring on four crystals.

$\{\overline{501}\}$ is present but once; $\Delta=11^{\prime} . \quad\{\overline{7} 01\}$ occurs once as a line face; $A=18^{\prime} . \quad\{\overline{12} \cdot 0.1\}$ occurs once as a minute face; $A=14^{\prime}$. All three are established forms.

The form $\{\overline{13} .0 .12\}$ is a doubtful one. The angles agree fairly closely, but from its occurrence the form can not be considered as an established one (see p. 108).

The results obtained by splitting the series $N_{4}$ into smaller series is the same as that obtained by considering the series $N_{4}$, and shows that, of the negative orthodomes, the following do not fit in the normal series: $\{\overline{1} 07\},\{\overline{4} 05\},\{\overline{6} 05\},\{\overline{5} 01\},\{\overline{7} 01\},\{\overline{1} 2.0 .1\}$.

The zone shows disturbances near the base and orthopinacoid, and also near the unit dome.

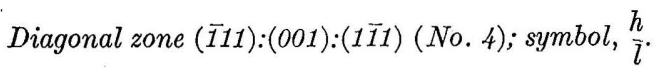

Form. . $\left\{\begin{array}{cccccccccccc}e & \Xi & \rho & H & \beta & c & \lambda & O & \mathcal{l} & \pi & k & p \\ \overline{1} 11 & \overline{3} 34 & \overline{1} 13 & \overline{1} 14 & \overline{1} 15 & 001 & 1 \overline{1} 5 & 1 \overline{1} 3 & 3 \overline{3} 7 & 1 \overline{1} 2 & 3 \overline{3} 4 & 1 \overline{1} 1\end{array}\right.$

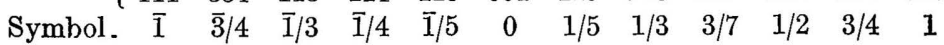

Dividing the series at $\overline{1} / 3$ or $\{\overline{1} 13\}$ :

\begin{tabular}{|c|c|c|c|c|c|c|c|c|c|}
\hline & $\overline{1} / 3$ & $\overline{1} / 4$ & $\overline{\mathbf{1}} / 5$ & 0 & $1 / 5$ & $1 / 3$ & $3 / 7$ & $1 / 2$ & $3 / 4$ \\
\hline$v+1$ & $2 / 3$ & $3 / 4$ & $4 / 5$ & 1 & $6 / 5$ & $4 / 3$ & $10 / 7$ & $3 / 2$ & $7 / 4$ \\
\hline$\frac{v-v_{1}}{v_{0}-v}$ & 0 & $1 / 15$ & $1 / 9$ & $1 / 3$ & $2 / 3$ & 1 & $4 / 3$ & $5 / 3$ & $13 / 3$ \\
\hline $3 v \ldots$ & 0 & $1 / 5$ & $1 / 3$ & 1 & 2 & 3 & 4 & 5 & 13 \\
\hline
\end{tabular}


Again dividing the series at 1 :

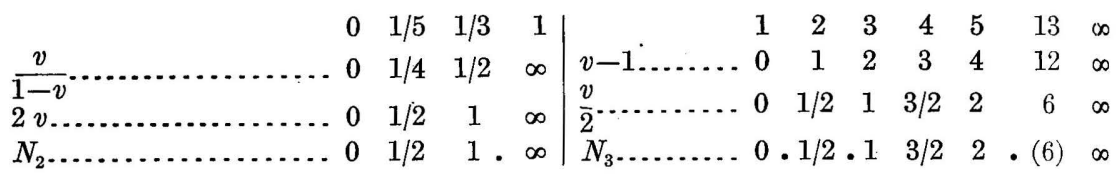

The only form which does not fit in is $\{334\}$ - a rare form not found by the writer, but noted by Moses.

The first part of the original zone from (111) to (001) gives:

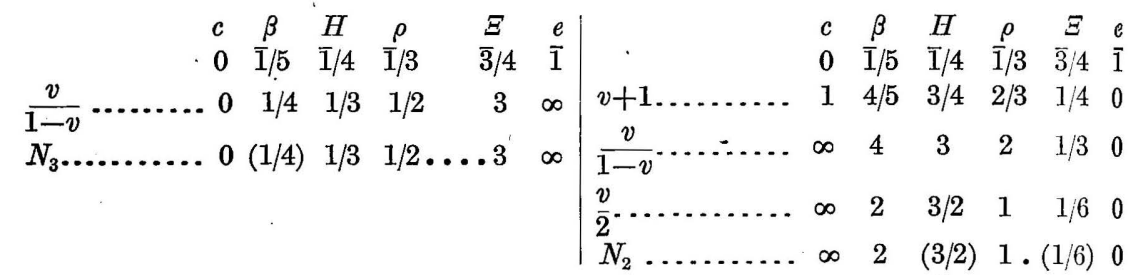

Positive pyramid zone (100):(111):(011) (No. 5a); symbol, $\frac{h}{l}$.

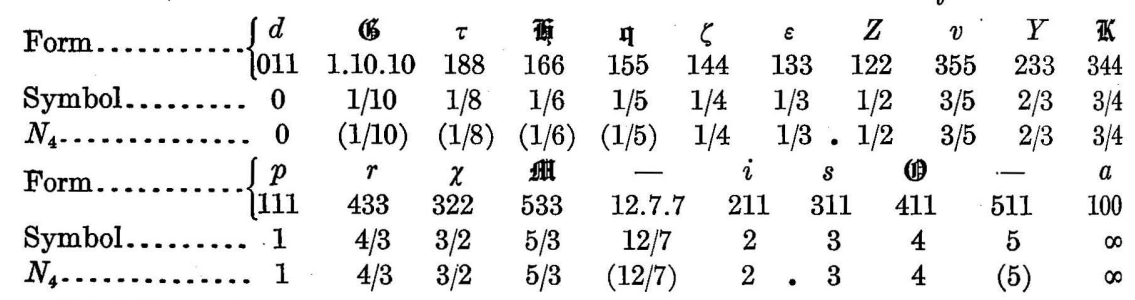

Dividing the series at 1 and considering the first part:

$$
\begin{aligned}
& \begin{array}{llllllllllll}
0 & 1 / 10 & 1 / 8 & 1 / 6 & 1 / 5 & 1 / 4 & 1 / 3 & 1 / 2 & 3 / 5 & 2 / 3 & 3 / 4 & 1
\end{array} \\
& \begin{array}{ccccccccccccc}
\frac{v}{1-v} \ldots \ldots \ldots & 0 & 1 / 9 & 1 / 7 & 1 / 5 & 1 / 4 & 1 / 3 & 1 / 2 & 1 & 3 / 2 & 2 & 3 & \infty
\end{array}
\end{aligned}
$$

Again dividing at 1 :

$$
\begin{aligned}
& \begin{array}{llllllll}
0 & 1 / 9 & 1 / 7 & 1 / 5 & 1 / 4 & 1 / 3 & 1 / 2 & 1
\end{array} \quad \begin{array}{rrrrr}
1 & 3 / 2 & 2 & 3 & \infty
\end{array}
\end{aligned}
$$

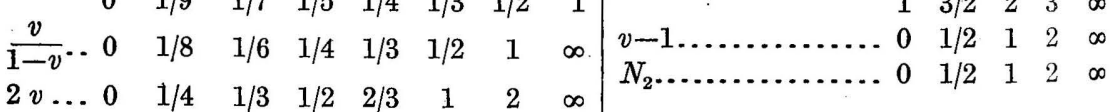

$$
\begin{aligned}
& \begin{array}{llllllllll}
N_{3} & \ldots & 0 & (1 / 4) & 1 / 3 & 1 / 2 & 2 / 3 & 1 & . & 2
\end{array}
\end{aligned}
$$

In the second division the zone is normal. Dividing the first division again at 1 :

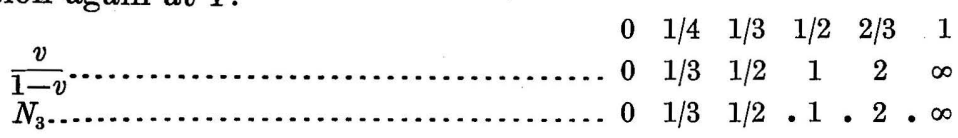

The zone, though incomplete, is normal.

The result shows that, by redividing, all of the members of the first part of the series $N_{4}$ can be made to fit into a normal series. The four members that do not belong in the first part of $N_{4}$ as normal members have the following characteristics:

$\{1.10 .10\}$ occurs on two crystals as line faces.

$\{188\}$ occurs once as a line face; $\Delta_{\varphi}=01^{\prime} ; \Delta_{\rho}=03^{\prime}$.

$\{166\}$ occurs once as a line face; $\Delta_{\varphi}=20^{\prime} ; \Delta_{\rho}=14^{\prime}$.

$\{155\}$ occurs on three crystals, but always as line faces. 
Considering now the second part of the series $N_{4}$ :

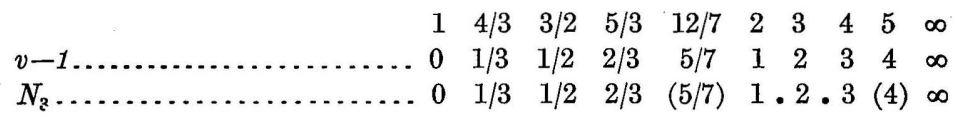

Dividing the series at 1 :

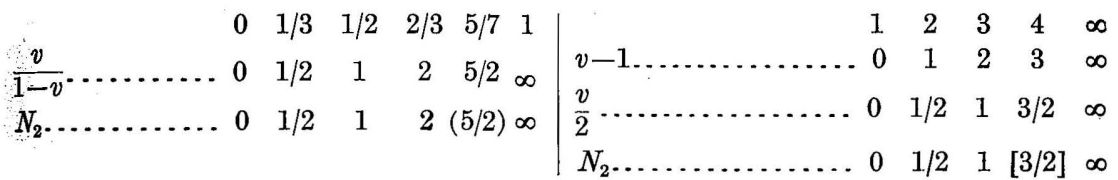

$5 / 2$ or $\{12.7 .7\}$ is a vicinal form to $\{533\}$, occurring once each on two crystals, on both accompanied by $\{533\}$.

Angle values for the forms $\{12.7 .7\}$ and $\{533\}$.

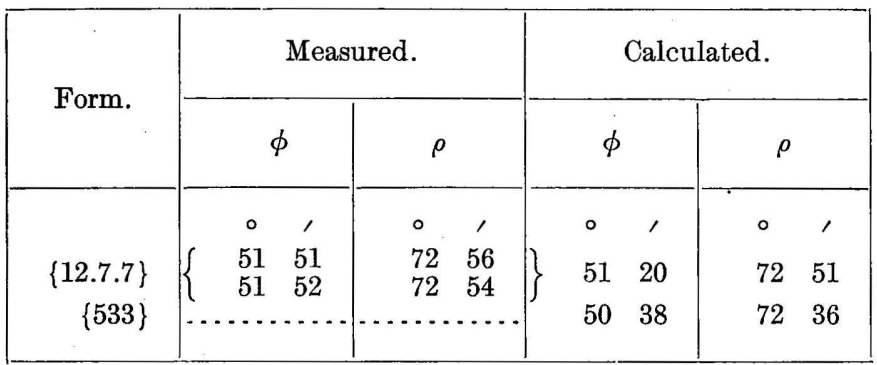

The form $3 / 2$ or $\{511\}$ occurred once as a minute face. We would expect 2 or $\{611\}$. The angles measured vary from those calculated for $\{511\}$ and agree almost as well with those for the form $\{922\}$.

Angle values for form of doubtful symbol.

\begin{tabular}{|c|c|c|}
\hline & $\phi$ & $\rho$ \\
\hline & $\circ$ & $\circ$ \\
\hline Calculated for $\{922\} \ldots$ & 71 & \\
\hline Calculated for $\{511\} \ldots$ & 73 & 820 \\
\hline Measured ............... & $73 \quad 04$ & 810 \\
\hline
\end{tabular}

The symbol is therefore in doubt.

The entire zone shows a strong disturbance near the unit clinodome $\{011\}$, and also slightly near the orthopinacoid, as can be seen best by the series $N_{4}$.

Negative pyramid zone $(\overline{1} 00):(\overline{1} 11):(011)$ (No. $5 b)$; symbol, $-\frac{h}{l}$.

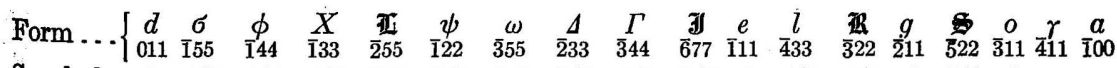
$\begin{array}{lllllllllllllllllll}\text { Symbol. } 0 & 1 / 5 & 1 / 4 & 1 / 3 & 2 / 5 & 1 / 2 & 3 / 5 & 2 / 3 & 3 / 4 & 6 / 7 & 1 & 4 / 3 & 3 / 2 & 2 & 5 / 2 & 3 & 4 & \infty\end{array}$

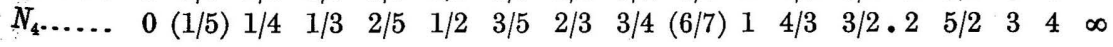

This zone is very nearly a perfect normal series $N_{4}$, with only one member missing and two extra. 
Of the forms which do not fit in the normal series, (1/5) or $\{155\}$ is well established. This is shown by dividing the series at 1 and reducing the first part:

$\begin{array}{lllllllllll}0 & 1 / 5 & 1 / 4 & 1 / 3 & 2 / 5 & 1 / 2 & 3 / 5 & 2 / 3 & 3 / 4 & 6 / 7 & 1 \\ 0 & 1 / 4 & 1 / 3 & 1 / 2 & 2 / 3 & 1 & 3 / 2 & 2 & 3 & 6 & \infty\end{array}$

Dividing at 1 :

\begin{tabular}{|c|c|c|c|c|c|c|c|c|c|c|}
\hline & $\begin{array}{ll}0 & 1 / 4\end{array}$ & $1 / 3$ & $1 / 2$ & $2 / 3$ & 1 & & $13 / 2$ & 2 & & \\
\hline$\frac{v}{1-v} \cdots \ldots \ldots \ldots$ & $1 / 3$ & $1 / 2$ & 1 & 2 & $\infty$ & $\begin{array}{l}v-1 \ldots \ldots \ldots \ldots \ldots \\
N_{2} \ldots \ldots \ldots \ldots \ldots \ldots\end{array}$ & $\begin{array}{ll}0 & 1 / 2 \\
0 & 1 / 2\end{array}$ & $\begin{array}{l}1 \\
1\end{array}$ & $\begin{array}{l}2 \\
2\end{array}$ & $\begin{array}{c}5 \\
(5)\end{array}$ \\
\hline
\end{tabular}

Dividing the first division again at 1 :

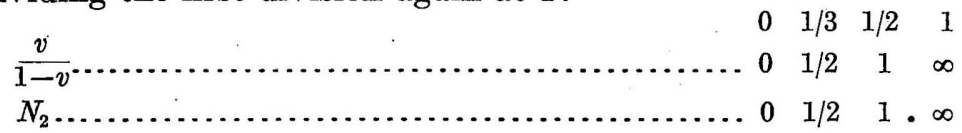

The only member that does not fit in is $\{\overline{6} 77\}$ a rare form near to $\{\overline{3} 44\}$.

Angle values for the form $\{\overline{3} 44\}$.

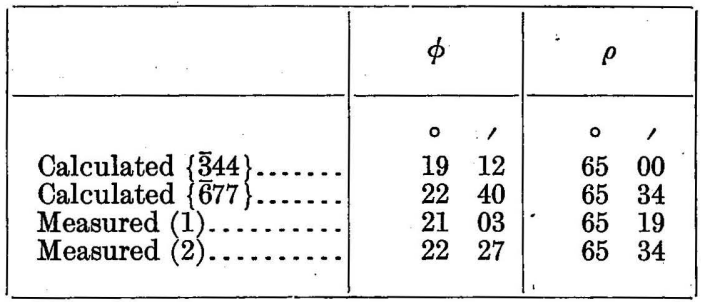

The second part of the zone $N_{4}$ is normal and, in fact, the entire zone shows very little disturbance. Both extra forms are nearest the simplest indices, namely, $\{011\}$ and $\{\overline{1} 11\}$.

Pyramid zone, $\frac{k}{l}=\frac{1}{5}$ (No.6); symbol, $\frac{h}{l}$.

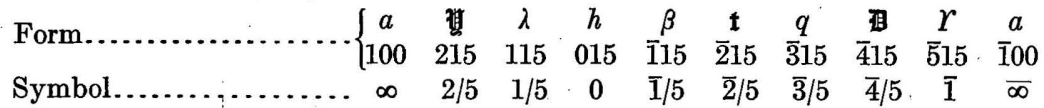

Dividing at 0 :

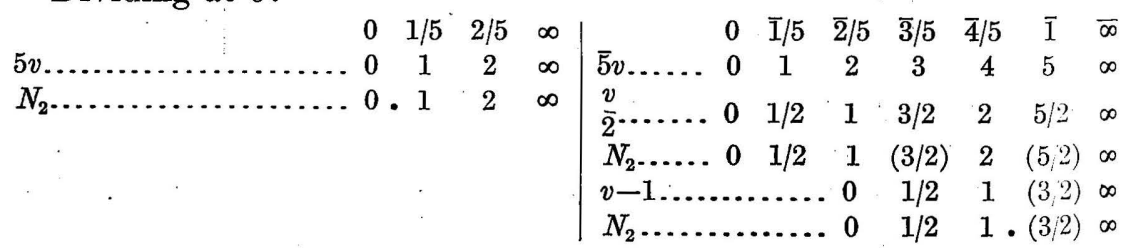

The series is normal with an extra form.

$$
\text { Pyramid zone, } \frac{k}{l}=\frac{1}{3} \text { (No. 7); symbol, } \frac{h}{l} \text {. }
$$

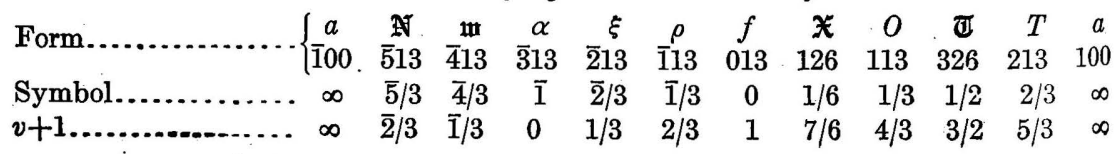


Dividing at 1 and reversing the first half:

$$
\begin{aligned}
& \begin{array}{lllllll}
1 & 2 / 3 & 1 / 3 & 0 & \overline{1} / 3 & \overline{2} / 3 & \infty
\end{array} \\
& v-1 \\
& \begin{array}{lllllll}
0 & 1 / 3 & 2 / 3 & 1 & 4 / 3 & 5 / 3 & \infty
\end{array}
\end{aligned}
$$

Dividing again at 1 :

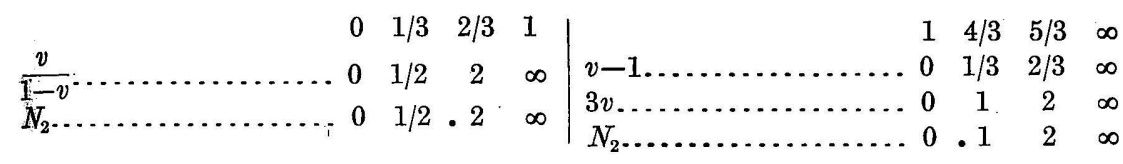

The second half of the original zone gives:

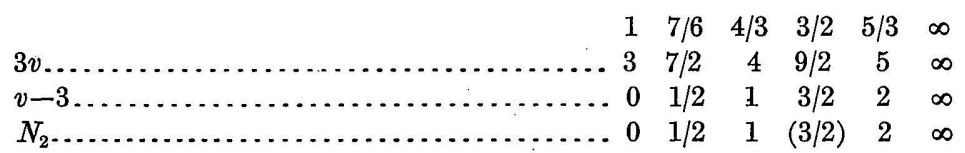

Dividing again at 1 , the second part gives:

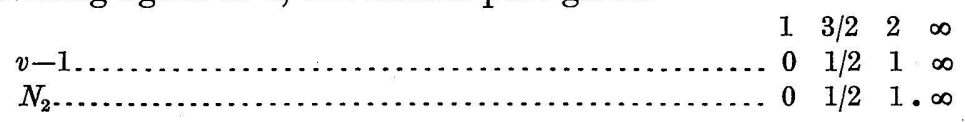

The zone can thus be reduced to smaller series and shown to be entirely normal.

Pyramid zone, $\frac{k}{l}=\frac{1}{\mathscr{Q}}($ No. 8$) ;$ symbol, $\frac{h}{l}$.

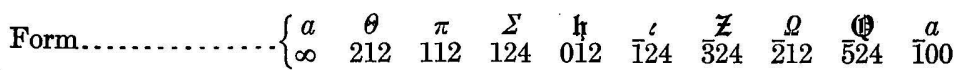

\begin{tabular}{|c|c|c|c|c|c|c|c|c|c|c|}
\hline & $\infty$ & 1 & $1 / 2$ & $1 / 4$ & 0 & 0 & $\overline{1} / 4$ & $\overline{3} / 4$ & $\overline{1}$ & $\overline{5} / 4$ \\
\hline Reversing........ & 0 & $1 / 4$ & $1 / 2$ & 1 & $\infty$ & $4 v \ldots \ldots \ldots . . .0$ & $\overline{1}$ & $\overline{3}$ & $\overline{4}$ & $\overline{5}$ \\
\hline $2 v \ldots \ldots \ldots \ldots \ldots$ & 0 & $1 / 2$ & 1 & 2 & $\infty$ & $v+1 \ldots \ldots \ldots 1$ & 0 & $\overline{2}$ & $\overline{3}$ & $\overline{4}$ \\
\hline$N_{2} \ldots \ldots \ldots \ldots \ldots$ & 0 & $1 / 2$ & 1 & 2 & $\infty$ & & 0 & 1 & $3 / 2$ & 2 \\
\hline & & & & & & $v-1 \ldots \ldots \ldots \ldots$ & & $\begin{array}{l}0 \\
0\end{array}$ & $\begin{array}{l}1 / 2 \\
1 / 2\end{array}$ & $\begin{array}{l}1 \\
1 .\end{array}$ \\
\hline
\end{tabular}

$\begin{array}{llllllllll}\text { Symbol.............. } \infty & 1 & 1 / 2 & 1 / 4 & 0 & \overline{1} / 4 & \overline{3} / 4 & \overline{1} & \overline{5} / 4 & \infty\end{array}$

Dividing the series at 0 :

The zone is normal.

$$
\text { Pyramid zone (1̄11) : (102) : (011) (No. 9); symbol, } \frac{h}{l} \text {. }
$$

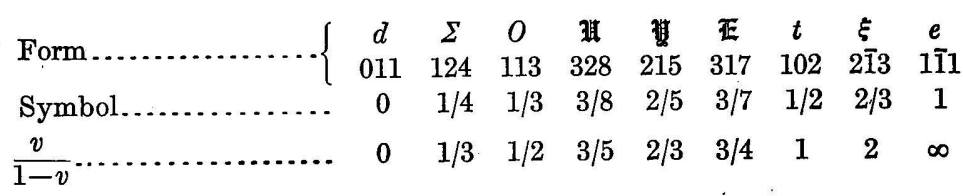

Dividing at 1 :

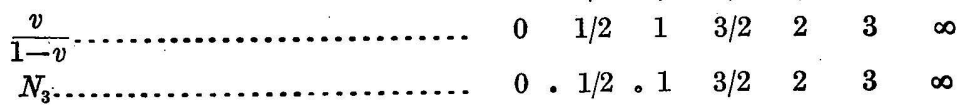

The zone is normal. 


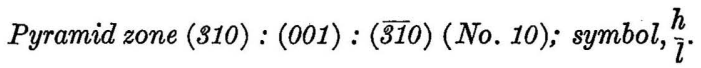

Form............ $\left\{\begin{array}{ccccccccc}s & - & \mathfrak{r} & c & U & V & q & \alpha & o \\ 311 & 314 & 317 & 001 & \overline{3} . \overline{1} .11 & \overline{3} 19 & \overline{3} 15 & \overline{3} 1 \overline{1} 3 & \overline{3} 11\end{array}\right.$

$\begin{array}{llllllllll}\text { Symbol........... } & 3 & 3 / 4 & 3 / 7 & 0 & \overline{3} / 11 & \overline{1} / 3 & \overline{3} / 5 & \overline{1} & \overline{3}\end{array}$

Dividing the series at 0 or $\{001\}$ :

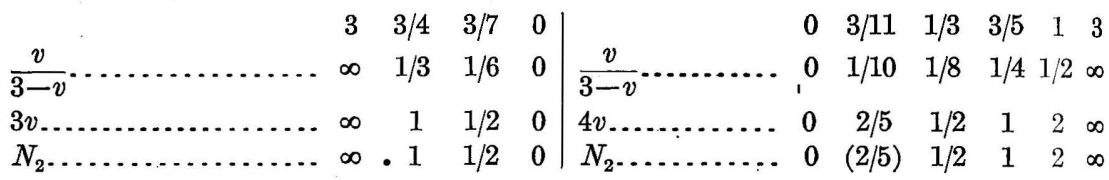

The series is normal, $2 / 5$ or $\{\overline{3} .1 .11\}$ being extra. Though rare, the form is considered as established.

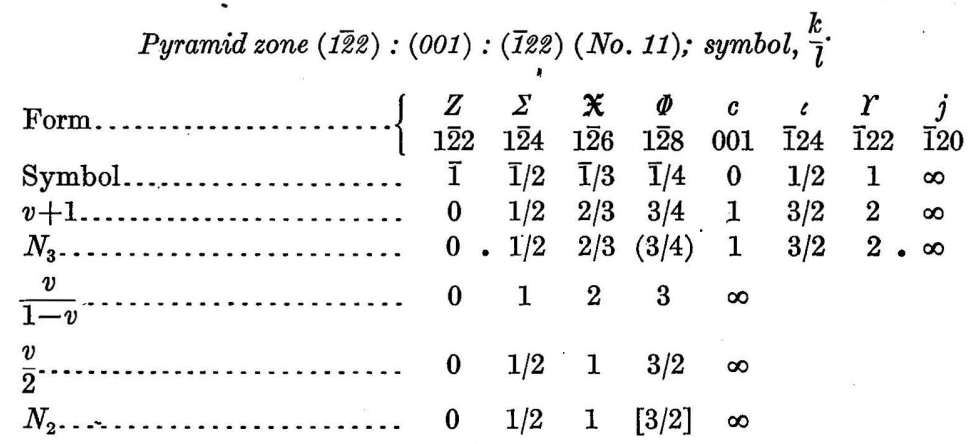

In place of $3 / 2$ we would expect 2 or $\{1, \overline{2} .10\}$. The form $\{1 \overline{2} 8\}$ is, however, well established.

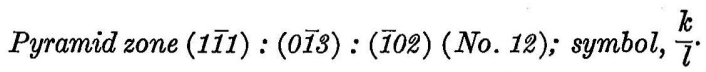

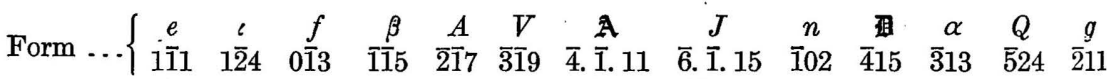
$\begin{array}{llllllllllllll}\text { Symbol ... } & \overline{1} & \overline{1} / 2 & \overline{1} / 3 & \overline{1} / 5 & \overline{1} / 7 & \overline{1} / 9 & \overline{1} / 11 & \overline{1} / 1.5 & 0 & 1 / 5 & 1 / 3 & 1 / 2 & 1\end{array}$

Dividing the series at 0 and considering only the first part, reversing:

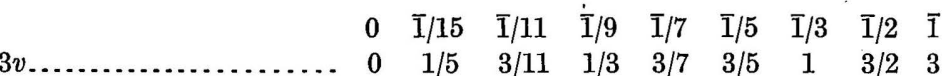

Dividing again at 1 :

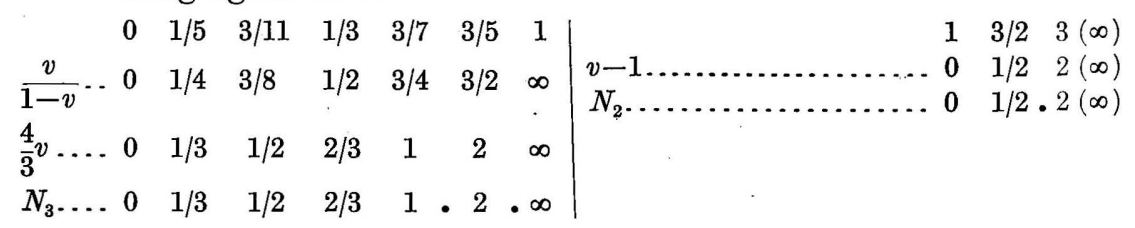

The second part of the original zone gives:

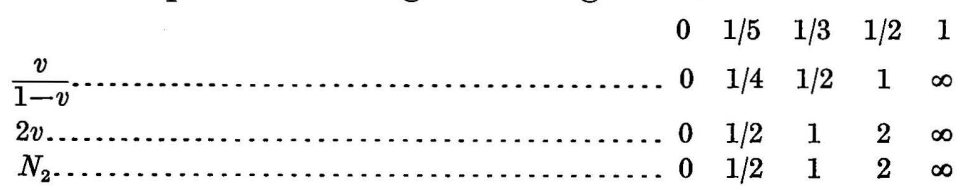

The entire zone is thus shown to be normal. 


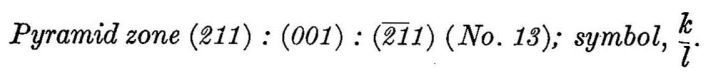

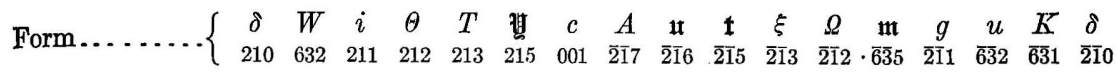

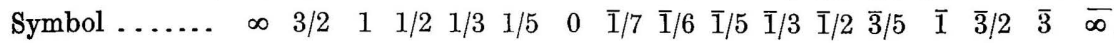

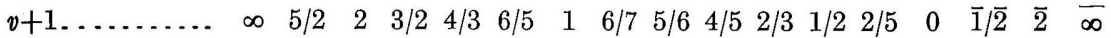

Dividing at 1 and at 0 , the first part gives:

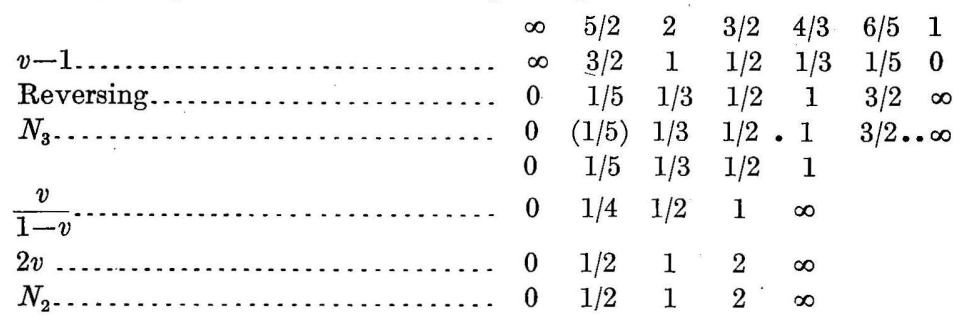

The second part gives:

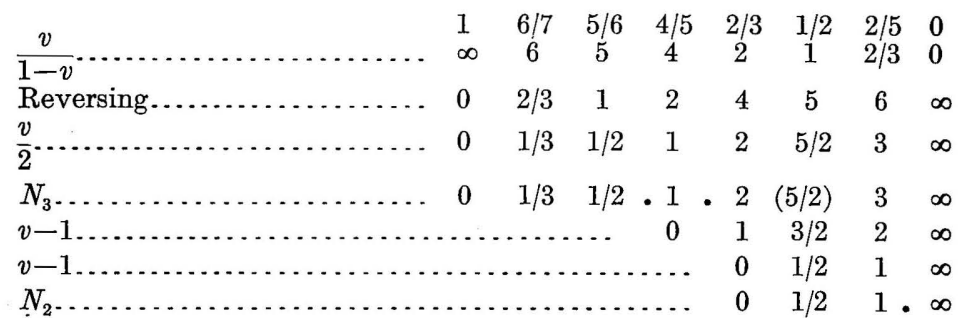

The last part gives:

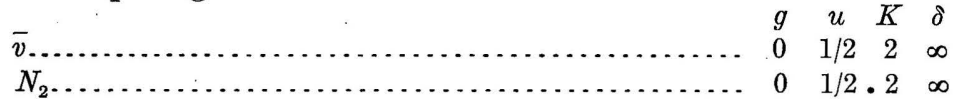

The zone is entirely normal.

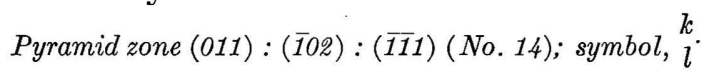

\begin{tabular}{|c|c|c|c|c|c|c|c|c|c|c|}
\hline Form .. & $\begin{array}{c}d \\
011\end{array}$ & $\stackrel{6}{124}$ & $\frac{\rho}{113}$ & $\begin{array}{c}\mathbf{t} \\
\overline{2} 15\end{array}$ & $\begin{array}{c}n \\
102\end{array}$ & $\frac{\mathfrak{Z}}{519}$ & $\frac{q}{315}$ & $\frac{\xi}{213}$ & $\frac{Z}{32} 4$ & $\overline{\overline{435}}$ \\
\hline Symbol....... & 1 & $1 / 2$ & $1 / 3$ & $1 / 5$ & 0 & $\overline{1} / 9$ & $\overline{1} / 5$ & $\overline{1} / 3$ & $\overline{1} / 2$ & $\overline{3} / 5$ \\
\hline $\begin{array}{l}v+1 \ldots . . . \\
\text { Reversing }\end{array}$ & 2 & $3 / 2$ & $4 / 3$ & $6 / 5$ & 1 & $8 / 9$ & $4 / 5$ & $2 / 3$ & $1 / 2$ & $2 / 5$ \\
\hline and $\frac{v}{2} \ldots$ & 0 & $1 / 5$ & $1 / 4$ & $1 / 3$ & $2 / 5$ & $4 / 9$ & $1 / 2$ & $3 / 5$ & $2 / 3$ & $3 / 4$ \\
\hline$\frac{v}{1-v} \cdots \cdots$ & 0 & $1 / 4$ & $1 / 3$ & $1 / 2$ & $2 / 3$ & $4 / 5$ & 1 & $3 / 2$ & 2 & 3 \\
\hline$N_{3} \ldots$ & 0 & $1 / 4)$ & $1 / 3$ & $1 / 2$ & $2 / 3$ & $(4 / 5)$ & 1 & $3 / 2$ & 2 & 3 \\
\hline
\end{tabular}

Dividing the series at 1 , we have:

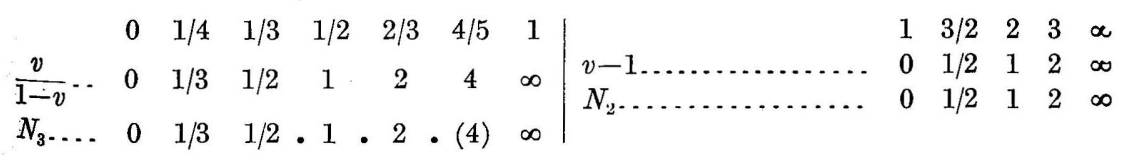

The form 4 or $\{\overline{5} \overline{1} 9\}$ is extra. Occurring on three crystals, the form is, however, well established. 


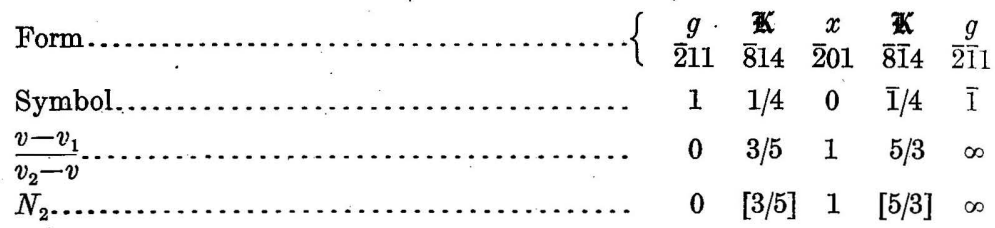

Instead of $3 / 5$ and $5 / 3$ we would expect $1 / 2$ and 2 or $\{\overline{6} 13\}$. The relation can be better shown by changing the symbols to $\mathrm{M}_{1}$, giving $\{\overline{8} .3 .12\} \mathrm{M}_{1} . \quad\{\overline{8} .4 .12\} \mathrm{M}_{1}$ would make the series normal.

Angle valües for $\{8.3 .12\} M_{1}$.

\begin{tabular}{|c|c|c|c|}
\hline$*$ & $\phi$ & $\rho$ & \\
\hline 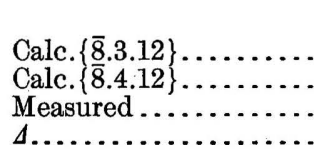 & $\begin{array}{cc}\circ & 1 \\
77 . & 48 \\
73 & 57 \\
77 & 42 \\
& 06\end{array}$ & $\begin{array}{l}\circ \\
67 \\
67 \\
67\end{array}$ & $\begin{array}{l}\prime \\
20 \\
43 \\
30 \\
10\end{array}$ \\
\hline
\end{tabular}

The measurement shows, however, that $\{\overline{8} .3 .12\} \mathrm{M}_{1}$ or $\{\overline{8} 14\} \mathrm{M}_{2}$ is the correct symbol.

$$
\text { Positive pyramid zone (010) : (101) (No. 16); symbol, } \frac{k}{l} \text {. }
$$

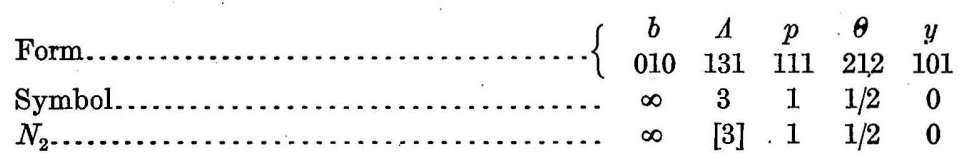

In place of 3 or $\{131\}$ we would expect 2 or $\{121\}$, but $\{131\}$ is the correct symbol. Negative pyramid zone, $\frac{h}{l}=\frac{1}{3}$ (No. 17); symbol, $\frac{k}{l}$.

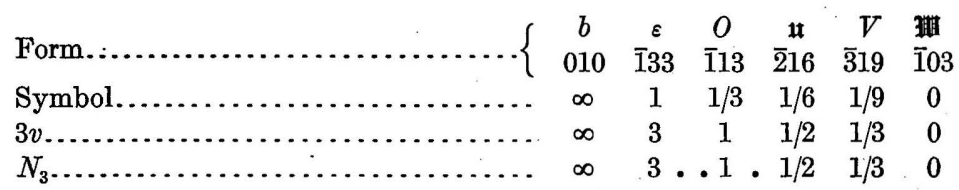

The zone is normal, though incomplete.

Negative pyramid zone $\frac{h}{l}=1$ (No. 18); symbol, $\frac{k}{l}$.

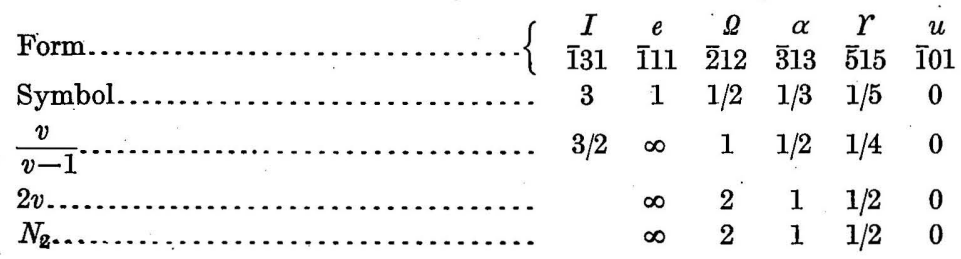

The zone is normal. 
Pyramid zone (102): (012) (No. 19); symbol, $\frac{k}{l}$.

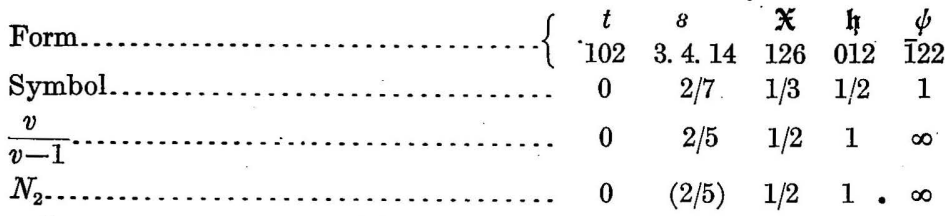

The form $2 / 5$ or $\{3.4 .14\}$ is extra. The form, though rare, is well established.

Combinations of forms on terlinguaite crystals.

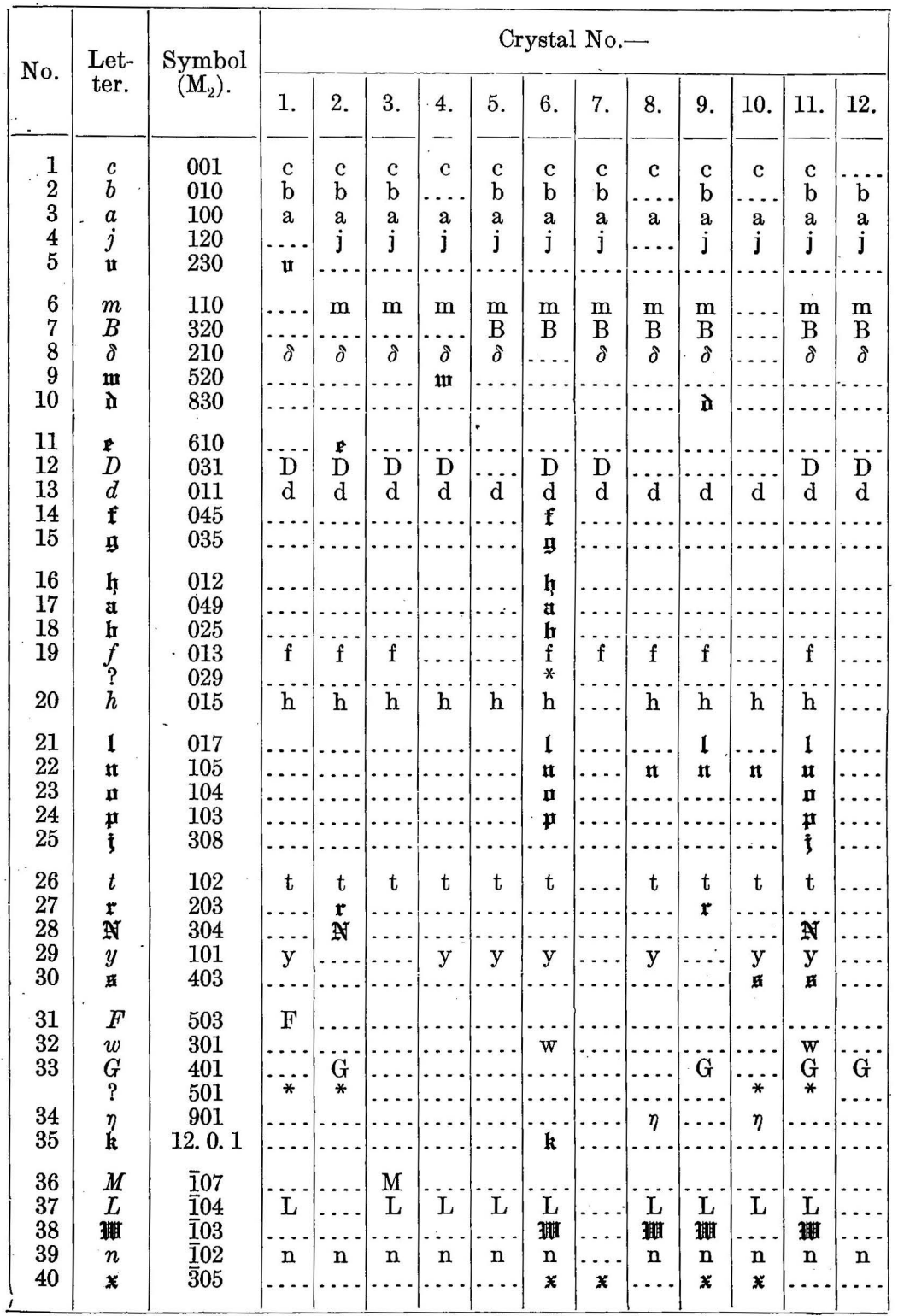


Combinations of forms on terlinguaite crystals-Continued.

\begin{tabular}{|c|c|c|c|c|c|c|c|c|c|c|c|c|c|c|}
\hline \multirow{2}{*}{ No. } & \multirow{2}{*}{$\begin{array}{l}\text { Let- } \\
\text { ter. }\end{array}$} & \multirow{2}{*}{$\begin{array}{c}\text { Symbol } \\
\left(\mathrm{M}_{2}\right) .\end{array}$} & \multicolumn{12}{|c|}{ Crystal No.- } \\
\hline & & & 1. & 2. & 3. & 4. & 5. & 6. & 7: & 8. & 9. & 10. & 11. & 12. \\
\hline 41 & $N$ & $\overline{2} 03$ & $\mathrm{~N}$ & & & & & $\mathrm{~N}$ & $\mathrm{~N}$ & & $\mathrm{~N}$ & & $\mathrm{~N}$ & \\
\hline 42 & y & $\overline{3} 04$ & $\ldots$ & & & $\cdots$ & $\cdots$ & y & y & $\cdots$ & is & $\cdots$ & & \\
\hline 43 & $\widetilde{R}$ & $\overline{4} 05$ & ... & & & & 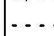 & & $\tilde{\mathrm{R}}$ & . & & & & \\
\hline 44 & $\begin{array}{l}u \\
?\end{array}$ & $\begin{array}{c}101 \\
12.0 .11\end{array}$ & $\mathrm{u}$ & $\mathrm{u}$ & $\mathrm{u}$ & $\mathrm{u}$ & $\mathrm{u}$ & u & $\cdots$ & $\mathrm{u}$ & $\mathrm{u}$ & $\mathrm{u}$ & $\mathrm{u}$ & $\mathrm{u}$ \\
\hline 45 & $\ddot{\Pi}$ & 605 & ... & & & $\Pi$ & & $\Pi$ & $\cdots$ & $\ldots$ & $\Pi$ & $\Pi$ & & \\
\hline 46 & $P$ & $\overline{4} 03$ & $\mathrm{P}$ & & & & & $\mathrm{P}$ & & & & $\mathbf{P}$ & & \\
\hline 47 & $Q$ & $\overline{3} 02$ & $\mathrm{Q}$ & Q & $\mathrm{Q}$ & Q & Q & $\mathbf{Q}$ & $\mathrm{Q}$ & & Q & $\ldots$ & $\mathrm{Q}$ & Q \\
\hline $\begin{array}{l}48 \\
49\end{array}$ & $\begin{array}{l}2 a^{2} \\
x\end{array}$ & $\frac{503}{201}$ & $\mathrm{x}$ & $\mathrm{x}$ & & $\mathrm{x}$ & $x$ & & x & x & $\mathrm{x}$ & $\ddot{x}$ & $x$ & $\mathrm{x}$ \\
\hline 50 & (iT & 502 & $\ldots$ & & & & & (II) & & & & UT & & \\
\hline 51 & $z$ & $\underline{3} 01$ & $\cdots$ & $\mathbf{z}$ & & $\mathrm{z}$ & & & & & & $\mathrm{z}$ & $\mathrm{z}$ & \\
\hline 52 & $\tilde{S}$ & $\underline{4} 01$ & ... & & $\mathrm{S}$ & & $\ldots$ & $\mathrm{S}$ & $\mathbf{S}$ & & $\mathrm{S}$ & & 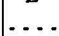 & $\mathrm{S}$ \\
\hline 53 & $\theta$ & 501 & $\cdots$ & & $\cdots$ & & $\ldots$ & - & $\theta$ & $\ldots$ & $\cdots$ & $\ldots$ & ... & . \\
\hline 54 & $z$ & 701 & $\cdots$ & $z$ & & & & & & & & & & \\
\hline & $\mathfrak{J}$ & $\overline{1} \overline{2} .0 .1$ & $\cdots$ & & & & & ... & $\cdots$ & $\cdots$ & $\mathfrak{I}$ & & & \\
\hline 56 & $\mathfrak{r}$ & 317 & & & & & & $\because$ & & & $\cdots$ & & f & \\
\hline & $?$ & 314 & & & & & & * & & & $\cdots$ & * & * & \\
\hline $\begin{array}{l}51 \\
58\end{array}$ & $\stackrel{s}{U}$ & $\overline{3}_{1}^{311}$ & $\stackrel{8}{U}$ & -. & 8 & $\cdots$ & 8 & $\mathbf{s}$ & $\cdots$ & $\mathbf{s}$ & $\mathbf{s}$ & s & $\mathbf{s}$ & s \\
\hline 59 & $V$ & $\overline{3} 19$ & $\mathrm{~V}$ & & $\mathrm{~V}$ & & & . & ... & V & V & V & & \\
\hline 60 & $q$ & $\overline{3} 15$ & $q$ & $\cdots$ & $q$ & $\cdots$ & $\cdots$ & $q$ & $\mathrm{q}$ & $\cdots$ & $q$ & $\ldots$ & .. & ... \\
\hline 61 & $\alpha$ & $\overline{3} 13$ & $\alpha$ & $\alpha$ & $\alpha$ & $\alpha$ & $\alpha$ & $\alpha$ & $\alpha$ & $\alpha$ & $\alpha$ & & & \\
\hline 62 & $o$ & $\overline{3} 11$ & 0 & 0 & 0 & 0 & $\ldots$ & 0 & 0 & 0 & 0 & ... & 0 & 0 \\
\hline 63 & (ro & 1. 10.10 & $\cdots$ & & & & $\cdots$ & $\mathbb{G}$ & (B) & $\ldots$ & & & & \\
\hline 64 & $\tau$ & 188 & $\cdots$ & . & & $\ldots$ & $\tau$ & $\cdots$ & 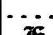 & $\cdots$ & $\ldots$ & $\cdots$ & $\cdots$ & .. \\
\hline & & & & & & & & $\cdots$ & 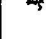 & $\cdots$ & & & & \\
\hline 66 & q & 155 & & & & & म & म & q & & & & & \\
\hline 67 & $\dot{\zeta}$ & 144 & $\zeta$ & & & $\cdots$ & & $\zeta$ & & ... & ... & $\ldots$ & $\zeta$ & $\ldots$ \\
\hline 68 & $\varepsilon$ & 133 & $\varepsilon$ & $\pi$ & $\stackrel{\varepsilon}{\eta}$ & $\varepsilon$ & $\varepsilon$ & $\varepsilon$ & $\varepsilon$ & $\stackrel{\varepsilon}{q}$ & $\varepsilon$ & $\stackrel{\varepsilon}{\eta}$ & 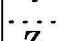 & $\varepsilon$ \\
\hline $\begin{array}{l}69 \\
70\end{array}$ & $\begin{array}{l}Z \\
v\end{array}$ & $\begin{array}{l}122 \\
355\end{array}$ & $\cdots$ & 2 & 2 & Z & $\mathrm{Z}$ & Z & $\mathrm{Z}$ & 2 & 2 & 2 & Z & Z \\
\hline 71 & $Y$ & 233 & $\mathrm{Y}$ & & $\mathrm{Y}$ & Y & & $Y$ & 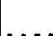 & $\therefore$ & & & & $\mathrm{Y}$ \\
\hline 72 & 跑 & 344 & & & & & & 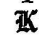 & & & & & & \\
\hline 73 & $p$ & 111 & $\mathrm{p}$ & $\mathrm{p}$ & $\mathrm{p}$ & $\mathrm{p}$ & $\mathrm{p}$ & $\mathrm{p}$ & $\mathrm{p}$ & $\mathrm{p}$ & $\mathrm{p}$ & $\mathrm{p}$ & $\mathrm{p}$ & $\mathrm{p}$ \\
\hline 74 & $r$ & 433 & & & & & & $\mathrm{r}$ & & $\mathrm{r}$ & $\mathrm{r}$ & $\mathrm{r}$ & $\mathbf{r}$ & $\mathrm{r}$ \\
\hline 75 & $\chi$ & 322 & $\chi$ & & $\chi$ & $\cdots$ & $\cdots$ & $\chi$ & $\chi$ & $\chi$ & $\chi$ & $\chi$ & $\cdots$ & $\chi$ \\
\hline 76 & stit & 533 & & & & & & Int & & 䑶 & 理 & m & & \\
\hline & $?$ & 12.7.7 & & & & & & & & & $\ddot{*}$ & * & & \\
\hline 77 & $i$ & 211 & i & .. & $\ldots$ & $\mathrm{i}$ & i & i & $i$ & $\mathrm{i}$ & $\mathbf{i}$ & i & $\mathrm{i}$ & i \\
\hline 78 & $\stackrel{(1)}{?}$ & $\begin{array}{l}411 \\
511\end{array}$ & $*$ & & & $\cdots$ & 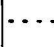 & (19) & & & 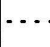 & (1) & $\cdots$ & $\cdots$ \\
\hline 79 & $\sigma$ & 155 & & & & $\ldots$ & $\sigma$ & & & & & $\sigma$ & $\sigma$ & $\ddot{\sigma}$ \\
\hline 80 & $\phi$ & $\overline{1} 44$ & & & & & $\phi$ & $\phi$ & $\therefore$ & $\phi$ & & & $\phi$ & \\
\hline & $X$ & $\overline{1} 33$ & & & & & $X$ & $X$ & $X$ & & $X$ & $X$ & $X$ & $X$ \\
\hline 82 & $\mathbf{T}$ & $\overline{2} 55$ & & & & & & & I & I & & & I & \\
\hline 83 & $\phi$ & $\frac{1}{2} 22$ & $\psi$ & $\phi$ & $\phi$ & $\cdots$ & $\phi$ & $\psi$ & $\psi$ & . & $\phi$ & $\psi$ & $\psi$ & $\phi$ \\
\hline 85 & $\Delta$ & $\frac{000}{233}$ & $\Delta$ & & & & & $\Delta$ & $\Delta$ & $\Delta$ & $\Delta$ & $\Delta$ & $A$ & $\Delta$ \\
\hline
\end{tabular}


Combinations of forms on terlinguaite crystals-Continued.

\begin{tabular}{|c|c|c|c|c|c|c|c|c|c|c|c|c|c|c|}
\hline \multirow{2}{*}{ No. } & \multirow{2}{*}{$\begin{array}{l}\text { Let- } \\
\text { ter. }\end{array}$} & \multirow{2}{*}{$\begin{array}{c}\text { Symbol } \\
\left(\mathbf{M}_{2}\right) .\end{array}$} & \multicolumn{12}{|c|}{ Crystal No.- } \\
\hline & & & 1. & 2. & 3. & 4. & 5. & 6. & 7. & 8. & 9. & 10. & 11. & 12. \\
\hline 86 & $\Gamma$ & $\overline{3} 44$. & $\Gamma$ & & & & & $\Gamma$ & $\Gamma$ & $\Gamma$ & $\Gamma$ & $\Gamma$ & & \\
\hline 87 & 3I & 677 & $\mathfrak{J}$ & & & & & & ปิ & & & & & \\
\hline 88 & $e$ & Iิ11 & $\mathrm{e}$ & e & $\cdots$ & $\mathrm{e}$ & $\mathrm{e}$ & $\mathrm{e}$ & $\mathrm{e}$ & e & $\mathrm{e}$ & .. & $\mathrm{e}$ & $\mathrm{e}$ \\
\hline $\begin{array}{l}89 \\
90\end{array}$ & $\stackrel{l}{l}$ & $\begin{array}{l}\overline{4} 333 \\
\overline{3} 22\end{array}$ & 1 & 1 & $\cdots$ & 1 & 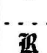 & 1 & 1 & $\mathbb{R}$ & 1 & .. & 1 & 1 \\
\hline 91 & $g$ & $\overline{2} 11$ & $\mathrm{~g}$ & g & $\mathrm{g}$ & $\mathrm{g}$ & $\mathrm{g}$ & $\mathrm{g}$ & $\mathrm{g}$ & g & $\mathrm{g}$ & & g & $\mathrm{g}$ \\
\hline 92 & s & $\underline{\mathbf{5}} 22$ & & & & & & 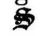 & & & & & & \\
\hline $\begin{array}{l}93 \\
94\end{array}$ & $\frac{\gamma}{\sqrt{1}}$ & $\begin{array}{l}\overline{4} 11 \\
326\end{array}$ & $\cdots$ & $\gamma$ & $r$ & $r$ & 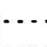 & $\frac{r}{\sigma \pi}$ & $r$ & $r$ & $r$ & $r$ & $\frac{\gamma}{\pi}$ & $r$ \\
\hline 95 & 护 & $\begin{array}{l}520 \\
328\end{array}$ & & & & $\ldots$ & & & & & .. & 相 & & \\
\hline 96 & $k$ & 334 & & & & & & & & & & & & \\
\hline 97 & $\pi$ & 112 & $\pi$ & $\pi$ & $\pi$ & $\ldots$ & $\pi$ & $\pi$ & .. & $\ldots$ & $\pi$ & $\cdots$ & $\pi$ & $\pi$ \\
\hline 98 & 猉 & 337 & & & & & & Z & & & & & 仴 & 调 \\
\hline 99 & 0 & 113 & $\mathrm{O}$ & & $\mathrm{O}$ & $\mathrm{O}$ & $\mathrm{O}$ & $\mathrm{O}$ & 0 & 0 & 0 & 0 & O & 0 \\
\hline 100 & $\lambda$ & 115 & $\lambda$ & & & ... & & $\lambda$ & & $\lambda$ & $\lambda$ & $\lambda$ & $\lambda$ & \\
\hline 101 & 8 & 3.4 .14 & & & & & & 8 & & & & & & \\
\hline 102 & $\Sigma$ & 124 & $\Sigma$ & & $\Sigma$ & ... & $\dot{\Sigma}$ & $\Sigma$ & & & .. & ... & $\Sigma$ & $\Sigma$ \\
\hline 103 & $\bar{X}$ & 126 & $\cdots$ & & & $\ldots$ & & $\nexists$ & $\cdots$ & & - & & X & \\
\hline 104 & $\Phi$ & 128 & $\cdots$ & & $\Phi$ & ... & & $\Phi$ & ... & $\Phi$ & $\ldots$ & $\Phi$ & $\ddot{\Phi}$ & \\
\hline 105 & $A$ & 131 & $\Lambda$ & & & $\ldots$ & & & & & & & & \\
\hline 106 & $W$ & 632 & & & W & & & & & & & & & \\
\hline 107 & $\ddot{\theta}$ & 212 & $\theta$ & & & $\ldots$ & & & & & $\theta$ & $\theta$ & & $\theta$ \\
\hline 108 & $T$ & 213 & $\mathrm{~T}$ & & $\cdots$ & $\ldots$ & & $\mathrm{T}$ & & $\mathrm{T}$ & $\mathrm{T}$ & $\mathrm{T}$ & $\mathrm{T}$ & $\mathrm{T}$ \\
\hline 109 & 巽 & 215 & & & & & & 省 & & & & & & \\
\hline 110 & $Z$ & $\overline{3} 24$ & $\ldots$ & $\cdot$ & $\cdots$ & ... & & & $z$ & $z$ & $z$ & $\ldots$ & $z$ & \\
\hline 111 & $\Xi$ & $\overline{3} 34$ & & & $\cdots$ & & & $\Xi$ & .. & & 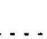 & & & \\
\hline 112 & $\rho$ & 113 & $\rho$ & $\cdots$ & $\rho$ & $\rho$ & & $\cdots$ & $\rho$ & $\rho$ & $\rho$ & $\cdots$ & $\rho$ & \\
\hline 113 & $\ddot{H}$ & 114 & H & & $\mathrm{H}$ & H & & 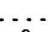 & & & & & & \\
\hline 114 & $\beta$ & 115 & $\beta$ & $\cdots$ & $\beta$ & $\beta$ & $\beta$ & $\beta$ & .. & $\beta$ & $\beta$ & $\beta$ & $\beta$ & \\
\hline 115 & $\iota$ & 124 & 6 & & $\cdots$ & $\iota$ & & & & & & & & \\
\hline 116 & $I$ & _131 & & I & & I & & I & I & & & & I & I \\
\hline 117 & $J$ & $\overline{6} .1 .15$ & $\mathbf{J}$ & & & & & $\mathbf{J}$ & & 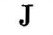 & & & & \\
\hline 118 & $K$ & $\overline{6} 31$ & & . & $\cdots$ & $\mathrm{K}$ & & $\cdots$ & $\mathrm{K}$ & & & & $\mathrm{K}$ & \\
\hline 119 & $\mu$ & 632 & $\cdot$ & - & . & $\cdots$ & & $\cdots$ & $\mu$ & & $\cdots$ & $\cdots$ & $\cdots$ & \\
\hline 120 & $\mathfrak{m}$ & 635 & & &. & $\mathfrak{m}$ & $\mathfrak{m} \mathfrak{t}$ & & & & & & & \\
\hline 121 & $\Omega$ & $\overline{2} 12$ & & & & $\Omega$ & $\Omega$ & & & & $\Omega$ & & & \\
\hline 122 & $\xi$ & $\underline{\overline{2}} 13$ & & - & $\xi$ & $\ldots$ & $\cdots$ & .. & $\xi$ & $\xi$ & $\xi$ & & $\xi$ & \\
\hline 123 & $t$ & $\overline{2} 15$ & $\mathbf{t}$ & & $\mathbf{t}$ & & & & $t$ & $\mathbf{t}$ & $t$ & & $\mathbf{t}$ & \\
\hline 124 & $\mathfrak{u}$ & $\overline{2} 16$ & - & & & & & & $\cdots$ & & & & $\mathfrak{u}$ & \\
\hline 125 & $A$ & $\overline{2} 17$ & & & & A & & A &. & A & A & A & A & \\
\hline 126 & $C$ & $\overline{4} 13$ & C & & & C & C & & C & C & C & & & \\
\hline 127 & 㫜 & -415 & 但 & & & & & 相 & 面 & & 相 & & & \\
\hline 128 & ลี & $\overline{4} .1 .11$ & & & & & & A & & A & $\lambda$ & & & \\
\hline 129 & E & $\overline{\underline{4}} 35$ & & & & & & & 玨 & & 正 & & 正 & \\
\hline 130 & $\bar{E}$ & $\overline{5} 13$ & $\mathrm{E}$ &. & $\mathrm{E}$ & 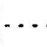 & & & $\overline{\mathrm{E}}$ & $\mathrm{E}$ & $\mathbf{E}$ & $\mathrm{E}$ & $\cdots$ & \\
\hline 131 & $r$ & $\overline{5} 15$ & $r$ & & & & & & $r$ & & $r$ & $r$ & & \\
\hline 132 & 芸 & $\overline{5} 19$ & \# & & & & $\ldots$ & 相 & & & 惧 & 鞠 & & \\
\hline $\begin{array}{l}133 \\
134\end{array}$ & $\stackrel{9}{\dddot{H}}$ & $\frac{524}{814}$ & (B) & $\overline{\mathrm{z}}$ & & & & $\cdots$ & (19) & (19) & & & $\cdots$ & \\
\hline & & & & & & & & & & & & & & \\
\hline
\end{tabular}


ZONAL RELATIONS AND GNOMONIC PROJECTION.

There are two very prominent zones for terlinguaite, namely the zone of orthodomes, with 36 forms, and the pyramid zone (100):(011):(100), with 33 forms. Only the first one, the zone of orthodomes, is characteristically striated, all the faces of this zone showing the horizontal striæ more or less developed. Many of these domes, especially among the rare forms, invariably occur as line faces, though quite a number are commonly present as narrow faces, as large as many of the pyramids. The pyramid zone (100):(011) is in some instances partly striated, though generally the faces of these forms are perfectly smooth. Between (144) and (011) were noted striations, among which the forms $\{155\},\{166\},\{188\}$, and $\{1.10 .10\}$ were determined. The large face of $\{\overline{3} 55\}$ or $\{\overline{1} 22\}$ on terlinguaite crystal 4 , shown in figure 25 , is strongly striated.

All the forms lie in well developed zones, whose relation can be best seen in the gnomonic projection here shown. The actual zones in which the forms lie can also be noted in the discussion of the forms just given. In this discussion the zones are numbered to correspond to the numbers as given on the zones in the projection of Plate V. Some of the pyramid zones, especially the negative ones, not only are well developed, but also show a great regularity in the indices of the various forms. Thus in the four pyramid zones, given below, the variable number in the symbols increases regularly by 1 , and there are only two exceptions to the completeness of all four series.

Table of zones showing regularity of symbols.

\begin{tabular}{|c|c|c|c|}
\hline 013 & 024 & 015 & $\overline{1} 10$ \\
$\overline{1} 13$ & $\overline{1} 24$ & $\overline{1} 15$ & $\overline{1} 11$ \\
$\overline{2} 13$ & $\overline{\overline{1}} 15$ \\
$\overline{3} 13$ & $\overline{3} 24$ & $\overline{2} 15$ & $\left(\frac{\overline{1} 14}{3} 15\right.$ \\
$\overline{4} 13$ & $\overline{4} 24$ & $\overline{4} 15$ & $\overline{1} 13$ \\
$\overline{5} 13$ & $\overline{5} 24$ & $\overline{5} 15$ & $\overline{1} 14$ \\
\hline
\end{tabular}

In the following tw.o zones the variable number increases by 2 instead of by 1 , except for the positive part of the second zone, where the number changes by 3 :

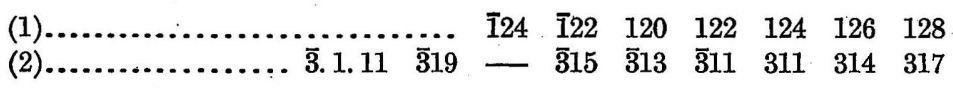

An odd zone, and one that is usually well developed on these crystals, is the negative zone (013):(102), with the forms-

\section{$\begin{array}{lllllllll}013 & \overline{1} 15 & \overline{2} 17 & \overline{3} 19 & \overline{4} .1 .11 & - & \overline{6} .1 .15 & \overline{1} 02\end{array}$}

in which only $\{\overline{5} .1 .13\}$ is missing. Other pyramids lie in this zone, but on the other side of (013) and (102), respectively, and notwithstanding the complexity of some of the forms, for example $\{\overline{4} .1 .11\}$, the zone is entirely normal, as shown on p. 118. 


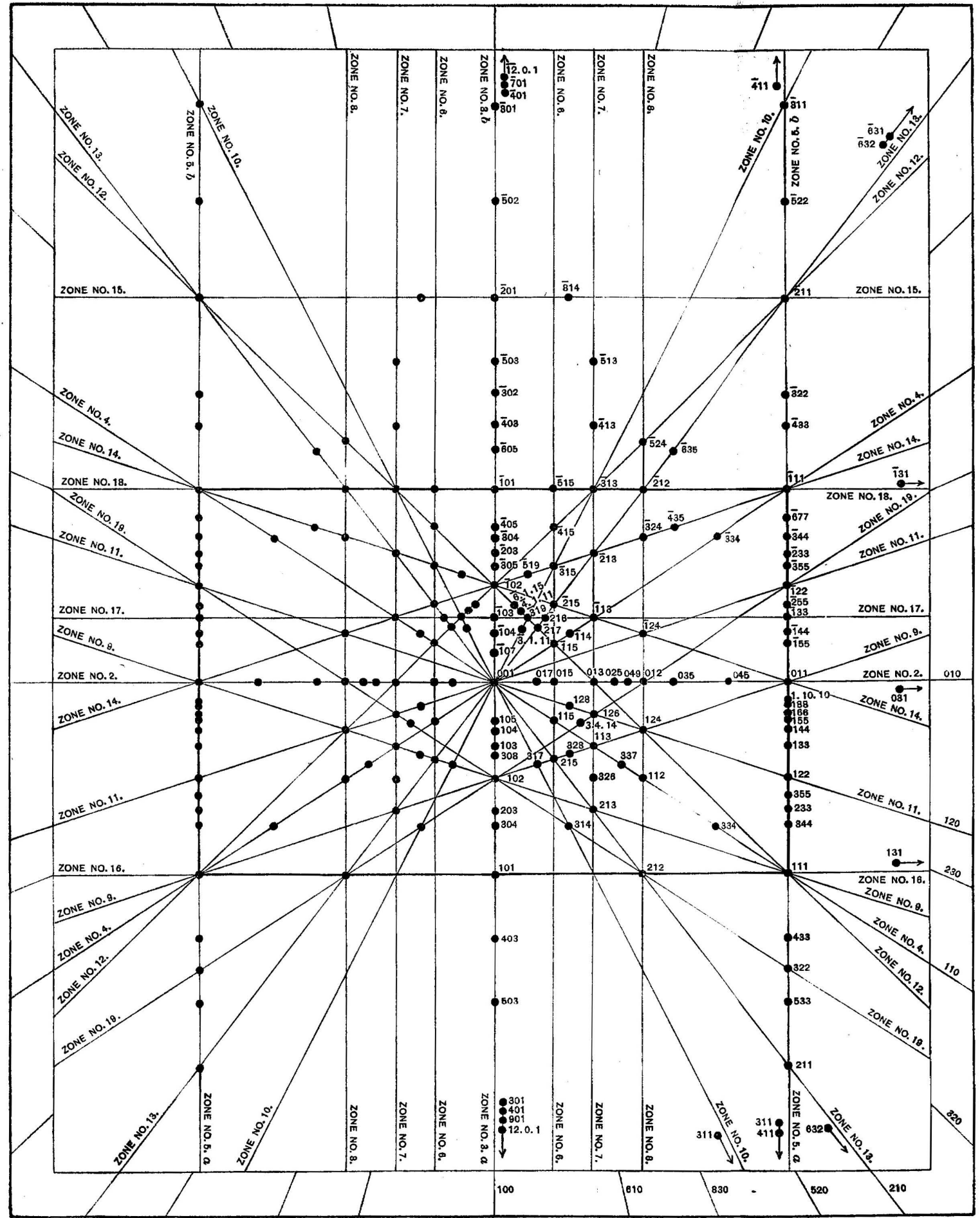



The accompanying gnomonic projection (Pl. V) shows the distribution of the forms and zonal relations better than a text description can. Though 134 forms have been determined, a glance at the gnomonic projection shows that a number of forms of very simple indices have not as yet been found, such as $\{130\},\{310\},\{201\},\{302\}$, $\{021\},\{\overline{1} 12\}$, etc. The measurement of more crystals will undoubtedly considerably extend the present list of forms, and in time terlinguaite will come to rank in the very first class of those minerals possessing an extraordinary richness of combination. It may be stated here that the forms are fairly well distributed over the entire crystal, no one zone having the greater number of forms, as given for epidote, for example, by Zambonini, ${ }^{a}$ who enumerates 299 forms, of which over half, or 173 , belong to the orthodome zone. The distribution of forms for terlinguaite is shown below:

Distribution of forms of terlinguaite.

Pinacoids........................

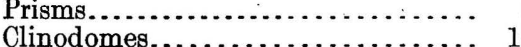

Positive orthodomes................. 14

Negative orthodomes................ 20

Positive pyramids $h l l \ldots \ldots \ldots \ldots \ldots .16$

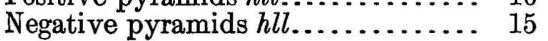

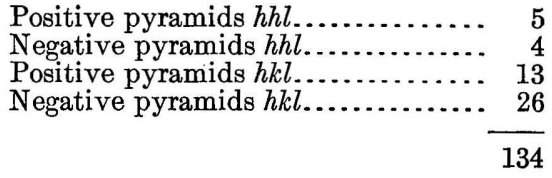

HABIT.

Crystals of terlinguaite possess three distinct habits:

1. Prismatic habit. In this habit the crystals are elongated in one direction, usually the $b$ axis, similarly to the common habit of epidute. Crystal 1 (fig. 23) shows this habit well. More rarely, the elongation is in a pyramidal direction, such as shown by crystals 6 and 7 (figs. $26,27,28)$. No crystal has been observed where the elongation is parallel to the vertical axis.

2. Equidimensional habit. The crystals of this habit are thick and short and very rich in faces, many of which are of about the same size. Crystal 9. (fig. 30) is of this habit.

3. Tabular to $a\{100\}$. The large development of the orthopinacoid causes the crystals to assume a tabular shape, though the other forms present are never so small as to make the crystals thin tabular. Crystals 3 and 4 (figs. 24 and 25) approach this habit.

All of the three habits described above were noted by Moses. Some of the crystals have a thin tabular appearance due to the development of a large "contact face" where the terlinguaite rested on the calcite. This "contact face" may be so large as to give an altogether different shape to the crystal, although it has of course no crystallographical significance.

c Zambonini, F., Krystallographisches über den Epidot: Zeitschr. Kryst. Min., vol. 37, 1903, p. 21. 
DESCRIPTION OF CRYSTALS.

Crystal 1 (fig. 23), the first crystal measured, is one which has a large number of forms, the crystal being extended in the direction of the $b$ axis, with the zone of orthodomes somewhat striated parallel to their intersection. The crystal, not complete, is terminated at both ends, and has in addition a small cavity, in the rear, the interior of which is profusely covered with faces. The drawing shown in figure 23 gives a general idea of the habit of the crystal, but shows only the largest faces. The exact relation of the small pyramids to the surrounding faces is difficult to decipher, on account of their small size. The rear of the crystal, not shown in the drawing, is very rich in faces. A total number of $\mathbf{1 0 6}$ faces were measured on this crystal,

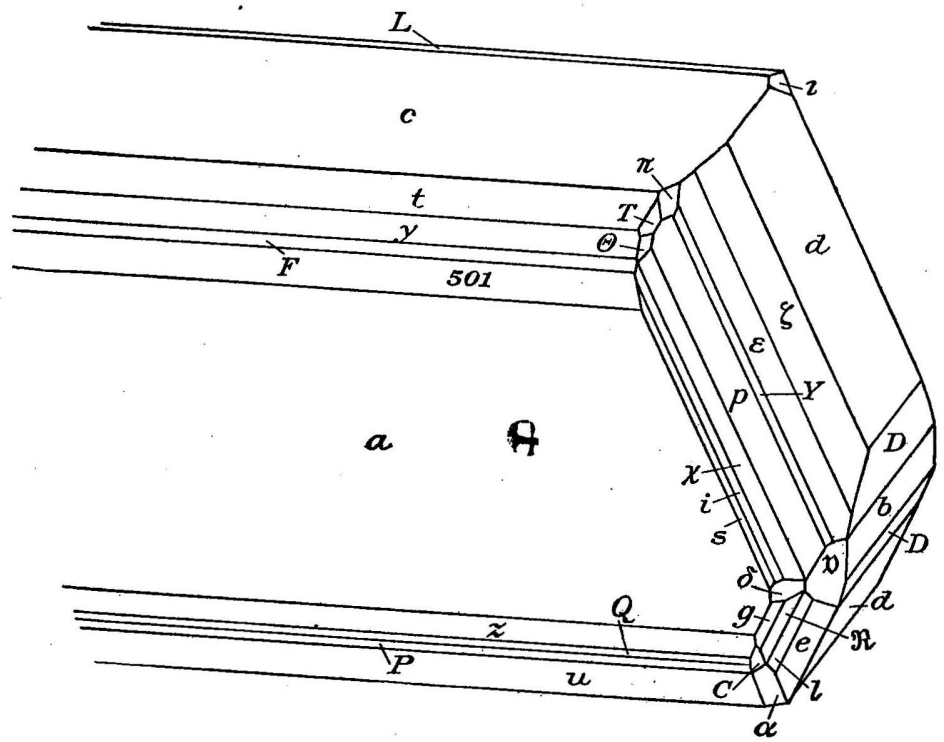

FIGURE 23.-Terlinguaite crystal 1: $c\{001\}, a\{100\}, b\{010\}, L\{\overline{1} 04\}, t\{102\}, y\{101\}, F\{503\}, z\{\overline{3} 01\}$, $Q\{\overline{3} 02\}, P\{\overline{4} 03\}, u\{\overline{1} 01\}, d\{011\}, D\{031\}, \zeta\{144\},\{\{133\}, \quad Y\{233\}, p\{111\}, \chi\{322\}, i\{211\}, s\{311\}$, $\delta\{210\}, \mathfrak{b}\{230\}, g\{\overline{2} 11\}, \mathbb{R}\{\overline{3} 22\}, l\{\overline{4} 33\}, e\{\overline{1} 11\}, \pi\{112\}, T\{213\}, \theta\{212\}, C\{\overline{4} 13\}, \sigma\{\overline{3} 13\}, \angle\{\overline{1} 24\}$.

but about 20 gave such poor reflections on account of their minute size or uneven surface that they could not definitely be determined. Four forms, all except the first one showing two faces, were noted only on this crystal. The forms are $\mathfrak{u}\{230\}, F\{503\}, U\{\overline{3} .1 .11\}$, $\Lambda\{131\}$. A few doubtful or vicinal forms also present on this crystal were described on page 109.

Crystal 3 (fig. 24) is a small incomplete crystal with a large striated face of $a\{100\}$ and a number of very small orthodomes, one of which, $M\{\overline{1} 07\}$, is of especial interest, for, though a negative dome, it lies in front of the pole in the gnomonic projection, the angle (107):(001) being less than $\beta$. The shape of this crystal is determined by the presence of a large "contact face," about in the position of $+\{3.4 .12\}$, 
which is in the rear of the crystal shown in figure 24. The broken space in the upper front part is occupied by irregularly bounded faces, some of which are parallel to those shown in the figure. The zone (111):(013) is a prominent one with a large face of $\{124\}$. Only one other form besides $M\{\overline{1} 07\}$, namely $W\{632\}$, was observed on this crystal and on no other.

Crystal 4 (fig. 25), like the preceding one, is somewhat flattened parallel to the large $a$ face. The clinodomes are present as large faces, but the clinopinacoid is entirely lacking. The zone (301) : (031) is well developed,large faces of (411) and

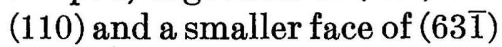

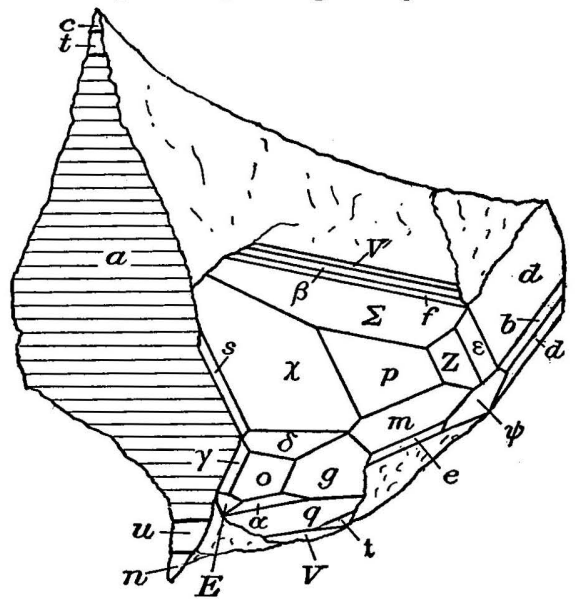

FIGURE 24.-Terlinguaite crystal 3: $u\{\overline{1} 01\}, \quad n\{\overline{1} 02\}$, $f\{013\}, Z\{122\}, \Sigma\{124\}, \beta\{\overline{1} 15\}, V\{\overline{3} 19\}, \gamma\{\overline{4} 11\}, \psi\{\overline{1} 22\}$, $E\{\overline{5} 13\}, q\{\overline{3} 15\}, t\{\overline{2} 15\}$.

being present. The large face of $(35 \overline{5})$ was strongly striated and gave two reflections, one of which agreed with (355) and the other with $(12 \overline{2})$. On the other side of the crystal a long line face of the rare

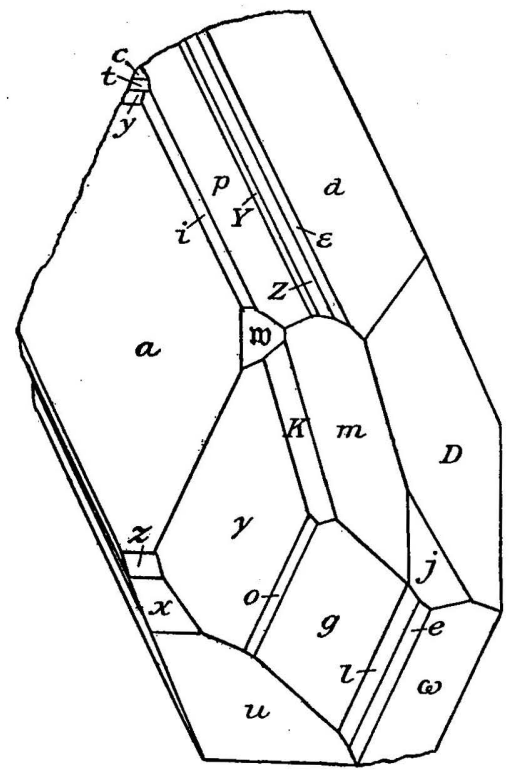

FrguRE 25.-Terlinguaite crystal 4: $\mathfrak{t n}\{520\}$, $j\{120\}, z\{\overline{3} 01\}, x\{\overline{2} 01\}, \omega\{\overline{3} 55\}, K\{\overline{6} 31\}$. form $\mathfrak{m}\{\overline{6} 35\}$, also noted on crystal 5 ,

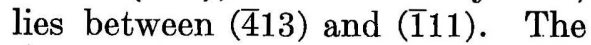
prism $\mathfrak{n t}\{520\}$, shown in figure 25 , occurs only on this crystal.

Crystal 6 (fig. 26) is the most interesting as well as the most complex of all those examined. The crystal originally measured 15 millimeters in length, but it was so firmly held on the specimen that on removal it cleaved into seven pieces, all of which were saved and measured. The central piece is the largest and is terminated at both ends by the cleavage faces of $\{\overline{1} 01\}$. The remarkable feature of this crystal is that its prismatic shape is due to the development of the zone (103): (010), the three faces $b\{010\}, \varepsilon\{133\}, O\{113\}$ being present as long faces with parallelintersections. Moreover, the orthodome zone is strongly striated and built up of alternating faces of (102) with (103) or (105), thus yielding a rounded dome surface 
whose intersections with $\{113\}$ are more or less parallel to the edgres of the zone (103):(010). The alternating faces of the orthodome zone make it difficult to represent the crystal in the drawing, therefore in figure 26 the intersection edges have been given an interme-

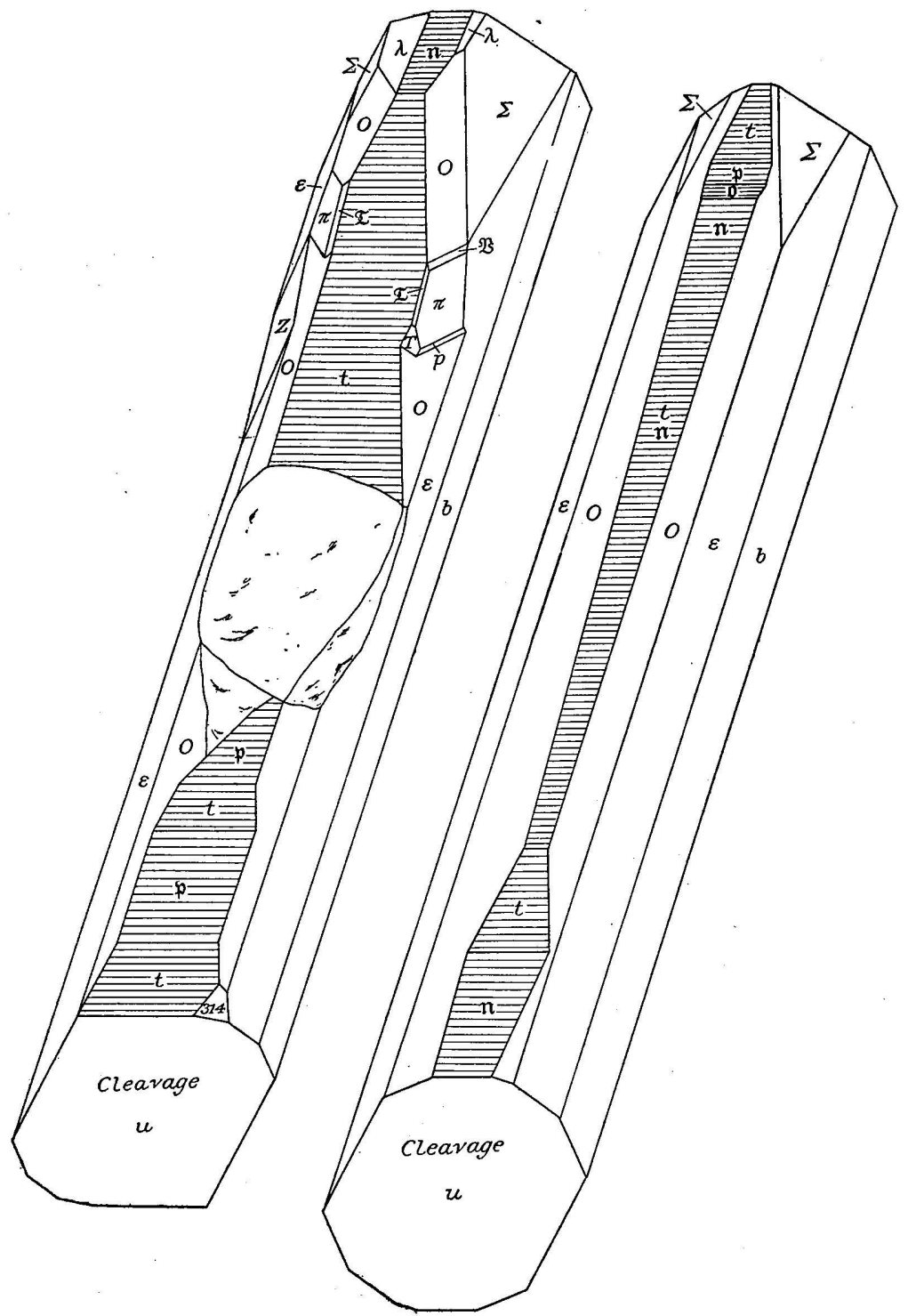

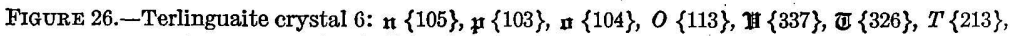
$\lambda\{115\}, Z\{122\}, \Sigma\{124\}, \in\{133\}, t\{102\}$.

diate position and drawn as straight lines. The faces of the form $\{124\}$ in reality extend down almost the entire length of the crystal, appearing as small facets between $\{113\}$ and $\{133\}$. In the drawings shown it was intended to give a general idea of the habit of the 
crystal rather than an absolutely correct view, which, by reason of the frequent alternating occurrence of two or more forms, would be very difficult. The two views shown in figure 26 represent the two sides of the crystal. None of the other six parts of the crystal have been illustrated, as they do not show any particular features.

This crystal is particularly rich in small or minute faces, many of them mere line faces. A total of 16 forms were observed only on this crystal. These are $\mathfrak{f}\{045\}, \mathfrak{y}\{035\}, \mathfrak{h}\{012\}$, a $\{049\}, \mathfrak{h}\{025\}$, a $\{104\}, W\{301\}, \mathfrak{k}\{12.0 .1\}, \mathfrak{C}\{\overline{5} 02\}$,

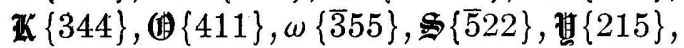
舀 $\{\overline{3} 34\}, 8\{3.4 .14\}$.

Crystal 7 (figs. 27 and 28) is a small crystal very rich in faces, being incomplete only on one end. By the large development of certain pyramids and the occurrence of the orthodomes as very narrow vertical faces, the crystal has a peculiar cone-shaped appearance which is illustrated in figures 27 and 28 , showing the front and back of this crystal. The upper termination on figure 27 is drawn larger than it is in reality, to better show the relations of the numerous forms occurring there. The zone (301): (031) is again well developed, except for $(30 \overline{1})$, which is not present, and it is the presence of $(41 \overline{1})$, (63) $),(110)$, and (031), all intersecting in parallel lines, which gives the crystal its curious appearance. The zone (13) $):(010)$ is also well developed, the large faces of $\{131\}$ and $\{010\}$ playing their share in the habit of the crystal. The faces (102) and (001) are, in reality, very minute, the upper end of the crystal appearing almost like a point, as is better shown in figure 28 .

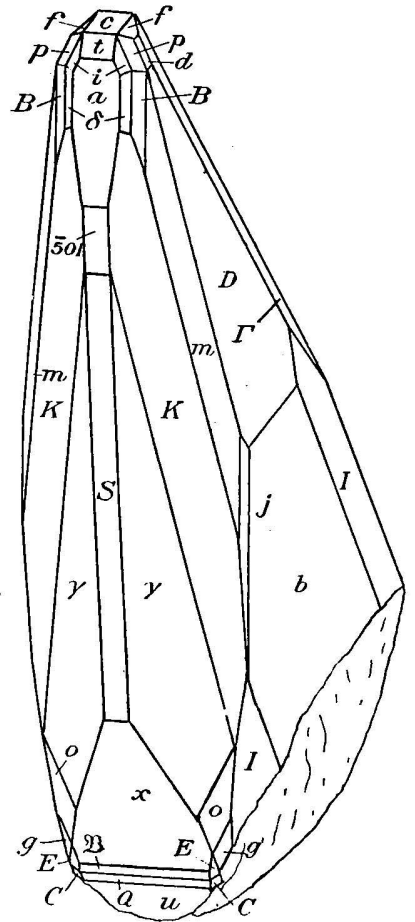

FIGURE 27.-Terlinguaite crystal 7 (front): $f\{013\}, D\{031\}, B\{320\}$, $x\{\overline{2} 01\}, Q\{\overline{3} 02\}, S\{\overline{4} 01\}$, 理 $\{\overline{5} 03\}$, $I\{\overline{1} 31\}, o\{\overline{3} 11\}, \gamma\{\overline{4} 11\}, \Gamma\{\overline{3} 44\}, K\{\overline{6} 31\}$, $E\{\overline{5} 13\}, C\{\overline{4} 13\}$.

While the side of the crystal shown in figure 27 is drawn in ideal proportion, the other side, figure 28 , is shown as it really appears. A different combination is seen here, though the essential pyramids of the entire crystal are negative. The pyramid $\{34 \overline{4}\}$ has a large face on one side and $\{4 \overline{3} \overline{5}\}$ occurs with a large face on the other side. These two forms with (031) determine the habit on this side of the crystal, the zone $(13 \overline{1}):(010)$, better developed on this side, also materially influencing its shape.

The prism zone is rather well developed, the forms present, in the order of their size, being $b\{010\}, m\{110\}, a\{100\}, j\{120\}, B\{320\}$, and $\delta\{210\}$. Altogether nineteen faces were measured in the prism 4494-Bull. 405- $-09-9$ 
zone. Of the orthodomes, $\theta\{\overline{5} 01\}$, present only once and only on

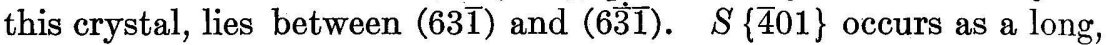
narrow face between the two faces of $\{\overline{4} 11\} . x\{\overline{2} 01\}$ is the largest orthodome on the crystal. $R\{\overline{4} 05\}$ and $y\{\overline{3} 04\}$ occur as long, narrow faces between $(43 \overline{5})$ and $(4 \overline{35})$ and $(32 \overline{4})$ and $(3 \overline{24})$, respectively. $D\{031\}$ is the only large clinodome on the crystal. To the brief description of the pyramids on this crystal, already given, need only be added the occurrence of $(51 \overline{5})$ and $(31 \overline{3})$, between $(11 \overline{1})$ and (10) the latter being probably a true crystal face and not a cleavage sur-

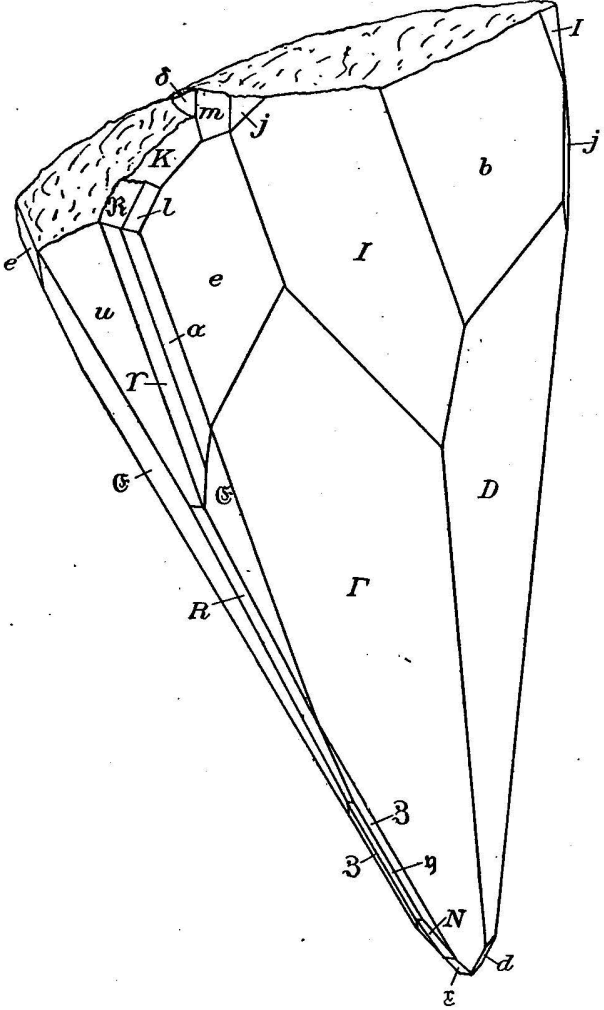

FIGURE 28.-Terlinguaite crystal 7 (back): $\delta\{210\}$, $\boldsymbol{x}\{\overline{3} 05\}, y\{304\}, \quad R\{\overline{4} 05\}, \quad N\{\overline{2} 03\}, \quad \Gamma\{\overline{3} 44\}, Z \mathbf{Z}\{\overline{3} 24\}$,

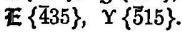

but more as they actually appear. The left-hand side of the crystal is, however, drawn in ideal proportion to the right-hand half. The crystal belongs to and well represents the second or equidimensional habit, and also shows the richness of combination usual on crystals of this habit. The zonal relations of the various faces can be made out in the drawing, every face present lying in at least one well developed zone. Some of the more prominent zones seen on this crystal, with the faces belonging to them, are: The orthodome zone with (001), (105), (102), (203), (401), (100), 
$(20 \overline{1}),(30 \overline{2}),(60 \overline{5}),(10 \overline{1}),(30 \overline{4}),(20 \overline{3}),(30 \overline{5}),(10 \overline{2})$; also, but not shown in the drawing, $(20 \overline{1}),(10 \overline{4}),(12.0 . \overline{1})$; the prism zone with

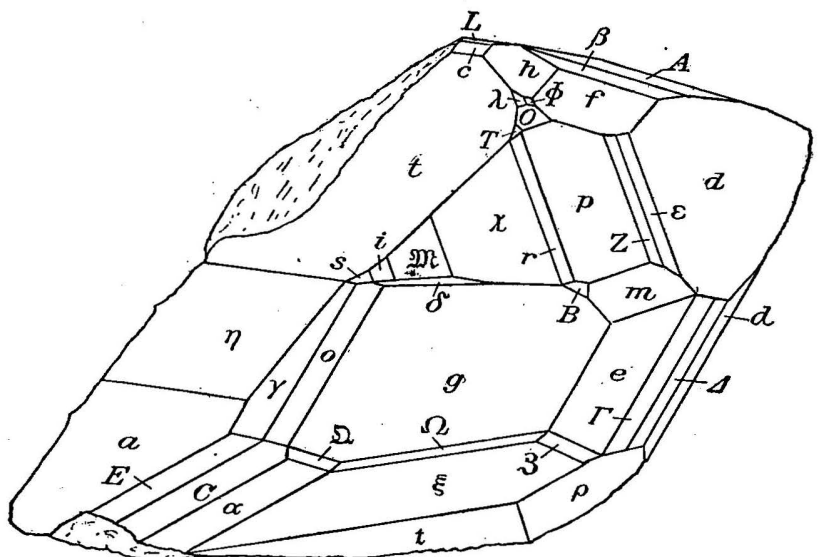

FIGURE 29.-Terlinguaite crystal 8: $L\{\overline{1} 04\}, h\{015\}, \eta\{901\}, \delta\{210\}, B\{320\}, A\{\overline{2} 17\}, r\{433\}, \chi\{322\}, \Delta\{\overline{2} 33\}$, $E\{\overline{5} 13\}$, 但 $\{\overline{5} 24\}, \xi\{\overline{2} 13\}, Z\{\overline{3} 24\}$, 赴 $\{533\}, \Gamma\{\overline{3} 44\}, g\{\overline{2} 11\}, \gamma\{\overline{4} 11\}, C\{\overline{4} 13\}, \Omega\{\overline{2} 12\}, \rho\{\overline{1} 13\}, \mathfrak{t}\{\overline{2} 15\}$.

(100), (830), (210), (320), (110), (120), (010); the clinodome zone, with (001), (017),. (015), (013,) (011), (010) (note that the last

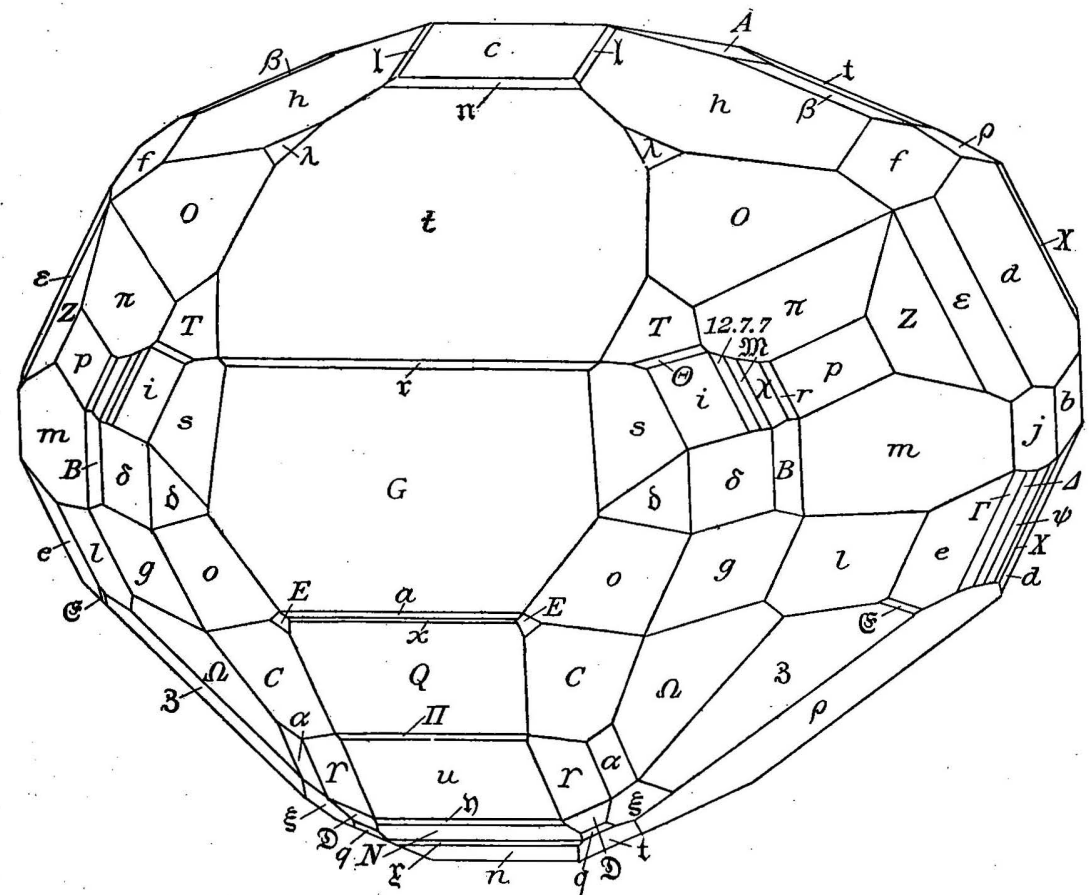

FIGURE 30.-Terlinguaite crystal 9: $\mathfrak{I}\{017\}, h\{015\}, f\{013\}, d\{011\}$, in $\{830\}, \delta\{210\}, B\{320\}, j\{120\}, \mathfrak{n}\{105\}$, $\mathbf{r}\{203\}, t\{102\}, G\{401\}, x\{\overline{2} 01\}, \Pi\{\overline{6} 05\}, u\{\overline{1} 01\}$, y $\{\overline{3} 05\}, N\{\overline{2} 03\}, x\{\overline{3} 05\}, n\{\overline{1} 02\}, s\{311\}, \lambda\{115\}, O\{113\}$, $p\{111\}, \pi\{112\}$, $\{533\}, r\{433\}, Z\{122\}, \epsilon\{133\}, X\{\overline{1} 33\}, g\{\overline{2} 11\}, \Psi\{\overline{1} 22\}, \Delta\{\overline{2} 33\}, l\{\overline{4} 33\}, \Gamma\{\overline{3} 44\}$, 正 $\{\overline{4} 35\}$, $Z\{\overline{3} 24\}, E\{\overline{5} 13\}, \Omega\{\overline{2} 12\}, C\{\overline{4} 13\}, \xi\{\overline{2} 13\}, t\{\overline{2} 15\}, \alpha\{\overline{3} 13\}, \beta\{\overline{1} 15\}, r\{\overline{5} 15\}$, 目 $\{\overline{4} 15\}, q\{\overline{3} 15\}, \rho\{\overline{1} 13\}, T\{2: 3\}$.

intercept decreases regularly by 2 ); the pyramid zones (positive and negative), (100), (311), (211), (12.7.7), (533), (322), (655), (111), 


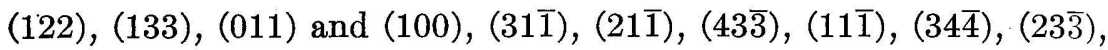
$(12 \overline{2}),(13 \overline{3}),(01 \overline{1})$, and several other forms not shown in the drawing. Further zones are (001), (115), (113), (112), (111), (110), (111) $,(11 \overline{3}),(00 \overline{1}) ;(213),(212),(211),(210),(21 \overline{1}),(21 \overline{2}),(21 \overline{3})$, (215). All of the positive forms shown in the drawing are included in one or more of the above zones. The negative pyramids are particularly well developed in zones, the forms shown in the figure falling in the zones $(100),(51 \overline{3}),(41 \overline{3}),(31 \overline{3}),(21 \overline{3}),(11 \overline{3}),(01 \overline{3})$;

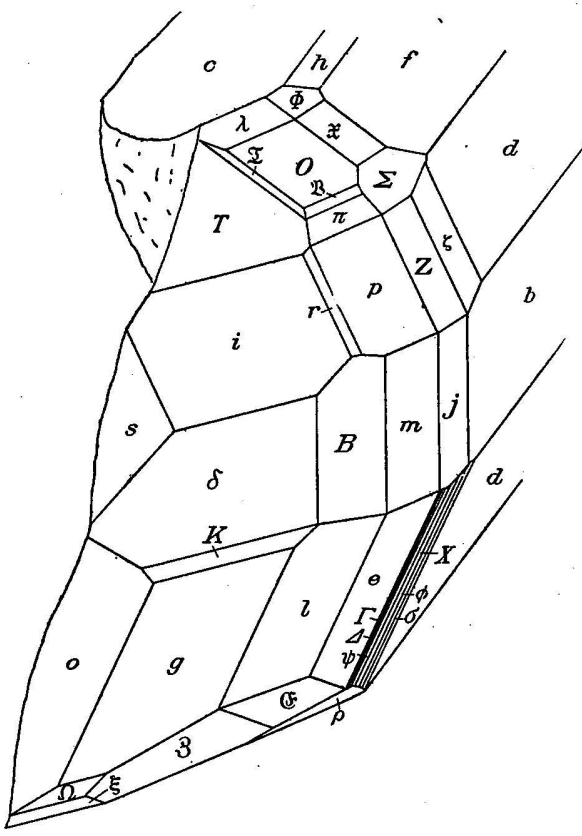

Figure 31.-Terlinguaite crystal 11: $o\{\overline{3} 11\}, \zeta\{144\}$, $r\{433\}, K\{\overline{6} 31\}, \sigma\{\overline{1} 55\}, l\{\overline{4} 33\}, \phi\{\overline{1} 44\}, X\{\overline{1} 33\}$, $\psi\{\overline{1} 22\}, \Delta\{\overline{2} 33\}, \Gamma\{\overline{3} 44\}, \Omega\{\overline{2} 12\}, \mathbb{E}\{\overline{4} 35\}, \xi\{\overline{2} 13\}$, $Z\{\tilde{3} 24\}, \rho\{\overline{1} 13\}$.

$(51 \overline{5}),(41 \overline{5}),(31 \overline{5}),(21 \overline{5}),(11 \overline{5})$, $(01 \overline{5}) ;(10 \overline{2}),(31 \overline{5}),(21 \overline{3}),(32 \overline{4})$, $(43 \overline{5}),(11 \overline{1})$. The zone (013),

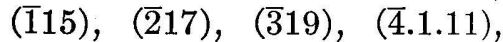
(102) is also well developed. The following forms were observed only on crystal 9: ป̀ $\{830\}, \mathfrak{I}\{\overline{1} \overline{2} .0 .1\}$.

On crystal 11 (fig. 31) the clinodomes are.:developed as large long faces, the base being present as the largest face on the crystal, thus giving it a rather unusual appearance. A part of the crystal is shown in figure 31 , where the unusual features are the relatively large development of the positive pyramids, lying in the zones (120), $Z(122), \quad \Sigma(124), \quad \not(126)$, $\Phi(128)$ (note that the last index increases regularly by 2); and $T(213)$, ㅈ (326), (113), (126), (013). The rather rare form $\{337\}$ is also shown. The following forms were observed only on this crystal: $\mathfrak{\mathfrak { y }}\{308\}, \mathfrak{r}\{317\}, \mathfrak{a}\{\overline{2} 16\}$.

DIFFERENT ORIENTATIONS AND TRANSFORMATION SYMBOLS.

No orientation was found which was better than the one here adopted, namely, $\mathrm{M}_{2}$. About the only drawback to it is that the cleavage form is not a pinacoid, such as $\{001\}$, but a rear dome $\{\overline{1} 01\}$. After considerable study of the gnomonic projection, the writer decided that the two orientations here given, $\mathrm{S}_{1}$ and $\mathrm{S}_{2}$, were the best that could be formed after $\mathrm{M}_{2}$. A glance at the list of forms on the following pages will show, however, that much of the 
simplicity of the indices under $\mathrm{M}_{2}$ is lost under $\mathrm{S}_{1}$ and $\mathrm{S}_{2}$. In the orientation $\mathrm{S}_{1}$ the cleavage is made the base, the orthopinacoid being kept as such, but the angle $\beta$ becomes very small $\left(44^{\circ} 04^{\prime}\right)$. Under $\mathrm{S}_{2}$ the cleavage again becomes the base, but the form $\{101\}$ $\mathrm{M}_{2}$ is now the orthopinacoid. While this affords a generally good orientation, the symbols of many of the forms become rather complex.

A good idea of the relative merits of the different orientations may be obtained from the following table, showing the relative indices of some forms:

Indices of several forms for different orientations of terlinguaite.

\begin{tabular}{|l|l|l|l|l|l|l|l|l|l|}
\hline $\mathrm{M}_{1} \ldots \ldots .$. & 001 & 100 & 130 & 011 & 103 & $\overline{1} 03$ & $\overline{2} 03$ & 133 & $\overline{1} 33$ \\
$\mathrm{M}_{2} \ldots \ldots$. & 001 & 100 & 110 & 011 & 101 & $\overline{1} 01$ & $\overline{2} 01$ & 111 & $\overline{1} 11$ \\
$\mathrm{~S}_{1} \ldots \ldots .$. & $\overline{1} 01$ & 100 & 110 & $\overline{1} 11$ & $\overline{2} 01$ & 001 & 101 & $\overline{2} 11$ & 011 \\
$\mathrm{~S}_{2} \ldots \ldots$. & $\overline{1} 01$ & 101 & 111 & $\overline{1} 11$ & 100 & 001 & 103 & 110 & 012 \\
\hline
\end{tabular}

Following are the elements for the different orientations:

Elements for different orientations of terlinguaite.

\begin{tabular}{|c|c|c|}
\hline $\begin{array}{c}\text { Orienta- } \\
\text { tion. }\end{array}$ & $a: b: c$. & $\beta$ \\
\hline & & $\circ$, \\
$\mathrm{M}_{1} \ldots \ldots$. & $.5338: 1: 2.0245$ & 7423 \\
$\mathrm{M}_{2} \ldots \ldots$. & $1.6050: 1: 2.0245$ & 7423 \\
$\mathrm{~S}_{1} \ldots \ldots .$. & $2.2169: 1: 2.0245$ & 4404 \\
$\mathrm{~S}_{2} \ldots \ldots .$. & $1.1088: 1: 1.4499$ & 7612 \\
\hline
\end{tabular}

Following are the transformation symbols:

$$
\begin{aligned}
& p \cdot q\left(\mathrm{M}_{1}\right)=3 p \cdot q\left(\mathrm{M}_{2}\right), \quad \text { or } h_{1} \cdot k_{1} \cdot l_{1}\left(\mathrm{M}_{2}\right)=3 h \cdot k \cdot l\left(\mathrm{M}_{1}\right) . \\
& p \cdot q\left(\mathrm{M}_{2}\right)=-(p+1) \cdot q\left(\mathrm{~S}_{1}\right), \text { or } h_{2} \cdot k_{2} \cdot l_{2}\left(\mathrm{~S}_{1}\right)=-\left(h_{1}+l_{1}\right) \cdot k_{1} \cdot l_{1}\left(\mathrm{M}_{2}\right) . \\
& p \cdot q\left(\mathrm{M}_{2}\right)=\frac{p+1}{p-1} \cdot \frac{q}{p-1}\left(\mathrm{~S}_{2}\right), \text { or } h_{3} \cdot k_{3} \cdot l_{3} \cdot\left(\mathrm{S}_{2}\right)=-\left(h_{1}+l_{1}\right) \cdot 2 k_{1} \cdot-\left(h_{1}-l_{1}\right)\left(\mathrm{M}_{2}\right) .
\end{aligned}
$$

The following table shows the indices of all the forms in the four different orientations given above. As can readily be seen, that of $M_{2}$ is much to be preferred. 
Indices for different orientations of terlinguaite forms.

\begin{tabular}{|c|c|c|c|c|c|c|c|c|}
\hline Letter. & $\begin{array}{l}\text { Gdt. } \\
\mathrm{M}_{1} .\end{array}$ & $\begin{array}{c}\text { Miller } \\
\mathrm{M}_{1} .\end{array}$ & $\begin{array}{l}\text { Gdt. } \\
\mathrm{M}_{2} .\end{array}$ & $\begin{array}{c}\text { Miller } \\
\mathrm{M}_{2} .\end{array}$ & $\begin{array}{c}\text { Gdt. } \\
\mathrm{S}_{1} .\end{array}$ & $\underset{\mathrm{S}_{1} \text {. }}{\text { Miller }}$ & $\begin{array}{c}\text { Gdt. } \\
\mathrm{S}_{2} .\end{array}$ & $\begin{array}{c}\text { Miller } \\
\mathrm{S}_{2}\end{array}$ \\
\hline $\begin{array}{l}c \\
b \\
a \\
j \\
\mathfrak{u}\end{array}$ & $\begin{array}{c}0 \\
0 \infty \\
\infty 0 \\
\infty 6 \\
\infty \frac{9}{2}\end{array}$ & $\begin{array}{l}001 \\
010 \\
100 \\
160 \\
290\end{array}$ & $\begin{array}{c}0 \\
0 \infty \\
\infty 0 \\
\infty 2 \\
\infty \frac{3}{2}\end{array}$ & $\begin{array}{l}001 \\
010 \\
100 \\
120 \\
230\end{array}$ & $\begin{array}{c}-10 \\
0 \infty \\
\infty 0 \\
\infty 2 \\
\infty \frac{3}{2}\end{array}$ & $\begin{array}{l}101 \\
010 \\
100 \\
120 \\
230\end{array}$ & $\begin{array}{r}-10 \\
0 \infty \\
+10 \\
+12 \\
+1_{2}^{3}\end{array}$ & $\begin{array}{l}701 \\
010 \\
101 \\
1: 1 \\
2: 32\end{array}$ \\
\hline $\begin{array}{l}m \\
B \\
\delta \\
\mathfrak{w} \\
\mathfrak{d}\end{array}$ & $\begin{array}{l}\infty 3 \\
\infty 2 \\
\infty \frac{3}{2} \\
\infty \frac{6}{5} \\
\infty \frac{9}{8}\end{array}$ & $\begin{array}{l}130 \\
120 \\
230 \\
560 \\
890\end{array}$ & $\begin{array}{c}\infty \\
\frac{3}{2} \infty \\
2 \infty \\
\frac{5}{2} \infty \\
\frac{8}{3} \infty\end{array}$ & $\begin{array}{l}110 \\
320 \\
210 \\
520 \\
830\end{array}$ & $\begin{array}{c}\infty \\
\frac{3}{2} \infty \\
2 \infty \\
\frac{5}{2} \infty \\
\frac{8}{3} \infty\end{array}$ & $\begin{array}{l}110 \\
320 \\
210 \\
520 \\
830\end{array}$ & $\begin{array}{l}+1 \\
+1 \frac{2}{3} \\
+1 \frac{1}{2} \\
+1 \frac{2}{5} \\
+1 \frac{3}{8}\end{array}$ & $\begin{array}{l}111 \\
323 \\
212 \\
525 \\
838\end{array}$ \\
\hline $\begin{array}{l}\stackrel{p}{D} \\
D \\
d \\
\mathfrak{f} \\
\mathfrak{g}\end{array}$ & $\begin{array}{c}2 \infty \\
03 \\
01 \\
05 \\
0 \frac{1}{5}\end{array}$ & $\begin{array}{l}210 \\
031 \\
011 \\
045 \\
035\end{array}$ & $\begin{array}{c}6 \infty \\
03 \\
01 \\
04 \\
0 \frac{4}{5}\end{array}$ & $\begin{array}{l}610 \\
031 \\
011 \\
045 \\
035\end{array}$ & $\begin{array}{c}6 \infty \\
-13 \\
-1 \\
-14 \\
-1 \frac{3}{5}\end{array}$ & $\begin{array}{l}610 \\
131 \\
111 \\
\overline{5} 45 \\
\overline{5} 35\end{array}$ & $\begin{array}{c}+1 \frac{1}{6} \\
-13 \\
-1 \\
-1 \frac{4}{5} \\
-1 \frac{3}{5}\end{array}$ & $\begin{array}{l}616 \\
131 \\
111 \\
515 \\
535\end{array}$ \\
\hline $\begin{array}{l}\mathfrak{h} \\
\mathfrak{a} \\
\mathfrak{h} \\
f \\
h\end{array}$ & $\begin{array}{l}0 \frac{1}{2} \\
04 \\
0 \frac{4}{5} \\
0 \frac{1}{3} \\
0 \frac{1}{5}\end{array}$ & $\begin{array}{l}012 \\
049 \\
025 \\
013 \\
015\end{array}$ & $\begin{array}{l}0 \frac{1}{2} \\
04 \\
0 \frac{4}{5} \\
0 \frac{1}{3} \\
0 \frac{1}{5}\end{array}$ & $\begin{array}{l}012 \\
049 \\
025 \\
013 \\
015\end{array}$ & $\begin{array}{l}-1 \frac{1}{2} \\
-1 \\
-1 \frac{1}{15} \\
-1 \frac{1}{3} \\
-1 \frac{1}{5}\end{array}$ & $\begin{array}{l}\overline{2} 12 \\
\overline{9} 49 \\
\overline{5} 25 \\
\overline{3} 13 \\
\overline{5} 15\end{array}$ & $\begin{array}{l}-1 \frac{1}{2} \\
-1 \frac{4}{9} \\
-1 \frac{2}{5} \\
-1 \frac{1}{3} \\
-1 \frac{1}{5}\end{array}$ & $\begin{array}{l}\overline{3} 12 \\
\overline{5} 19 \\
\overline{5} 25 \\
\overline{3} 13 \\
\overline{5} 15\end{array}$ \\
\hline $\begin{array}{l}\mathfrak{l} \\
\mathfrak{n} \\
\mathfrak{n} \\
\mathfrak{p} \\
\mathfrak{z}\end{array}$ & $\begin{array}{r}01 \\
+\frac{1}{7} \\
+\frac{1}{15} 0 \\
+\frac{1}{12} 0 \\
+190 \\
+\frac{1}{8} 0\end{array}$ & $\begin{array}{r}017 \\
\text { 1. } 0.15 \\
\text { 1. } 0.12 \\
109 \\
108\end{array}$ & $\begin{array}{r}01 \\
+\frac{1}{7} 0 \\
+\frac{1}{4} 0 \\
+\frac{1}{3} 0 \\
+\frac{3}{8} 0\end{array}$ & $\begin{array}{l}017 \\
105 \\
104 \\
103 \\
308\end{array}$ & $\begin{array}{r}-1 \frac{1}{7} \\
-\frac{6}{5} 0 \\
-\frac{5}{4} 0 \\
-10 \\
-\frac{1}{8} 0\end{array}$ & $\begin{array}{r}\overline{7} 17 \\
\overline{6} 05 \\
\overline{5} 04 \\
\overline{4} 03 \\
\overline{11} .0 .8\end{array}$ & $\begin{array}{r}-1 \frac{1}{7} \\
-32 \\
-50 \\
-20 \\
-20 \\
-\frac{11}{5} 0\end{array}$ & $\begin{array}{r}\overline{7} 17 \\
502 \\
\overline{5} 03 \\
\overline{5} 01 \\
\overline{1} 1.01\end{array}$ \\
\hline $\begin{array}{l}t \\
\mathfrak{r} \\
\mathbb{2} \\
y \\
y\end{array}$ & $\begin{array}{r}+\frac{1}{6} 0 \\
+20 \\
+\frac{1}{4} 0 \\
+\frac{1}{3} 0 \\
+40\end{array}$ & $\begin{array}{r}106 \\
209 \\
104 \\
103 \\
409\end{array}$ & $\begin{array}{l}+\frac{1}{2} 0 \\
+\frac{2}{3} 0 \\
+\frac{3}{4} 0 \\
+10 \\
+{ }_{3}^{4} 0\end{array}$ & $\begin{array}{l}102 \\
203 \\
304 \\
101 \\
403\end{array}$ & $\begin{array}{l}-\frac{3}{2} 0 \\
-\frac{5}{3} 0 \\
-\frac{7}{4} 0 \\
-20 \\
-\frac{7}{3} 0\end{array}$ & $\begin{array}{l}\overline{3} 02 \\
\overline{5} 03 \\
\overline{7} 04 \\
\overline{2} 01 \\
\overline{7} 03\end{array}$ & $\begin{array}{r}-30 \\
-50 \\
-70 \\
\infty 0 \\
+70\end{array}$ & $\begin{array}{l}301 \\
501 \\
\overline{7} 01 \\
100 \\
701\end{array}$ \\
\hline $\begin{array}{l}F \\
w \\
G \\
\eta \\
\mathfrak{k}\end{array}$ & $\begin{array}{l}+50 \\
+10 \\
+130 \\
+30 \\
+30 \\
+40\end{array}$ & $\begin{array}{l}509 \\
101 \\
403 \\
301 \\
401\end{array}$ & $\begin{array}{r}+50 \\
+30 \\
+40 \\
+90 \\
+12.0\end{array}$ & $\begin{array}{r}503 \\
301 \\
401 \\
901 \\
12.0 .1\end{array}$ & $\begin{array}{r}-\frac{8}{3} 0 \\
-40 \\
-50 \\
-10.0 \\
-13.0\end{array}$ & $\begin{array}{r}\overline{8} 03 \\
\overline{4} 01 \\
\overline{501} \\
\overline{1} \overline{0} .0 .1 \\
\overline{1} \overline{3} .0 .1\end{array}$ & $\begin{array}{r}+40 \\
+20 \\
+530 \\
+54 \\
+\frac{5}{14} 0 \\
+\frac{1}{11} 0\end{array}$ & $\begin{array}{r}401 \\
201 \\
503 \\
504 \\
13.0 .11\end{array}$ \\
\hline 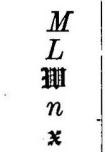 & $\begin{array}{r}-\frac{1}{21} 0 \\
-\frac{1}{12} 0 \\
-\frac{1}{1} 0 \\
-\frac{1}{4} 0 \\
-\frac{1}{6} 0 \\
-\frac{1}{5} 0\end{array}$ & $\begin{array}{r}\text { 1. } 0.21 \\
\text { 1. } 0.12 \\
\overline{1} 09 \\
\overline{1} 06 \\
\overline{1} 05\end{array}$ & $\begin{array}{l}-\frac{1}{7} 0 \\
-\frac{1}{4} 0 \\
-\frac{1}{3} 0 \\
-\frac{1}{2} 0 \\
-\frac{3}{5} 0\end{array}$ & $\begin{array}{l}\overline{1} 07 \\
\overline{1} 04 \\
\overline{1} 03 \\
\overline{1} 02 \\
\overline{1} 05\end{array}$ & $\begin{array}{l}-\frac{6}{7} 0 \\
-\frac{3}{4} 0 \\
-\frac{2}{3} 0 \\
-\frac{1}{2} 0 \\
-\frac{2}{5} 0\end{array}$ & $\begin{array}{l}\overline{6} 07 \\
\overline{3} 04 \\
\overline{2} 03 \\
\overline{1} 02 \\
\overline{2} 05\end{array}$ & $\begin{array}{l}-\frac{3}{4} 0 \\
-\frac{3}{5} 0 \\
-\frac{1}{2} 0 \\
-\frac{1}{3} 0 \\
-\frac{1}{4} 0\end{array}$ & $\begin{array}{l}\overline{3}(04 \\
\overline{3} 05 \\
\overline{1}(02 \\
\overline{1} 03 \\
\overline{1} 04\end{array}$ \\
\hline $\begin{array}{l}N \\
\mathbf{u} \\
R \\
u \\
I I\end{array}$ & $\begin{array}{r}-20 \\
-10 \\
-10 \\
-40 \\
-150 \\
-\frac{1}{3} 0 \\
-\frac{2}{5} 0\end{array}$ & $\begin{array}{r}\overrightarrow{2} 09 \\
\overline{1} 04 \\
\overline{4} .0 .15 \\
\overline{1} 03 \\
\overline{2} 05\end{array}$ & $\begin{array}{l}-\frac{2}{3} 0 \\
-\frac{3}{4} 0 \\
-40 \\
-40 \\
-10 \\
-\frac{6}{5} 0\end{array}$ & $\begin{array}{l}\overline{2} 03 \\
\overline{3} 04 \\
\overline{4} 05 \\
\overline{1} 01 \\
\overline{6} 05\end{array}$ & $\begin{array}{c}-\frac{1}{3} 0 \\
-\frac{1}{4} 0 \\
-\frac{1}{5} 0 \\
0 \\
+\frac{1}{5} 0\end{array}$ & $\begin{array}{l}\overline{1} 03 \\
\overline{1} 04 \\
\tilde{1} 05 \\
001 \\
105\end{array}$ & $\begin{array}{r}-\frac{1}{5} 0 \\
-\frac{1}{7} 0 \\
-\frac{1}{9} 0 \\
0 \\
+\frac{1}{11} 0\end{array}$ & $\begin{array}{r}\overline{1} 05 \\
\overline{1} 07 \\
109 \\
001 \\
\text { 1. } 0.11\end{array}$ \\
\hline 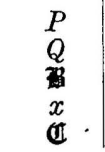 & $\begin{array}{l}-40 \\
-\frac{4}{9} 0 \\
-\frac{1}{2} 0 \\
-\frac{5}{4} 0 \\
-\frac{2}{3} 0 \\
-\frac{5}{6} 0\end{array}$ & $\begin{array}{l}\overline{4} 09 \\
\overline{1} 02 \\
\overline{5} 09 \\
\overline{2} 03 \\
\overline{5} 06\end{array}$ & $\begin{array}{r}-\frac{4}{3} 0 \\
-30 \\
-5,50 \\
-20 \\
-20 \\
-\frac{5}{2} 0\end{array}$ & $\begin{array}{l}\overline{4} 03 \\
\overline{3} 02 \\
\overline{5} 03 \\
\overline{2} 01 \\
\overline{5} 02\end{array}$ & $\begin{array}{l}+\frac{1}{3} 0 \\
+\frac{1}{2} 0 \\
+\frac{2}{3} 0 \\
+10 \\
+\frac{3}{2} 0\end{array}$ & $\begin{array}{l}103 \\
102 \\
203 \\
101 \\
302\end{array}$ & $\begin{array}{l}+10 \\
+150 \\
+15 \\
+10 \\
+10 \\
+30 \\
+\frac{1}{7} 0\end{array}$ & $\begin{array}{l}107 \\
105 \\
104 \\
103 \\
307\end{array}$ \\
\hline
\end{tabular}


TERLINGUAITE.

Indices for different orientations of terlinguaite forms-Continued.

\begin{tabular}{|c|c|c|c|c|c|c|c|c|}
\hline Letter. & $\begin{array}{l}\text { Gdt. } \\
\mathrm{M}_{1} .\end{array}$ & $\underset{\mathbf{M}_{1} .}{\text { Miller }}$ & $\begin{array}{l}\text { Gdt. } \\
\mathrm{M}_{2} .\end{array}$ & $\begin{array}{c}\text { Miller } \\
\mathrm{M}_{2} \text {. }\end{array}$ & $\begin{array}{c}\text { Gdt. } \\
\mathrm{S}_{1} .\end{array}$ & $\begin{array}{c}\text { Miller } \\
\mathrm{S}_{1} .\end{array}$ & $\begin{array}{c}\text { Gdt. } \\
\mathrm{S}_{2} \text {. }\end{array}$ & $\underset{\mathrm{S}_{2} .}{\text { Miller }}$ \\
\hline $\begin{array}{l}z \\
S \\
\theta \\
Z \\
z \\
\mathfrak{J}\end{array}$ & $\begin{array}{l}-10 \\
-\frac{40}{3} 0 \\
-\frac{5}{3} 0 \\
-\frac{7}{3} 0 \\
-40\end{array}$ & $\begin{array}{l}\overline{1} 01 \\
\overline{4} 03 \\
\overline{5} 03 \\
\overline{7} 03 \\
\overline{4} 01\end{array}$ & $\begin{array}{r}-30 \\
-40 \\
-50 \\
-70 \\
-12.0\end{array}$ & $\begin{array}{r}\overline{3} 01 \\
\overline{4} 01 \\
\overline{5} 01 \\
\overline{7} 01 \\
\overline{12} .0 .1\end{array}$ & $\begin{array}{r}+20 \\
+30 \\
+40 \\
+60 \\
+11.0\end{array}$ & $\begin{array}{r}201 \\
301 \\
401 \\
601 \\
11.0 .1\end{array}$ & $\begin{array}{r}+\frac{1}{2} 0 \\
+\frac{3}{5} 0 \\
+30 \\
+30 \\
+\frac{2}{4} 0 \\
+1 \frac{1}{13} 0\end{array}$ & $\begin{array}{r}102 \\
305 \\
203 \\
304 \\
11.0 .13\end{array}$ \\
\hline $\begin{array}{l}\mathbf{r} \\
s \\
U \\
V \\
q\end{array}$ & $\begin{array}{l}+\frac{1}{4} \\
+1 \\
+\frac{1}{11} \\
-19 \\
-\frac{1}{5}\end{array}$ & $\begin{array}{r}117 \\
111 \\
\text { 1. } 1.11 \\
\overline{11} 19 \\
\overline{11} 15\end{array}$ & $\begin{array}{r}+\frac{3}{7} \frac{1}{7} \\
+31 \\
-\frac{3}{1} \frac{1}{11} \\
-\frac{1}{3} \frac{1}{9} \\
-\frac{3}{5} \frac{1}{5}\end{array}$ & $\begin{array}{r}317 \\
311 \\
\overline{3} .1 .11 \\
\overline{3} 19 \\
\overline{3} 15\end{array}$ & $\begin{array}{r}-101 \\
-7 \\
-41 \\
-\frac{1}{7} \\
-\frac{8}{11} \\
-\frac{2}{3} \frac{1}{9} \\
-\frac{2}{5} \frac{1}{5}\end{array}$ & $\begin{array}{r}10 . \frac{1}{4} .7 \\
\overline{4} .11 \\
\frac{6}{6} 19 \\
215\end{array}$ & $\begin{array}{r}-\frac{5}{2} 1 \\
+2 \frac{4}{4} \\
-\frac{4}{7} 14 \\
-\frac{1}{11} \\
-\frac{1}{2} 12 \\
-\frac{1}{4} \frac{1}{8}\end{array}$ & $\begin{array}{r}\overline{1} \overline{0} .1 .4 \\
412 \\
\overline{8} .1 .14 \\
\overline{6} .1 .12 \\
\overline{2} 18\end{array}$ \\
\hline 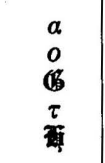 & $\begin{aligned} &-\frac{1}{3} \\
&-1 \\
&+\frac{1}{30} 1 \\
&+\frac{1}{24} 1 \\
&+\frac{1}{18} 1\end{aligned}$ & $\begin{array}{r}\overline{1} 13 \\
111 \\
1.30 .30 \\
1.24 .24 \\
1.18 .18\end{array}$ & $\begin{array}{r}-1 \frac{1}{3} \\
-31 \\
+1 \frac{1}{10} \\
+11 \\
+\frac{1}{6} 1\end{array}$ & $\begin{array}{r}\overline{3} 13 \\
\overline{3} 11 \\
1.10 .10 \\
188 \\
166\end{array}$ & $\begin{array}{r}01 \\
+21 \\
-21 \\
-\frac{11}{1} 1 \\
-\frac{9}{8} 1 \\
-\frac{7}{6} 1\end{array}$ & $\begin{array}{r}013 \\
211 \\
\text { 1̄1. } 10.10 \\
\overline{\overline{9}} 88 \\
\overline{7} 66\end{array}$ & $\begin{array}{r}01 \\
+\frac{1}{2} \\
-11 \\
-\frac{11}{9} \frac{10}{9} \\
-\frac{9}{7} 7 \\
-\frac{7}{5} \frac{6}{5}\end{array}$ & $\begin{array}{r}016 \\
214 \\
\text { I1. } 10.9 \\
\overline{9} 87 \\
\overline{7} 65\end{array}$ \\
\hline $\begin{array}{l}\mathbf{q} \\
\zeta \\
\varepsilon \\
Z \\
v\end{array}$ & $\begin{array}{r}+\frac{1}{151} \\
+\frac{1}{12} 1 \\
+\frac{1}{9} 1 \\
+\frac{1}{6} 1 \\
+\frac{1}{5} 1\end{array}$ & $\begin{array}{r}1.15 .15 \\
1.12 .12 \\
199 \\
166 \\
155\end{array}$ & $\begin{array}{l}+\frac{1}{5} 1 \\
+11 \\
+1 \\
+\frac{1}{3} 1 \\
+\frac{1}{2} 1 \\
+\frac{3}{5} 1\end{array}$ & $\begin{array}{l}155 \\
144 \\
133 \\
122 \\
355\end{array}$ & $\begin{array}{l}-\frac{6}{5} 1 \\
-\frac{5}{4} 1 \\
-\frac{4}{3} 1 \\
-\frac{3}{2} 1 \\
-\frac{8}{5} 1\end{array}$ & $\begin{array}{l}\overline{6} 55 \\
\overline{5} 44 \\
\overline{4} 33 \\
\overline{3} 22 \\
\overline{8} 55\end{array}$ & $\begin{array}{l}-\frac{3}{2} \frac{5}{4} \\
-\frac{5}{3} 3 \\
-2 \frac{3}{3} \\
-32 \\
-3 \frac{5}{2} \\
-4\end{array}$ & $\begin{array}{l}\overline{6} 54 \\
\overline{5} 43 \\
\overline{4} 32 \\
\overline{3} 21 \\
\overline{8} 52\end{array}$ \\
\hline $\begin{array}{l}Y \\
\stackrel{Y}{r} \\
p \\
r \\
\chi\end{array}$ & $\begin{array}{l}+\frac{2}{9} 1 \\
+\frac{1}{4} 1 \\
+\frac{1}{3} 1 \\
+\frac{4}{9} 1 \\
+\frac{1}{2} 1\end{array}$ & $\begin{array}{l}299 \\
144 \\
133 \\
499 \\
122\end{array}$ & $\begin{array}{l}+\frac{2}{3} 1 \\
+\frac{3}{4} 1 \\
+1 \\
+\frac{4}{3} 1 \\
+\frac{3}{2} 1\end{array}$ & $\begin{array}{l}233 \\
344 \\
111 \\
433 \\
322\end{array}$ & $\begin{array}{l}-\frac{5}{3} 1 \\
-\frac{7}{4} 1 \\
-21 \\
-\frac{7}{3} 1 \\
-\frac{5}{2} 1\end{array}$ & $\begin{array}{l}\overline{5} 33 \\
\overline{7} 44 \\
211 \\
\overline{7} 33 \\
\overline{5} 22\end{array}$ & $\begin{array}{r}-53 \\
-74 \\
\infty \\
+73 \\
+52\end{array}$ & $\begin{array}{l}\overline{5} 31 \\
741 \\
110 \\
731 \\
521\end{array}$ \\
\hline $\begin{array}{l}\text { 艘 } \\
i \\
0 \\
\sigma \\
\phi\end{array}$ & $\begin{array}{r}+5 \\
+51 \\
+31 \\
+\frac{3}{3} 1 \\
-\frac{1}{15} \\
-\frac{1}{12} 1\end{array}$ & $\begin{array}{r}599 \\
233 \\
433 \\
\overline{1} .15 .15 \\
\overline{1} .12 .12\end{array}$ & $\begin{array}{l}+51 \\
+31 \\
+21 \\
+41 \\
-\frac{1}{5} 1 \\
-\frac{1}{4} 1\end{array}$ & $\begin{array}{l}533 \\
211 \\
411 \\
155 \\
\overline{1} 44\end{array}$ & $\begin{array}{l}-\frac{8}{3} 1 \\
-31 \\
-51 \\
-\frac{4}{5} 1 \\
-\frac{3}{4} 1\end{array}$ & $\begin{array}{l}\overline{8} 33 \\
\overline{3} 11 \\
\overline{5} 11 \\
\overline{4} 55 \\
\overline{3} 44\end{array}$ & $\begin{array}{l}+43 \\
+31 \\
+31 \\
+\frac{5}{3} \\
-\frac{25}{35} \\
-\frac{3}{5} \\
-\frac{3}{5}\end{array}$ & $\begin{array}{l}832 \\
311 \\
513 \\
\frac{4}{4} 56 \\
345\end{array}$ \\
\hline $\begin{array}{l}X \\
\text { 零 } \\
\phi \\
\omega \\
\Delta\end{array}$ & $\begin{array}{r}-\frac{1}{9} 1 \\
-\frac{2}{15} \\
-\frac{1}{6} 1 \\
-\frac{11}{5} \\
-\frac{2}{9} 1\end{array}$ & $\begin{array}{r}\overline{1} 99 \\
\overline{2} .15 .15 \\
\overline{1} 66 \\
\overline{1} 55 \\
\overline{2} 99\end{array}$ & $\begin{array}{l}-\frac{1}{3} 1 \\
-\frac{2}{5} 1 \\
-\frac{1}{2} 1 \\
-\frac{3}{5} 1 \\
-\frac{2}{3} 1\end{array}$ & $\begin{array}{l}\overline{1} 33 \\
\overline{2} 55 \\
\overline{1} 22 \\
\overline{3} 55 \\
\overline{2} 33\end{array}$ & $\begin{array}{l}-\frac{2}{3} 1 \\
-\frac{3}{5} 1 \\
-\frac{1}{2} 1 \\
-\frac{2}{5} 1 \\
-\frac{1}{3} 1\end{array}$ & $\begin{array}{l}\overline{2} 33 \\
\overline{3} 55 \\
\overline{1} 22 \\
\overline{2} 55 \\
\overline{1} 33\end{array}$ & $\begin{array}{l}-\frac{1}{2} \frac{3}{4} \\
-\frac{3}{7} \frac{5}{7} \\
-\frac{1}{3} 3 \\
-\frac{1}{4} \\
-\frac{1}{5} \\
-\frac{1}{5}\end{array}$ & $\begin{array}{l}\overline{2} 34 \\
\overline{3} 57 \\
\overline{1} 23 \\
\overline{2} 58 \\
\overline{1} 35\end{array}$ \\
\hline $\begin{array}{l}\Gamma \\
\mathfrak{y} \\
e \\
l \\
\text { 色 }\end{array}$ & $\begin{array}{l}-11 \\
-\frac{2}{7} 1 \\
-\frac{1}{3} 1 \\
-\frac{4}{9} 1 \\
-\frac{1}{2} 1\end{array}$ & $\begin{array}{l}\overline{1} 44 \\
\overline{2} 77 \\
\overline{1} 33 \\
\mathbf{4} 99 \\
122\end{array}$ & $\begin{array}{l}-\frac{3}{4} 1 \\
-\frac{6}{7} 1 \\
-1 \\
-\frac{4}{3} 1 \\
-\frac{3}{2} 1\end{array}$ & $\begin{array}{l}\overline{3} 44 \\
\overline{6} 77 \\
\overline{1} 11 \\
\overline{4} 33 \\
\overline{3} 22\end{array}$ & $\begin{array}{r}-\frac{1}{4} 1 \\
-\frac{1}{7} 1 \\
01 \\
+\frac{1}{3} 1 \\
+\frac{1}{2} 1\end{array}$ & $\begin{array}{l}\overline{1} 44 \\
\overline{1} 77 \\
011 \\
133 \\
122\end{array}$ & $\begin{array}{r}-\frac{1}{7} \\
-\frac{1}{13} 1 \\
0 \\
+\frac{1}{7} \\
+\frac{1}{5}\end{array}$ & $\begin{array}{r}\overline{1} 47 \\
\text { 1. } 7.13 \\
012 \\
137 \\
125\end{array}$ \\
\hline 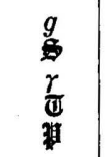 & $\begin{array}{l}-\frac{2}{3} 1 \\
-\frac{5}{6} 1 \\
-\frac{41}{3} 1 \\
+\frac{1}{6} \frac{1}{3} \\
+\frac{1}{8} \frac{1}{4}\end{array}$ & $\begin{array}{l}\overline{2} 33 \\
\overline{5} 66 \\
\overline{4} 33 \\
126 \\
128\end{array}$ & $\begin{array}{l}-21 \\
-\frac{5}{2} 1 \\
-41 \\
+\frac{1}{3} \\
+\frac{3}{8} \frac{1}{4}\end{array}$ & $\begin{array}{l}\overline{2} 11 \\
\overline{5} 22 \\
411 \\
326 \\
328\end{array}$ & $\begin{array}{r}+1 \\
+\frac{3}{2} 1 \\
+31 \\
+\frac{3}{2} \frac{1}{3} \\
-\frac{11}{8} \frac{1}{4}\end{array}$ & $\begin{array}{r}211 \\
322 \\
311 \\
926 \\
\overline{1} \overline{1} .2 .8\end{array}$ & $\begin{array}{r}+\frac{1}{3} \\
+\frac{3}{7} 7 \\
+\frac{3}{5} \\
+3 \\
-3 \frac{3}{3} \\
-\frac{11}{5} \frac{2}{5}\end{array}$ & $\begin{array}{r}113 \\
327 \\
315 \\
\overline{9} 23 \\
\text { 11. } 2.5\end{array}$ \\
\hline $\begin{array}{l}k \\
\pi \\
\text { H } \\
O \\
\lambda\end{array}$ & $\begin{array}{r}+\frac{1}{4} \\
+\frac{3}{6} \\
+\frac{1}{2} \\
+\frac{1}{7} 7 \\
+1 \frac{1}{3} \\
+\frac{1}{3} \\
+\frac{1}{15} \frac{1}{5}\end{array}$ & $\begin{array}{r}134 \\
136 \\
137 \\
139 \\
1.3 .15\end{array}$ & $\begin{array}{l}+\frac{3}{4} \\
+\frac{1}{2} \\
+\frac{3}{7} \\
+\frac{1}{3} \\
+\frac{1}{5}\end{array}$ & $\begin{array}{l}334 \\
112 \\
337 \\
113 \\
115\end{array}$ & $\begin{array}{r}-\frac{7}{4} \frac{3}{4} \\
-\frac{3}{2} \frac{1}{2} \\
-10 \frac{3}{4} \\
-\frac{4}{7} \\
-\frac{4}{3} \\
-\frac{6}{5} \\
-\frac{1}{5}\end{array}$ & $\begin{array}{r}\overline{7} 34 \\
\overline{3} 12 \\
\overline{10} .3 .7 \\
\overline{4} 13 \\
\overline{6} 15\end{array}$ & $\begin{array}{l}-73 \\
-31 \\
-\frac{5}{2} \\
-2 \frac{3}{2} \\
-\frac{3}{2} \frac{3}{4}\end{array}$ & $\begin{array}{r}\overline{7} 31 \\
\overline{3} 11 \\
\overline{1} \overline{0} . \\
\overline{4} .4 \\
\overline{4} 12 \\
634\end{array}$ \\
\hline
\end{tabular}


MERCURY MINERALS FROM TERLINGUA, TEXAS.

Indices for different orientations of terlinguaite forms - Continued.

\begin{tabular}{|c|c|c|c|c|c|c|c|c|}
\hline Letter. & $\begin{array}{l}\text { Gdt. } \\
\mathrm{M}_{1} .\end{array}$ & $\underset{\mathrm{M}_{1}}{\text { Miller }}$ & $\begin{array}{l}\text { Gdt. } \\
\mathrm{M}_{2} .\end{array}$ & $\underset{\mathbf{M}_{2} .}{\text { Miller }}$ & $\begin{array}{l}\text { Gdt. } \\
\mathrm{S}_{1} .\end{array}$ & $\begin{array}{c}\text { Miller } \\
\mathrm{S}_{1} .\end{array}$ & $\begin{array}{l}\text { Gdt. } \\
\mathrm{S}_{2} .\end{array}$ & $\underset{\mathrm{S}_{2}}{\text { Miller }}$ \\
\hline $\begin{array}{l}\sum_{Z}^{8} \\
\not{X} \\
\Phi \\
\Lambda\end{array}$ & $\begin{array}{r}+\frac{1}{14} \\
+1 \frac{1}{7} \\
+12 \\
+\frac{1}{18} \\
+\frac{1}{24} \\
+\frac{1}{24} \\
+\frac{1}{3} 3\end{array}$ & $\begin{array}{r}1.4 .14 \\
1.6 .12 \\
\text { 1. } 6.18 \\
1.6 .24 \\
193\end{array}$ & $\begin{array}{r}+\frac{3}{+}+\frac{2}{74} \\
+\frac{1}{4} \\
+\frac{1}{6} \\
+\frac{1}{6} \\
+\frac{1}{8} \\
+13 \\
+13\end{array}$ & $\begin{array}{r}3.4 .14 \\
124 \\
126 \\
128 \\
131\end{array}$ & $\begin{array}{l}-\frac{17}{14} \frac{2}{7} \\
-\frac{5}{4} \frac{1}{2} \\
-\frac{7}{6} \frac{1}{3} \\
-\frac{9}{8} 4 \\
-23 \\
-23\end{array}$ & $\begin{array}{r}\overline{17} .4 .14 \\
\overline{5} 24 \\
\overline{7} 26 \\
\overline{9} 28 \\
\overline{2} 31\end{array}$ & $\begin{array}{r}-\frac{17}{11} \frac{4}{17} \\
-\frac{5}{3} \\
-\frac{7}{5} \\
-\frac{1}{7} \\
-\frac{2}{7} \\
\infty \frac{3}{2}\end{array}$ & $\begin{array}{r}\text { 17. } 4.11 \\
\overline{5} 23 \\
\overline{7} 15 \\
\overline{9} 27 \\
230\end{array}$ \\
\hline $\begin{array}{l}W \\
\theta \\
T \\
Y \\
Z\end{array}$ & $\begin{array}{r}+2 \frac{3}{2} \\
+\frac{1}{2} \\
+\frac{1}{3} \\
+\frac{2}{3} \\
+\frac{2}{5}+1 \\
-15 \\
-1 \frac{1}{4}\end{array}$ & $\begin{array}{r}232 \\
236 \\
239 \\
2.3 .15 \\
\overline{1} 24\end{array}$ & $\begin{array}{l}+3 \frac{3}{2} \\
+1 \frac{1}{2} \\
+\frac{2}{3} 3 \\
+\frac{2}{5} 5 \\
-\frac{3}{4} \frac{1}{2}\end{array}$ & $\begin{array}{r}632 \\
212 \\
213 \\
215 \\
\overline{3} 24\end{array}$ & $\begin{array}{l}-4 \frac{3}{2} \\
-2 \frac{1}{2} \\
-\frac{5}{3} \\
-\frac{7}{5} \\
-\frac{1}{5} \\
-\frac{1}{2}\end{array}$ & $\begin{array}{l}\overline{8} 32 \\
412 \\
\overline{5} 13 \\
\overline{7} 15 \\
\overline{1} 24\end{array}$ & $\begin{array}{r}+2 \frac{3}{4} \\
4 \infty \\
-51 \\
-\frac{7}{3} \frac{1}{3} \\
-\frac{1}{7} \frac{2}{7}\end{array}$ & $\begin{array}{l}834 \\
410 \\
\overline{5} 11 \\
\overline{7} 13 \\
\overline{1} 27\end{array}$ \\
\hline $\begin{array}{l}g \\
\rho \\
\stackrel{\rho}{H} \\
\beta \\
\varrho\end{array}$ & $\begin{array}{r}-\frac{1}{4} \\
-\frac{1}{4} \\
-\frac{1}{3} \\
-\frac{1}{12} \\
-\frac{1}{15} \\
-\frac{1}{12} \\
-\frac{1}{12}\end{array}$ & 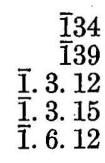 & $\begin{array}{l}-\frac{3}{4} \\
-\frac{1}{3} \\
-\frac{1}{4} \\
-\frac{1}{5} \\
-\frac{1}{4} \frac{1}{2}\end{array}$ & $\begin{array}{l}\overline{3} 34 \\
\overline{1} 13 \\
\overline{1} 14 \\
\overline{1} 15 \\
\overline{1} 15 \\
\overline{1} 24\end{array}$ & $\begin{array}{l}-\frac{1}{4} \\
\text { - } \frac{2}{3} \frac{1}{3} \\
-\frac{3}{4} \\
-\frac{1}{5} \\
-\frac{1}{5} \\
-\frac{3}{4} \frac{1}{2}\end{array}$ & $\begin{array}{l}\overline{1} 34 \\
\overline{2} 13 \\
\overline{3} 14 \\
\overline{4} 15 \\
\overline{3} 24\end{array}$ & $\begin{array}{l}-\frac{1}{7} \frac{3}{7} \\
-\frac{1}{2} \\
-\frac{3}{5} \\
-\frac{3}{5} \\
-\frac{2}{3} \\
-\frac{3}{5} \\
-\frac{2}{5}\end{array}$ & $\begin{array}{l}\overline{1} 37 \\
\overline{2} 14 \\
\overline{3} 15 \\
\overline{4} 16 \\
\overline{3} 25\end{array}$ \\
\hline $\begin{array}{l}I \\
J \\
K \\
\mu \\
\mathfrak{m}\end{array}$ & $\begin{array}{r}-\frac{1}{3} 3 \\
-\frac{2}{15} \frac{1}{15} \\
-23 \\
-1 \frac{3}{2} \\
-\frac{2}{5} \frac{3}{5}\end{array}$ & $\begin{array}{r}\overline{1} 93 \\
\overline{2} .1 .15 \\
\overline{2} 31 \\
\overline{2} 32 \\
\overline{2} 35\end{array}$ & $\begin{array}{r}-13 \\
-\frac{2}{5} \frac{1}{15} \\
-63 \\
-3 \frac{3}{2} \\
-\frac{6}{5} \frac{3}{5}\end{array}$ & $\begin{array}{r}\overline{1} 31 \\
\overline{6} .1 .15 \\
\overline{6} 31 \\
\overline{6} 32 \\
\overline{6} 35\end{array}$ & $\begin{array}{r}03 \\
-\frac{3}{5} 1 \\
+53 \\
+2 \frac{3}{2} \\
+1 \frac{3}{5}\end{array}$ & $\begin{array}{r}031 \\
9.1 .15 \\
531 \\
432 \\
135\end{array}$ & $\begin{array}{r}0 \frac{3}{2} \\
-\frac{3}{7} \frac{1}{2 \cdot 1} \\
+\frac{5}{7} 7 \\
+\frac{1}{2} \frac{3}{8} \\
+\frac{1}{11} \frac{3}{11}\end{array}$ & $\begin{array}{r}032 \\
\text { 9. } 1.21 \\
537 \\
438 \\
1.3 .11\end{array}$ \\
\hline $\begin{array}{l}Q \\
\xi \\
\mathfrak{t} \\
\mathfrak{u} \\
A\end{array}$ & $\begin{array}{r}-\frac{1}{3} \\
-\frac{1}{2} \\
-\frac{2}{3} \\
-\frac{2}{15} \\
-\frac{1}{9} \\
-\frac{1}{6} \\
-\frac{2}{21} \frac{1}{7}\end{array}$ & $\begin{array}{r}\overline{2} 36 \\
\overline{2} 39 \\
\overline{2} .3 .15 \\
\overline{2} .3 .18 \\
\overline{2} .3 .21\end{array}$ & $\begin{array}{l}-1 \frac{1}{2} \\
-\frac{2}{3} \frac{1}{3} \\
-\frac{2}{5} \frac{1}{5} \\
-\frac{1}{3} \frac{1}{6} \\
-\frac{2}{7} \frac{1}{7}\end{array}$ & $\begin{array}{l}\overline{2} 12 \\
\overline{2} 13 \\
\overline{2} 15 \\
\overline{2} 16 \\
\overline{2} 17\end{array}$ & $\begin{array}{c}0 \frac{1}{2} \\
-\frac{1}{3} \\
-\frac{3}{5} \frac{1}{5} \\
-\frac{2}{3} 6 \\
-\frac{5}{7} \\
-\frac{1}{7}\end{array}$ & $\begin{array}{l}012 \\
\overline{1} 13 \\
\overline{3} 15 \\
\overline{4} 16 \\
\overline{5} 17\end{array}$ & $\begin{array}{r}01 \\
-\frac{1}{5} \\
-\frac{3}{7} \\
-\frac{1}{2} \\
-\frac{1}{9} \\
-\frac{1}{9}\end{array}$ & $\begin{array}{l}014 \\
\overline{1} 15 \\
\overline{3} 17 \\
\overline{4} 18 \\
\overline{5} 19\end{array}$ \\
\hline 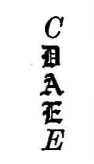 & $\begin{array}{r}-\frac{4}{9} \frac{1}{3} \\
-\frac{4}{15} \frac{1}{5} \\
-\frac{4}{3} \frac{1}{11} \\
-\frac{4}{15} \\
-\frac{4}{15} \\
-\frac{5}{9} \frac{1}{3}\end{array}$ & $\begin{array}{r}\overline{4} .3 .9 \\
\overline{4} .3 .15 \\
\overline{4} .3 .33 \\
\overline{4} .9 .15 \\
\overline{5} 39\end{array}$ & $\begin{array}{r}-\frac{4}{3} \frac{1}{3} \\
-\frac{4}{5} 5 \\
-\frac{4}{11} \frac{1}{11} \\
-\frac{4}{5} 5 \\
-\frac{5}{3} \frac{1}{3}\end{array}$ & 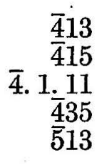 & $\begin{array}{r}+\frac{1}{3} \\
\frac{-1}{5} \\
-\frac{7}{11} \frac{1}{11} \\
\frac{1}{5} \frac{3}{5} \\
+\frac{2}{3} \frac{1}{3}\end{array}$ & 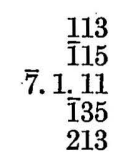 & $\begin{array}{r}+\frac{1}{7} \\
\frac{1}{9} \\
-\frac{7}{15} \\
\frac{1}{15} \\
\frac{1}{9} \frac{1}{3} \\
+\frac{1}{4} \frac{1}{8}\end{array}$ & $\begin{array}{r}117 \\
\overline{11} 19 \\
\overline{7} .1 .15 \\
\overline{1} 39 \\
218\end{array}$ \\
\hline $\begin{array}{l}r \\
\text { 筷 } \\
\text { 通 }\end{array}$ & $\begin{array}{r}-\frac{1}{3} \\
-\frac{5}{25} \\
-\frac{1}{9} \\
-\frac{5}{12} \\
-12 \\
-\frac{2}{3} \frac{1}{4}\end{array}$ & $\begin{array}{l}\overline{5} .3 .15 \\
\overline{5} .3 .27 \\
\overline{5} .6 .12 \\
\overline{8} .3 .12\end{array}$ & $\begin{array}{l}-1 \frac{1}{5} \\
-\frac{5}{9} 9 \\
-\frac{5}{4} \frac{1}{2} \\
-2 \frac{1}{4}\end{array}$ & $\begin{array}{l}\overline{5} 15 \\
\overline{5} 19 \\
\overline{5} 24 \\
\overline{8} 14\end{array}$ & $\begin{array}{r}0 \frac{1}{5} \\
-\frac{4}{9} 9 \\
+\frac{1}{4} \frac{1}{2} \\
+1 \frac{1}{4}\end{array}$ & $\begin{array}{l}015 \\
419 \\
124 \\
414\end{array}$ & $\begin{array}{r}0 \frac{1}{10} \\
-\frac{2}{71} \\
++\frac{1}{91} \\
+\frac{1}{3} \frac{1}{12}\end{array}$ & $\begin{array}{l}0.1 .10 \\
\frac{1}{4} .1 .14 \\
2.1 .18 \\
4.1 .12\end{array}$ \\
\hline
\end{tabular}


COORDINATE ANGLES ARRANGED IN ORDER OF INCREASING $\phi$ VALUE.

The following table is arranged in the order of increasing values of the $\phi$ angle to enable one more easily to find a given form of terlinguaite from the measurements. These angles are given for the normal position, the plane perpendicular to the prisms being polar and the clinopinacoid being the first meridian. In a table following this one (p. 140) the angular values are given for the clinopinacoid as pole, the orthodome zone being used as the prism zone.

Forms of terlinguaite arranged in order of increasing $\phi$ value.

\begin{tabular}{|c|c|c|c|c|c|}
\hline \multirow{2}{*}{ No. } & \multirow{2}{*}{ Letter. } & \multicolumn{2}{|c|}{ Symbol $\mathrm{M}_{2}$. } & \multirow{2}{*}{$\phi$} & \multirow{2}{*}{$\rho$} \\
\hline & & Gdt. & Miller. & & \\
\hline $\begin{array}{r}1 \\
2 \\
3 \\
4 \\
5\end{array}$ & $\begin{array}{l}b \\
\sigma \\
\phi \\
\beta \\
D\end{array}$ & $\begin{array}{r}0 \infty \\
-\frac{1}{5} 1 \\
-\frac{1}{4} 1 \\
-\frac{1}{5} \\
03\end{array}$ & $\begin{array}{l}010 \\
155 \\
\overline{1} 144 \\
\overline{11} 5 \\
031\end{array}$ & $\begin{array}{lc}\circ & , \\
0 & 00 \\
0 & 29 \\
1 & 22 \\
2 & 25 \\
2 & 38\end{array}$ & $\begin{array}{cc}\circ & , \\
90 & 00 \\
63 & 43 \\
63 & 43 \\
22 & 04 \\
80 & 40\end{array}$ \\
\hline $\begin{array}{r}6 \\
7 \\
8 \\
9 \\
10\end{array}$ & $\begin{array}{l}\stackrel{\ell}{X} \\
H \\
\stackrel{H}{L} \\
d\end{array}$ & $\begin{array}{r}-\frac{1}{4} \frac{1}{2} \\
-\frac{1}{3} 1 \\
-\frac{1}{1} \\
-\frac{2}{5} \\
01\end{array}$ & $\begin{array}{r}\overline{1} 24 \\
\overline{1} 33 \\
\overline{1} 14 \\
\overline{2} 55 \\
011\end{array}$ & $\begin{array}{ll}2 & 45 \\
4 & 28 \\
5 & 29 \\
6 & 55 \\
7 & 52\end{array}$ & $\begin{array}{ll}45 & 23 \\
63 & 47 \\
26 & 57 \\
63 & 53 \\
63 & 56\end{array}$ \\
\hline $\begin{array}{l}11 \\
12 \\
13 \\
14 \\
15\end{array}$ & $\begin{array}{l}I \\
\mathfrak{f} \\
r \\
\mathfrak{G} \\
\tau\end{array}$ & $\begin{array}{r}-13 \\
0 \frac{4}{5} \\
-\frac{1}{2} 1 \\
+\frac{1}{10} 1 \\
+\frac{1}{8} 1\end{array}$ & $\begin{array}{r}\overline{1} 31 \\
045 \\
\overline{1} 22 \\
\text { 1. } 10.10 \\
188\end{array}$ & $\begin{array}{rr}9 & 39 \\
9 & 48 \\
10 & 33 \\
11 & 28 \\
12 & 25\end{array}$ & $\begin{array}{ll}80 & 47 \\
58 & 41 \\
64 & 06 \\
64 & 10 \\
64 & 15\end{array}$ \\
\hline $\begin{array}{l}16 \\
17 \\
18 \\
19 \\
20\end{array}$ & $\begin{array}{l}\underset{\mathbf{y}}{\mathbf{z}} \\
\rho \\
\rho \\
\omega \\
\Lambda \\
\Lambda\end{array}$ & $\begin{array}{r}0 \frac{3}{5} \\
+\frac{1}{6} 1 \\
-\frac{1}{3} \\
-\frac{3}{5} 1 \\
+13\end{array}$ & $\begin{array}{l}035 \\
166 \\
\overline{1} 13 \\
\overline{3} 55 \\
131\end{array}$ & $\begin{array}{ll}12 & 58 \\
13 & 10 \\
13 & 11 \\
14 & 05 \\
14 & 41\end{array}$ & $\begin{array}{ll}51 & 16 \\
64 & 23 \\
34 & 44 \\
64 & 24 \\
80 & 57\end{array}$ \\
\hline $\begin{array}{l}21 \\
22 \\
23 \\
24 \\
25\end{array}$ & $\begin{array}{l}\dot{y} \\
y \\
\Delta \\
\zeta \\
\mathfrak{a}\end{array}$ & $\begin{array}{r}+\frac{1}{5} 1 \\
0 \frac{1}{2} \\
-\frac{2}{3} 1 \\
+\frac{1}{4} 1 \\
0 \frac{4}{9}\end{array}$ & $\begin{array}{l}155 \\
012 \\
233 \\
144 \\
049\end{array}$ & $\begin{array}{ll}15 & 00 \\
15 & 26 \\
16 & 23 \\
16 & 43 \\
17 & 15\end{array}$ & $\begin{array}{ll}64 & 30 \\
46 & 24 \\
64 & 39 \\
64 & 41 \\
43 & 18\end{array}$ \\
\hline $\begin{array}{l}26 \\
27 \\
28 \\
29 \\
30\end{array}$ & $\begin{array}{l}j \\
A \\
\mathfrak{h} \\
\Gamma \\
\varepsilon\end{array}$ & $\begin{array}{r}\infty 2 \\
-\frac{2}{7} \frac{1}{7} \\
0 \frac{2}{5} \\
-\frac{31}{41} \\
+\frac{1}{3} 1\end{array}$ & $\begin{array}{l}120 \\
\overline{2} 17 \\
025 \\
\overline{3} 44 \\
133\end{array}$ & $\begin{array}{ll}17 & 58 \\
18 & 16 \\
19 & 03 \\
19 & 12 \\
19 & 30\end{array}$ & $\begin{array}{ll}90 & 00 \\
16 & 56 \\
40 & 35 \\
65 & 00 \\
65 & 02\end{array}$ \\
\hline $\begin{array}{l}31 \\
32 \\
33 \\
34 \\
35\end{array}$ & $\begin{array}{l}f \\
I \\
U \\
\mathfrak{u} \\
Z\end{array}$ & $\begin{array}{r}0 \frac{1}{3} \\
+\frac{6}{7} \\
-\frac{3}{1} 1 \\
11 \\
\infty \frac{3}{2} \\
+\frac{1}{2} 1\end{array}$ & $\begin{array}{r}013 \\
677 \\
\overline{3} .1 .11 \\
230 \\
122\end{array}$ & $\begin{array}{ll}22 & 30 \\
22 & 40 \\
23 & 05 \\
23 & 23 \\
24 & 49\end{array}$ & $\begin{array}{ll}36 & 09 \\
65 & 30 \\
11 & 19 \\
90 & 00 \\
65 & 51\end{array}$ \\
\hline
\end{tabular}


Forms of terlinguaite arrainged in order of increasing $\phi$ value-Continued.

\begin{tabular}{|c|c|c|c|c|c|}
\hline \multirow{2}{*}{ No. } & \multirow{2}{*}{ Letter. } & \multicolumn{2}{|c|}{ Symbol $\mathrm{M}_{2}$. } & \multirow{2}{*}{$\phi$} & \multirow{2}{*}{$\rho$} \\
\hline & & Gdt. & Miller. & & \\
\hline $\begin{array}{l}36 \\
37 \\
38 \\
39 \\
40\end{array}$ & $\begin{array}{l}\Xi \\
\mathfrak{u} \\
e \\
v \\
Y\end{array}$ & $\begin{array}{r}-\frac{3}{4} \\
-\frac{1}{3} \\
-1 \\
+1 \\
+\frac{3}{51} \\
+\frac{21}{3} 1\end{array}$ & $\begin{array}{l}\overline{3} 34 \\
\overline{2} 16 \\
\overline{1} 11 \\
355 \\
233\end{array}$ & $\begin{array}{cc}\circ & \prime \\
24 & 54 \\
25 & 05 \\
27 & 02 \\
27 & 48 \\
29 & 42\end{array}$ & $\begin{array}{cc}\circ & \prime \\
59 & 09 \\
20 & 26 \\
66 & 15 \\
66 & 24 \\
66 & 47\end{array}$ \\
\hline $\begin{array}{l}41 \\
42 \\
43 \\
44 \\
45\end{array}$ & $\begin{array}{l}\Sigma \\
\mathbf{1} \\
\mathbb{2} \\
m \\
\text { T } \\
\text { 正 }\end{array}$ & $\begin{array}{r}+\frac{1}{4} \\
-\frac{2}{5} 5 \\
+\frac{3}{5} 1 \\
\infty \\
-\frac{4}{5} \frac{3}{5}\end{array}$ & $\begin{array}{l}124 \\
\overline{2} 15 \\
344 \\
110 \\
435\end{array}$ & $\begin{array}{ll}30 & 59 \\
31 & 14 \\
31 & 59 \\
32 & 58 \\
33 & 20\end{array}$ & $\begin{array}{ll}49 & 44 \\
25 & 20 \\
67 & 16 \\
90 & 00 \\
55 & 29\end{array}$ \\
\hline $\begin{array}{l}46 \\
47 \\
48 \\
49 \\
50\end{array}$ & $\begin{array}{l}h \\
Z \\
V \\
l \\
X\end{array}$ & $\begin{array}{r}0 \frac{1}{5} \\
-\frac{3}{2} \frac{1}{2} \\
-\frac{1}{3} \frac{1}{9} \\
-\frac{4}{3} 1 \\
+\frac{1}{6} \frac{1}{3}\end{array}$ & $\begin{array}{l}015 \\
324 \\
\overline{3} 19 \\
433 \\
126\end{array}$ & $\begin{array}{ll}34 & 37 \\
34 & 51 \\
35 & 05 \\
36 & 00 \\
36 & 27\end{array}$ & $\begin{array}{ll}26 & 12 \\
50 & 58 \\
15 & 22 \\
68 & 13 \\
40 & 00\end{array}$ \\
\hline $\begin{array}{l}51 \\
52 \\
53 \\
54 \\
55\end{array}$ & $\begin{array}{l}p \\
k \\
\text { 奋 } \\
\phi \\
\xi\end{array}$ & $\begin{array}{r}+1 \\
+\frac{3}{4} \\
-\frac{34}{2} \\
-\frac{1}{8} \frac{1}{4} \\
-\frac{2}{3} \frac{1}{3}\end{array}$ & $\begin{array}{l}111 \\
334 \\
322 \\
128 \\
\overline{2} 13\end{array}$ & $\begin{array}{ll}38 & 11 \\
39 & 47 \\
39 & 51 \\
41 & 14 \\
41 & 26\end{array}$ & $\begin{array}{ll}68 & 47 \\
63 & 09 \\
69 & 14 \\
33 & 56 \\
41 & 59\end{array}$ \\
\hline $\begin{array}{l}56 \\
57 \\
58 \\
59 \\
60\end{array}$ & $\begin{array}{l}\pi \\
\mathbf{1} \\
8 \\
\underset{B}{H} \\
B\end{array}$ & $\begin{array}{r}+\frac{1}{2} \\
00 \frac{1}{7} \\
+\frac{3}{14} \frac{2}{7} \\
+\frac{3}{7} \\
\frac{3}{2} \infty\end{array}$ & $\begin{array}{r}112 \\
017 \\
\text { 3. } 4.14 \\
337 \\
320\end{array}$ & $\begin{array}{ll}42 & 45 \\
44 & 01 \\
44 & 07 \\
44 & 09 \\
44 & 12\end{array}$ & $\begin{array}{ll}54 & 02 \\
21 & 55 \\
38 & 52 \\
50 & 25 \\
90 & 00\end{array}$ \\
\hline $\begin{array}{l}61 \\
62 \\
63 \\
64 \\
65\end{array}$ & $\begin{array}{l}r \\
\Omega \\
O \\
\mathfrak{m} \\
\AA\end{array}$ & $\begin{array}{r}+\frac{4}{3} 1 \\
-1 \frac{1}{2} \\
+\frac{1}{3} \\
-\frac{6}{5} \\
-\frac{3}{5} \\
-\frac{4}{11} \frac{1}{11}\end{array}$ & $\begin{array}{r}433 \\
\overline{2} 12 \\
113 \\
\overline{6} 335 \\
\overline{4} .1 .11\end{array}$ & $\begin{array}{ll}45 & 00 \\
45 & 35 \\
46 & 44 \\
46 & 47 \\
47 & 03\end{array}$ & $\begin{array}{ll}70.45 \\
55 & 20 \\
44 & 33 \\
60 & 35 \\
15 & 07\end{array}$ \\
\hline $\begin{array}{l}66 \\
67 \\
68 \\
69 \\
70\end{array}$ & $\begin{array}{c}\chi \\
g \\
\mu \\
\mu \\
\text { 然 } \\
K\end{array}$ & $\begin{array}{r}+\frac{3}{2} 1 \\
-21 \\
-3 \frac{3}{2} \\
+\frac{5}{3} 1 \\
\quad-63\end{array}$ & $\begin{array}{l}322 \\
\overline{2} 11 \\
632 \\
533 \\
631\end{array}$ & $\begin{array}{ll}48 & 00 \\
49 & 12 \\
50 & 18 \\
50 & 38 \\
51 & 18\end{array}$ & $\begin{array}{ll}71 & 43 \\
72 & 07 \\
78 & 07 \\
72 & 36 \\
84 & 07\end{array}$ \\
\hline $\begin{array}{l}71 \\
72 \\
73 \\
74 \\
75\end{array}$ & $\begin{array}{l}q \\
\delta \\
\lambda \\
\hat{\mathbf{S}} \\
\mathbb{U}\end{array}$ & $\begin{array}{r}-\frac{3}{5} \frac{1}{5} \\
2 \infty \\
+\frac{1}{5} \\
-\frac{5}{4} \frac{1}{2} \\
+\frac{1}{2} \frac{1}{3}\end{array}$ & $\begin{array}{l}\overline{3} 15 \\
210 \\
115 \\
\overline{5} 24 \\
326\end{array}$ & $\begin{array}{ll}51 & 27 \\
52 & 22 \\
53 & 15 \\
53 & 22 \\
54 & 09\end{array}$ & $\begin{array}{ll}33 & 01 \\
90 & 00 \\
34 & 05 \\
59 & 29 \\
49 & 03\end{array}$ \\
\hline $\begin{array}{l}76 \\
77 \\
78 \\
79 \\
80\end{array}$ & 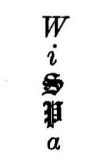 & $\begin{array}{l}+3 \frac{3}{2} \\
+21 \\
+\frac{5}{2} 1 \\
+\frac{3}{8} \frac{1}{4} \\
-1 \frac{7}{3}\end{array}$ & $\begin{array}{l}632 \\
211 \\
\overline{5} 22 \\
328 \\
\overline{3} 13\end{array}$ & $\begin{array}{ll}54 & 15 \\
55 & 08 \\
55 & 57 \\
56 & 45 \\
56 & 51\end{array}$ & $\begin{array}{ll}79 & 07 \\
74 & 14 \\
74 & 32 \\
42 & 43 \\
50 & 59\end{array}$ \\
\hline $\begin{array}{l}81 \\
82 \\
83 \\
84 \\
85\end{array}$ & $\begin{array}{l}\theta \\
\mathfrak{w} \\
T \\
\mathfrak{d} \\
o\end{array}$ & $\begin{array}{r}+1 \frac{1}{2} \\
\frac{5}{2} \infty \\
+\frac{2}{3} \frac{1}{3} \\
\frac{8}{3} \infty \\
-31\end{array}$ & $\begin{array}{l}212 \\
520 \\
213 \\
830 \\
\overline{3} 11\end{array}$ & $\begin{array}{ll}57 & 32 \\
58 & 20 \\
59 & 42 \\
59 & 58 \\
61 & 02\end{array}$ & $\begin{array}{ll}62 & 04 \\
90 & 00 \\
53 & 13 \\
90 & 00 \\
76 & 33\end{array}$ \\
\hline
\end{tabular}


Forms of terlinguaite arranged in order of increasing $\phi$ value-Continued.

\begin{tabular}{|c|c|c|c|c|c|}
\hline \multirow{2}{*}{ No. } & \multirow{2}{*}{ Letter. } & \multicolumn{2}{|c|}{ Symbol $\mathrm{M}_{2}$. } & \multirow{2}{*}{$\phi$} & \multirow{2}{*}{$\rho$} \\
\hline & & Gdt. & Miller. & & \\
\hline $\begin{array}{l}86 \\
87 \\
88 \\
89 \\
90\end{array}$ & $\begin{array}{c}J \\
\text { 皇 } \\
\text { 㫷 } \\
s\end{array}$ & $\begin{array}{r}-\frac{2}{5} \frac{1}{15} \\
-\frac{4}{5} \frac{1}{5} \\
+\frac{2}{5} \\
+\frac{5}{9} \\
+\frac{5}{9} \\
+31\end{array}$ & $\begin{array}{r}\overline{6} .1 .15 \\
\overline{4115} \\
215 \\
\overline{5} 19 \\
311\end{array}$ & $\begin{array}{cc}\circ & , \\
61 & 12 \\
62 & 17 \\
63 & 17 \\
63 & 21 \\
64 & 22\end{array}$ & $\begin{array}{cc}\circ & \prime \\
15 & 39 \\
41 & 03 \\
42 & 00 \\
26 & 38 \\
77 & 56\end{array}$ \\
\hline $\begin{array}{l}91 \\
92 \\
93 \\
94 \\
95\end{array}$ & $\begin{array}{l}C \\
\underset{\mathbf{r}}{r} \\
\underset{E}{E}\end{array}$ & $\begin{array}{r}-\frac{4}{3} \\
-41 \\
-1 \frac{1}{5} \\
+41 \\
-\frac{51}{3} \frac{1}{3}\end{array}$ & $\begin{array}{l}\overline{4} 13 \\
\overline{4} 11 \\
\overline{5} 15 \\
411 \\
\overline{5} 13\end{array}$ & $\begin{array}{ll}65 & 21 \\
67 & 50 \\
68 & 36 \\
69 & 54 \\
70 & 31\end{array}$ & $\begin{array}{ll}58 & 17 \\
79 & 27 \\
47 & 59 \\
80 & 22 \\
63 & 45\end{array}$ \\
\hline $\begin{array}{r}96 \\
97 \\
98 \\
99 \\
100\end{array}$ & $\begin{array}{l}\mathbf{r} \\
\mathfrak{E} \\
\mathfrak{T H} \\
L \\
M\end{array}$ & $\begin{array}{r}+\frac{3}{7} \frac{1}{7} \\
6 \infty \\
-2 \frac{1}{4} \\
-\frac{1}{4} 0 \\
-\frac{1}{7} 0\end{array}$ & $\begin{array}{l}317 \\
610 \\
814 \\
104 \\
107\end{array}$ & $\begin{array}{ll}71 & 03 \\
75 & 35 \\
77 & 48 \\
90 & 00 \\
90 & 00\end{array}$ & $\begin{array}{rr}41 & 41 \\
90 & 00 \\
67 & 20 \\
2 & 13 \\
5 & 16\end{array}$ \\
\hline $\begin{array}{l}101 \\
102 \\
103 \\
104 \\
105\end{array}$ & $\begin{array}{l}\text { 䁌 } \\
c \\
n \\
\boldsymbol{x} \\
\mathfrak{n}\end{array}$ & $\begin{array}{c}-\frac{1}{3} 0 \\
0 \\
-\frac{1}{2} 0 \\
-\frac{3}{5} 0 \\
+\frac{1}{5} 0\end{array}$ & $\begin{array}{l}\overline{1} 03 \\
001 \\
\overline{1} 02 \\
\overline{3} 05 \\
105\end{array}$ & $\begin{array}{ll}90 & 00 \\
90 & 00 \\
90 & 00 \\
90 & 00 \\
90 & 00\end{array}$ & $\begin{array}{rr}8 & 59 \\
15 & 37 \\
20 & 39 \\
26 & 56 \\
28 & 28\end{array}$ \\
\hline $\begin{array}{l}106 \\
107 \\
108 \\
109 \\
110\end{array}$ & $\begin{array}{l}N \\
\mathfrak{a} \\
\mathfrak{y} \\
\mathfrak{p} \\
R\end{array}$ & $\begin{array}{l}-20 \\
+\frac{1}{4} 0 \\
+\frac{1}{4} 0 \\
-\frac{3}{4} 0 \\
+\frac{1}{3} 0 \\
-\frac{4}{5} 0\end{array}$ & $\begin{array}{r}\overline{2} 03 \\
104 \\
\overline{3} 04 \\
\overline{103} \\
\overline{4} 05\end{array}$ & $\begin{array}{ll}90 & 00 \\
90 & 00 \\
90 & 00 \\
90 & 00 \\
90 & 00\end{array}$ & $\begin{array}{ll}30 & 47 \\
31 & 18 \\
35 & 11 \\
35 & 39 \\
37 & 37\end{array}$ \\
\hline $\begin{array}{l}111 \\
112 \\
113 \\
114 \\
115\end{array}$ & $\begin{array}{l}\mathbf{y} \\
t \\
u \\
\mathbf{r} \\
\mathbf{y}\end{array}$ & $\begin{array}{r}+\frac{3}{8} 0 \\
+\frac{1}{2} 0 \\
-10 \\
+10 \\
+\frac{2}{3} 0 \\
+\frac{3}{4} 0\end{array}$ & $\begin{array}{l}308 \\
102 \\
101 \\
203 \\
304\end{array}$ & $\begin{array}{ll}90 & 00 \\
90 & 00 \\
90 & 00 \\
90 & 00 \\
90 & 00\end{array}$ & $\begin{array}{ll}37 & 40 \\
43 & 06 \\
45 & 56 \\
49 & 07 \\
51 & 39\end{array}$ \\
\hline $\begin{array}{l}116 \\
117 \\
118 \\
119 \\
120\end{array}$ & $\begin{array}{l}I I \\
P \\
y \\
Q \\
\end{array}$ & $\begin{array}{l}-\frac{6}{5} 0 \\
-\frac{4}{3} 0 \\
+10 \\
-10 \\
-\frac{3}{3} 0\end{array}$ & $\begin{array}{l}\overline{6} 05 \\
\overline{4} 03 \\
101 \\
\overline{3} 02 \\
\overline{5} 03\end{array}$ & $\begin{array}{ll}90 & 00 \\
90 & 00 \\
90 & 00 \\
90 & 00 \\
90 & 00\end{array}$ & $\begin{array}{ll}52 & 20 \\
55 & 47 \\
57 & 52 \\
59 & 23 \\
62 & 21\end{array}$ \\
\hline $\begin{array}{l}121 \\
122 \\
123 \\
124 \\
125\end{array}$ & $\begin{array}{l}y \\
x \\
F \\
\mathbb{U} \\
z\end{array}$ & $\begin{array}{l}+\frac{4}{3} 0 \\
-20 \\
+\frac{5}{3} 0 \\
-\frac{5}{2} 0 \\
-30\end{array}$ & $\begin{array}{l}403 \\
\overline{2} 01 \\
503 \\
\overline{5} 02 \\
\overline{3} 01\end{array}$ & $\begin{array}{ll}90 & 00 \\
90 & 00 \\
90 & 00 \\
90 & 00 \\
90 & 00\end{array}$ & $\begin{array}{ll}63 & 46 \\
66 & 55 \\
67 & 56 \\
71 & 35 \\
74 & 43\end{array}$ \\
\hline $\begin{array}{l}126 \\
127 \\
128 \\
129 \\
130\end{array}$ & $\begin{array}{l}w \\
S \\
G \\
\theta \\
z\end{array}$ & $\begin{array}{l}+30 \\
-40 \\
+40 \\
-50 \\
-70\end{array}$ & $\begin{array}{l}\frac{301}{401} \\
401 \\
\overline{5} 01 \\
\overline{7} 01\end{array}$ & $\begin{array}{ll}90 & 00 \\
90 & 00 \\
90 & 00 \\
90 & 00 \\
90 & 00\end{array}$ & $\begin{array}{ll}76 & 40 \\
78 & 38 \\
79 & 45 \\
80 & 58 \\
83 & 36\end{array}$ \\
\hline $\begin{array}{l}131 \\
132 \\
133 \\
134\end{array}$ & $\begin{array}{l}n \\
\mathfrak{j} \\
\mathbf{k} \\
a\end{array}$ & $\begin{array}{r}+90 \\
-12.0 \\
+12.0 \\
\infty 0\end{array}$ & $\begin{array}{r}901 \\
\overline{12} .0 .1 \\
12.0 .1 \\
100\end{array}$ & $\begin{array}{ll}90 & 00 \\
90 & 00 \\
90 & 00 \\
90 & 00\end{array}$ & $\begin{array}{ll}85 & 16 \\
86 & 18 \\
86 & 26 \\
90 & 00\end{array}$ \\
\hline
\end{tabular}


FORMS AND CORRESPONDING ANGLES WITH (010) AS POLE.

In the following table the 134 forms are given with the angle values for each form when the crystal is set up with $b\{010\}$ as pole and a plane normal to the prisms as first meridian. As the crystals of terlinguaite are often extended in the direction of the $b$ axis and this zone is, moreover, always striated and the only one which is nearly completely striated, it is often advantageous first to set up the crystal in this way and by the measurements then to find the correct orientation.

Forms of terlinguaite arranged in order of increasing $\phi$ value, with $b(010)$ as pole and plane normal to prism zone as first meridian.

\begin{tabular}{|c|c|c|c|c|c|c|c|}
\hline \multirow{2}{*}{ No. } & \multirow{2}{*}{ Letter. } & \multicolumn{2}{|c|}{ Symbol $\mathrm{M}_{2}$. } & \multirow{2}{*}{\multicolumn{2}{|c|}{$\phi$}} & \multirow{2}{*}{\multicolumn{2}{|c|}{$\rho$}} \\
\hline & & Gdt. & Miller. & & & & \\
\hline $\begin{array}{l}1 \\
2 \\
3 \\
4 \\
5\end{array}$ & $\begin{array}{l}b \\
\sigma \\
\beta \\
\phi \\
\iota\end{array}$ & $\begin{array}{c}0 \\
-\frac{1}{5} 1 \\
-\frac{1}{5} \\
-11 \\
-\frac{1}{4} \frac{1}{2}\end{array}$ & $\begin{array}{l}010 \\
155 \\
115 \\
115 \\
144 \\
.124\end{array}$ & $\begin{array}{c}\circ \\
- \\
0 \\
0 \\
2 \\
2\end{array}$ & \begin{tabular}{r}
$\prime$ \\
\hdashline 59 \\
59 \\
13 \\
13
\end{tabular} & $\begin{array}{c}\circ \\
90 \\
26 \\
67 \\
26 \\
44\end{array}$ & $\begin{array}{l}1 \\
00 \\
17 \\
57 \\
19 \\
41\end{array}$ \\
\hline $\begin{array}{r}6 \\
7 \\
8 \\
9 \\
10\end{array}$ & $\begin{array}{l}H \\
L \\
U \\
M \\
A\end{array}$ & $\begin{array}{r}-\frac{1}{4} \\
-\frac{1}{4} 0 \\
-\frac{3}{1} \frac{1}{11} \\
-\frac{1}{7} 0 \\
-\frac{2}{7} \frac{1}{7}\end{array}$ & $\begin{array}{r}\overline{1} 14 \\
\overline{1} 04 \\
\overline{3} .1 .11 \\
\overline{1} 07 \\
\overline{2} 17\end{array}$ & $\begin{array}{l}2 \\
2 \\
4 \\
5 \\
5\end{array}$ & $\begin{array}{l}13 \\
13 \\
29 \\
16 \\
27\end{array}$ & $\begin{array}{l}63 \\
90 \\
79 \\
90 \\
73\end{array}$ & $\begin{array}{l}11 \\
00 \\
36 \\
00 \\
57\end{array}$ \\
\hline $\begin{array}{l}11 \\
12 \\
13 \\
14 \\
15\end{array}$ & $\begin{array}{c}X \\
\rho \\
\mathfrak{a} \\
V \\
\mathfrak{z}\end{array}$ & $\begin{array}{l}-\frac{1}{3} 1 \\
-\frac{1}{3} \\
-\frac{1}{3} \frac{1}{6} \\
-\frac{1}{3} \frac{1}{9} \\
-\frac{1}{3} 0\end{array}$ & 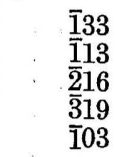 & $\begin{array}{l}8 \\
8 \\
8 \\
8 \\
8\end{array}$ & $\begin{array}{l}59 \\
59 \\
59 \\
59 \\
59\end{array}$ & $\begin{array}{l}26 \\
56 \\
71 \\
77 \\
90\end{array}$ & $\begin{array}{l}34 \\
18 \\
34 \\
29 \\
00\end{array}$ \\
\hline $\begin{array}{l}16 \\
17 \\
18 \\
19 \\
20\end{array}$ & $\begin{array}{l}A \\
\text { Ti } \\
\mathbf{1} \\
J \\
D\end{array}$ & $\begin{array}{r}-\frac{4}{11} \frac{1}{11} \\
-\frac{2}{5} 1 \\
-\frac{2}{5} 1 \\
-\frac{2}{5} \frac{1}{15} \\
03\end{array}$ & $\begin{array}{r}\overline{4} .1 .11 \\
\overline{2} 55 \\
\overline{2} 15 \\
\overline{6} .1 .15 \\
031\end{array}$ & $\begin{array}{l}11 \\
13 \\
13 \\
13 \\
15\end{array}$ & $\begin{array}{l}11 \\
48 \\
48 \\
48 \\
37\end{array}$ & $\begin{array}{r}79 \\
26 \\
68 \\
82 \\
9\end{array}$ & $\begin{array}{l}46 \\
57 \\
32 \\
32 \\
42\end{array}$ \\
\hline $\begin{array}{l}21 \\
22 \\
23 \\
24 \\
25\end{array}$ & $\begin{array}{l}d \\
\mathfrak{f} \\
\mathfrak{a} \\
\mathfrak{h} \\
\mathfrak{d}\end{array}$ & $\begin{array}{l}01 \\
0 \frac{4}{5} \\
0 \frac{3}{5} \\
0 \frac{1}{2} \\
0 \frac{4}{9}\end{array}$ & 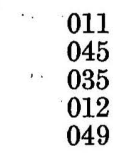 & $\begin{array}{l}15 \\
15 \\
15 \\
15 \\
15\end{array}$ & $\begin{array}{l}37 \\
37 \\
37 \\
37 \\
37\end{array}$ & $\begin{array}{l}27 \\
32 \\
40 \\
45 \\
49\end{array}$ & $\begin{array}{l}09 \\
40 \\
31 \\
44 \\
05\end{array}$ \\
\hline $\begin{array}{l}26 \\
27 \\
28 \\
29 \\
30\end{array}$ & $\begin{array}{l}\text { h } \\
f \\
h \\
\mathfrak{l} \\
c\end{array}$ & $\begin{array}{c}0 \frac{2}{5} \\
0 \frac{1}{3} \\
0 \frac{1}{5} \\
0 \frac{1}{7} \\
0\end{array}$ & $\begin{array}{l}025 \\
013 \\
015 \\
017 \\
001\end{array}$ & $\begin{array}{l}15 \\
15 \\
15 \\
15 \\
15\end{array}$ & $\begin{array}{l}37 \\
37 \\
37 \\
37 \\
37\end{array}$ & $\begin{array}{l}52 \\
56 \\
68 \\
74 \\
90\end{array}$ & $\begin{array}{l}03 \\
59 \\
42 \\
26 \\
00\end{array}$ \\
\hline $\begin{array}{l}31 \\
32 \\
33 \\
34 \\
35\end{array}$ & $\begin{array}{l}\phi \\
n \\
\text { (5) } \\
\Phi \\
\tau\end{array}$ & $\begin{array}{r}-\frac{1}{2} 1 \\
-\frac{1}{2} 0 \\
+\frac{1}{10} 1 \\
+\frac{1}{8} 1 \\
+\frac{1}{8} 1\end{array}$ & $\begin{array}{r}\overline{1} 22 \\
102 \\
1.10 .10 \\
128 \\
188\end{array}$ & $\begin{array}{l}20 \\
20 \\
22 \\
23 \\
23\end{array}$ & $\begin{array}{l}39 \\
39 \\
18 \\
55 \\
55\end{array}$ & $\begin{array}{l}27 \\
90 \\
28 \\
65 \\
28\end{array}$ & $\begin{array}{l}50 \\
00 \\
06 \\
11 \\
24\end{array}$ \\
\hline $\begin{array}{l}36 \\
37 \\
38 \\
39 \\
40\end{array}$ & 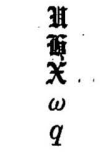 & $\begin{array}{r}-\frac{5}{9} \frac{1}{9} \\
+\frac{1}{6} 1 \\
+\frac{1}{6} \frac{1}{3} \\
-\frac{3}{5} 1 \\
-\frac{3}{5} \frac{1}{5}\end{array}$ & $\begin{array}{r}\overline{5} 19 \\
166 \\
\mathbf{1} 26 \\
\overline{3} 55 \\
\overline{3} 15\end{array}$ & $\begin{array}{l}24 \\
26 \\
26 \\
26 \\
26\end{array}$ & $\begin{array}{l}09 \\
29 \\
29 \\
56 \\
56\end{array}$ & $\begin{array}{l}78 \\
28 \\
58 \\
28 \\
70\end{array}$ & $\begin{array}{l}24 \\
36 \\
52 \\
59 \\
09\end{array}$ \\
\hline
\end{tabular}


Forms of terlinguaite arranged in order of increasing $\phi$ value, with $b(010)$ as pole and plane normal to prism zone as first meridian-Continued.

\begin{tabular}{|c|c|c|c|c|c|c|c|}
\hline \multirow{2}{*}{ No. } & \multirow{2}{*}{ Letter. } & \multicolumn{2}{|c|}{ Symbol $\mathrm{M}_{2}$. } & \multirow{2}{*}{\multicolumn{2}{|c|}{$\phi$}} & \multirow{2}{*}{\multicolumn{2}{|c|}{$\rho$}} \\
\hline & & Gdt. & Miller. & & & & \\
\hline $\begin{array}{l}41 \\
42 \\
43 \\
44 \\
45\end{array}$ & $\begin{array}{l}\mathbf{x} \\
\text { म } \\
\lambda \\
\mathfrak{n} \\
8\end{array}$ & $\begin{array}{r}-\frac{3}{5} 0 \\
+\frac{1}{5} 1 \\
++\frac{1}{5} \\
+\frac{1}{5} 0 \\
+\frac{3}{14}\end{array}$ & $\begin{array}{r}\overline{3} 05 \\
155 \\
115 \\
105 \\
3.4 .14\end{array}$ & $\begin{array}{c}\circ \\
26 \\
28 \\
28 \\
28 \\
29\end{array}$ & $\begin{array}{c}\prime \\
56 \\
28 \\
28 \\
28 \\
18\end{array}$ & $\begin{array}{c}\circ \\
90 \\
29 \\
70 \\
90 \\
63\end{array}$ & $\begin{array}{c}\prime \\
00 \\
20 \\
25 \\
00 \\
13\end{array}$ \\
\hline $\begin{array}{l}46 \\
47 \\
48 \\
49 \\
50\end{array}$ & $\begin{array}{l}\Delta \\
\xi \\
N \\
\zeta \\
\Sigma\end{array}$ & $\begin{array}{r}-\frac{2}{3} 1 \\
-\frac{21}{3} \\
-\frac{2}{3} 0 \\
+\frac{1}{4} \\
+\frac{1}{4} \frac{1}{2}\end{array}$ & $\begin{array}{l}\overline{2} 33 \\
\overline{2} 13 \\
\overline{2} 03 \\
144 \\
124\end{array}$ & $\begin{array}{l}30 \\
30 \\
30 \\
31 \\
31\end{array}$ & $\begin{array}{l}47 \\
47 \\
47 \\
18 \\
18\end{array}$ & $\begin{array}{l}29 \\
59 \\
90 \\
30 \\
49\end{array}$ & $\begin{array}{l}53 \\
54 \\
00 \\
02 \\
09\end{array}$ \\
\hline $\begin{array}{l}51 \\
52 \\
53 \\
54 \\
55\end{array}$ & $\begin{array}{l}\mathbf{n} \\
\Gamma \\
\Xi \\
\mathbf{z} \\
\mathbf{y}\end{array}$ & $\begin{array}{l}+\frac{1}{4} 0 \\
-\frac{3}{4} 1 \\
-\frac{3}{4} \\
-\frac{3}{4} \frac{1}{2} \\
-\frac{3}{4} 0\end{array}$ & $\begin{array}{l}104 \\
\overline{3} 44 \\
\overline{3} 34 \\
\overline{3} 24 \\
\overline{3} 04\end{array}$ & $\begin{array}{l}31 \\
35 \\
35 \\
35 \\
35\end{array}$ & $\begin{array}{l}18 \\
11 \\
11 \\
11 \\
11\end{array}$ & $\begin{array}{l}90 \\
28 \\
38 \\
50 \\
90\end{array}$ & $\begin{array}{l}00 \\
51 \\
51 \\
24 \\
00\end{array}$ \\
\hline $\begin{array}{l}56 \\
57 \\
58 \\
59 \\
60\end{array}$ & $\begin{array}{l}\varepsilon \\
O \\
\mathfrak{p} \\
\text { 焉 } \\
\text { 通 }\end{array}$ & $\begin{array}{r}+\frac{1}{31} \\
+1 \\
+\frac{1}{3} \\
+\frac{1}{30} \\
-\frac{4}{5} 5 \\
-\frac{4}{5} 5\end{array}$ & $\begin{array}{l}133 \\
113 \\
103 \\
\overline{4} 35 \\
\overline{4} 15\end{array}$ & $\begin{array}{l}35 \\
35 \\
35 \\
37 \\
37\end{array}$ & $\begin{array}{l}39 \\
39 \\
39 \\
37 \\
37\end{array}$ & $\begin{array}{l}31 \\
61 \\
90 \\
46 \\
72\end{array}$ & $\begin{array}{l}17 \\
16 \\
00 \\
30 \\
13\end{array}$ \\
\hline $\begin{array}{l}61 \\
62 \\
63 \\
64 \\
65\end{array}$ & 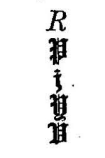 & $\begin{array}{r}-\frac{4}{5} 0 \\
+\frac{3}{8} \frac{1}{4} \\
+\frac{3}{8} 0 \\
+\frac{2}{5} 5 \\
+\frac{3}{7} \\
+\frac{3}{7}\end{array}$ & $\begin{array}{l}\overline{4} 05 \\
328 \\
308 \\
215 \\
337\end{array}$ & $\begin{array}{l}37 \\
37 \\
37 \\
38 \\
40\end{array}$ & $\begin{array}{l}37 \\
40 \\
40 \\
49 \\
07\end{array}$ & $\begin{array}{l}90 \\
68 \\
90 \\
72 \\
56\end{array}$ & $\begin{array}{l}00 \\
10 \\
00 \\
30 \\
26\end{array}$ \\
\hline $\begin{array}{l}66 \\
67 \\
68 \\
69 \\
70\end{array}$ & $\begin{array}{l}\mathbf{r} \\
\mathfrak{z} \\
Z \\
\pi \\
\pi \\
\mathbb{U}\end{array}$ & $\begin{array}{r}+\frac{3}{7} \frac{1}{7} \\
-\frac{6}{7} 1 \\
+\frac{1}{2} 1 \\
+\frac{1}{2} \\
+\frac{1}{2} \frac{1}{3}\end{array}$ & $\begin{array}{l}317 \\
677 \\
122 \\
112 \\
326\end{array}$ & $\begin{array}{l}40 \\
40 \\
43 \\
43 \\
43\end{array}$ & $\begin{array}{l}07 \\
13 \\
06 \\
06 \\
06\end{array}$ & $\begin{array}{l}77 \\
32 \\
34 \\
53 \\
63\end{array}$ & $\begin{array}{l}32 \\
54 \\
05 \\
32 \\
45\end{array}$ \\
\hline $\begin{array}{l}71 \\
72 \\
73 \\
74 \\
75\end{array}$ & $\begin{array}{l}t \\
I \\
e \\
\Omega \\
a\end{array}$ & $\begin{array}{c}+\frac{1}{2} 0 \\
-13 \\
-1 \\
-1 \frac{1}{2} \\
-1 \frac{1}{3}\end{array}$ & $\begin{array}{l}102 \\
\overline{1} 31 \\
\overline{1} 11 \\
\overline{2} 11 \\
\overline{3} 12\end{array}$ & $\begin{array}{l}43 \\
45 \\
45 \\
45 \\
45\end{array}$ & $\begin{array}{l}06 \\
56 \\
56 \\
56 \\
56\end{array}$ & $\begin{array}{l}90 \\
13 \\
35 \\
54 \\
64\end{array}$ & $\begin{array}{l}00 \\
19 \\
23 \\
41 \\
51\end{array}$ \\
\hline $\begin{array}{l}76 \\
77 \\
78 \\
79 \\
80\end{array}$ & $\begin{array}{l}r \\
u \\
v \\
Y \\
T\end{array}$ & $\begin{array}{r}-1 \frac{1}{5} \\
-10 \\
+131 \\
+\frac{3}{3} 1 \\
+\frac{2}{3} \frac{1}{3}\end{array}$ & $\begin{array}{l}\overline{5} 15 \\
101 \\
355 \\
233 \\
213\end{array}$ & $\begin{array}{l}45 \\
45 \\
46 \\
49 \\
49\end{array}$ & $\begin{array}{l}56 \\
56 \\
52 \\
07 \\
07\end{array}$ & $\begin{array}{l}74 \\
90 \\
35 \\
37 \\
66\end{array}$ & $\begin{array}{l}16 \\
00 \\
51 \\
02 \\
10\end{array}$ \\
\hline $\begin{array}{l}81 \\
82 \\
83 \\
84 \\
85\end{array}$ & $\begin{array}{l}\mathbf{r} \\
\underset{2}{k} \\
k \\
\mathbb{2} \\
\mathbf{m}\end{array}$ & $\begin{array}{r}+\frac{2}{3} 0 \\
+\frac{3}{4} 1 \\
+\frac{3}{4} \\
++\frac{3}{4} 0 \\
-\frac{6}{5} \frac{3}{5}\end{array}$ & $\begin{array}{l}203 \\
344 \\
334 \\
304 \\
635\end{array}$ & $\begin{array}{l}49 \\
51 \\
51 \\
51 \\
52\end{array}$ & $\begin{array}{l}07 \\
39 \\
39 \\
39 \\
20\end{array}$ & $\begin{array}{l}90 \\
38 \\
46 \\
90 \\
53\end{array}$ & $\begin{array}{l}00 \\
32 \\
43 \\
00 \\
23\end{array}$ \\
\hline $\begin{array}{l}86 \\
87 \\
88 \\
89 \\
90\end{array}$ & $\begin{array}{l}I \\
\text { (9) } \\
l \\
C \\
P\end{array}$ & $\begin{array}{l}-\frac{6}{5} 0 \\
-\frac{5}{4} \frac{1}{2} \\
-\frac{4}{3} 1 \\
-\frac{4}{3} \frac{1}{3} \\
-\frac{4}{3} 0\end{array}$ & $\begin{array}{l}\overline{6} 05 \\
\overline{5} 24 \\
\overline{4} 33 \\
\overline{4} 13 \\
403\end{array}$ & $\begin{array}{l}52 \\
53 \\
55 \\
55 \\
55\end{array}$ & $\begin{array}{l}20 \\
42 \\
47 \\
47 \\
47\end{array}$ & $\begin{array}{l}90 \\
59 \\
41 \\
69 \\
90\end{array}$ & $\begin{array}{l}00 \\
04 \\
18 \\
13 \\
00\end{array}$ \\
\hline
\end{tabular}


Forms of terlinguaite arranged in order of increasing $\phi$ value, with $b(010)$ as pole and plane normal to prism zone as first meridian-Continued.

\begin{tabular}{|c|c|c|c|c|c|c|c|}
\hline \multirow{2}{*}{ No. } & \multirow{2}{*}{ Letter. } & \multicolumn{2}{|c|}{ Symbol $\mathrm{M}_{2}$. } & \multirow{2}{*}{\multicolumn{2}{|c|}{$\phi$}} & \multirow{2}{*}{\multicolumn{2}{|c|}{$\rho$}} \\
\hline & & Gdt. & Miller. & & & & \\
\hline $\begin{array}{l}91 \\
92 \\
93 \\
94 \\
95\end{array}$ & $\begin{array}{c}A \\
p \\
\theta \\
y \\
\mathbb{R}\end{array}$ & $\begin{array}{l}+13 \\
+1 \\
+1 \frac{1}{2} \\
+10 \\
-\frac{3}{2} 1\end{array}$ & $\begin{array}{l}131 \\
111 \\
212 \\
101 \\
\overline{3} 22\end{array}$ & $\begin{array}{c}\circ \\
57 \\
57 \\
57 \\
57 \\
59\end{array}$ & $\begin{array}{l}\text { ' } \\
52 \\
52 \\
52 \\
52 \\
23\end{array}$ & $\begin{array}{c}\circ \\
17 \\
42 \\
61 \\
90 \\
44\end{array}$ & $\begin{array}{c}\prime \\
12 \\
53 \\
41 \\
00 \\
07\end{array}$ \\
\hline $\begin{array}{r}96 \\
97 \\
98 \\
99 \\
100\end{array}$ & $\begin{array}{l}Q \\
E \\
\text { Z2 } \\
r \\
\square\end{array}$ & $\begin{array}{r}-\frac{3}{2} 0 \\
-\frac{5}{3} \frac{1}{3} \\
-\frac{5}{3} 0 \\
++\frac{4}{3} 1 \\
+\frac{4}{3} 0\end{array}$ & $\begin{array}{l}\overline{3} 02 \\
\overline{5} 13 \\
\overline{5} 03 \\
433 \\
403\end{array}$ & $\begin{array}{l}-59 \\
62 \\
62 \\
63 \\
63\end{array}$ & $\begin{array}{l}23 \\
21 \\
21 \\
46 \\
46\end{array}$ & $\begin{array}{l}90 \\
72 \\
90 \\
48 \\
90\end{array}$ & $\begin{array}{l}00 \\
36 \\
00 \\
07 \\
00\end{array}$ \\
\hline $\begin{array}{l}101 \\
102 \\
103 \\
104 \\
105\end{array}$ & $\begin{array}{l}\chi \\
g \\
g \\
x \\
x \\
\text { 靕 }\end{array}$ & $\begin{array}{l}+\frac{3}{2} 1 \\
-21 \\
-21 \\
-20 \\
+\frac{5}{3} 1\end{array}$ & $\begin{array}{l}322 \\
\overline{2} 11 \\
\overline{8} 14 \\
201 \\
533\end{array}$ & $\begin{array}{l}66 \\
66 \\
66 \\
66 \\
67\end{array}$ & $\begin{array}{l}02 \\
55 \\
55 \\
55 \\
56\end{array}$ & $\begin{array}{l}50 \\
51 \\
78 \\
90 \\
52\end{array}$ & $\begin{array}{l}33 \\
33 \\
45 \\
00 \\
45\end{array}$ \\
\hline $\begin{array}{l}106 \\
107 \\
108 \\
109 \\
110\end{array}$ & $\begin{array}{l}F \\
i \\
\text { 霖 } \\
\mu \\
\mu\end{array}$ & $\begin{array}{r}+\frac{5}{3} 0 \\
+21 \\
+\frac{5}{2} 1 \\
-\frac{5}{2} 0 \\
-3 \frac{3}{2}\end{array}$ & $\begin{array}{l}503 \\
211 \\
\overline{5} 22 \\
\overline{5} 02 \\
\overline{6} 32\end{array}$ & $\begin{array}{l}67 \\
71 \\
71 \\
71 \\
74\end{array}$ & $\begin{array}{l}56 \\
01 \\
35 \\
35 \\
43\end{array}$ & $\begin{array}{l}90 \\
56 \\
57 \\
90 \\
51\end{array}$ & $\begin{array}{l}00 \\
37 \\
20 \\
00 \\
19\end{array}$ \\
\hline $\begin{array}{l}111 \\
112 \\
113 \\
114 \\
115\end{array}$ & $\begin{array}{l}o \\
z \\
W \\
s \\
w\end{array}$ & $\begin{array}{l}-31 \\
-30 \\
+3 \frac{s}{2} \\
+31 \\
+30\end{array}$ & $\begin{array}{l}\overline{3} 11 \\
\overline{3} 01 \\
632 \\
311 \\
301\end{array}$ & $\begin{array}{l}74 \\
74 \\
76 \\
76 \\
76\end{array}$ & $\begin{array}{l}43 \\
43 \\
40 \\
40 \\
40\end{array}$ & $\begin{array}{l}61 \\
90 \\
54 \\
64 \\
90\end{array}$ & $\begin{array}{l}54 \\
00 \\
49 \\
58 \\
00\end{array}$ \\
\hline $\begin{array}{l}116 \\
117 \\
118 \\
119 \\
120\end{array}$ & $\begin{array}{l}\tau \\
S \\
\mathscr{G} \\
G \\
\theta\end{array}$ & $\begin{array}{l}-41 \\
-40 \\
+41 \\
+40 \\
-50\end{array}$ & $\begin{array}{l}\overline{4} 11 \\
\overline{4} 01 \\
411 \\
401 \\
501\end{array}$ & $\begin{array}{l}78 \\
78 \\
79 \\
79 \\
80\end{array}$ & $\begin{array}{l}38 \\
38 \\
45 \\
45 \\
58\end{array}$ & $\begin{array}{l}68 \\
90 \\
70 \\
90 \\
90\end{array}$ & $\begin{array}{l}14 \\
00 \\
12 \\
00 \\
00\end{array}$ \\
\hline $\begin{array}{l}121 \\
122 \\
123 \\
124 \\
125\end{array}$ & $\begin{array}{l}K \\
z \\
\eta \\
3 \\
k\end{array}$ & $\begin{array}{r}-63 \\
-70 \\
+90 \\
-12.0 \\
+12.0\end{array}$ & $\begin{array}{r}\overline{6} 31 \\
701 \\
901 \\
\overline{12} .0 .1 \\
12.0 .1\end{array}$ & $\begin{array}{l}82 \\
83 \\
85 \\
86 \\
86\end{array}$ & $\begin{array}{l}29 \\
36 \\
16 \\
18 \\
26\end{array}$ & $\begin{array}{l}51 \\
90 \\
90 \\
90 \\
90\end{array}$ & $\begin{array}{l}32 \\
00 \\
00 \\
00 \\
00\end{array}$ \\
\hline $\begin{array}{l}126 \\
127 \\
128 \\
129 \\
130\end{array}$ & $\begin{array}{l}j \\
\mathfrak{u} \\
m \\
B \\
\delta\end{array}$ & $\begin{array}{c}\infty 2 \\
\infty \frac{3}{2} \\
\infty \\
\frac{3}{2} \infty \\
2 \infty\end{array}$ & $\begin{array}{l}120 \\
230 \\
110 \\
320 \\
210\end{array}$ & $\begin{array}{l}90 \\
90 \\
90 \\
90 \\
90\end{array}$ & $\begin{array}{l}00 \\
00 \\
00 \\
00 \\
00\end{array}$ & $\begin{array}{l}18 \\
23 \\
32 \\
44 \\
52\end{array}$ & $\begin{array}{l}58 \\
28 \\
57 \\
11 \\
21\end{array}$ \\
\hline $\begin{array}{l}131 \\
132 \\
133 \\
134\end{array}$ & $\begin{array}{l}\text { mat } \\
\text { d } \\
a \\
a\end{array}$ & $\begin{array}{l}\frac{5}{2} \infty \\
\frac{8}{3} \infty \\
6 \infty \\
\infty 0\end{array}$ & $\begin{array}{l}520 \\
830 \\
610 \\
100\end{array}$ & $\begin{array}{l}90 \\
90 \\
90 \\
90\end{array}$ & $\begin{array}{l}00 \\
00 \\
00 \\
00\end{array}$ & $\begin{array}{l}58 \\
60 \\
76 \\
90\end{array}$ & $\begin{array}{l}21 \\
10 \\
20 \\
00\end{array}$ \\
\hline
\end{tabular}




\section{EGLESTONITE.}

FORMS.

Eglestonite is known to occur in two forms and possibly a third. The distinction between the first two is not very clear and this, with the uncertainty regarding the third occurrence, justifies the statement that the mineral is found in only one really distinct form, as well developed crystals. The three forms into which the occurrences are divided are given below:

1. Distinct crystals are the characteristic form for eglestonite. They are found as such on nearly all of the specimens containing the mineral. These crystals, mostly equidiametrical, are rarely over 1 millimeter in diameter and usually about one-half millimeter and smaller. They occur in two distinct habits and also as a peculiarly distorted form, while the crystal described and illustrated by Moses has a different combination from those seen by the writer. These distinct crystals may thus be classed under three habits as follows-

(a) Rhombic dodecahedral habit.

(b) Octahedral habit.

(c) Distorted and thereby prismatic crystals.

These three habits are fully described on pages 155-156 and illustrated in figures $32-37$.

One of our specimens shows a group of dull dark-gray crystals considerably rounded, which seem, however, to consist chiefly of faces of rhombic dodecahedra. On breaking these open the interior is seen to be of a yellow color, always dull and earthy looking, instead of bright and glistening like ordinary eglestonite. It seems to have altered or undergone some change and an analysis showed considerable differences from eglestonite (p. 146). It is possible that some new species is at hand or that the eglestonite has changed over to some other compound, forming a pseudomorph, but such difference could not be proved.

2. The mineral is sometimes found as a massive crust, not showing any crystal faces itself but occasionally including well-developed crystals. As the mineral is isometric it is not possible to say whether this erust is crystalline or truly amorphous. It often shows a conchoidal surface, which, however, seems to be a growth effect rather than an evidence of conchoidal fracture, as such a fracture can not be produced artificially in such development as is found on the natural mineral.

3. If eglestonite occurs as a powder this would be a distinct form, but no specimen that we have offers positive proof of the presence of powdery eglestonite. Some of the apparent powdery mixtures seem to contain terlinguaite and eglestonite, but for the present such a form of eglestonite must be considered as doubtful. 
PHYSICAL PROPERTIES.

COHESION, ETC.

No cleavage could be detected. The fracture is uneven and apparently somewhat conchoidal. The usual surface obtained by breaking a crystal is uneven, but on some crystals there is a decided suggestion of a conchoidal surface. On some of the more massive eglestonite there were natural surfaces that were conchoidal, but it is difficult to say whether they were fracture surfaces or the natural crystalline surface of a mass of eglestonite.

The crystals are brittle, and no indications of plasticity or sectility were observed, though on such minute crystals as are available it is difficult to obtain satisfactory results.

As determined by Moses the hardness lies between 2 and 3 .

DENSITY.

The great difficulty found in obtaining a large quantity of material free from calomel and mercury prevented any determinations of the specific gravity. Two determinations are given by Moses, 8.309 and 8.345.

LUSTER, COLOR, ETC.

The definition that was given by Moses of the luster of these crystals, brilliant adamantine to resinous, applies very well to the crystals that we have. This mineral differs from the others in that the luster is often decidedly resinous.

The first specimens received by us were dark brownish, but the last specimens were almost all of a light brownish yellow. They all darken quickly on exposure to light, becoming dark brown and finally black, but retaining their high luster. The streak is yellow, rapidly becoming black. Moses describes the streak as "in powder, greenish yellow to canary yellow, becoming quickly green and finally black on exposure to light." Repeated trials made by us failed to show any green color in any of the changes from yellow to black. In transmitted light the crystals are brown, hardly different from the color seen by reflected light. If a crystal could be viewed through parallel faces it would doubtless be transparent, but as they are they are translucent.

OPTICAL PROPERTIES.

The crystals are isotropic, and it was not found possible to measure the index of refraction. Several attempts were made to grind down and polish small prisms for a determination of the refractive index, but the smallness and brittleness of the crystals prevented any results from being obtained. 


\section{CHEMISTRY.}

PYROGNOSTIC BEHAVIOR.

Eglestonite, on being heated in a closed tube, comports itself very much like terlinguaite, decrepitation and sublimation of calomel starting at the same time, mercury adding itself to the calomel and oxygen escaping. In vacuo, when slowly heated, the crystals become red as the first sublimate appears, soon black, then brown-red, cooling to orange-red and orange-yellow. The residue seems then to be mercuric oxide, as with terlinguaite, formed, with eglestonite, however, from mercurous oxide at the expense of half the mercury of the latter, a reaction that accords with the observation that no oxygen escapes till all the calomel and some mercury have sublimed. Finally, a reddish sublimate may appear immediately over the decomposing. oxide, but it disappears on further heating.

BEHAVIOR TOWARD REAGENTS.

Hydrogen sulphide and ammonia blacken eglestonite at once, the latter reaction serving as a ready distinguishing test with respect to its occasionally immediate associate, terlinguaite. Hydrochloric and nitric acids decompose the mineral with separation of calomel. The filtrate from the hydrochloric acid solution contains no mercury. When cold dilute acetic acid is allowed to act, a reaction that proceeds quicker than with terlinguaite, calomel is left, and from the filtrate much more calomel is afforded by adding hydrochloric acid. The filtrate from this precipitate is free from mercury. These tests, confirmed by the analysis, show clearly the wholly mercurous nature of the compound, which is the first authentic instance of a mercurous oxychloride, native or artificial.

QUANTITATIVE COMPOSITION.

Analysis did not confirm the empirical formula $\mathrm{Hg}_{6} \mathrm{Cl}_{3} \mathrm{O}_{2}$, deduced from McCord's analyses in the paper by Moses, a formula which, in fact, is invalidated by the qualitative data above communicated, since it calls for mercuric as well as mercurous mercury. The analyses were made in the main as for terlinguaite (p. 87) with the exception that the chlorine and mercury in the sublimate were each time determined, the separation being effected by sodium hydroxide. A little mercury went in this operation into solution with the chlorine, but was recovered.

In all cases the mercury is probably low, and calomel was present in sample 1 at least. It is probable that the oxygen was less accurately determined than the chlorine, but the effect of low mercury and the presence of calomel are better brought out by the ratio based on oxygen than on chlorine as unity. The formula plainly indicated is $\mathrm{Hg}_{4} \mathrm{Cl}_{2} \mathrm{O}$, or $\mathrm{Hg}_{2} \mathrm{O} .2 \mathrm{HgCl}$, one that is in full agreement with the qualitative behavior of the mineral.

4494-Bull. 405-09-10 
Analyscs of eglestonite.

\begin{tabular}{|c|c|c|c|}
\hline & 1. & 2. & 3. \\
\hline $\begin{array}{l}\mathrm{Hg} \\
\mathrm{Cl} \\
\mathrm{C} \\
\mathrm{O} \\
\text { Nonvolatile......... }\end{array}$ & $\begin{array}{r}87.77 \\
8.27 \\
1.71 \\
0.63\end{array}$ & $\begin{array}{l}87.70 \\
8.11 \\
1.816 \\
1.39\end{array}$ & $\begin{array}{r}87.48 \\
7.92 \\
1.76 \\
2.50\end{array}$ \\
\hline & 98.38 & 99.016 & 99.66 \\
\hline
\end{tabular}

Analyses of eglestonite calculated to gangue-free basis.

\begin{tabular}{|c|c|c|c|c|c|c|c|}
\hline & 1. & $\begin{array}{l}\text { Atomic } \\
\text { ratio. }\end{array}$ & 2. & $\begin{array}{l}\text { Atomic } \\
\text { ratio. }\end{array}$ & 3. & $\begin{array}{l}\text { Atomic } \\
\text { ratio. }\end{array}$ & $\begin{array}{c}\text { Theory } \\
\left(\mathrm{Hg}_{4} \mathrm{Cl}_{2} \mathrm{O}\right) \text {. }\end{array}$ \\
\hline \multirow[t]{2}{*}{$\begin{array}{l}\mathrm{Hg} . . . \\
\mathrm{Cl} . . . \\
\mathrm{O} \ldots . .\end{array}$} & $\begin{array}{r}88.33 \\
8.32 \\
1.72\end{array}$ & $\begin{array}{l}\text { 4. } 11 \\
\text { 2. } 18 \\
1 .\end{array}$ & $\begin{array}{r}88.94 \\
8.23 \\
a 1.84\end{array}$ & $\begin{array}{l}3.87 \\
2.02 \\
1 .\end{array}$ & $\begin{array}{r}89.73 \\
8.12 \\
1.80\end{array}$ & $\begin{array}{l}3.99 \\
\text { 2. } 03 \\
1 .\end{array}$ & $\begin{array}{r}90.21 \\
7.99 \\
1.80\end{array}$ \\
\hline & 98.37 & & 99.01 & & 99.65 & & 100.00 \\
\hline
\end{tabular}

$a 1.90$ by loss in weight of ignition tube.

1. Weight, 0.1195 gram. Selected crystals, nearly free from native mercury and calomel, which it is usually impossible to exclude completely. Nonvolatile gangue mostly calcite.

2. Weight, 0.1008 gram. Selected crystals.

3. Weight, 0.1198 gram.

The variations in the analy tical data reported by Moses are so wide, as shown by the subjoined table, that the excellent agreement of his averages with the requirements of the formula $\mathrm{Hg}_{6} \mathrm{Cl}_{3} \mathrm{O}_{2}$ can be due only to a fortuitous balancing of large errors. The oxygen values of the table, determined indirectly, are affected by whatever errors may be involved in the other determinations, and it is evident by inspection that these are large.

Analyses of eglestonite from paper by Moses.

\begin{tabular}{|c|c|c|c|c|c|c|c|}
\hline & 1. & 2. & 3. & 4. & 5. & A verage. & $\begin{array}{c}\text { Theory } \\
\left(\mathrm{Hg}_{6} \mathrm{Cl}_{3} \mathrm{O}_{2}\right) \text {. }\end{array}$ \\
\hline \multirow[t]{2}{*}{$\begin{array}{l}\mathrm{Hg} \ldots \ldots . \\
\mathrm{Cl} \ldots \ldots \ldots \\
\mathrm{O} . \ldots . . .\end{array}$} & \multirow[t]{2}{*}{$\begin{array}{r}88.67 \\
8.72 \\
2.60\end{array}$} & \multirow{2}{*}{$\begin{array}{r}90.45 \\
7.24 \\
2.26 \\
.\end{array}$} & \multirow[t]{2}{*}{$\begin{array}{r}90.72 \\
7.81\end{array}$} & \multirow[t]{2}{*}{$\begin{array}{r}88.25 \\
7.68\end{array}$} & \multirow[t]{2}{*}{$\begin{array}{r}89.70 \\
8.20\end{array}$} & $\begin{array}{r}89.56 \\
7.93 \\
2.43\end{array}$ & $\begin{array}{r}89.66 \\
7.95 \\
2.39\end{array}$ \\
\hline & & & & & & 99.92 & 100.00 \\
\hline
\end{tabular}

Two other samples of what was supposed to be eglestonite were analyzed, more for purposes of identification than with expectation of getting results that would lead to a formula. One sample seemed pure, and was made up of a compacted mass of indeterminable crystals, gray-black on the surface but yellow within and dull. The other was not well crystallized, and its freedom from calomel at least was 
problematical. The analyses revealed a content in both chlorine and oxygen much in excess of those shown by the selected crystals of eglestonite, and indicated, if anything, a new oxychloride rather than a mixture of eglestonite with calomel. Indeed, the presence of eglestonite as a component seemed positively excluded by the high oxygen (2.16-2.36 per cent, approximately). The chlorine ran in one as high as 9.95 per cent. The results are more indicative, if not of a new species, of a mixture of terlinguaite and calomel, but the appearance of both specimens was distinctly against this.

\section{CRYSTALLOGRAPHY.}

GENERAI DESCRIPTION.

The minute crystals of eglestonite lose their bright color so rapidly on exposure to light that they can not be kept on exhibition, which is unfortunate, as the small crystals have such a striking color and high luster, and are so rich in faces, that they afford most interesting specimens for study. The distorted crystals, few of them 1 millimeter long, are extremely thin, scarcely thicker than a fine hair, and present an entirely different appearance from the common eglestonite crystals, which are generally very symmetrical in their development. In size, the crystals very rarely exceed 1 millimeter in thickness, and are usually one-half millimeter or less thick.

FORMS AND ANGLES.

Though minute, the crystals of eglestonite of the octahedral habit are rich in forms, a total of 20 having been determined for the mineral. Four of these, $a\{100\}, d\{110\}, n\{112\}$, and $s\{123\}$, were found by Moses on crystals of habit 1 . The others are new for eglestonite. The total list of forms present on these crystals is shown below, new forms being indicated by stars:

$$
\begin{array}{r|r|c}
a=100 & { }^{*} r=332 & { }^{*} \sum=145 \\
d=110 & { }^{*} p=221 & { }^{*} F=126 \\
*_{o}=111 & { }^{*} \rho=441 & s=123 \\
*_{e}=120 & { }^{*} i=189 & { }^{*} v=4.7 .11 \\
*^{*}=130 & { }^{*} j=167 & { }^{*} M=234 \\
{ }^{*} \phi=116 & { }^{*} w=156 & { }^{*} l=347 \\
n=112 & { }^{*} k=146 &
\end{array}
$$

The table following shows the average of the measured angles compared with the calculated ones. 
Angle values of forms on eglestonite crystals.

[Starred letters indicate new forms.]

\begin{tabular}{|c|c|c|c|c|c|c|c|c|c|c|c|c|}
\hline \multirow{2}{*}{ No. } & \multirow{2}{*}{$\begin{array}{l}\text { Let- } \\
\text { ter. }\end{array}$} & \multirow{2}{*}{$\begin{array}{l}\text { Num- } \\
\text { ber of } \\
\text { meas- } \\
\text { ure- } \\
\text { ments. }\end{array}$} & \multicolumn{2}{|c|}{ Symbol. } & \multicolumn{4}{|c|}{ Measured. } & \multicolumn{4}{|c|}{ Calculated. } \\
\hline & & & Gdt. & $\begin{array}{l}\text { Mil- } \\
\text { ler. }\end{array}$ & \multicolumn{2}{|c|}{$\phi$} & \multicolumn{2}{|c|}{$\rho$} & $\phi$ & & \multicolumn{2}{|c|}{$\rho$} \\
\hline & & & & & $\circ$ & , & & , & $\circ$ & , & $\circ$ & , \\
\hline 1 & $a$ & $\therefore$ & $0 \infty$ & 100 & $\ldots$ & & 90 & 00 & $\ldots \ldots$ & & 90 & 00 \\
\hline 2 & $d$ & $\ldots .$. & $\infty$ & 110 & 45 & 00 & 90 & 00 & 45 & 00 & 90 & 00 \\
\hline$\overline{3}$ & $*_{0}$ & 19 & 1 & 111 & 45 & 00 & 54 & 44 & 45 & 00 & 54 & 44 \\
\hline 4 & ${ }^{*} e$ & 8 & $\infty 2$ & 120 & 26 & 25 & 90 & 00 & 26 & 34 & 90 & 00 \\
\hline 5 & $* f$ & & $\infty 3$ & 130 & 18 & 26 & 90 & 00 & 18 & 26 & 90 & 00 \\
\hline 6 & $* \phi$ & 28 & $\frac{1}{6}$ & 116 & 45 & 15 & 13 & 13 & 45 & 00 & 13 & 16 \\
\hline 6 & ${ }^{*} \phi$ & 28 & 16 & 161 & 9 & 29 & 80 & 34 & 9 & 28 & 80 & 40 \\
\hline & & & $\frac{1}{2}$ & 112 & 45 & 00 & 35 & 17 & 45 & 00 & 35 & 16 \\
\hline 7 & $n$ & 52 & 12 & 121 & 26 & 34 & 65 & 54 & 26 & 34 & 65 & 54 \\
\hline & ${ }^{*} r$ & & $\frac{3}{2}$ & 332 & 45 & 02 & 64 & 38 & 45 & 00 & 64 & 46 \\
\hline 8 & ${ }^{n} r$ & 27 & $\frac{2}{3} 1$ & 233 & 33 & 43 & 50 & 20 & 33 & 41 & 50 & 15 \\
\hline 9 & ${ }^{*} p$ & 2 & 2 & 221 & 45 & 02 & 70 & 29 & 45 & 00 & 70 & 32 \\
\hline & $p$ & 1 & $\frac{1}{2} 1$ & 122 & 26 & 33 & 46 & 40 & 26 & 34 & 48 & 11 \\
\hline 10 & ${ }^{*} \rho$ & 1 & 4 & 441 & 45 & 02 & 79 & 28 & 45 & 00 & 79 & 58 \\
\hline 11 & $*_{i}$ & 3 & $\frac{1}{8} \frac{9}{8}$ & 198 & 6 & 17 & 48 & 37 & 6 & 20 & 48 & 34 \\
\hline & & & 89 & 891 & 41 & 38 & 84 & 48 & 41 & 38 & 85 & 15 \\
\hline 12 & ${ }^{*} j$ & 1 & $\frac{1}{7} \frac{6}{7}$ & 167 & 9 & 19 & 41 & 20 & 9 & 28 & 40 & 59 \\
\hline 13 & * & 6 & $\frac{1}{6} \frac{5}{6}$ & 156 & 11 & 38 & 40 & 15 & 11. & 19 & 40 & 21 \\
\hline 10 & & 6 & $\frac{1}{5} \frac{6}{5}$ & 165 & 9 & 39 & 50 & 48 & 9 & 28 & 50 & 35 \\
\hline 14 & $* k$ & 2 & $\frac{1}{6} \frac{2}{3}$ & 146 & 13 & 39 & 35 & 25 & 14 & 02 & 34 & 30 \\
\hline 14 & & 2 & & 164 & 9 & 34 & 54 & 29 & 9 & 28 & 56 & 40 \\
\hline 15 & ${ }^{*} \Sigma$ & 1 & $45^{4}$ & 451 & 38 & 52 & 81 & 35 & 38 & 40 & 81 & 08 \\
\hline 16 & ${ }^{*} F$ & 1 & 26 & 261 & 18 & 23 & 80 & 08 & 18 & 26 & 81 & 01 \\
\hline & $\cdot$ & & $\frac{1}{3} \frac{2}{3}$ & 123 & 26 & 35 & 36 & 40 & 26 & 34 & 36 & 42 \\
\hline 17 & $s$ & 81 & $\frac{1}{2} \frac{3}{2}$ & 132 & 18 & 29 & 57 & 43 & 18 & 26 & 57 & 41 \\
\hline & & & & 231 & 33 & 40 & 74 & 33 & 33 & 41 & 74 & 30 \\
\hline & & & $\frac{4}{11} \frac{7}{11}$ & 4.7.11 & 29 & 45 & 36 & 23 & 29 & 45 & 36 & 14 \\
\hline 18 & ${ }^{*} v$ & 12 & $\frac{x}{7}-\frac{1}{7}$ & 4.11 .7 & 19 & 55 & 59 & 00 & 19 & $5 \dot{9}$ & 59 & 07 \\
\hline & & & $\frac{7}{4} \frac{11}{4}$ & 7.11 .4 & 32 & 02 & 72 & 31 & 32 & 28 & 72 & 57 \\
\hline 19 & ${ }^{*} M$ & 1 & $\frac{1}{2} \frac{3}{4}$ & 234 & 32 & 22 & 41 & 46 & 33 & 41 & 42 & 02 \\
\hline 20 & $* l$ & 2 & $\frac{5}{4} \frac{1}{4}$ & 374 & 23 & 01 & 62 & 17 & 23 & 12 & 62 & 17 \\
\hline 20 & & & $\frac{4}{3} \frac{7}{8}$ & 473 & 30 & 04 & 70 & 35 & 29 & 45 & 69 & 35 \\
\hline
\end{tabular}

The common forms for eglestonite are seven in number, namely: $a\{100\}, d\{110\}, o\{111\}, \phi\{116\}, n\{112\}, r\{332\}$, and $s\{123\}$. The forms which are somewhat less common but still occur so often that they can by no means be referred to as rare forms are, in approximately their order of importance, $v\{4.7 .11\}, e\{120\}, w\{156\}, f\{130\}$, and $i\{198\}$. The following three forms were observed but twice: $p\{221\}, k\{146\}$, and $l\{374\}$; while the remainder, or $\rho\{441\}, j\{167\}$, $\Sigma\{451\}, F\{261\}, M\{234\}$, were observed but once. This last group, or those that were observed only once, constitute the rare forms. 
Summary of eglestonite forms.

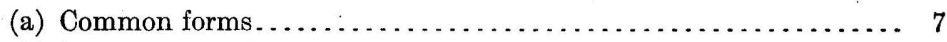

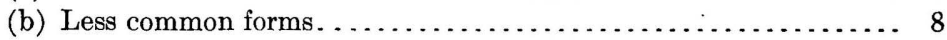

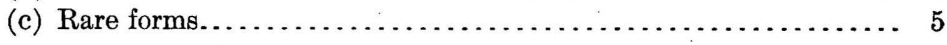

DESCRIPTION OF COMMON FORMS.

$a\{100\}$, the cube, is present on all the octahedral crystals, while absent on all those of the dodecahedral habit. It is so minute that many faces give no signal on the goniometer.

$d\{110\}$, the rhombic dodecahedron, is the dominant face of habit 1 , and on these crystals is invariably striated, many faces being built up of inscribed rhombs. On the octahedral crystals (habit 2) it is the second largest face, being smaller than the octahedron. On these crystals it is rarely striated.

$o\{111\}$, the octahedron; occurs as very minute faces on the dodecahedral crystals, but becomes the dominant form on the more complicated crystals of octahedral habit. No difference in character could be distinguished between the different faces of the octahedron.

$\phi\{116\}$ is present on all the octahedral crystals, and while invariably minute is one of the common forms of eglestonite.

$n\{112\}$ is one of the principal forms of this mineral and with the dodecahedron is present on all the crystals of eglestonite so far examined. It is usually a small face, though on the octahedral crystals it is third in size. The form is almost invariably striated.

$r\{332\}$ occurs often as minute faces on the dodecahedral habit, but as long line faces on the octahedral habit.

$s\{123\}$ is absent on the dodecahedral crystals, but occurs on all others as small faces. In all such octants of the crystal as were complete there were six faces of this form, indicating holohedral symmetry.

DESCRIPTION OF LESS COMMON FORMS.

All the measurements are here given for the less common forms. Occurrence and measurements of less common forms (all new) on eglestonite crystals.

[Bold-faced figures give calculated values.]

\begin{tabular}{|c|c|c|c|c|c|}
\hline $\begin{array}{c}\text { Form and } \\
\text { crystal } \\
\text { No. }\end{array}$ & $\begin{array}{l}\text { Reflec- } \\
\text { tion. }\end{array}$ & Size of face. & $\phi$ & & $\rho$ \\
\hline $\begin{array}{r}e\{120\} \\
2 \\
4 \\
4 \\
5 \\
5 \\
5 \\
5 \\
6\end{array}$ & $\begin{array}{l}\text { Poor... } \\
\text { Poor.... } \\
\text { Poor.... } \\
\text { Poor.... } \\
\text { Poor.... } \\
\text { Poor.... } \\
\text { Poor.... } \\
\text { Poor.... }\end{array}$ & 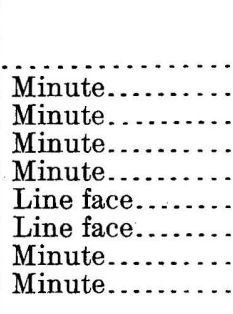 & $\begin{array}{c}\circ \\
\mathbf{2 6} \\
26 \\
26 \\
26 \\
26 \\
26 \\
26 \\
26 \\
25\end{array}$ & $\begin{array}{l}\prime \\
\mathbf{3 4} \\
09 \\
27 \\
44 \\
44 \\
21 \\
30 \\
04 \\
58\end{array}$ & 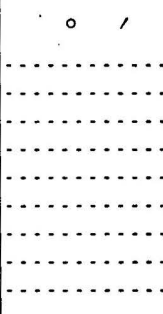 \\
\hline
\end{tabular}


Occurrence and measurements of less common forms on eglestonite crystals-Continued.

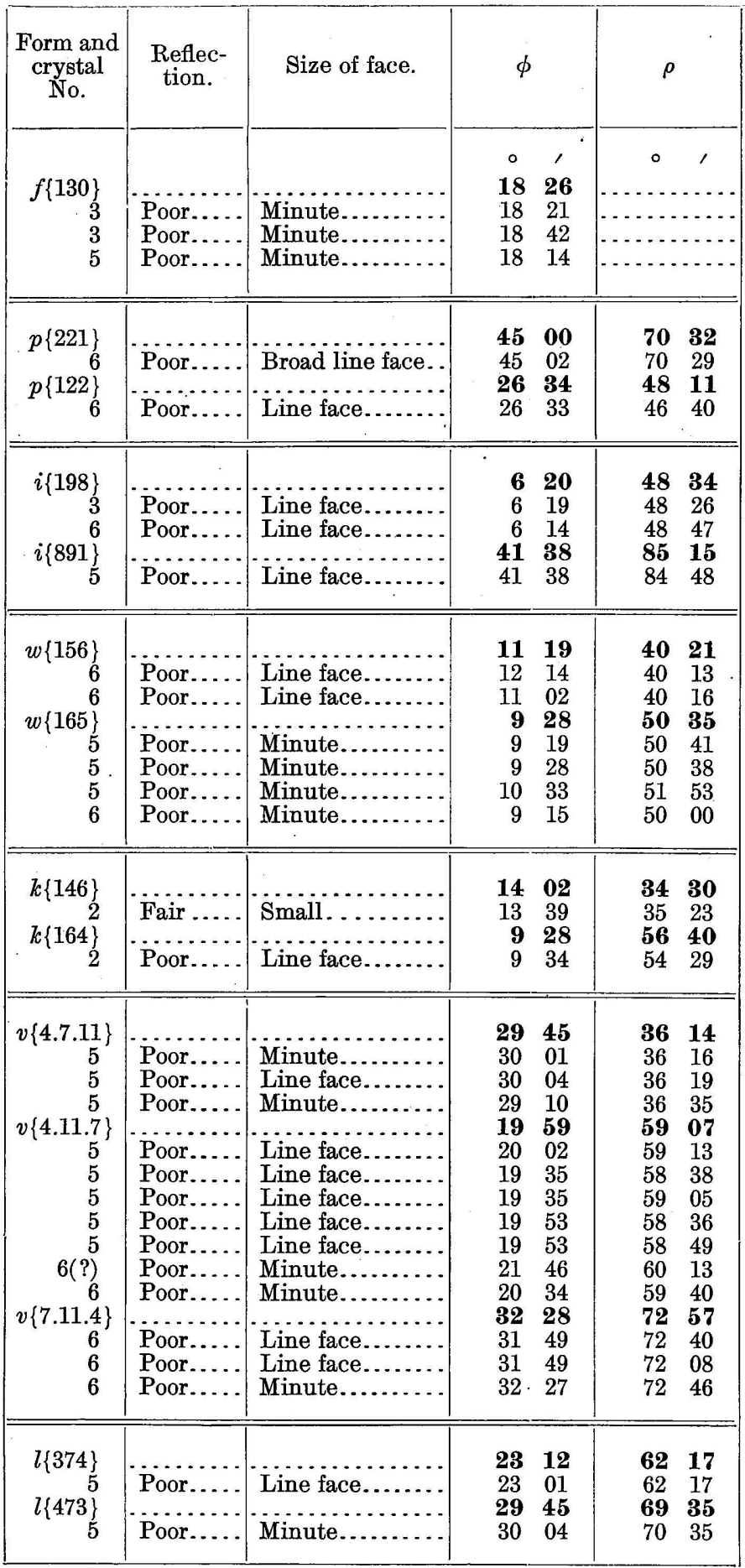


DESCRIPTION OF RARE FORMS.

The following forms were observed once each:

Occurrence and measurements of rare forms on eglestonite crystals.

\begin{tabular}{|c|c|c|c|c|c|c|c|}
\hline \multirow{2}{*}{ Symbol. } & \multirow{2}{*}{$\begin{array}{l}\text { Crys- } \\
\text { tal } \\
\text { No. }\end{array}$} & \multirow{2}{*}{$\begin{array}{l}\text { Reflec- } \\
\text { tion. } \\
:\end{array}$} & \multirow{2}{*}{ Size of face. } & \multicolumn{2}{|c|}{ Measured. } & \multicolumn{2}{|c|}{ Calculated. } \\
\hline & & & & $\phi$ & $\rho$ & $\phi$ & $\rho$ \\
\hline $\begin{array}{l}\rho\{441\} \\
j\{167\} \\
F\{261\} \\
M\{234\} \\
\Sigma\{451\}\end{array}$ & $\begin{array}{l}6 \\
5 \\
6 \\
2 \\
5\end{array}$ & $\begin{array}{l}\text { Poor.. } \\
\text { Poor.. } \\
\text { Poor.. } \\
\text { Poor.. } \\
\text { Poor.. }\end{array}$ & $\begin{array}{l}\text { Broad line face. } \\
\text { Minute.......... } \\
\text { Minute......... } \\
\text { Minute......... } \\
\text { Line face....... }\end{array}$ & $\begin{array}{rl}\circ & \prime \\
45 & 02 \\
9 & 19 \\
18 & 23 \\
33 & 22 \\
38 & 52\end{array}$ & $\begin{array}{cc}\circ & \prime \\
79 & 28 \\
41 & 20 \\
80 & 08 \\
41 & 46 \\
81 & 35\end{array}$ & $\begin{array}{rl}\circ & \prime \\
45 & 00 \\
9 & 28 \\
18 & 26 \\
33 & 41 \\
38 & 40\end{array}$ & $\begin{array}{cc}\circ & \prime \\
79 & 58 \\
40 & 59 \\
81 & 01 \\
42 & 02 \\
81 & 08\end{array}$ \\
\hline
\end{tabular}

The following forms were also observed once each, but the angles did not agree closely and the forms are more than doubtful. They are recorded only for reference: $\{343\},\{447\}$ or $\{559\},\{551\}$, $\{235\}$, and $\{251\}$.

DISCUSSION OF FORMS.

$$
\text { Zone (100):(010) (No. 1); symbol, } \frac{k}{h} \text {. }
$$

\begin{tabular}{|c|c|c|c|c|c|c|c|}
\hline Form...... & $a$ & $f$ & $e$ & $d$ & $e$ & $f$ & $a$ \\
\hline & & 310 & 210 & 110 & 120 & 130 & 010 \\
\hline n..., & 0 & $1 / 3$ & $1 / 2$ & 1 & 2 & 3 & $\infty$ \\
\hline & 0 & $1 / 3$ & $1 / 2$ & 1 & 2 & 3 & $\infty$ \\
\hline
\end{tabular}

The zone is normal.

Zone (001):(111):(110) (No. 2); symbol, $-\frac{h}{l}$.

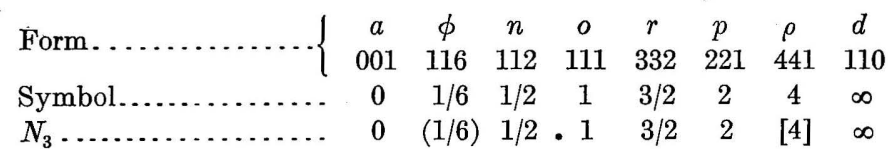

In place of 4 or $\{441\}$ we would expect $\{331\}$.

Values of $\rho$ for the form $\{441\}$.

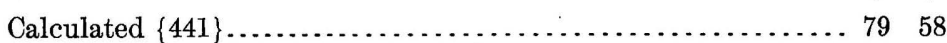

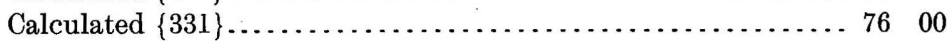

Measured....................................... 7928

Though $\{441\}$ is considered certain, it is one of the rarest forms, having been noted but once. The form $\phi\{116\}$ is extra but is well established. Both of these forms, which cause a disturbance in the otherwise normal zone, are nearest the end members or members with the simplest indices, $\{001\}$ and $\{110\}$.

$$
\text { Zone (101):(211) (No. 3); symbol, } \frac{k}{l} \text {. }
$$

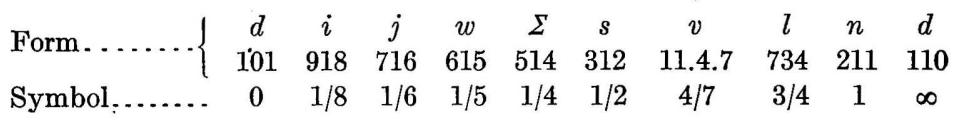


Dividing the series at $1 / 2$, or $\{312\}$, we have:

\begin{tabular}{|c|c|c|c|c|c|c|c|c|c|c|c|}
\hline & 0 & $1 / 8$ & $1 / 6$ & $1 / 5$ & $1 / 4$ & $1 / 2$ & & $1 / 2$ & $4 / 7$ & $3 / 4$ & 1 \\
\hline $2 v \ldots \ldots \ldots \ldots$ & 0 & $1 / 4$ & $1 / 3$ & $2 / 5$ & $1 / 2$ & 1 & $2 v \ldots \ldots \ldots \ldots$ & 1 & $8 / 7$ & $3 / 2$ & 2 \\
\hline$\frac{v}{v-1} \ldots \ldots \ldots$ & 0 & $1 / 3$ & $1 / 2$ & $2 / 3$ & 1 & $\infty$ & $v-1 \ldots \ldots \ldots$ & 0 & $1 / 7$ & $1 / 2$ & 1 \\
\hline$N_{3} \ldots \ldots \ldots$ & 0 & $1 / 3$ & $1 / 2$ & $2 / 3$ & & & $N_{2} \ldots \ldots$ & 0 & $(1 / 7)$ & $1 / 2$ & $1 . \infty$ \\
\hline
\end{tabular}

The form $\{11.4 .7\}$ is extra, as might be expected, as it is very close to $\{312\}$. It is considered, however, as an established form (see p. 150 for angles).

$$
\text { Zone (160):(001) (No. 4); symbol, } \frac{h}{l} \text {. }
$$

\begin{tabular}{|c|c|c|c|c|c|c|c|}
\hline Form...... & $\overline{(160)}$ & $\begin{array}{c}\phi \\
161\end{array}$ & $\begin{array}{c}F \\
162\end{array}$ & $\begin{array}{c}k \\
164\end{array}$ & $\begin{array}{c}w \\
165\end{array}$ & $\underset{167}{j}$ & $\begin{array}{c}a \\
001\end{array}$ \\
\hline Symbol......................... & $(\infty)$ & 1 & $1 / 2$ & $1 / 4$ & $1 / 5$ & $1 / 7$ & 0 \\
\hline $2 v \ldots \ldots$ & $(\infty)$ & 2 & 1 & $1 / 2$ & $2 / 5$ & $2 / 7$ & 0 \\
\hline$N_{3} \cdot \ldots \ldots \ldots \ldots \ldots \ldots \ldots \ldots \ldots \ldots \ldots$ & $(\infty)$ & 2 & 1 & $1 / 2$ & $(2 / 5)$ & $(2 / 7)$ & 0 \\
\hline
\end{tabular}

The extra forms are $\{165\}$ and $\{167\}$, both of which are well established. See discussion of preceding zone.

$$
\text { Zone (120):(001) (No. 5); symbol, } \frac{h}{l} \text {. }
$$

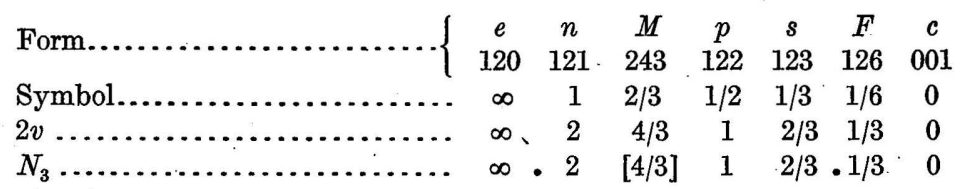

In place of $4 / 3\{243\}$, we would expect $3 / 2\{364\}$, but the measurements show that $\{243\}$ are the correct indices.

\begin{tabular}{|c|c|c|c|c|c|c|c|}
\hline \multirow{2}{*}{ Letter. } & \multirow{2}{*}{ Symbol. } & \multicolumn{6}{|c|}{ - Crystal No. - } \\
\hline & & 1. & 2. & 3. & 4. & 5. & 6. \\
\hline$a$ & 100 & & $a$ & $a$ & $a$ & $a$ & $a$ \\
\hline$d$ & 110 & $\ddot{d}$ & $d$ & $d$ & $d$ & $d$ & $d$ \\
\hline 0 & 111 & 0 & $o$ & 0 & $o$ & $o$ & 0 \\
\hline$e$ & 120 & $\ldots \ldots$ & $e$ & $\because$ & $e$. & $e$ & $e$ \\
\hline$f$ & $\begin{array}{l}130 \\
116\end{array}$ & $\cdots \cdots \cdot$ & $\ddot{\phi}$ & $f$ & $\ddot{\phi}$ & $f$ & $\ddot{\phi}$ \\
\hline$n$ & 112 & $n$ & $\begin{array}{l}\varphi \\
n\end{array}$ & $\begin{array}{l}\varphi \\
n\end{array}$ & $\begin{array}{l}\varphi \\
n\end{array}$ & $\begin{array}{l}\varphi \\
n\end{array}$ & $\begin{array}{l}\varphi \\
n\end{array}$ \\
\hline$r$ & 332 & $r$ & $r$ & $r$ & $r$ & $r$ & $r$ \\
\hline$p$ & 221 & - & 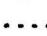 & & 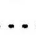 & .. & $p$ \\
\hline$\rho$ & 441 & & 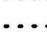 & & $\cdots$ & $\because$ & $\rho$ \\
\hline$i$ & 189 & ....... & .. & $i$ & $\cdots$ & $i$ & $i$ \\
\hline$j$ & $\begin{array}{l}167 \\
156\end{array}$ & $\cdots \cdots$ & & 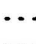 & $\cdots$ & $j$ & 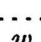 \\
\hline $\begin{array}{l}w \\
k\end{array}$ & $\begin{array}{l}106 \\
146\end{array}$ & & $\ddot{k}$ & & & $w$ & $w$ \\
\hline$\Sigma$ & 145 & & 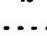 & & . & $\Sigma$ & \\
\hline$F$ & 126 &. & .. & & & $\cdots$ & $F$ \\
\hline$s$ & 123 & ..... & $s$ & $s$ & $s$ & $s$ & $s$ \\
\hline$v$ & 4.7.11 & & & & . & $v$ & $v$ \\
\hline$l$ & $\begin{array}{l}234 \\
347\end{array}$ & & $M$ & & & $i$ & \\
\hline
\end{tabular}

Combinations of forms on eglestonite crystals. 
U. S. GEOLOGICAL SURVEY

BULLETIN 405 PLATE VI

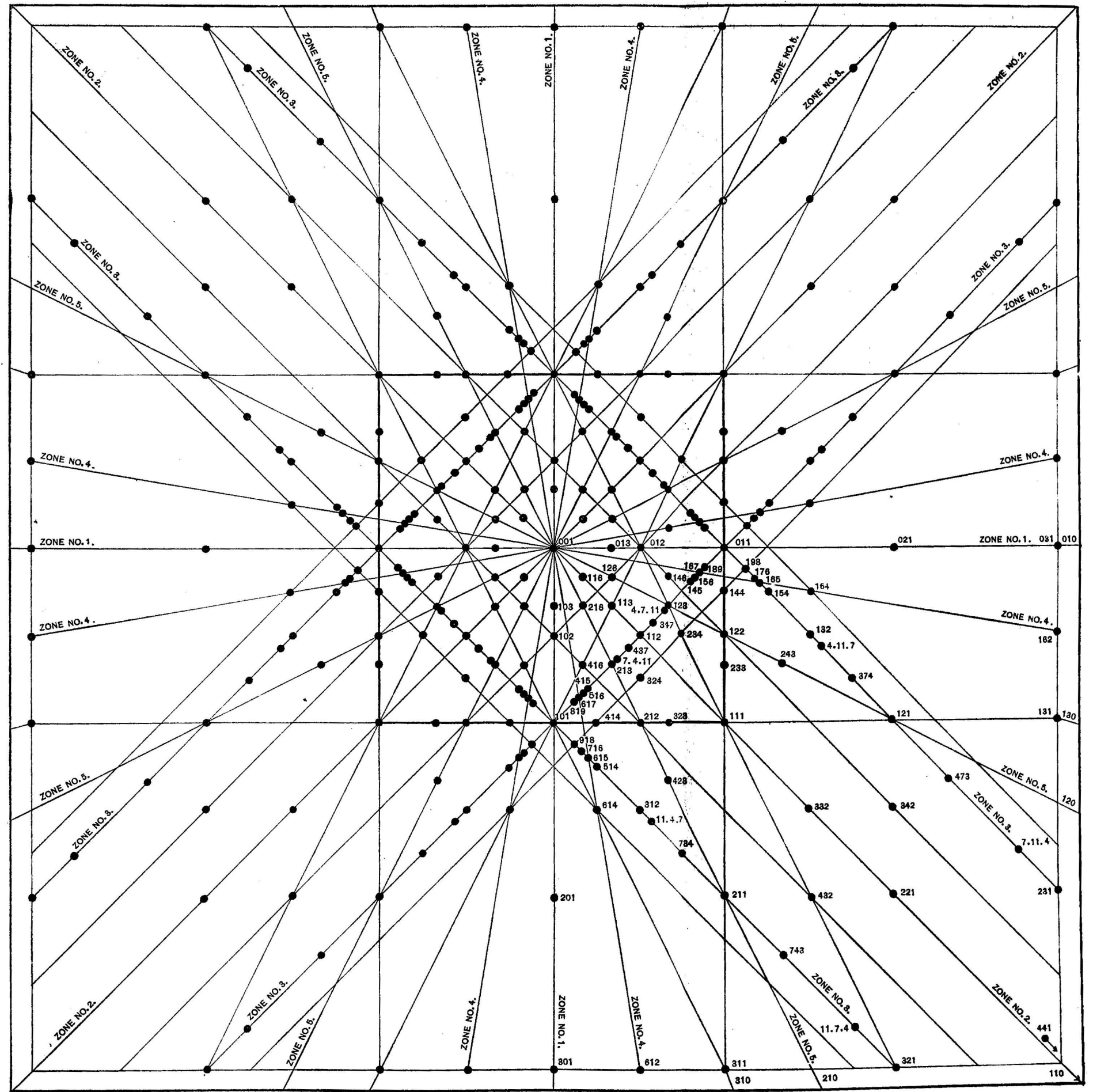

GNOMONIC PROJECTION OF EGLESTONITE FORMS. 



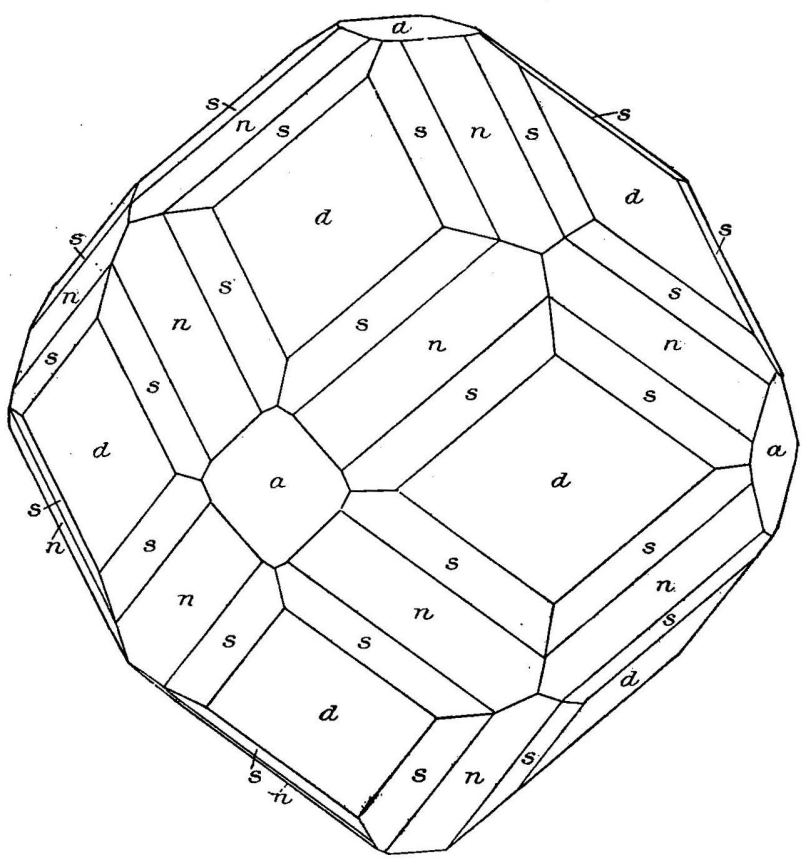

FIGURE 32.-Eglestonite, dodecahedral habit (after Moses): $a\{100\}, d\{101\}, n\{112\}, s\{123\}$.

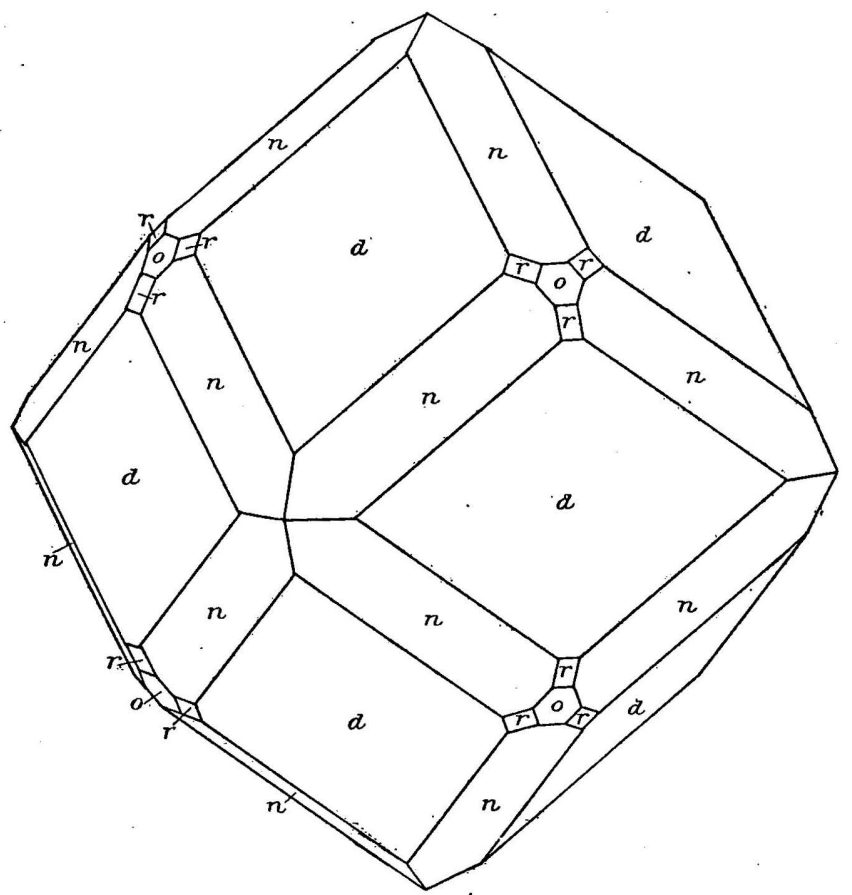

FIGURE 33.-Eglestonite, dodecahedral habit: $d\{101\}, n\{112\}, o\{111\}, r\{332\}$. 
Crystal 1 is of the dodecahedral habit (see next page), the others of the octahedral habit. Notice the difference in the richness of combination as shown by crystals of the two habits.

ZONAL RELATIONS AND GNOMONIC PROJECTION.

The forms of eglestonite are arranged in a few well-defined zones, and one of these, the striated zone nd, contains nine forms. The

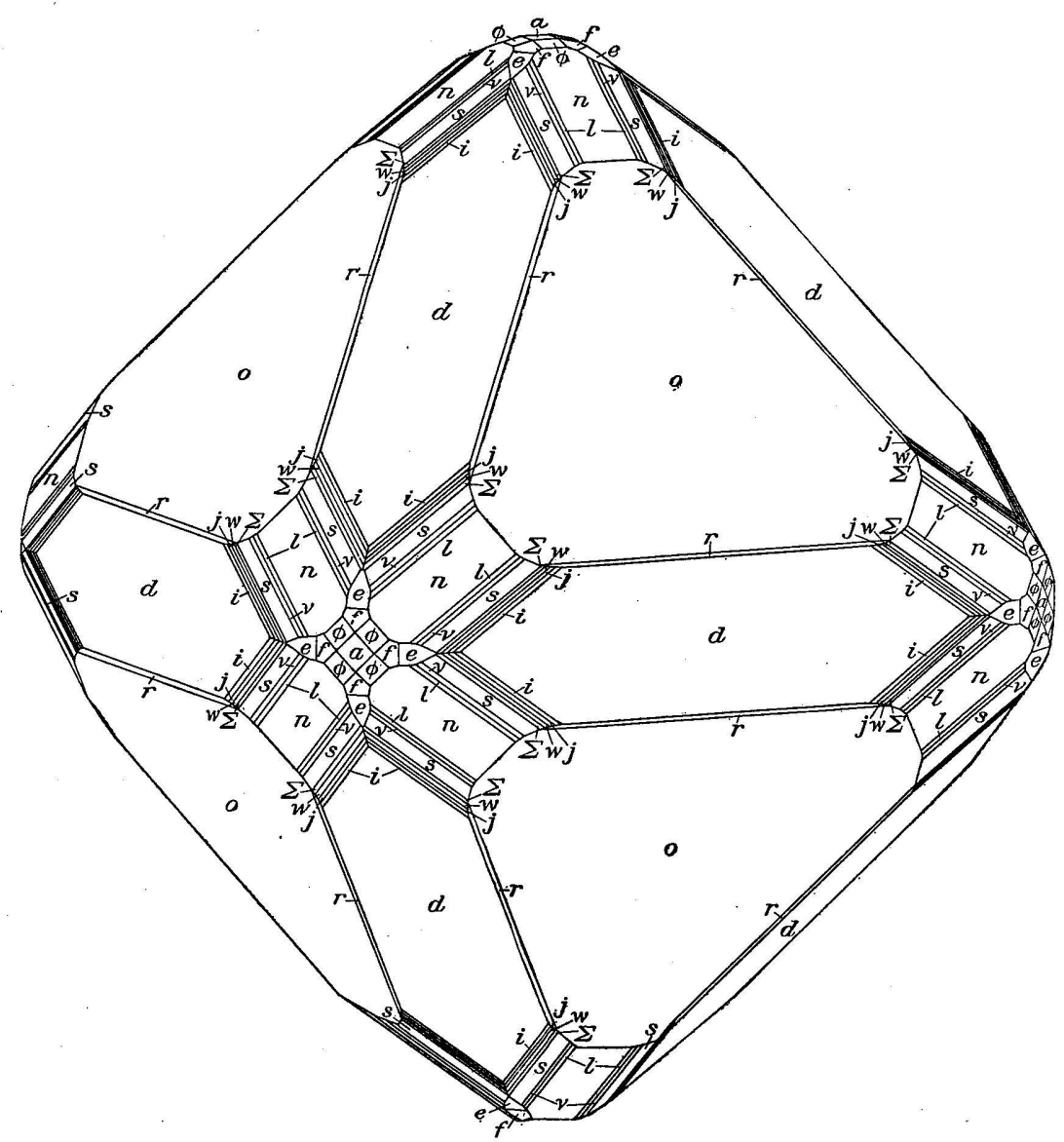

FIGURE 34.-Eglestonite crystal, octahedral habit: $a\{100\}, d\{101\}, o\{111\}, e\{120\}, f\{130\}, \phi\{116\}, n\{112\}$, $r\{332\}, i\{189\}, j\{167\}, w\{156\}, \Sigma\{145\}, s\{123\}, v\{4.7 .11\}, l\{347\}$.

prism zone with $a, d, e, f$ is free from any striations, except that $d$ is striated in the zone direction $d n$. The other three forms of this zone occur as bright even faces. Another fairly rich zone, free from striations, is (001), (116), (111), (332), (221), (441), (110). Other well-developed zones, (116), (216), (416), (516), (716), (100); (001), (216), (213), (212), (423), (211), (210); (918), (414), (324), (234), (144), (198) are all free from striæ. In fact, it is only the one zone $n d$, that is striated, and this is often very much striated. It 
has been possible, however, to determine numerous forms in this zone, though a few of these belong to the rare forms, being noticed but once or twice. The forms determined, besides $n$ and $d$, are $\{918\},\{716\},\{615\},\{514\},\{312\}$, $\{11.4 .7\},\{734\}$. Some of these are rather complex, but, as the discussion on page 151 showed, they all (except $\{11.4 .7\}$ ) fall into the normal series and $\{11.4 .7\}$ is amply substantiated by the measurements given on page 150 .

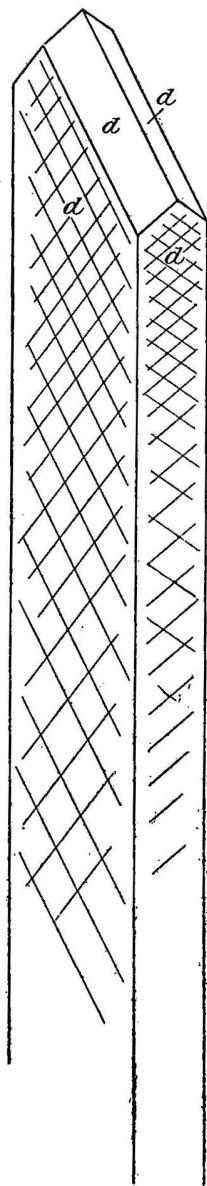
tened eglestonite crystal: $d\{110\}$.
Figure 36. - Flat-

The zonal relations can be very well seen by reference to the gnomonic projection $^{a}$ shown in Plate VI. The numbered zones refer to the discussion on pages $151-152$.

\section{HAB̀IT.}

Crystals of eglestonite may be classed under three habits.

Habit 1. One form of this habit was described by Moses and is shown in figure 32, reproduced from his paper. This form was not observed by the writer.

All the eglestonite crystals that were on the specimens first received are of this dodecahedral habit (fig. 33).

The crystals are simple in their combination, the only forms present being $\{110\},\{111\},\{112\},\{332\}$. Of these $\{111\}$ and $\{332\}$ are very minute, while $\{110\}$ is large and $\{112\}$ small. Owing to the predominance of the rhombic dodecahedron, the habit is described as dodecahedral. The dodecahedron is invariably striated and built up of inscribed rhombs, while $\{112\}$ is strongly striated. These crystals were all either brown or black when first received. The interior was often of a lighter brown, but none were such a light yellow brown as the crystals of the third or octahedral habit. In size the crystals are fairly uniform, the larger number being about 1 millimeter in diameter, though some were smaller, down to very minute.

Habit 2. In the last package received were a number of eglestonite specimens, the crystals appearing entirely different from those earlier received, owing to the large development of the octahedron. Crystals of this habit are shown in figure 34. The octahedron, the largest 
form, is bright and even, and no difference suggestive of tetrahedrism could be detected between the different faces. After the octahedron in size comes the dodecahedron and then the trisoctahedron $\{112\}$. These crystals are very rich in forms, a feature which also distinguishes them from those of the other habit. For comparison and to show how rich in faces these crystals are, the following table is given of the number of faces actually measured. The crystalis

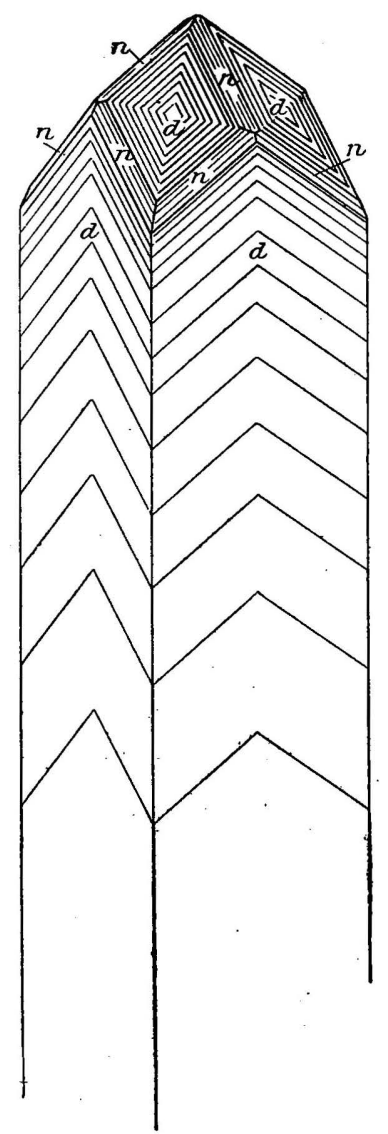

Figure 37.--Striated distorted eglestonite crystal: $d\{110\}, \underline{n}\{112\}$. are so minute that no readjustment of them on the wax was made after all faces possible were measured. Therefore only one-half of each crystal was measured.

Number of faces measured on half of each eglestonite crystal.

Crystal $1 \ldots \ldots \ldots \ldots \ldots \ldots \ldots \ldots \ldots \ldots \ldots$

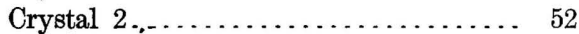

Crystal 3..................... 41

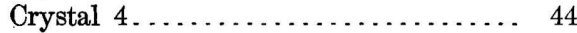

Crystal 5..................... 92

Crystal 6..................... 102

If the crystals were complete and hat the entire number of faces for each form, they would have the following number of faces:

Number of faces indicated for complete eglestonite crystals.

Crystal 1..................... 68

Crystal $2 \ldots \ldots \ldots \ldots \ldots \ldots \ldots \ldots \ldots \ldots \ldots \ldots \ldots$

Crystal $3 \ldots \ldots \ldots \ldots \ldots \ldots \ldots \ldots . . . \ldots 218$

Crystal 4...................... 170

Crystal 5..................... 482

Crystal 6..................... 410

Habit 3. Crystals of this habit are very long prismatic, becoming almost hairlike, owing to the distortion of $d\{101\}$. Three such crystals are shown in figures 35,36 , and 37.

DESCRIPTION OF CRYSTALS.

Such crystals as the one shown in figure 32, reproduced from the paper by Moses, were not observed by the writer. The common habit of the dodecahedral crystals is depicted in figure 33. The dodecahedron is always built up of inscribed rhombs, and the faces of $n\{112\}$ are strongly striated. Though some of these crystals are somewhat distorted, they usually are fairly constant in the relative development of their faces. 
The octahedral crystals, such as Nos. 2, 3, 4, 5, and 6, are, however, the most interesting, as they are exceedingly rich in forms. Figure 34 shows an ideal development of crystal 5, all of the forms found on it being shown in the drawing. The large octahedral faces are bright and even, and the dodecahedron faces are but little striated, thus differing from those on the crystals of the dodecahedral habit. The faces of $n\{112\}$, however, are strongly striated, and it is, in fact, in the striated zone of (112) : (101) that so many of the faces lie. The cube faces, and those lying around the cube, such as $\phi, f, e$, are all small but brilliant. The actual relations of the various forms and their mode of intersection with each other could not, of course, be actually seen, but the drawing is intended to represent the true combination as closely as it could be determined.

A number of curiously distorted crystals, those already mentioned under habit 3, were noticed on a very few specimens. They are distorted dodecahedrons resembling the drawing shown in figure' 35 . Some are still further distorted in that they are somewhat flattened as shown in figure 36 . There is also a series of crossing striations on these faces, the lines being parallel to the edges $(1 \overline{1} 0):(101):(011)$ and (110): (101): (011), as shown in figure 36. Finally, some of the thicker of these distorted crystals showed the combination reproduced in figure 37 , but here the lines or striæ on the dodecahedral faces have the appearance shown instead of as in the previous figure. These crystals are thus seen to be directly related to those of habit 1 (fig. 33).

\section{CALOMEL.}

FORMS.

Calomel is found in two forms.

1. Usually it is in distinct crystals, often twinned, and also irregularly grouped together. Most of the crystals are up to one-half centimeter in diameter, though a few are over $1 \frac{1}{2}$ centimeters thick. Some of the well-developed crystals are very minute. In general, two habits were noticed:

(a) Prismatic, mostly short prismatic.

(b) Equidimensional, the common habit.

2. Calomel is rather abundant on some of the specimens as a crystalline crust showing large cleavage faces. This crust in some parts is intimately mixed with eglestonite, giving it a yellow or brownish color. Many of the separate crystals (form 1) are situated on this crystalline crust. 


\section{PHYSICAL PROPERTIES.}

COHESION, ETC.

These crystals possess good cleavage parallel to $a\{100\}$. The cleavage faces, however, are never perfectly smooth, but are slightly uneven, and on the goniometer give several faint reflections besides the one bright one. The cleavage, then, is much poorer than that of terlinguaite and montroydite, but is better than that of kleinite.

\section{DENSITY.}

Attention may be called to the fact, stated by Groth, ${ }^{a}$ that the exact density of calomel is not known. The results obtained by different authors vary somewhat. Groth gives 6.71-7.18. Unfortunately the present material is not suited for a density determination. It was found on examining the material at hand that it all contained inclosed mercury, which sometimes became visible only on a fresh cleavage surface.

\section{CRYSTALLOGRAPHY.}

PREVIOUS PUBLICATION.

The writer had gone into a full discussion of the form system of calomel, taking the published data as well as his own results into consideration. A discussion of the forms, carried out in a way similar to that used for the already described minerals, led to several important conclusions, and the form system of calomel was thereby freed from many of its encumbering and questionable data. The entire paper has, however, been subjected to so much unavoidable delay that a description by other writers of these calomel crystals from Terlingua, Tex., ${ }^{b}$ has already appeared in print, though the present paper had been written a considerable time before the one referred to was published. In their paper Goldschmidt and Mauritz go very fully into a discussion of the form system of calomel, and arrive at, results very similar to those obtained by the writer. He has, therefore, rewritten his crystallographical description of calomel, omitting the discussions and parts which would only result in needless repetition.

\section{GENERAL DESCRIPTION.}

The majority of the calomel crystals are directly on the soft earthy matrix, which usually has a deep red-brown color and contains only a very small amount of carbonate. The crystals on this matrix are generally equidiametral, several millimeters in diameter, and are 
usually twinned. The associated minerals are calcite, mercury, and eglestonite. The matrix specimens with calomel average about 5 to 6 centimeters in size and perhaps half as much in thickness. A few of the crystals on the matrix reach a diameter of 1 centimeter, though they are usually somewhat less than 5 millimeters thick. A few specimens show the calomel with other associations. It has been found with kleinite, montroydite, and terlinguaite. Here the crystals tend to a more prismatic habit and are much simpler in their combinations. A few large, loose crystals of simple habit and covered with mercury and eglestonite were also received. Three of the largest of these ose crystals measured (1) 15 by 14 by 11 millimeters, (2) 17 by 10 by 10 millimeters, and (3) 16 by 11 by 11 millimeters.

CALCULATION OF ELEMENTS.

From the measurements of the pyramids of the first and second order, those that gave good sharp signals were taken for a calculation of the $c$ axis. There were not very many that allowed of sufficient accuracy of measurement to be used in calculating a fundamental constant, but 37 were taken and the value for $c$ calculated from each angle value. These gave:

Values of $\mathrm{c}$ for calomel.

\begin{tabular}{|l|l|l|}
\hline 1.7239 & 1.7323 & 1.7227 \\
1.7251 & 1.7364 & 1.7227 \\
1.7262 & 1.7419 & 1.7085 \\
1.7228 & 1.7229 & 1.7270 \\
1.7262 & 1.7419 & 1.7332 \\
1.7228 & 1.7175 & 1.7260 \\
1.7239 & 1.7122 & 1.7260 \\
1.7321 & 1.7199 & 1.7224 \\
1.7332 & 1.7227 & 1.7148 \\
1.7229 & 1.7185 & 1.7173 \\
1.7117 & 1.7185 & 1.7170 \\
1.7136 & 1.7254 & Av., 1.7234 \\
1.7173 & 1.7199 & \\
\hline
\end{tabular}

The value found by the writer, namely $c=1.7234$, agrees very well with existing determinations. Thus Goldschmidt and Mauritz give $c=1.7236$ (Texas) and $c=1.7220$ (Avala); and Schrauf gives $c=1.7229$.

Taking an average of these determinations we have:

Determination, by average, of $c$ for calomel.

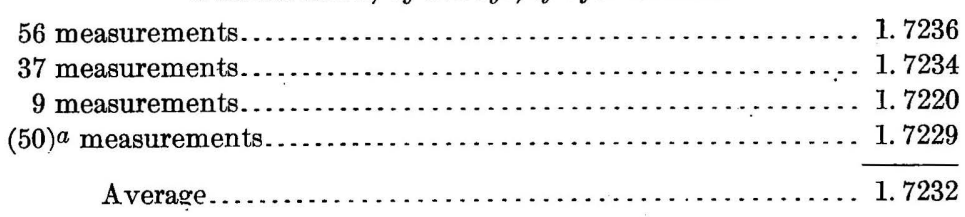


This average value, $c=1.7232$, is almost identical with the one of Schrauf generally adopted.

FORMS AND ANGLES.

The complete number of forms present on the twelve crystals measured is 29 . Of these 21 have already been determined for calomel, leaving eight here described for the first time. But a careful study of these eight forms has shown that all except one must still be considered doubtful, and that they can not be classed with the typical forms of calomel. This is in part due to the striated character of the faces and in part to the twinning which is often present on these crystals. The only new form which is considered as well established is $K\{553\}$. The other seven are described fully below, but for the present they must be relegated to the already large class of uncertain forms.

The 21 known forms present on the crystals examined by the writer are:

$$
\begin{array}{c|c|l}
c=001 & s=021 & p=331 \\
a=100 & d=031 & v=153 \\
g=160 & a=113 & n=132 \\
q=015 & i=112 & \rho=135 \\
r=014 & r=111 & \psi=131 \\
t=012 & o=221 & \pi=124 \\
e=011 & \mu=552 & F=3.5 .11
\end{array}
$$

The eight forms, besides those given above, found on these crystals are:

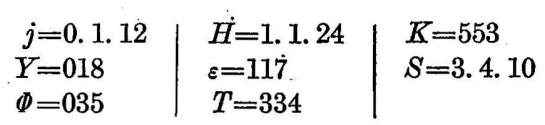

The form $z\{013\}$ was described by Moses as present on a crystal from Terlingua, but was not found by the writer. Goldschmidt and Mauritz found, in addition to those given above, $m\{110\}$ and $\delta\{016\}$, new.

The following table gives the average of the measured angles as compared with the values calculated $(c=1.7232)$. For the common forms, the average measured value is the average of only the best measurements. 
Angle values for forms on calomel crystals.

[New forms are indicated by stars.]

\begin{tabular}{|c|c|c|c|c|c|c|}
\hline \multirow{2}{*}{ No. } & \multirow{2}{*}{ Letter. } & \multirow{2}{*}{ Symbol. } & \multicolumn{2}{|c|}{ Measured. } & \multicolumn{2}{|c|}{ Calculated. } \\
\hline & & & $\phi$ & $\rho$ & $\phi$ & $\rho$ \\
\hline & & & 0,1 & $\circ$, & 0,1 & $\circ$, \\
\hline 1 & $c$ & 001 & $\ldots \ldots$ & 000 & & 000 \\
\hline 2 & $a$ & 100 & & 9000 & 9000 & 9000 \\
\hline 3 & $g$ & 160 & 931 & $\begin{array}{ll}80 & 08\end{array}$ & 927 & 9000 \\
\hline 4 & $*_{j}$ & 0.1 .12 & 000 & 822 & 000 & 810 \\
\hline 5 & $* Y$ & 018 & 000 & 1212 & 000 & 1209 \\
\hline 6 & $q$ & 015 & 000 & 1901 & 000 & 1901 \\
\hline 7 & $\gamma$ & 014 & 000 & 2315 & 000 & 2318 \\
\hline 8 & $t$ & 012 & 000. & $40 \quad 45$ & 000 & 4040 \\
\hline 9 & ${ }^{*} \Phi$ & 035 & 000 & 4520 & 000 & $45 \quad 57$ \\
\hline 10 & $\hat{e}$ & 011 & 000 & 5952 & 000 & 5952 \\
\hline 11 & $s$ & 021 & 000 & 7352 & 000 & 7349 \\
\hline 12 & $d$ & 031 & 000 & 7907 & 000 & $\begin{array}{lll}79 & 03\end{array}$ \\
\hline 13 & ${ }^{*} H$ & 1. 1.24 & 4500 & 548 & 4500 & 548 \\
\hline 14 & $*_{\varepsilon}$ & 117 & 4457 & 1921 & 4500 & $19 \quad 12$ \\
\hline 15 & $a$ & 113 & 4510 & 3907 & 4500 & 3905 \\
\hline 16 & $i$ & 112 & $45 \quad 17$ & 5030 & 4500 & 5037 \\
\hline 17 & ${ }^{*} T$ & 334 & 4500 & $\begin{array}{ll}60 & 17\end{array}$ & 4500 & $61 \quad 19$ \\
\hline 18 & $r$ & 111 & $44 \quad 59$ & 6745 & 4500 & 6741 \\
\hline 19 & ${ }^{*} K$ & 553 & $45 \quad 46$ & $75 \quad 53$ & 4500 & 7610 \\
\hline 20 & $o$ & 221 & 4455 & $78 \quad 15$ & 4500 & 7824 \\
\hline 21 & $\mu$ & 552 & $45 \quad 46$ & 8047 & 4500 & 8040 \\
\hline 22 & $p$ & 331 & 4458 & 8207 & 4500 & $82 \quad 12$ \\
\hline 23 & $v$ & 153 & 1122 & $71 \quad 19$ & 1119 & 7108 \\
\hline 24 & $\rho$ & 135 & 1824 & 4726 & 1826 & $47 \quad 27$ \\
\hline 25 & $n$ & 132 & 1820 & 7008 & 1826 & 6950 \\
\hline 26 & $\psi$ & 131 & 1818 & 7.938 & 1826 & 7936 \\
\hline 27 & $\pi$ & 124 & 2627 & 4355 & 2634 & 4355 \\
\hline 28 & $F$ & 3. 5. 11 & 3129 & 4238 & 3058 & $42 \quad 24$ \\
\hline 29 & ${ }^{*} S$ & 3.4 .10 & 3632 & 4137 & $36 \quad 52$ & 4045 \\
\hline
\end{tabular}

DESCRIPTION OF FORMS.

Of the known forms found by the writer and given in the foregoing table, Goldschmidt and Mauritz exclude $g\{160\}, \mu\{552\}$, and $F\{3.5 .11\}$. Though the prism $g\{160\}$ was noted by the writer as two faces, they were both very rounded and uneven and the form should not be included in the typical forms of calomel. The form $\mu\{552\}$, however, should be included, as it was noted as a small narrow face in the zone $\mathrm{cm}$, the measured and calculated angles agreeing well. The form $F\{3.5 .11\}$, first described by Websky ${ }^{a}$ without any angles, should also be included, the form being substantiated by the measurements following.

$a$ Monatsber. K. Akad. Wiss., Berlin, 1877, p. 461.

4494-Bull. 405-09-11 
Occurrence and measurements of the form $F\{3.5 .11\}$, calomel.

\begin{tabular}{|c|c|c|c|c|}
\hline $\begin{array}{l}\text { Crystal } \\
\text { No.- }\end{array}$ & Reflection. & Size of face. & $\begin{array}{c}\phi\left(\mathbf{3 0}^{\circ} \mathbf{5 8}\right. \\
\text { calc. }) .\end{array}$ & $\begin{array}{c}\rho\left(\mathbf{4 2}^{\circ} \mathbf{2 4}^{\prime}\right. \\
\text { calc. }) .\end{array}$ \\
\hline $\begin{array}{l}6 \\
6 \\
8 \\
9\end{array}$ & $\begin{array}{l}\text { Poor....... } \\
\text { Poor...... } \\
\text { Poor...... } \\
\text { Poor...... }\end{array}$ & $\begin{array}{l}\text { Line face........ } \\
\text { Line face...... } \\
\text { Line face....... } \\
\text { Line face...... }\end{array}$ & $\begin{array}{cc}\circ & \prime \\
30 & 54 \\
32 & 41 \\
32 & 19 \\
30 & 00\end{array}$ & $\begin{array}{cc}\circ & \prime \\
43 & 13 \\
42 & 00 \\
43 & 41 \\
41 & 39\end{array}$ \\
\hline
\end{tabular}

For the new forms all the measurements are given in the following pages.

$j\{0.1 .12\}$ is a dome characteristic for the crystals from Terlingua, the true symbol of which is in doubt, since it is always strongly striated. The form was also noted by Goldschmidt and Mauritz, without, however, the variation in angles found by the writer, their measurements indicating rather constantly the form $\{0.1 .13\}$. All of the measurements made by the writer are here given in increasing values. It is, of course, possible that more than one form is present, as is suggested by a comparison with the calculated values given for different forms in the last column. Being such a common form for these crystals, it is included in the list of forms for calomel from Terlingua, with a question mark to show that its correct symbol is not yet determined.

Occurrence and measurements of $\rho$ for $j\{0.1 .12\}$.

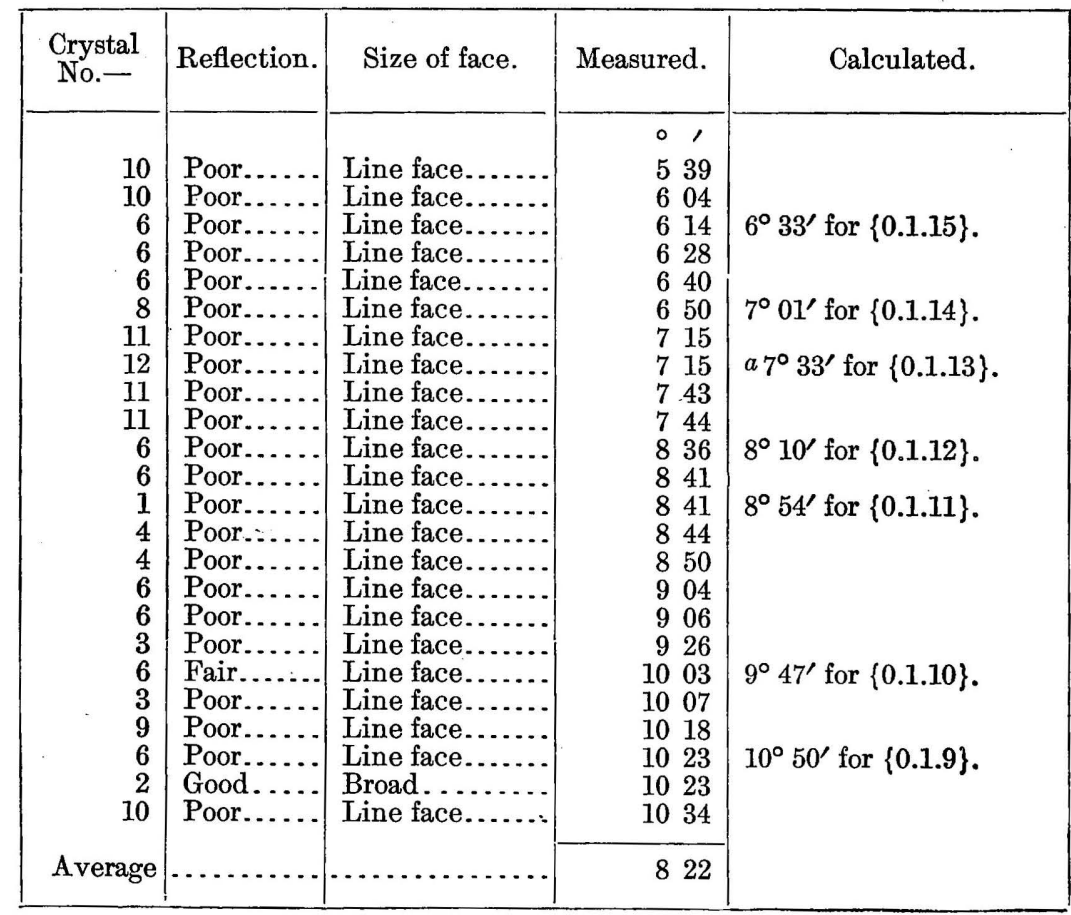

$a$ Goldschmidt and Mauritz neasure: $7^{\circ} 22^{\prime}, 7^{\circ} 46^{\prime}, 7^{\circ} 56^{\prime}, 7^{\circ} 23^{\prime}, 7^{\circ} 30^{\prime}, 7^{\circ} 30^{\prime}$, 
The form $Y\{018\}$ was observed on two crystals as the merest line faces. The character of the faces was, however, too poor to allow of their definite determination. The form $\{018\}$ also lies very near to that of $\{0 \overline{2} 1\}$ ir twin position and may, perhaps, belong to that form.

Occurrence and measurements of $Y\{018\}$, calomel.

\begin{tabular}{|c|c|c|c|}
\hline $\begin{array}{c}\text { Crystal } \\
\text { No. }\end{array}$ & Reflection. & Size of face. & $\begin{array}{l}\rho\left(\mathbf{1 2}^{\circ} \mathbf{0 9}^{\prime}\right. \\
\text { calc. }) .\end{array}$ \\
\hline $\begin{array}{r}9 \\
10\end{array}$ & $\begin{array}{l}\text { Poor....... } \\
\text { Poor...... }\end{array}$ & $\begin{array}{l}\text { Line face........ } \\
\text { Line face....... }\end{array}$ & $\begin{array}{cc}\circ & , \\
12 & 00 \\
12 & 23\end{array}$ \\
\hline
\end{tabular}

The dome $\Phi\{035\}$ occurred once on crystal 6 , as a mere line face or as fine striæ; $\rho$ measured $45^{\circ} 20^{\prime}$ (calc. $45^{\circ} 57^{\prime}$ ). The position of $\{035\}$ on the gnomonic projection is likewise very close to that of $\{021\}$ in twin position, and like $\{018\}$ may belong to that form.

The measured angles for $T\{334\}$ vary considerably from the calculated values, and the form is therefore considered doubtful:

Occurrence and measurements of $T$ \{394\} (?), calomel.

\begin{tabular}{|c|c|c|c|c|}
\hline $\begin{array}{c}\text { Crystal } \\
\text { No. }\end{array}$ & $\begin{array}{l}\text { Reflec- } \\
\text { tion. }\end{array}$ & Size of face. & $\begin{array}{l}\phi\left(\mathbf{4 5}^{\circ} \mathbf{0 0}^{\prime}\right. \\
\text { calc. }) .\end{array}$ & $\begin{array}{c}\rho\left(\mathbf{6 1}^{\circ} \mathbf{1 9}^{\prime}\right. \\
\text { calc. }) .\end{array}$ \\
\hline $\begin{array}{l}5 \\
7\end{array}$ & $\begin{array}{l}\text { Poor....... } \\
\text { Poor.... . . }\end{array}$ & $\begin{array}{l}\text { Small .......... } \\
\text { Line face....... }\end{array}$ & $\begin{array}{cc}\circ & \prime \\
45 & 00 \\
45 & 00\end{array}$ & $\begin{array}{cc}\circ & \prime \\
6 & 28 \\
60 & 05\end{array}$ \\
\hline
\end{tabular}

$K\{553\}$ occurs on crystal 4 as a narrow face giving a fairly good

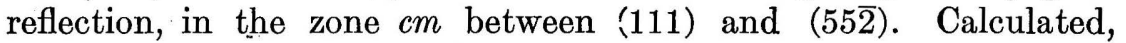
$\rho=76^{\circ} 10^{\prime}$, measured $\rho=75^{\circ} 53^{\prime}$. The face is shown in figure 41 .

One face of $S\{3.4 .10\}$ was observed. It lies in the zone (124) and (113), but on account of its somewhat complex symbol and not very close agreement in angles is included only with a query and is omitted from the list of well-established forms:

Occurrence and measurements of $S\{3.4 .10\}$ (?), calomel.

\begin{tabular}{|c|c|c|c|c|}
\hline $\begin{array}{c}\text { Crystal } \\
\text { No. }\end{array}$ & $\begin{array}{l}\text { Reflec- } \\
\text { tion. }\end{array}$ & Size of face. & $\begin{array}{l}\phi\left(\mathbf{3 6}^{\circ} \mathbf{5 2}^{\prime}\right. \\
\text { calc.). }\end{array}$ & $\begin{array}{c}\rho\left(40^{\circ} \mathbf{4 5} 5^{\prime}\right. \\
\text { calc. }) .\end{array}$ \\
\hline 4 & Poor.. & Very narrow... & $\begin{array}{cc}\circ & \prime \\
36 & 32\end{array}$ & $\begin{array}{cl}\circ & i \\
41 & 37\end{array}$ \\
\hline
\end{tabular}


The form $H\{1.1 .24\}$ seems to lie in the zone $j^{\prime} j$, the striated dome with symbol very near to $\{0.1 .12\}$, but this could not definitely be determined on account of the striated character of the faces.

Occurrence and measurements of $B$ i1.1.24\}, calomel.

\begin{tabular}{|c|c|c|c|c|}
\hline $\begin{array}{l}\text { Crystal } \\
\text { No. }\end{array}$ & $\begin{array}{l}\text { Reflec- } \\
\text { tion. }\end{array}$ & Size of face. & $\begin{array}{c}\phi\left(45^{\circ} 00^{\prime}\right. \\
\text { calc. }) .\end{array}$ & $\begin{array}{c}\rho\left(5^{\circ} 48^{\prime}\right. \\
\text { calc. }) .\end{array}$ \\
\hline & & & 0,1 & 0, \\
\hline 3 & & Minute and very & 4500 & 556 \\
\hline 4 & Poor..... . & Minute and very & 4500 & 620 \\
\hline 6 & Poor... & $\begin{array}{l}\text { Minuteand very } \\
\text { narrow. }\end{array}$ & 4500 & 530 \\
\hline 10 & Poor..... & Minute......... & 4500 & 557 \\
\hline 10 & Fair...... & Minute........ & 4500 & 516 \\
\hline
\end{tabular}

On crystal 10 two faces of the form are present, of which only one could be accurately measured. This gave $\rho=5^{\circ} 57^{\prime}$, and the other face gave a fairly distinct signal, but the basal plane gave two signals, and it was not possible to determine which was the correct one to use. The two measurements gave $5^{\circ} 01^{\prime}$ and $5^{\circ} 30^{\prime}$, the average of which, or $5^{\circ} 16^{\prime}$, is the value given for the second face. The reflections were all too poor to decide definitely the indices of the form. But as the form occurs a number of times it is included in the list of forms (p. 171), with a query to indicate that its correct symbols are still to be determined.

The form $\varepsilon\{117\}$ occurs once as a medium-sized face on a crystal referred to below as No. 13, which shows a large base, a few pyramids of the first order and $\{113\}$. Measurements of $\{113\}$ and $\{014\}$ served to establish the correct orientation of the crystal. A study of the gnomonic projection of twinned crystals has shown that the form $\{117\}$ is so near to $\{135\}$ in twinned position (twinning plane $e\{101\})$ that it is questionable whether the face is not in reality $\{135\}$ instead of $\{117\}$. Some of these twin crystals are rather complex, being usually interpenetrating, with but a very small part of the twinned crystal appearing. The indices $\{117\}$ are very unusual for calomel, and the form is therefore considered doubtful.

Occurrence and measurements of $\varepsilon\{117\}$, calomel.

\begin{tabular}{|c|c|c|c|c|}
\hline $\begin{array}{c}\text { Crystal } \\
\text { No. }\end{array}$ & $\begin{array}{l}\text { Reflec- } \\
\text { tion. }\end{array}$ & Size of face. & $\begin{array}{l}\phi\left(45^{\circ} \mathbf{0 0}^{\prime}\right. \\
\text { calc. }) .\end{array}$ & $\begin{array}{c}\rho\left(\mathbf{1 9}^{\circ} \mathbf{1 2}^{\prime}\right. \\
\text { calc. }) .\end{array}$ \\
\hline $\begin{array}{r}3 \\
7 \\
13\end{array}$ & $\begin{array}{l}\text { Poor...... } \\
\text { Poor..... } \\
\text { Fair...... }\end{array}$ & $\begin{array}{l}\text { Narrow ....... } \\
\text { Narrow ....... } \\
\text { Medium...... }\end{array}$ & $\begin{array}{cc}\circ & \\
44 & 11 \\
45 & 00 \\
45 & 39\end{array}$ & $\begin{array}{cc}\circ & \prime \\
19 & 57 \\
19 & 16 \\
18 & 50\end{array}$ \\
\hline
\end{tabular}


DISCUSSION OF FORMS.

The main part of the discussion of the forms of calomel has, as already mentioned, been omitted from this paper. Only such parts as belong to the new forms and to one old form are here given.

\begin{tabular}{|c|c|c|c|c|c|c|c|c|c|c|}
\hline \multirow{3}{*}{ Form. . } & \multicolumn{7}{|c|}{ Zone $(001)$ : (011). } & & \\
\hline & $c$ & $j$ & $Y$ & $\delta$ & $q$ & $r$ & $z$ & $t$ & $\Phi$ & $e$ \\
\hline & 001 & 0.1 .12 & 018 & 016 & 015 & 014 & 013 & 012 & 035 & 011 \\
\hline Symbol.. & 0 & $1 / 12$ & $1 / 8$ & $1 / 6$ & $1 / 5$ & $1 / 4$ & $1 / 3$ & $1 / 2$ & $3 / 5$ & 1 \\
\hline$\frac{1-v}{1+v} \ldots \ldots \ldots$ & 1 & $11 / 13$ & $7 / 9$ & $5 / 7$ & $2 / 3$ & $3 / 5$ & $1 / 2$ & $1 / 3$ & $1 / 4$ & 0 \\
\hline$\frac{v}{1-v} \cdots \ldots \ldots \ldots$ & $\infty$ & $11 / 2$ & $7 / 2$ & $5 / 2$ & 2 & $3 / 2$ & 1 & $1 / 2$ & $1 / 3$ & 0 \\
\hline$v-1 \ldots \ldots \ldots$ & $\infty$ & $9 / 2$ & $5 / 2$ & $3 / 2$ & 1 & $1 / 2$ & 0 & & & \\
\hline$\frac{2 v-1}{2}$. & $\infty$ & 4 & 2 & 1 & $1 / 2$ & 0 & & & & \\
\hline$N_{2} \ldots$ & $\infty$ & (4) & 2 & 1 & $1 / 2$ & 0 & & & & \\
\hline
\end{tabular}

The form $\{0.1 .12\}$ does not fit in the series. Of the other forms the new doubtful ones $\{018\}$ and $\{035\}$ pass well in the zone.

Zone (001): (110).

Form...... $\left\{\begin{array}{ccccccccccccc}c & H & \varepsilon & h & \alpha & i & T & r & K & o & \mu & p & m \\ 001 & 1.1 .24 & 117 & 114 & 113 & 112 & 334 & 111 & 553 & 221 & 552 & 331 & 110\end{array}\right.$ $\begin{array}{llllllllllllll}\text { Symbol .... } & 0 & 1 / 24 & 1 / 7 & 1 / 4 & 1 / 3 & 1 / 2 & 3 / 4 & 1 & 5 / 3 & 2 & 5 / 2 & 3 & \infty\end{array}$

Dividing the zone at 1 and considering only the first part, we have:

$\begin{array}{ccccccccc}v & 0 & 1 / 24 & 1 / 7 & 1 / 4 & 1 / 3 & 1 / 2 & 3 / 4 & 1 \\ 1-v \cdots \ldots \ldots \ldots \ldots \ldots \ldots \ldots & 0 & 1 / 23 & 1 / 6 & 1 / 3 & 1 / 2 & 1 & 3 & \infty \\ N_{3} \ldots \ldots \ldots \ldots \ldots \ldots \ldots \ldots \ldots \ldots & 0 & (1 / 23) & (1 / 6) & 1 / 3 & 1 / 2 & 1 \ldots 3 & \ldots\end{array}$

The two forms $\{1.1 .24\}$ and $\{117\}$, already considered as doubtful, do not fit in well. The last part of the zone gives:

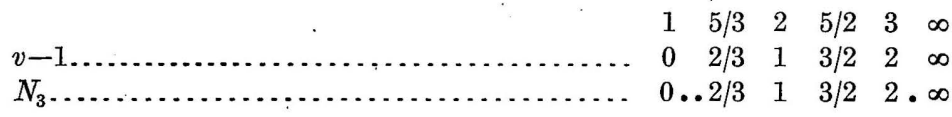

Zone (102):(011).

\begin{tabular}{|c|c|c|c|c|c|c|c|}
\hline Form.. & $\begin{array}{c}t \\
102\end{array}$ & $\begin{array}{c}\alpha \\
113\end{array}$ & $\begin{array}{c}S \\
\text { 3. } 4.10\end{array}$ & $\begin{array}{c}F \\
3.5 .11\end{array}$ & $\begin{array}{c}\pi \\
124\end{array}$ & $\stackrel{\rho}{135}$ & $\begin{array}{c}e \\
011\end{array}$ \\
\hline ym & 0 & $1 / 3$ & $2 / 5$ & $5 / 11$ & $1 / 2$ & $3 / 5$ & 1 \\
\hline$\frac{v}{-v}$ & 0 & $1 / 2$ & $2 / 3$ & $5 / 6$ & 1 & $3 / 2$ & \\
\hline & 0 . & $1 / 2$ & $2 / 3$ & $(5 / 6)$ & 1 & $3 / 2$. & $\infty$ \\
\hline
\end{tabular}

The form $\{3.5 .11\}$, very near $\{124\}$, is extra. The form $S\{3.4 .10\}$ fits in well, but is, as already stated, considered as doubtful.

A few words about one old form, classed as doubtful by Goldschmidt and Mauritz. This form, $\beta\{054\}$ given by Traube, ${ }^{a}$ should be $\{043\}$. This is brought out by the discussion of the zone. 
Zone (010):(011).

Form............................ $\left\{\begin{array}{cccccc}a & k & d & s & \beta & e \\ 010 & 041 & 031 & 021 & 054 & 011\end{array}\right.$

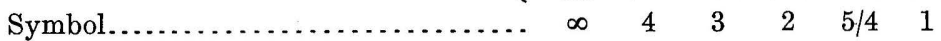

If the form $\beta$ were $\{043\}$, then we would have-

$$
\begin{array}{llllll}
\infty & 3 & 2 & 1 & 1 / 3 & 0
\end{array}
$$

which would compare better with the normal series $N_{3}$.

Traube's measurements are:

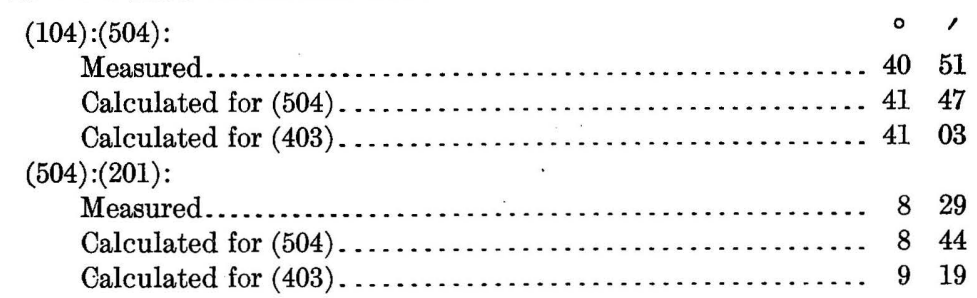

The variations are too great, however, to consider the form as definitely established, though $\{403\}$ seems more probable than $\{504\}$.

Combinations of forms on calomel crystals.

\begin{tabular}{|c|c|c|c|c|c|c|c|c|c|c|c|c|c|c|}
\hline \multirow{2}{*}{ No. } & \multirow{2}{*}{ Letter. } & \multirow{2}{*}{$\begin{array}{c}\text { Sym- } \\
\text { bol. }\end{array}$} & \multicolumn{12}{|c|}{ Crystal No. - } \\
\hline & & & 1. & 2. & 3. & 4. & 5. & 6. & 7. & 8. & 9. & 10. & 11. & 12. \\
\hline 1 & $c$ & 001 & (c). & $c$ & $c$ & $c$ & $c$ & $c$ & $c$ & $c$ & $c$ & $c$ & $c$ & $c$ \\
\hline 2 & $a$ & 100 & $a$ & $a$ & $a$ & $a$ & $a$ & $a$ & $a$ & $\ldots$ & .. & $\ldots$ & $a$ & .. \\
\hline 3 & $g$ & 160 & & & & & & $g$ & & & & & & \\
\hline $\begin{array}{l}4 \\
5\end{array}$ & $\stackrel{j}{Y}$ & $\begin{array}{c}0.1 .12 \\
018\end{array}$ & $j$ & $j$ & $j$ & $j$ & $j$ & $j$ & $j$ & $j$ & $\stackrel{j}{Y}$ & $\begin{array}{l}j \\
Y\end{array}$ & $j$ & $j$ \\
\hline 6 & $q$ & 015 & .. & ... & . & $q$ & & - & $q$ & & $\cdots$ & $q$ & & \\
\hline 7 & $\gamma$ & 014 & $r$ & $r$ & $r$ & $\gamma$ & $r$ & $r$ & $\gamma$ & $r$ & $r$ & $\gamma$ & $r$ & $r$ \\
\hline 8 & $t$ & 012 & $t$ & $t$ & $t$ & $t$ & $t$ & $t$ & $t$ & & $t$ & $t$ & $t$ & $t$ \\
\hline $\begin{array}{r}9 \\
10\end{array}$ & $\begin{array}{l}\Phi \\
e\end{array}$ & $\begin{array}{l}035 \\
011\end{array}$ & $\ddot{e}$ & $\ddot{e}$ & e & $\ddot{e}$ & $\ddot{e}$ & $\Phi$ & $e$ & $\ddot{e}$ & $e$ & $e$ & & $\ddot{e}$ \\
\hline 11 & $s$ & 021 & $s$ & $s$ & $s$ & $s$ & $s$ & $s$ & $s$ & $s$ & $s$ & $s$ & $s$ & $s$ \\
\hline 12 & $d$ & 031 & $d$ & $\ldots$ & $d$ & $d$ & $d$ & $d$ & $d$ & $d$ & $d$ & & $d$ & $d$ \\
\hline 13 & $\ddot{H}$ & 1. 1.24 & 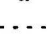 & & $\cdots$ & $H$ & & $H$ & & & & $H$ & & \\
\hline 14 & $\varepsilon$ & 117 & ... & $\cdots$ & $\varepsilon$ & $\cdots$ & & $\ldots$ & $\varepsilon$ & ... & .. & & & \\
\hline 15 & $\alpha$ & 113 & $\alpha$ & ... & $\alpha$ & $\alpha$ & $\alpha$ & $\alpha$ & $\alpha$ & $\alpha$ & $\alpha$ & $\alpha$ & $\alpha$ & $\alpha$ \\
\hline 16 & $i$ & 112 & $\ldots$ & ... & $i$ & $\ldots$ & $i$ & $i$ & $i$ & $i$ & . & $\ldots$ & $i$ & \\
\hline 17 & $T$ & 334 & $\cdots$ & $\ldots$ & $\cdots$ & ... & $\cdots$ & $\ldots$ & $T$ & $\cdots$ & .. & & $\cdots$ & \\
\hline 18 & $r$ & 111 & $r$ & $r$ & $r$ & $r$ & $r$ & $r$ & $r$ & $r$ & $r$ & $\ldots$ & $r$ & \\
\hline 19 & $\mathcal{K}$ & 553 & & $\cdots$ & & $K$ & & & & & & & & \\
\hline 20 & $o$ & 221 & .. & $\cdots$ & 0 & $\cdots$ & $o$ & $o$ & $\cdots$ & $o$ & $\cdots$ & $\cdots$ & & \\
\hline 21 & $\mu$ & 552 & $\cdots$ & $\cdots$ & $\because$ & $\mu$ & & & $\cdots$ & $\cdots$ & $\cdots$ & $\cdots$ & 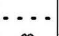 & \\
\hline 22 & $p$ & 331 & $\cdots$ & $\cdots$ & $p$ & & $p$ & $p$ & .. & $\cdots$ & $\cdots$ & $\cdots$ & $p$ & \\
\hline 23 & $v$ & 153 & $v$ & $v$ & $v$ & $v$ & $v$ & $v$ & $v$ & $v$ & $v$ & $v$ & $v$ & \\
\hline 24 & $\rho$ & 135 & $\cdots$ & $\rho$ & $\rho$ & $\rho$ & $\rho$ & $\rho$ & $\rho$ & $\rho$ & $\rho$ & $\rho$ & & $\rho$ \\
\hline 25 & $n$ & 132 & 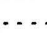 & $n$ & $n$ & $n$ & $n$ & $n$ & & $n$ & $n$ & $n$ & $n$ & \\
\hline 26 & $\phi$ & 131 & $\ldots$ & $\phi$ & & $\ldots$ & $\psi$ & & ... & $\psi$ & $\psi$ & $\cdots$ & & \\
\hline 27 & $\pi$ & 124 & $\pi$ & $\pi$ & $\pi$ & $\pi$ & $\pi$ & $\pi$ & $\pi$ & $\pi$ & $\pi$ & $\pi$ & & $\pi$ \\
\hline $\begin{array}{l}28 \\
29\end{array}$ & $F$ & $\begin{array}{l}\text { 3. . } 11 \\
\text { 3.4. }\end{array}$ & & & & $\ddot{S}$ & $\cdots$ & & & $F^{2}$ & $F^{\prime}$ & $\cdots$ & & $\cdots$ \\
\hline & & & & & & & & & & & & & & \\
\hline
\end{tabular}


HABIT.

1. Prismatic habit.-Crystals of a prismatic habit are very rare. A crystal of this habit with $c, a, \alpha, r$, and $z\{013\}$ was figured and described by Moses. A few prismatic crystals were noticed by the writer on one of the specimens. They were very small and showed $c a$ with possibly $m\{110\}$ and $s\{021\}$, as very small faces, though the edges and corners were so rounded and uneven as to make the identification of any forms almost impossible. This habit, therefore, seems to be a very rare one for calomel of this locality.

2. Equidiametral habit.-Almost all of the crystals are of this habit and most of them are very rich in faces. As a sort of intermediate between these two

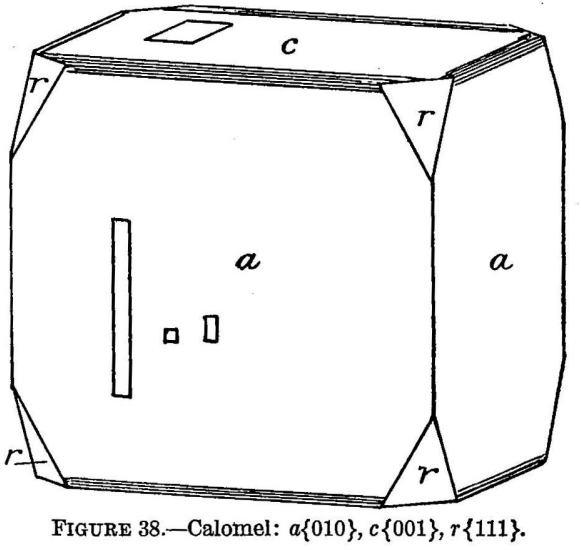
habits there may be described two forms of crystals. The one, which is the habit of the very large crystals, has $a$ and $c$ large with the corners truncated by $r\{111\}$. Some pyramids of the first order, as possibly $\{014\}$ and $\{011\}$, are probably also present, but the edges

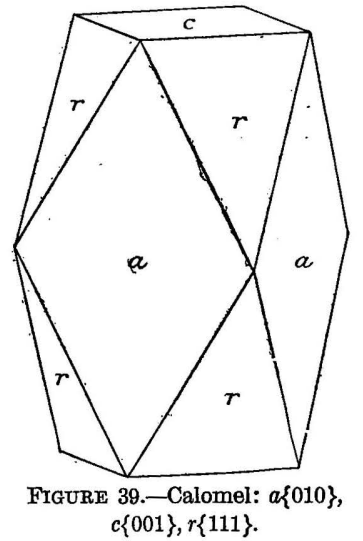

Their general appearance is shown in figure 39 . are too rounded for any determination. These crystals are covered with eglestonite and mercury and many appear considerably etched. Many faces of $\{100\}$ are finely striated vertically. On one specimen etch faces were noticed on (100). Their appearance is shown in figure 38. In general they are slightly elongated in the vertical direction. The other intermediate habit was noticed on a number of the crystals that are on the pink rock, heavily impregnated with calomel. The crystals are very rounded and uneven and many seem to be attached in parallel position. The prism $m\{110\}$ seems to be present. The other forms are $c, a$, and $r$.

TWIN CRYSTALS.

Goldschmidt and Mauritz do not mention any twinning in their description of the crystals from Terlingua. Many of those examined by the writers are twinned, and others are placed together in irregular position. Such an irregular grouping is shown in figure 41, and a 
study of the gnomonic projection shows that the displacement of the two parts is irregular and is not to be ascribed to twinning. On the other hand, a twinned crystal is shown in figure 43.

The twinning plane is $e\{101\}$, and the crystals are usually more or less interpenetrating. While the line of demarcation is very prominent in some crystals, in others it is not, and when, in addition, the crystals are very minute it often becomes questionable whether a given face belongs to the twinned or the untwinned crystal.

DESCRIPTION OF CRYSTALS.

Crystal 1 is incomplete and has $\{010\},\{124\},\{113\}$, and $\{014\}$ developed as large faces, the other forms being present as very sub-

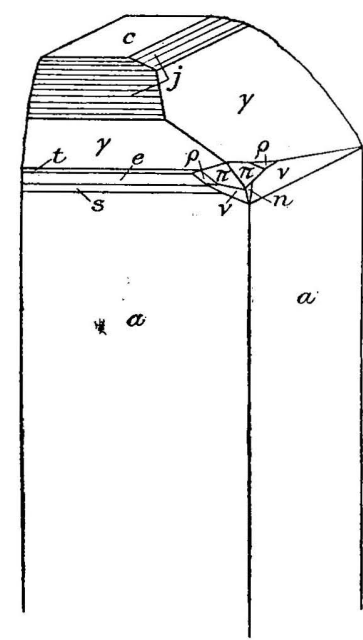

Figure 40.-Calomel crystal 2: $j\{0.1 .12\}, r\{014\}, t\{012\}, e\{011\}$, $s\{021\}, \rho\{124\}, a\{135\}, n\{132\}$, $v\{153\}$. ordinate ones. The crystal shows the new form $\{0.1 .12\}$.

Crystal 2 is a cleavage part of a large crystal and is shown in figure 40 . In its present shape it has a prismatic appearance, while the complete original crystal was probably about equidiametrical. It shows a large face of the new form $\{0.1 .12\}$ and a smaller face of the same form, both very much striated.

Crystal 3 is incomplete and shows a large base with the pyramid $\{111\}$ next in size. A number of small faces give readings which do not agree with any known form but are too poorly developed to warrant any description. The prism $g\{160\}$ seems to be present as a narrow, uneven face. It measures: $\phi=9^{\circ}$ $32^{\prime}$ (calc. $\left.9^{\circ} 27^{\prime}\right) ; \rho=87^{\circ} 15^{\prime}$ (calc. $\left.90^{\circ} 00^{\prime}\right)$. The three new forms $\{0.1 .12\},\{117\}$, and $\{1.1 .24\}$ are present. The form $\{117\}$ is present on a portion of the crystal projecting above the main part, and probably belongs to a face of $\{135\}$ in twin position.

Crystal 4 consists essentially of two parts which are slightly displaced in reference to each other. After each part had been measured to determine the forms present, the entire group was measured as one unit. In figure 41 the larger part is set up in normal position. By plotting the readings it can be seen that there is no definite relation between the two parts; they are not twinned, but the one part has become shifted with regard to the other. The rare form $q\{015\}$ is present as a line face giving a fair reflection, with $\rho=19^{\circ} 52^{\prime}$ (calc. $\left.19^{\circ} 01^{\prime}\right)$. The rare form $\mu\{552\}$ is also present as a narrow face giving a fair reflection. It measures: $\phi=45^{\circ} 46^{\prime}$ (calc. $45^{\circ} 00^{\prime}$ ); $\rho=80^{\circ} 47^{\prime}$ (calc. $80^{\circ} 40^{\prime}$ ). It follows the new form $K\{553\}$ and lies between (111) and (11). The new form $S\{3.4 .10\}$ occurs as a nar- 
row face broader than a line face but narrower than the other forms in the same zone. Only one face of the form is present. Between (101) and (111) is a rounded line face which gives a band of signals, so that no accurate measurementwas possible. The middle of the band of signals gave a measurement agreeing for the form $\{122\}$, but as this would be a new form, and it is questionable whether there really is a plane face present the form is not put forward. It measured: $\phi=27^{\circ} \quad 48^{\prime}$ (calc. $\left.\{122\} 26^{\circ} 34^{\prime}\right)$; $\rho=62^{\circ} 11^{\prime}$ (calc. $\{122\}$ $\left.62^{\circ} 34^{\prime}\right)$. The new form $H\{1.1 .24\} \quad$ is present as a very small face, striated nearly normal to its Figure 41.-Calomel crystal 4: $H\{1.1 .24\}, \alpha\{113\}, K\{553\}, \mu\{552\}$, intersection with the

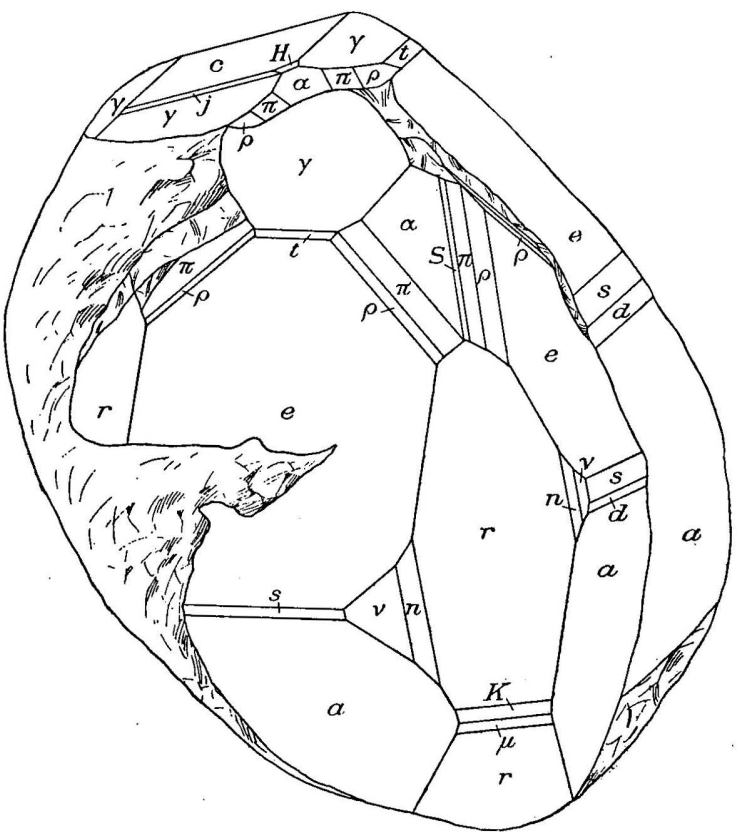
base. This rendered it difficult to measure the $\phi$ angle, though the $\rho$ angle could be measured accurately.

Crystal 5 (fig. 42). shows the rare form $p\{331\}$ as a minute face

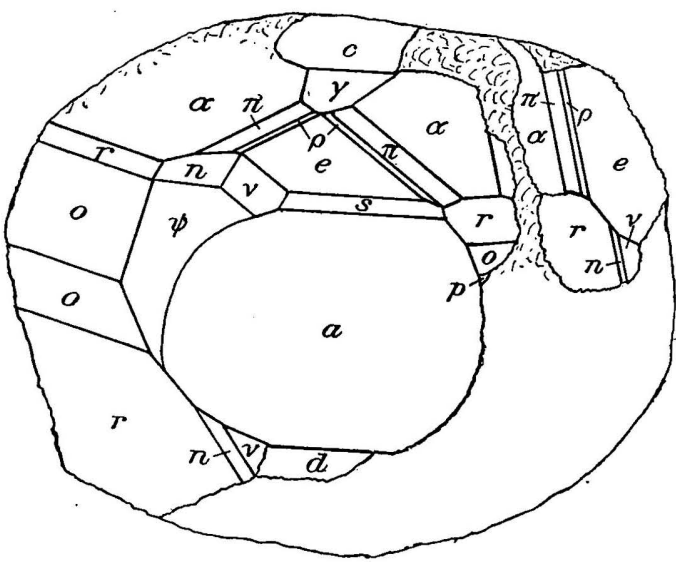

Figure 42.-Calomel crystal 5: $p\{331\}, \psi\{131\}$. giving a poor reflection. It measured: $\rho=81^{\circ}, 57^{\prime}$ (calc. $82^{\circ} 12^{\prime}$ ). The new form $T\{334\}$ is present on this crystal as a small face.

Crystal 6 is the most interesting of the entire series. It measures about 4 by 5 by 7 millimeters and consists essentially of five different crystals twinned on each other. Three of these are large and well developed, while the remainder are much smaller. The new forms $\Phi\{035\}, j\{0.1 .12\}, H\{1.1 .24\}$ occur as well as the established but rare forms $p\{331\}, g\{160\}$, and $F\{3.5 .11\}$. For $p\{331\}$ there was 
measured $\rho=82^{\circ} 11^{\prime}, 81^{\circ} 52^{\prime}$ (calc. $82^{\circ} 12^{\prime}$ ). For $g\{160\}$, which was broken and uneven, there was measured: $\phi=9^{\circ} 30^{\prime}$ (calc. $9^{\circ} 27^{\prime}$ ); $\rho=89^{\circ} 00^{\prime}$ (calc. $90^{\circ} 00^{\prime}$ ). The general features of this crystal are shown in figure 43 , the smaller details being omitted.

Crystal 7 shows the rare form $q\{015\}$ as a line face giving a very poor reflection, $\rho$ measuring $18^{\circ} 30^{\prime}$ (calc. $19^{\circ} 01^{\prime}$ ). The new forms

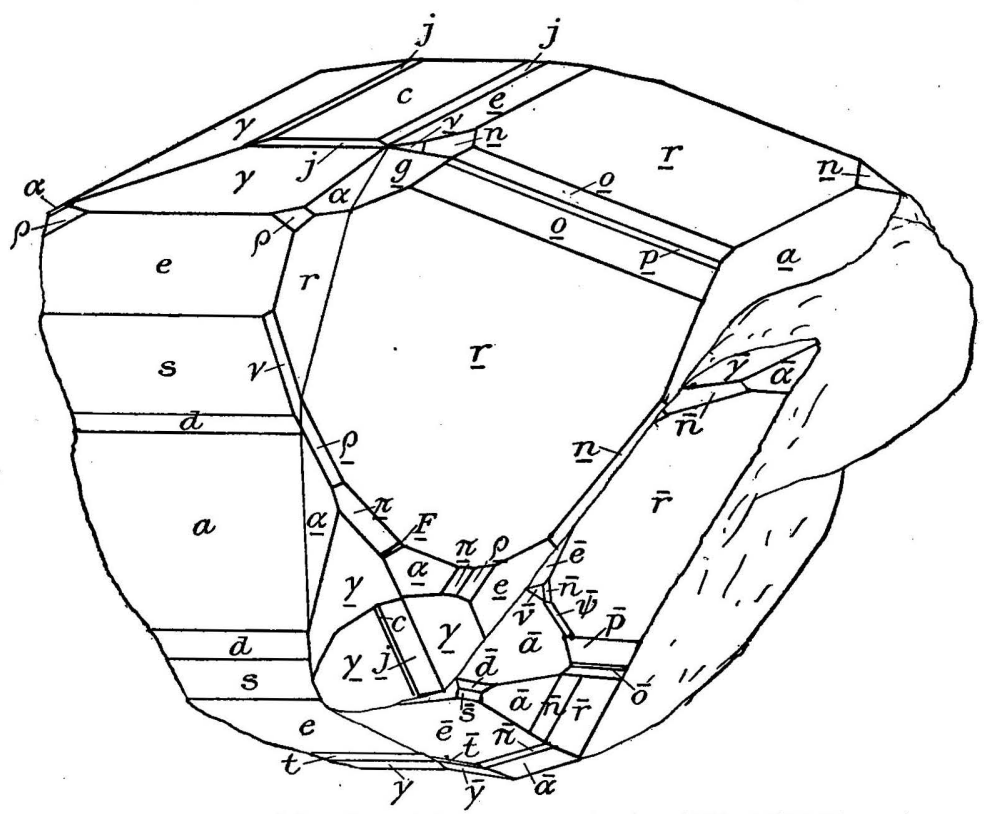

FIGURE 43.-Calomel crystal 6: $g\{160\}, \psi\{131\}, p\{331\}, F\{3.5 .11\}$.

$j\{0.1 .12\}, \varepsilon\{117\}$ and $T\{334\}$ are present. A number of forms vicinal to $\{113\}$ occur, their measurements being shown below:

Measurements of $\{113\}$ and vicinal forms on crystal $\%$, calomel.

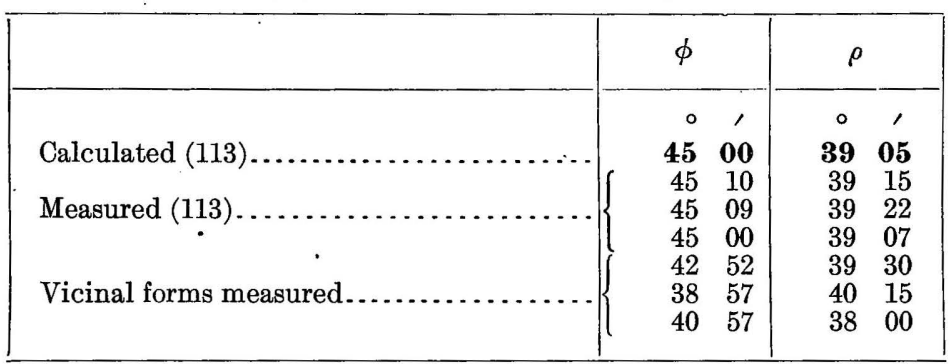

Crystal 10 shows the new forms $j\{0.1 .12\}, Y\{018\}, H\{1.1 .24\}$, and also the rare form $q\{015\}$ as a line face giving a poor reflection, measuring $\rho=18^{\circ} 41^{\prime}$ (calc. $19^{\circ} 01^{\prime}$ ). A part of this crystal showing $H\{1.1 .24\}$ is shown in figure 44 .

FORM SYSTEM.

The writer has arranged the following table of the forms and coordinate angles of calomel in a form that he thinks is most prac- 
tical. The table differs from those given by Goldschmidt in his Winkeltabellen in some features. First, only the $\phi$ and $\rho$ angles are given, as these are the only values needed to identify a form during the measurements. Second, references are given for each form, unless the form has been observed by at least three independent workers. Third, except for the prism zones, the forms are arranged in increasing values of the angles. The table given by Goldschmidt and Mauritz is used as a basis, the following forms being added to their table for the reasons set forth

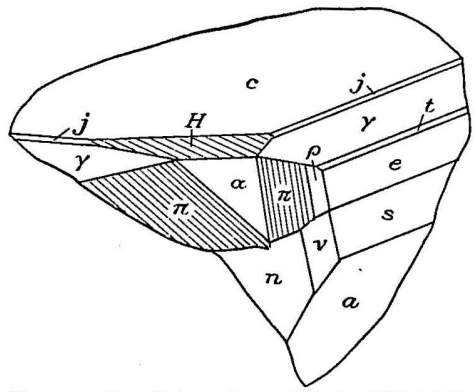

FIGURE 44.-Calomel crystal 10: $H\{1.1 .24\}$, $a\{113\}, j\{0.1 .12\}$. in the foregoing pages: $\mu\{552\}, K\{553\}, F\{3.5 .11\}, j\{0.1 .12\}$ (?), and $H\{1.1 .24\}$ (?)

Forms and coordinate angles for calomel.

[Tetragonal. $c=p_{0}=1.7232$.]

\begin{tabular}{|c|c|c|c|c|c|c|}
\hline \multirow{2}{*}{ No. } & \multirow{2}{*}{ Letter. } & \multicolumn{2}{|c|}{ Symbol. } & \multirow{2}{*}{$\phi$} & \multirow{2}{*}{$\rho$} & \multirow{2}{*}{ References. } \\
\hline & & Gdt. & Miller. & & & \\
\hline & & & & $0 \quad 1$ & 0,1 & \\
\hline 1 & $c$ & 0 & 001 & & $\begin{array}{ll}0 & 00\end{array}$ & \\
\hline 2 & $a$ & $0 \infty$ & 010 & 000 & 9000 & \\
\hline 3 & $m$ & $\infty$ & 110 & 4500 & 9000 & \\
\hline 4 & $l$ & $\infty 2$ & 120 & 2634 & $90 \quad 00$ & 4,5 \\
\hline 5 & $j(?)$ & $0 \frac{1}{12}$ & 0.1 .12 & 000 & 810 & 5,6 \\
\hline 6 & $\delta$ & $0 \frac{1}{6}$ & 016 & 000 & 1601 & 5 \\
\hline 7 & $q$ & $0 \frac{1}{5}$ & 015 & 000 & 1901 & 2,6 \\
\hline 8 & $\gamma$ & $0 \frac{1}{4}$. & 014 & 000 & 2318 & \\
\hline 9 & $z$ & $0 \frac{1}{3}$ & 013 & 000 & 2952 & \\
\hline "10 & $t$ & $0 \frac{1}{2}$ & 012 & 000 & 4040 & \\
\hline 11 & $e$ & 01 & 011 & 000 & 5952 & \\
\hline 12 & $s$ & 02 & 021. & 000 & 7349 & \\
\hline 13 & $d$ & 03 & 031 & 000 & 7903 & 5,6 \\
\hline 14 & $v$ & $\frac{1}{3} \frac{5}{3}$ & 153 & 1119 & 71. 08 & \\
\hline 1.5 & $\rho$ & $\frac{1}{5} \frac{3}{5}$ & 135 & 1826 & $\begin{array}{lll}47 & 27\end{array}$ & \\
\hline 16 & $n$ & $\begin{array}{l}\frac{1}{3} \\
\frac{1}{2} \frac{3}{2}\end{array}$ & 132 & 1826 & & \\
\hline 17 & $\psi$ & 13 & 131 & 1826 & 7936 & \\
\hline 18 & $\pi$ & $\frac{1}{4} \frac{1}{2}$ & 124 & 2634 & & \\
\hline 19 & $F$ & $\frac{3^{4}}{11} \frac{5}{11}$ & 3.5 .11 & 3058 & $42 \quad 24$ & 3,6 \\
\hline 20 & $H(?)$ & $\frac{1}{24}$ & 1.1 .24 & 4500 & 548 & 6 \\
\hline 21 & $h$ & $\frac{1}{4}$ & 114 & 4500 & 3121 & 1,2 \\
\hline 22 & $a$ & $\frac{4}{3}$ & 113 & 4500 & $\begin{array}{ll}39 & 05\end{array}$ & \\
\hline 23 & $i$ & $\frac{1}{2}$ & 112 & 4500 & & \\
\hline 24 & $r$ & 1 & 111 & 4500 & $\begin{array}{lll}67 & 41\end{array}$ & \\
\hline 25 & $K$ & $\frac{5}{3}$ & 553 & 4500 & $\begin{array}{ll}76 \quad 10\end{array}$ & 6 \\
\hline 26 & 0 & 2 & 221 & 4500 & 7824 & \\
\hline 27 & $\mu$ & $\frac{5}{2}$ & 552 & 4500 & 8040 & 1,6 \\
\hline 28 & $p$ & $\overline{3}$ & 331 & 4500 & $82 \quad 12$ & \\
\hline
\end{tabular}

1. Traube, Zeitschr. Kryst. Min., vol. 14, 1888, p. 571.

2. Vrba, Zeitschr. Kryst. Min., vol. 15, 1889, p. 455.

3. Websky, Monatsber. K. Akad. Wiss., Berlin, 1877, p. 461.

4. Moses, Am. Jour. Sci., 4th ser., vol. 16, 1903, p. 253.

5. Goldschmidt and Mauritz, Zeitschr. Kryst. Min., vol. 44, 1907-8, p. 393.

6. The present publication. 
MERCURY.

Being a liquid, mercury can not show any crystals under ordinary conditions, but the occurrences of mercury shown by these specimens may nevertheless be grouped under two heads:

1. Distinct globules.

2. Mixed with some of the other minerals and forming a sort of stiff paste which may be the "amalgam" referred to in previous papers on these minerals. 


\section{INDEX.}

Acknowledgments to those aiding........... ${ }_{7}^{\text {Page. }}$

Analyses. See particular minerals.

Barite, crystal forms of.

Boltwood, B. B., aid of

on kleinite

Calcite, crystal forms of . . . . . . . . . . . . . . 15-16 crystal forms of, figure showing........ 16 new form of ........................ 15 occurrence of, as matrix. ............... 10

California Hill, kleinite from near ........ 10

Calomel, associations of. .................. 11

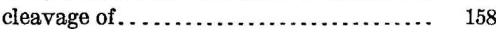
crystallography of .................. 158-171 crystals of, description of. . . . . 158-159, 168-170 elements of ................... 159-160 forms of . ............... 160-166, 170-171 combinations of.............. 166 description of . ... . ............ 161-164 discussion of . . . . . . . . . . . . . . 165-166 table of coordinate angles and ... 171

habit of . . . . . . . . . . . . . . . . . 167-168

measurement of . ................ 161

publication on ................. 158

system of. . . . ............... 170 171

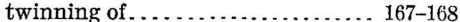

density of . . . . . 158

forms of $\ldots \ldots \ldots \ldots \ldots \ldots \ldots \ldots \ldots \ldots \ldots . .157$

physical properties of. .............. 158

Chlorine, occurrence of. See particular minerals.

Cinnabar, confusion of montroydite with .... occurrence of

Cieavage. See particular minerals.

Cohesion. See Cleavage.

Crystals, faces of, measurement of, method of. 12

Crystallography, introduction to . . . . . . . . 12-15

Crystallography of mercury minerals. See particular minerals.

Crystals, forms of

See also particular minerals.

Density. See particular minerals.

Eakle, A. S., on calcite crystals. .......... . 15

Eglestonite, analyses of. .............. 146-147

associations of...................... 11

chemistry of. . .................... 145-147

cleavage of . ........................ 144

color of ............................. 144

composition of . . . . . . . . . . . . . . . . . 145-147

crystallography of . ................ 147-157

crystals of ......................... 147-152

faces of, number of. . . . . . . . . . . 156

forms of . ...................... 147-154

forms of (common), description and measurement of. ......... 148,149

forms of (less common), description and measurement of ...... 149-150
Eglestonite, crystals of, forms of (rare), de-

scription of ............... 151

crystals of, forms of, combinations of. ... 152 forms of, description of. . . 149-151, 156-157

discussion of. . . . . . . . . . . . 151-152

figures showing.............. 154-158

gnomonic projection of. . . . . . 154-155

plate showing. . . . . . . . . . 152

zonal relations of . . .......... 154-155

habit of . . . . . . . . . . . 155 . 156

density of . . . . . . . . . . . . . . . . . . .

forms of . ................. 143

luster of........................... 144

optical properties of................. 144

physical properties of................ 144

pyrognastic behavior of................. 145

reagents with, reactions of............ 145

Fischer, T., and Von Wartenberg, H., on artificial terlinguaite.......... 88

Flexibility of montroydite, data on... . . . . . 53-54

Goldschmidt, V., on crystal forms . . . . . . . . . 12-13

Goldschmidt, V., and Mauritz, B., on crystal-

lography of calomel.... 158, 161-162,165

Goniometer, capabilities of............ 12

Groth, P., on density of calomel......... 158

Gypsum, crystal forms of. . . . . . . . . . . . 16-17

Gnomonic projections, plates showing .. 74,124,152

Hartley, J. H., aid of ............... 7,9

Hillebrand, W. F., on kleinite.. . . . . . . . . . 18,19

Holland, T. H., on sodalite............... . 22

Hydroxyl, occurrence of, in kleinite........ 32

Jarosite, crystal forms of. . . . . . . . . . . . . . . 17

Kleinite, analyses of. .............. 18-19,40-43

associations of ..................... 10

chemistry of...................... 27-43

chlorine in . . . . . . . . . . . . . . . . 29-30,46

determination of.............. 38

cleavage of . . . . . . . . . . . . . . . . . 20,46

figure showing................ 21

color of . . . . . . . . . . . . . . . . . . . 21-23,46

crystallography of . . . . . . . . . . . . . . 43-45

crystals of, forms of. . . . . . . . . . . . . 43-46

figures showing. ............... 45, 46

density of. . . . . . . . . . $\ldots \ldots \ldots \ldots \ldots \ldots . .21,46$

dimorphism of. . . . . . . . . . . . . . . 24-25

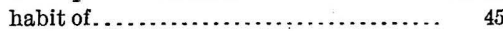

hardness of ...................... 46

forms and cQordinate angles of, table of. . $\quad 45$

heating of, effect of ............... 25

effect of, plate showing........... 26

history of...................... 18-19

hydroxyl in ...................... $\quad 32$

identification of.................. 18

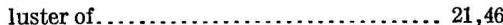

mercury in, determination of. . . . . . . 37-38

nature of . . . . . . . . . . . . . 18, 27, $42-43,47$ 
Page.

Kleinite, nitrogen in nitrogen in, determination of...... 33-37, 46-47 occurrence of

optical properties of.

effect of heating on

figure illustrating.

oxygen in . ......................... 28-31

physical properties of.................. 20-26

pyrognostic characters of ............... 27-28

reagents with, reactions of.............. 28

sections of, figures showing............ 21,24

study of.

sulphurin.

$29-30,46$

determination of

38

summary of

46

water from....................... 32-33,46

determination of .................. 39-40

Marfa and Mariposa Mining Company, mine of, minerals from........... $8-9$

Matrix, nature of...................... 9-10

Mauritz, B., and Goldschmidt, V., on crystallography of calomei.......... 158,

$161-162,165$

Mercury, proportions of, in minerals. See particular minerals.

Mercury, native, associations of............ 12

forms of........... 172

Mercury-ammonium chloride, artificial, analysis of .................... 33

Mercury minerals, occurrence of........... 8-9

Montroydite, analysis of.................. $\quad 55$ associations of ....................... 10-11

chemistry of......................... 55

cleavage of .......................... 52-53

color of............................ 54-55

confusion of cinnabar and .............. 9

crystallography of ................... 56-83

crystals of, axial elements of............ 57-58

forms of (common), description of... 61-64

forms of (less common), description and measurements of .......65-67

forms of (new) ................. 61-68

forms of (rare), description and measurements of............ 68

forms of (vicinal) .................. 64

combinations of ................ 73

description of . ............ 56-72,76-83

discussion of ................. 69-72

figures showing.................. 75-85

gnomonic projections of......... 74-75

plate showing.............. 74

striations on.................. 74-75

summary of. . ............... 68-69

zonal relations of............. 74-75

habit of ....................... 75-78

density of.......................... $\quad 54$

dimensions of .......................... 56

flexibility of............................ 53-54

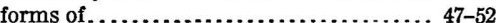

luster of

optical properties of

oxygen in.............................. 55

physical properties of ................. 52-55

Moses, A. J., on crystal forms ............. 13

on kleinite.......................... 23

on new mercury minerals............. Passim.

Moses, A. J., and Rogers, A. F., on crystal

measurem
Nitrogen, occurrence of, in kleinite........ 28-31,46 occurrence of, determination of.... 33-37,46-47

Nutting, P. G., aid of.................. 7,29

Optical properties. See particular minerals.

Oxygen. See particular minerals.

Pesci, L., nitrogen determination method of. .

Rogers, A. F., and Moses, A. J., on crystal measurement............... 13

Sachs, A., analyses by .................. 18-19

on calcite crystals.................... 15

on gypsum......................... 17 on kleinite.................... 18-20,22,43,44

Sulphur, occurrence of, in kleinite....... 29-30,46 occurrence of, determination of.......... 38

Terlinguaite, analyses of................... 87-88

associations of........................ 11

chemistry of.......................... 86-88

cleavage of. . . . . . . . . . . . . .

color of .............................. 84-85

crystallography of.................. 88-142

crystals of, axial elements of............ 89-93

coordinate angles of............ 137-142

description of ................... 126-132

dimensions of................... 89

forms of . . ................... 93-121

forms of (common), description and measurement of............ 96-98

forms of (doubtful), description and measurement of.......... 108-110

forms of (less common), description and measurement of........ 98-106

forms of (rare), description and measurement of................. 107

forms of (vicinal) ............... 108-110

combinations on............... 121-123 coordinate angles of, normal orientation of........... 93-95,137-139 coordinate angles of, with (010) as pole.................... 140-142 description of........... 88-89,96-110 discussion of ................. 110-121 distribution of................... 125 gnomonic projections of....... 154-155 plate showing............... 152

zonal relations of............... 124

habit of.......................... 125

orientation of. ................ 132-137

indices for.................... 133-136

transformation symbols of......... 133

density of.............................. 84

forms of.............................. 83

luster of............................. 84

optical properties of .................. $85-86$

physical properties of.................. 83-86

pyrognostic behavior of................ 86

reagents with, reactions of............. $86-87$

study of .............................. 7

Traube, H., on form of calomel ........... 165

Turner, H. W., aid of.................. $7,9,16$

on terlinguaite....................... 84

on mercury deposits................... 8

Von Wartenberg, H., and Fischer, F., on artificial terlinguaite.......... 88

Water, occurrence of in kleinite........... 32-33,46 occurrence of, determination of .......... 39-40

Websky, M., on calomel form............. 161

Wilke, R. M., aid of .................... 7,17

13 Zambonini, F., on water in minerals.........

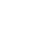

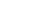

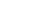











